

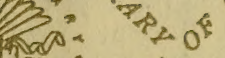 \\ a 40 : a lo \\ 30.0}

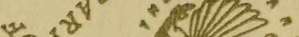
(1) (1)

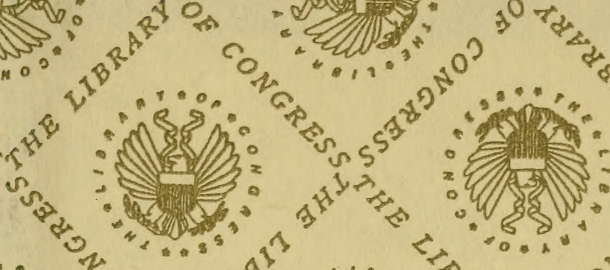

Dii: 0 -

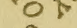

(6)

${ }^{2}+x_{\Delta / 2}$

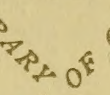

$\therefore$

से

- Nony

s.

$23^{2}={ }^{2}$

$\mathrm{C}^{\circ} \mathrm{O}$

$202:$

40

:

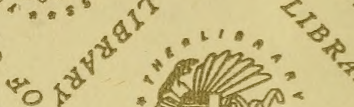

inis "nk

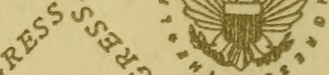

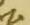

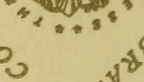

1 s.

$\mathrm{N}^{\beta^{3}}$

in

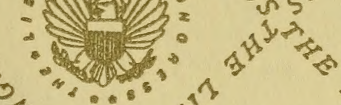

(1)

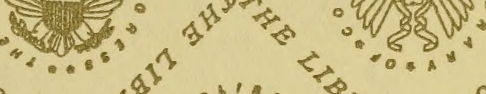

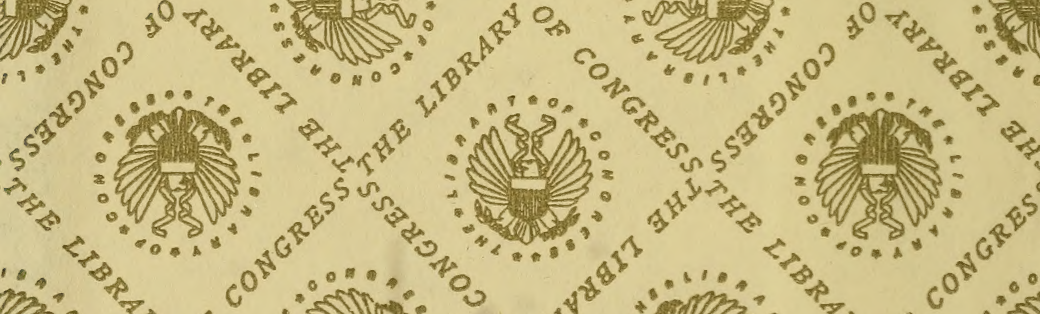

- O

告:

30

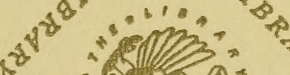

$1^{0} \nabla$

$5^{3}$

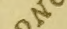

$45^{4} \div$

${ }_{1}^{0} \pi^{2}$

, \& $\%$ 2.<smiles>[131In]</smiles>

: $1300^{\circ}$

Ps of

$c^{0}$

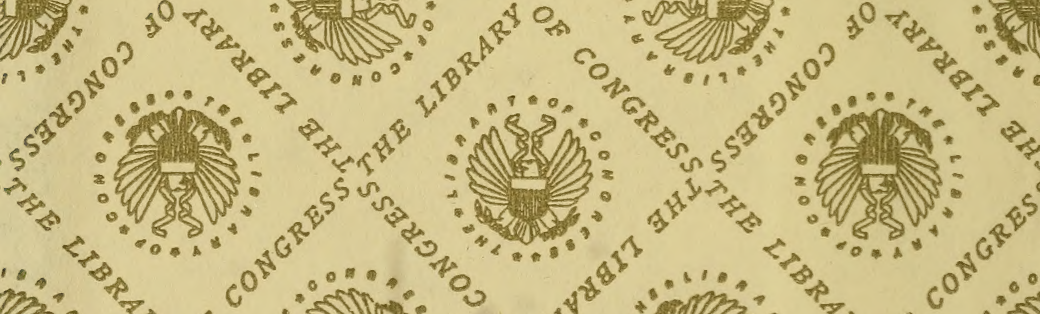

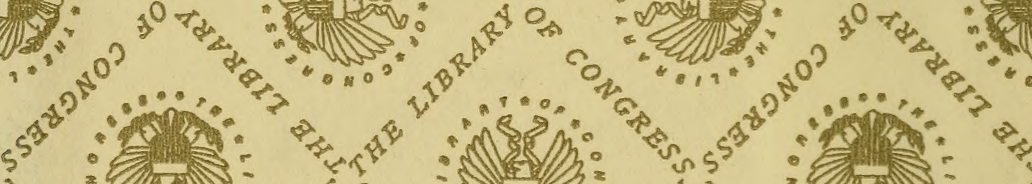

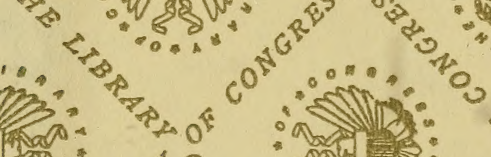

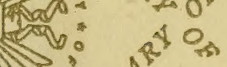

然

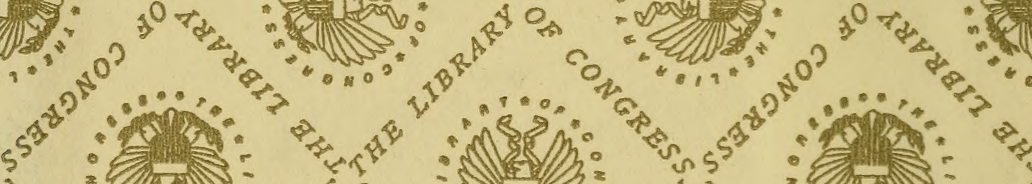

:

सर

H. .

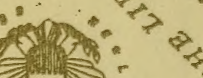

:

$\beta$

\&

$\rightarrow$

s.

$=x^{5 n}=25$

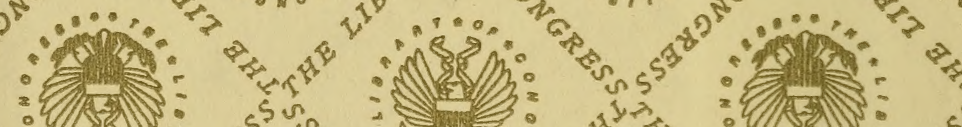

$=0, p^{3}+C_{2}$ 急 


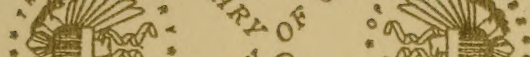

"0

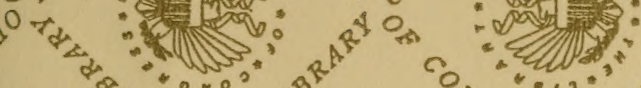

2. " 15: $80^{4} \cdot 0 \cdots$ ${ }^{\circ} 0^{\circ}$ :

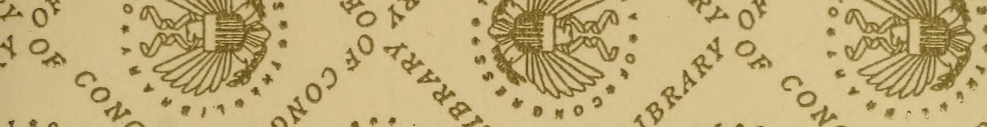

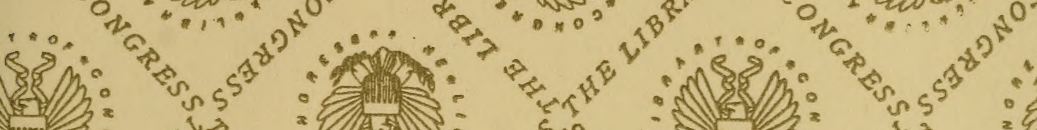
(2) 0 to

07

: 1 而

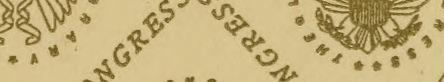
50

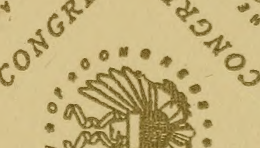
$0^{8}=0$

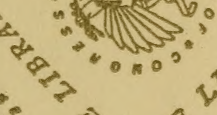
$40^{\circ}$ \% :(5)

$40_{\infty}^{+\infty}$ an: ........

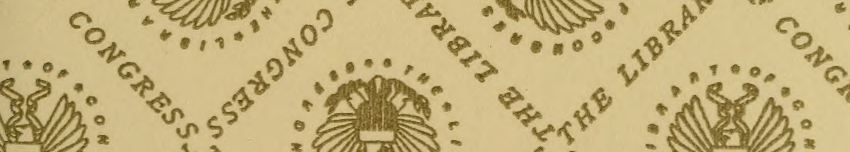

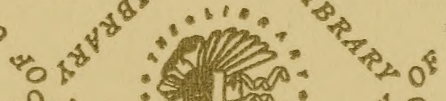
sonal cyll: co "Clls:" (3) of

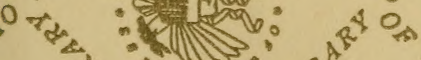

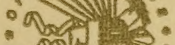

of

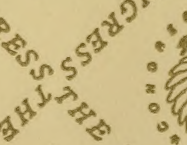








\section{FLOWERS}

FOR THE

\section{PARLOR AND GARDEN.}

BY

EDWARD SPRAGUE. RAND, JR.

ILLUSTRATIONS BY JOHN ANDREW AND A. C. WARREN.
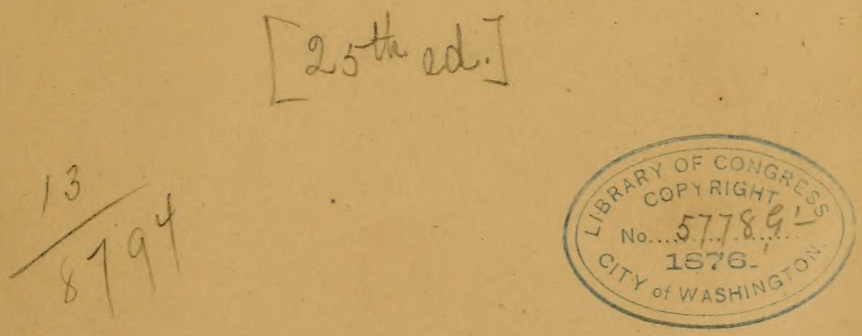

NEW YORK:

PUBLISHED BY HURD AND HOUGHTON:

Cambrtoge: The kíbersion 羽ress. 1876. 


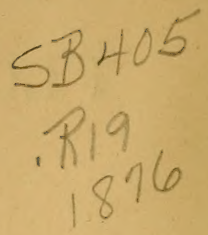

Entered, according to Act of Congress, in the year 1863, by EDWARD S. RAND, JR.,

In the Office of the Librarian of Congress, at Washington.

Entered, according to Act of Congress, in the year 1876 , by EDWARD SPRAGUE RAND, JR.,

In the Office of the Librarian of Congress, at Washington 
To

臣。臣。财。

IN MEMORY OF PLEASANT HOURS

$\Delta x$

VIOLET BANK. 



\section{PREFACE}

\section{TO THE TWENTY-FIFTH EDITION.}

HEW would have predicted, when in 1863 the first edition of "Flowers for the Parlor and Garden" was issued, the favorable manner in which it would be received by the public.

There was at the time a want of a manual of culture, which the volume supplied. From the position it then took as the standard work on popular floriculture, it has never been displaced, and now, thirteen years from the time of its first publication, it remains the recognized authority on the subject.

The present time, however, seems fitting to issue the work in an enlarged form, with additions which bring its pages up to the horticultural standard of the present day.

This has been done by the addition of three new chapters, in which will be found concise notices of many new and rare plants, as well as notes on improved methods of cultivation.

In a manual of culture, embracing many classes of plants, it is impossible, without exceeding the reasonable limits of the work, to give long lists or extended descrip- 
tions, and in the present volume these have not been attempted.

The object has been to give brief notices of the best species, trustworthy directions for culture, and practical suggestions as to the adaptation of various plants to special modes of culture.

Those who wish more extended directions, or longer lists of species and varieties, are referred to the companion volumes, "Garden Flowers," "Bulbs," " Popular Flowers," "The Window Gardener," and "Rhododendrons and American Plants," in which the several subjects will be found treated at length with all the suggestions and practical knowledge which an experience of many years has afforded.

The six volumes now before the public as just issued in revised editions, form an indispensable guide to the amateur cultivator. While they touch upon matters in all branches of floriculture, there are subjects which demand still more elaborate treatment.

To this end we have in preparation six other volumes, on Greenhouse Plants, Stove Plants, Hardy Shrubs, Orchids, Ferns, and Horticultural Nomenclature, which, with the volumes already issued, will form a complete library of horticulture, and for these we bespeak the favor of all lovers of flowers.

GLen RIDGe, January, 1876. 


\section{CONTENTS.}

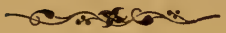

CHAPTER

PAGE

INTRODUCTION. . . . . . . . . . . . 7

I. The Green-house and Conservatory. . . . . 15

II. Window GaRdening. . . . . . . . . . 48

III. Plants for Window Gardening. . . . . . . 62

IV. Plants for Window Gardening-Continued. . 88

V. Plants for. Window Gardening-Continued. . 117

VI. Plants for Window Gardening-Continued. . . 140

vil. Cape Bulas. . . . . . . . . . . . . 160

VIII. Dutch Bulas. • . . . . . . . . . 180

IX. The Culture of the Tube Rose. . . . . . . 198

X. The Gladiolus and its Culture. • • • . . 203

XI. How to force Flowers to Bloom in Winter. . 213

XII. BaLcony Gardening. • . . . . . . . . . 224

XiII. The Wardian Case, and Winter Garden. • . 232

XIV. Stocking and Managing Wardian Cases. . . . 244

XV. Hanging Baskets and Suitable Plants, and

Treatment of Iry. . . . . . . . . . 253 
XVI. The Waltonian Case. . . . . . . . 262 XViI. The Aquarium and Watet Plants. . . . . 273 XVIII. How to grow Specinen Plaxts. • • • . 286 XIX. OUt-Door Gardening. - Hot-Bepls. . . . . . 307 XX. The Gardeit。 . . . . . . . . . . 313 XXI, Syati Trees and Shrubs. . . . . . . . 326 XXII. Hardy Herbaceous Plants. . . . •. . . 344 XXIII. Hardy Annuals. . . . . . . . . . . 352 XXIV. Bedding Plants. . . . . . . . . . 364 XXV. Hardy and Half-hardy Garden Btlbs.... . . 370 XXVI. Spring Flowers, and where to Find them. . . 381

\section{APPENDIX.}

XXViI. New Azaleas. - Notes on Cyctamen. - New PelargoniUms. - Verbenas. - Heliotrope. - New Roses. Pinks. - Fuchsias. - Abutilon. - Callas. - Cuphea. - Chrysanthemums.

XXVIII. New Hyacinthis. - Gladiolus. - Bedding Calceolarias. - Forrcing Lily of the Valley. - Lantanas. - Neiv Cannas. - Orchids for the Parlor. - Ferns for THE PARLoR.

XXIX. New Hardy Shrubs. - Amygdalopsis. - Hydrangea. Exochorda. - New LILACS. - Rhodotypus.-RATHLOLePis - Magnolia: - Spirea. - New Hardy Roses. Ampelopsis. - Lonicera. - Clematis. 

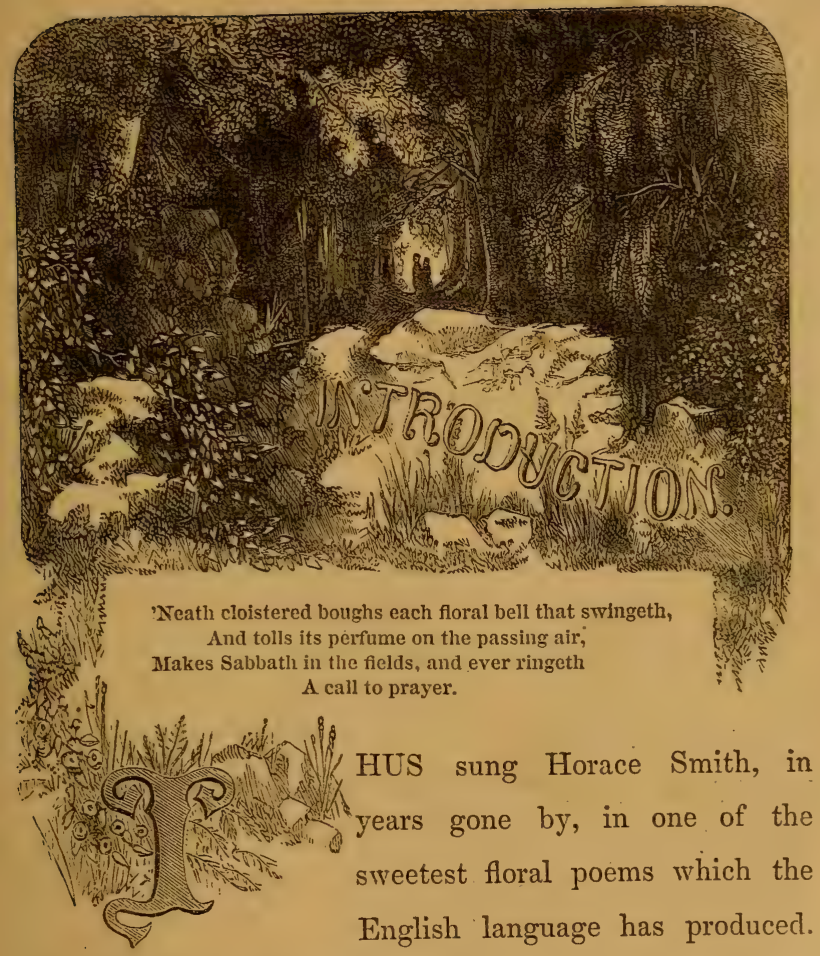

- a verse which speaks to the heart, where its measured cadences flow in sympathy with the uprising love of Nature which springs unbidden, and sends forth its music to gladden many a rugged path of life.

The love of flowers is universal : it is an old melody, 
which, first attuned, in earliest time, in the golden age of legendary lore, has come down to us, growing more mellow and sweeter as it chimed through the centuries, and now, as then, echoed, with a music akin to that of heaven, in the human heart.

And this floral music has not been without its deep and lasting influence: little may we know of the countless paths of life which it has made brighter, and which have, long ages since, ended beneath a grassy, flower-sprinkled grave; but we see it breathing over us from the acanthus leaves of the Corinthian capital, sounding from the silence of mediæval marble, and echoing, again and again, in the rich strains of deathless poesy. It is one of the links binding the present to the past, joining us in sympathy with those who lived long ago; and while we gather the rose, the lily, or the riolet, we but renew a pledge with the olden time, and our heart beats in sympathy with the universal heart-beat of the human race for centuries.

What volumes might be written on the history, the legends, the poetry of flowers! Yet, dear reader, pleasant, and profitable withal, as such reading might be, ours is a homelier purpose. We glean not the legends of the past, 
but offer you what may give promise for the future; and believing this love of flowers to be a good, an almost holy feeling, it is our wish to minister to its development.

It has been said that no botanist was ever an infidel; may we not also say that no true lover of flowers can be a bad man?

There is a secret influence arising from these bright gems of nature, which imperceptibly makes one holier and purer.

And for this let the love of flowers be encouraged. Develop it in the mind of a child. Let him grow up surrounded by flowers, and be assured that, in the garden of the heart, the blossoms will unfold, and golden fruit ripen in after years.

We have said that the love of flowers is universal: we see them alike in the dwellings of the rich and the poor; in the workman's shop, in the window of the busy factory, peeping into the poor man's window, and trellised round the abode of the rich.

Yet with all this love for flowers, there is very little knowledge of culture.

A plant is a living being; it drinks and breathes; it is sensitive as the most delicate constitution to changes of 
temperature, and extremes of cold and heat; its tissues are as delicate as any in nature; it has wants, which must ibe attended to as they arise, and neglect is sure to result in disease or death. There are two extremes in plant culfure, as usually pursued: the plants are either starved to :death or overfed; the result is the same, whether caused by neglect or kindness.

We have often heard wonder expressed at the beauty of :some plant grown in the poor man's parlor - a beauty which those of his wealthy neighbor do not attain. The reason is simple: in the one case, the wants are well provided for; in the other, they are neglected or over supplied.

And here we touch the object of this little book, which is to tell, in as few and simple words as possible, what these wants are, and how they may best be attended to.

A plant, or a stand of flowers, is a constant source of pleasure in a room; it is a spring of sunshine, and its silent influence makes all the household more cheerful and better.

We would have flowers in every house, for their sunny light, for their cheerful teaching, for their insensibly ennobling influence.

"But they are so much trouble!" exclaims one. Granted, 
dear madam. But has your experience thus far in life failed to teach you that all the good things of God come but from our own exertions? Are they not the dearer to us because we have labored to bring them home?

Yet again I touch my theme: I would teach you how to have the finest flowers with the least trouble.

"But flowers in a room are so unhealthy!" exclaims the nervously sensitive.

By no means. "Do they not exhale poisonous gases?" But slightly; and never can the few plants you would have produce enough to be hurtful.

The smallest lamp burning in your bedroom will poison the air, by abstracting its oxygen, more than a whole bay window full of plants.

There are, however, two other considerations which should not be overlooked - the effect of powerful perfumes from flowers, which, being, in some cases, such as tuberoses, many orchids, \&ic., given off very powrerfully by night, may cause headache by impregnating the air; and the dampness, which is exhaled from plants in pots.

What, however, can be easier than the remedy, in the former case? Simply remove the blooming plants from the room at night. 
And in the latter, the dampness will hardly be perceptible from any number of pots one would be likely to have in a single room.

And yet again we propose to tell how even this may be avoided, by the growth of plants in the Wardian case an experiment at once beautiful and interesting.

We have said that plants breathed and drank; and so, as living beings, they have many different modifications of the same organization. What is nourishment and life to some is poison and death to others. Who has not been seized, when entering some well-stocked green-house, with the desire to carry home some of the floral treasures? and who has not been perplexed what to choose?

And with reason : some plants. will flourish with window culture; others droop and die. Our subject, again: it is to tell you what to choose that we have taken our pen.

Your neighbor, the florist, grows tuberoses to perfection; yours are profuse in leaves, but never bloom: we will tell you the secret of culture.

$\mathrm{He}$ has violets all winter, and you sigh for a greenhouse: it is not necessary; he does not grow his violets in the green-house; you may have them, as well as he.

And once again: admire as we will and must the exotic 
beauties of our gardens and green-houses, there are floral treasures few have dreamed of. The road sides, the fields, the meadows, the river side, the woods, are teeming with them - delicate flowers, graceful grasses, filmy ferns, radiant lichens, and lovely mosses.

Have you never gathered these? Then let us take you by the hand on some sunny day in early June, and lead you with us. Sit with us on the lap of Nature, and cull her precious but ever-renewed store, and you will find a new and unimagined pleasure, a joy as free as God's own sun and air, the child of sunlight and vernal breezes.

Did you ever think of the difference in meaning between the two verbs, to live and to exist? Did you ever think how few people live, compared with those who exist? Did you ever think there may be a blindness far worse than loss of vision - a blindness of the spirit's eye to the beauty which the hand of a bountiful Creator has so lavishly spread around us? And again for this I write; to tell you of that beauty, to open the eye to it; not to tell you where to find it, for it is every where on this broad earth; but, by pointing out its most striking features, to gradually lead you to see it all around.

And from this contemplation of Nature's beauty there 
is but the uplifting of the eye to the footstool of the Creator.

As we began, so let us end, in the soulful poem, -

"Were I in churchless solitudes remaining,

Far from all voice of teachers and divines,

My soul would find, in flowers of God's ordaining, Priests, sermons, shrines."

Ǵlen Ridge, April, 1863.

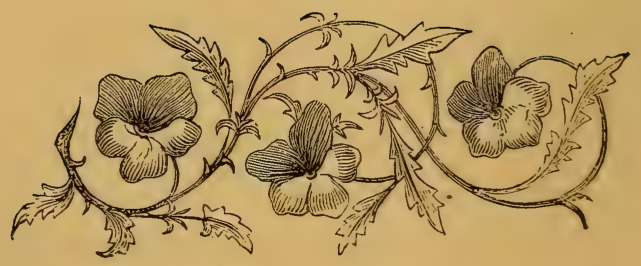




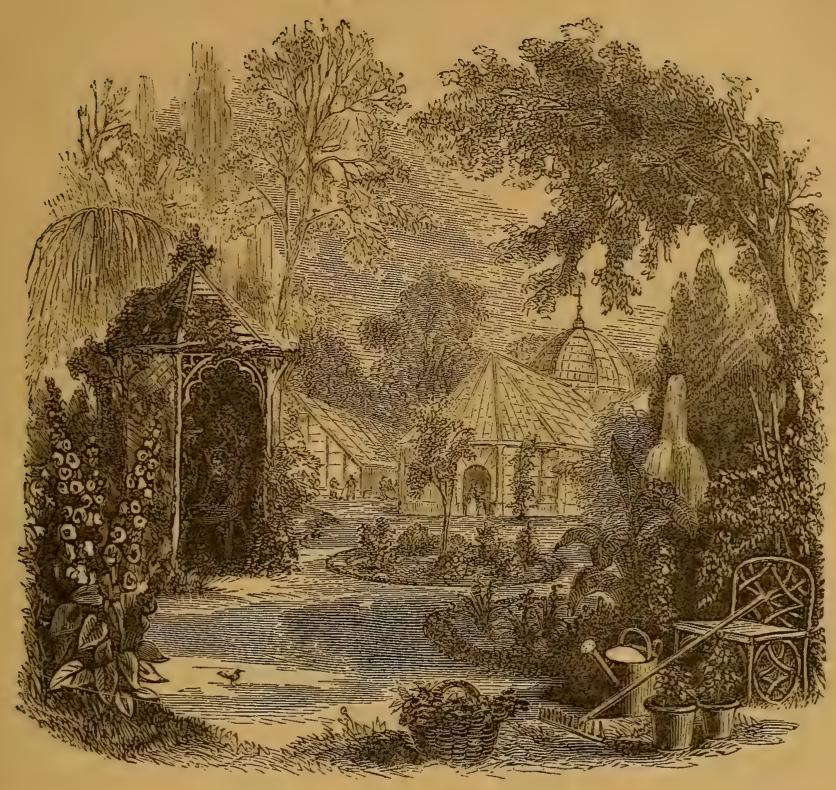

CHAPTER I.

THE GREEN-HOUSE AND CONSERVATORY.

The Store. - The Hot-house. - The Green-house. - The Conservatory. - The Pit. - "Span-roofed" and "Lean-to" Houses. - Exposure. Construction and Materials. - Piteh of Roof and Cost.-Interior Arrangements. - Heating. - "Lean-to" House. - Interior Arraugement. A Pit.-Proper Heating Apparatus. - The Brick Stove.-The Water Boiler. - Shutters. - A Cheap Green-house. - Its Construction and Cost. - Yentilation. - The Parlor Conservatory. - Heating. - Interior Ar- 
rangements.-Stocking the Green-house. - Mristakes of Overstocking.Neglected Plants. - Symmetrical Growth. - Camellias. - Daphnes. Azaleas. - Acacias. - Fuchsias. - Climbers. - Miscellancous Plants. One Húndred Choice Plants.

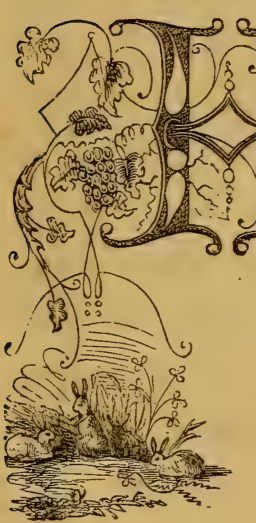

is the question that arises in the mind of the amateur, when the happy time arrives which permits him to indulge the dream of many years. Straightway he applies to an architect, or consults some book on horticultural buildings: the result is a glass structure, which fulfils all architectural requirements, is in good taste and of elegant appearance, and which lacks but one thing - adaptation to its purpose; that is, the healthy growing of plants.

Now, why is this failure? Simply because the rules governing the growth of plants under glass were not followed; we must adapt our houses to the plants, and not expect the plants to conform to the houses. As a general rule, in building a green-house, avoid "cheap buildings," for, be assured, they will become dear enough 
in the end. Use only the best materials, and these of the most durable kind. Remember that the alternations of temperature, and the constant moisture, speedily affect the best timber, and that poor material is sure to be soon rendered useless by dampness and decay.

But, as many are not able to build expensive structures, we propose to give a number of plans for buildings, of various cost.

Let us first, however, thoroughly understand the subject, and find out what we need.

There are many glass structures, all indiscriminately called "green-houses." In common parlance, any glass house for the growth of plants is a green-house; but, horticulturally, there are different names for structures of different forms, and adapted for different purposes. What, then, is the difference between a hot-house and a stove? a green-house and a hot-house? a conservatory and a green-house?

A Stove is a plant house, constructed with reference to obtaining a great degree of heat, where the temperature should never fall below seventy degrees Fahrenheit, and may rise even to one hundred and twenty degrees. The atmosphere is kept moist by constant evaporation of water, 
and external air, when admitted, is tempered by passing over heated surfaces, lest the tender plant receive a chill. In this building are grown plants natives of the equator, and the East Indian orchids. It is often arranged so as to afford bottom heat, without which many of these plants do not succeed.

The term Hot-house, properly speaking, is synonymous with stove: it is, however, used to designate any building in which artificial heat is used; a hot-house, or stove, being a house in which such a high temperature is maintained.

A Green-house is a glass structure, where the temperature ranges from forty to seventy degrees, and is calculated for the growth of those plants which will not bear the cold of our winters without injury. The term is, horrerer, improperly and indiscriminately applied to any glass structure, either with or without fire heat.

The term " conservatory" is used properly to designate a show house, where the temperature ranges from forty to sixty degrees, and into which plants are remored, when coming into bloom, from the other houses. It is improperly applied, however, to any glass structure in which plants and flowers are grown.

The glass structures connected with parlors are also 
called conserratories, and this signification of the word is generally accepted.

A Pit is a structure below the surface of the ground, generally excavated six to eight feet, and covered with a glass roof. From such a structure the frost is excluded with little expense, and a great heat may be maintained. It is usually a cheap building, used for propagation, growing roses, and forcing vegetables.

The glass structure which will be in general request is the green-house, which is adapted for the growth of most of. our flowering plants. The same structure may be converted into a stove by merely increasing the power of the heating apparatus.

A green house may be "span-roofed" (Fig. 1), or "lean-to". (Fig. 2),

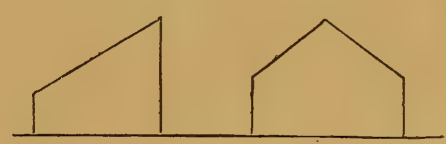

FIG. 2.

FIG. 1.

that is, with both sides of the roof of glass, or with a back wall of brick, stone, or wood, the roof and front being glass.

The former is better for the symmetrical and healthy growth of the plants, but requires powerful furnaces to maintain sufficient heat; the latter is more economical, both in structure and heating, and is sufficient to grow most of our ordinary "green-house plants." 
A span-roofed house should run north and south, so as to receive the greatest possible amount of sun in the winter; or, if this is impossible, it will be necessary to provide close shutters for all the northern exposure.

A "lean-to" house should run east and west, thus facing the south.

Now, having selected our site, which should be sheltered from the north as much as possible, let us mark out a space, say forty feet long and tivelve feet wide; around the outside of this excavate a trench, from two to four feet in depth, according to the nature of the soil (a damp, clayey soil requiring more depth than one of light, sandy consistency; the object being to get below the reach of the frost), and about one foot or more in width. This done, fill the trench to within a foot of the top with stones; on these build a eight-inch wall of brick or stone, laid in hydraulic cement, to the height of one foot above the surface level; on this lay a heavy wooden sill, which should be of seasoned pine, which bears exposure better than other woods.

Now for the carpenter work. You will have three feet of wood work, upright, in front, all round, both sides; you will need two lights, from eaves to cap, on each side, each six feet long and three to four feet wide. That would give 
you ten lights, of four feet in width, on each side, for your house of forty feet. But as three feet gives us a more manageable light, it will be better to have one or two more, and make them of that width. The upper lights, on both sides, should slide or swing so as to afford easy ventilation; the lower should be stationary. The upright windows of the side should swing out, being hinged at the top; the ends of the house should be permanently glazed, with a door in one, or, if desirable, in each end.

The pitch of the roof should be forty-five degrees. Now, a house of this description could be built for about ten dollars per running foot. The glazing, of good serviceable glass, is included in this estimate, as well as hinges, ropes, and pulleys. The interior arrangement must vary according to the taste and means of the owner.

If it is desired to make it a winter garden, a broad path should be laid, in gravel or cement, all round, at a distance of about two feet from the side. The centre should be a bed of rich, prepared soil, in which large plants, such as acacias, and abutilons, should be planted. All around the side, and even with the bottom of the glass, a shelf should be built, about two feet wide, to be filled with flowering plants, in pots. Roses and other climbcrs should be trained up the rafters. 
The heating apparatus should run under the shelf along the sides, and may be hot water, or, what is the simplest, though perhaps the most expensive, from the waste of heat, the old brick flue.

A house of this kind would present somewhat this appearance.

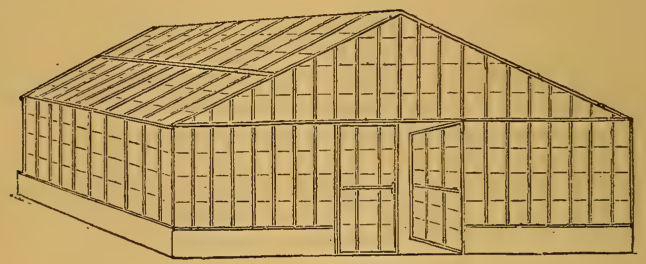

Now, if a span-roofed house is too expensive, or we wish something simpler, let us see how easy it is to build a "lean-to" on the same plan.

We have only to take one half of the span roof. Let us build our back wall of brick, good nine-inch work, with a suitable cap; and with a coat of paint given now and then, our green-house will last, without repairing, for many years.

A "lean-to" house, built after this plan, would present somerwhat the appearance of Figure A.

The cost would not be far from five hundred dollars. 
This might be much reduced by making the back wall of wood, instead of brick, and sheathing it inside; but it would not be so warm, and in the end would be more expensive, as it would, after a few years, require constant repairs.

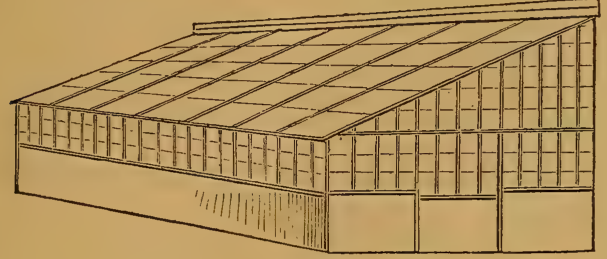

FIG. A.

Most of the houses of florists who raise flowers for the market are not properly green-houses, but pits; that is, they are excavated from two to four feet below the surface of the ground, and the roof laid on very low, so that a great saving of heat is effected. The dampness is congenial to the plants, which often thrive wonderfully; but these structures, being cheaply built, soon fall to pieces. As a general rule, in all horticultural structures, every part which is to come near, or in contact with, the ground, should be of stone or brick; and, carrying this principle still farther, the less wood work we have, the better. 
Could it be afforded at a reasonable price, it would be better to have the rafters of iron, as has been done in some cases.

The interior of the house may be arranged in two ways, if a staging is required; the first, and, to our mind, the preferable arrangement, is, to build side shelves, as above described, and to run a long, flat table through the middle of the house, on which to place the plants, in pots. In a stove, this table is made a box, about a foot deep, which is filled with moss, into which the plants are plunged, to the rims of the pots; the hot water pipes are carried under, or through, this box, the moss is kept constantly damp, and thus a moist bottom heat is obtained, most congenial to the growth of the plants.

The second mode is by a stage of ascending shelves, conforming to the roof of the house, a flat platform on top, for larger plants, the shelves again descending on the other side. By this mode, a great number of plants may be accommodated in a small house. The former mode is to be adopted where beautiful plants are desired; the latter, where quantity is the object, rather than quality.

In a lean-to house, unless it is very wide, the latter is the only method to be adopted; and if care is used not to 
crowd the plants, and the shelves are made wide enough, and the plants are frequently turned, to prevent them from growing one-sided, very creditable specimen plants may be produced. The accompanying sketch may serve to illustrate this mode of interior arrangement.

A small stove, or forcing house, is usually an adjunct to a conservatory; in this the plants are brought forward, and forced into bloom, and then brought into the conservatory, where, in the cooler

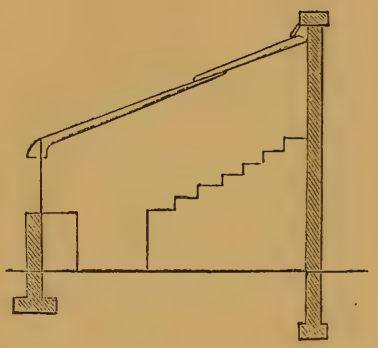
air, they will remain in perfection a long time. It is also very useful for forcing strawberries, and cucumbers, or early vegetables. All parts should be of masonry, and the large bed raised in the middle should have a hollow air chamber underneath, through which the hot-air pipes should pass, and should be built up of brick. The following sketch will give an idea of a pit of this kind.

The cost would vary very much with the size, and the materials used, but the best could be built for about ten dollars per running foot. 
The heating apparatus may vary at the caprice of the owner; as these pits waste but little heat, a common brick stove will answer every purpose, and consumes but little fuel.

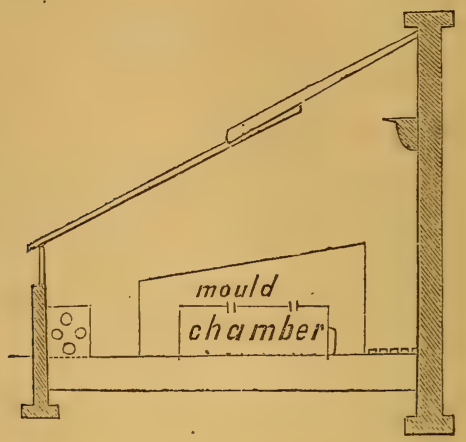

This mode of heating is used by Mr. Rivers in all his pits and green-houses, and is thus described:-

The stove is a small mass of brick work, about two feet square and three feet high; or it may be larger, if great heat is required, the front looking thus :-

On opening the cast iron door, you see a small chamber about twelve inches square, with a grate at the bottom, on which the fire is made; the other door, $b$, opens to an ash pit, of the same size, or perhaps deeper,

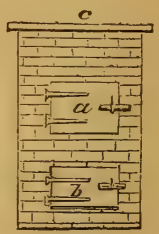
below the fire. 
In this ash-pit door there is a small hole, to admit air needful for combustion. This stove is on the principle of the air-tight stove, and consumes but little fuel, a small hod full keeping the fire for twenty-four hours.

The fire is surrounded by two thicknesses of brick, the inrer one fire brick; thus the heat giren out is gradual, and the plants are not injured, as is often the case with our iron stoves. There is, of course, a small flue, running back into a chimney, to carry off the smoke. The common covering of this stove is a thick cast iron plate, $c$.

If, however, a higher and more uniform temperature is required, an iron boiler may be added to the stove. This is cast in one piece; the pipes are of wrought iron, and screw on. It should be set directly orer the fire chamber, so that its bottom will be on a line with the top of the door, $a$, and its top is covered by the iron plate, $c$. As the water in this boiler becomes heated, it rises and flows through the pipe, $e$, which is run to one end, or quite round the house, and returning, enters the boiler again near its bottom, $f$, as shown in the figure.

As the boiler is tight, the water of course makes the circuit of the

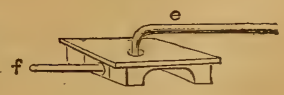
whole pipe, and keeps up a constant circulation. 
In fact, the whole pipe, which rises but a few inches in its course, may be considered a boiler, the only opening to which is at the highest point of the pipe, $e$, that is, if the pipes run around the housu at the end farthest from the bjiler, where there is an opening with a small reserroir for supplying it with water. This is the simplest form of hotwater heating; it may be varied in size to any extent, and will heat any pit sufficiently.

In heating green-houses, a great saving of fuel is effected by the use of wooden shutters fitted to all exposed portions of the range of glass. They may be made of rough boards, and should, while heavy enough to keep their place by their own weight, be of manageable size. They should be put on as soon as the sun leaves the house, and also on windy days and nights; some days in winter they should not be removed at all. The most difficult nights to keep a green-house warm are those when the mercury shows from twenty to thirty degrees of frost, with a violent wind sweeping over the house. The wind carries off the heat very rapidly, and it is easier to maintain a high temperature with the mercury twenty degrees below zero, and no wind, than in a windy night, when the thermometer only shows twenty degrees of frost. 
But, says my impatient reader, I cannot build spanroofed houses or pits at a cost of three to four hundred dollars; yet flowers are to me a necessity - I must have them. My carpenter has frightened me with estimates; tell me how to build a cheap house.

Attention, then: Your house must be about twenty-five feet long by twelve feet wide; smaller if you choose, but you will find this will give you little enough room. Procure ten stout cedar posts, the larger the better, each about eleven feet long. Set them in a line, two and one half feet apart, on the northerly line of the space marked out for your house, having previously charred them half an inch deep for at least three feet at the lower end. Set them three feet deep, and ram them well; they are the back wall of your house. Opposite each of these, and twelve feet from it, set ten cedar posts, six feet long, equally stout, charred, and set three feet deep. You have now the outline of the house, and the inclination which will give the proper pitch to your roof.

Board up your back wall with good pine boards, charred where they come in contact with the ground; also the three feet of front between the ground and the eaves (or, if stone is plenty, it is far better to lay up a wall in 
cement); shingle the back outside, and lathe and plaster, or rather back-plaster, as it is called, within. If your front is board, clapboards look better than shingles, and cost but little more. Board up and shingle the ends, leaving one or more doors, as may be desired. Sink a walk, two feet wide, through the middle of the length of the whole house, deep enough to give plenty of head room; board, stone, or brick up the sides. Your structure, thus far, is very inexpensive. Now for the rafters and glass roof. It is not, for our purpose, necessary to have sliding sashes, nicely fitted and framed, or grooved rafters; these are expensive. The roof must be one entire piece. But do you dispense with ventilation? By no means. This would be a fatal neglect, in our climate, with such a powerful summer sun.

It is easily provided for by having boards, $x$ and $y$, both

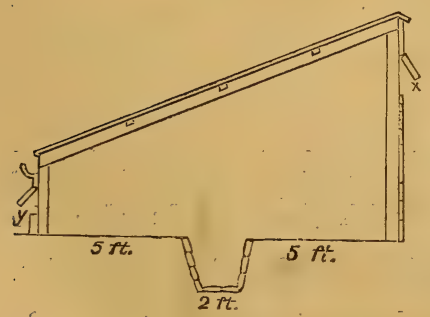
front and rear, either at intervals or along the whole line, as may be needful. These are hung on hinges, so as to open outwards, and permit a current of air to pass

through the whole breadth of the house, 
To construct the roof, form a "plate" along the posts, front and back; to this nail the rafters, running from post to post. Into these rafters fit lighter pieces of wood, running at right angles with the rafters the whole length of the house, letting the top be flush with the top of the rafter, thus, $\mathrm{R} \mathrm{R}$ being the rafters, $\mathrm{C} \mathrm{C}$ being the cross-pieces.

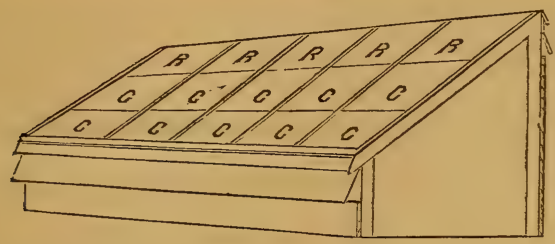

Then, parallel with the rafters, along the whole length of the house, nail other lighter strips to the cross-pieces, C C, securing them at eaves and top to the plate.

These strips should be grooved like a common sash bar, and laid upon the roof just far enough apart to receive the glass. Glaze with common clear glass. Paint all with fire-proof paint, and you have a green-house sufficient for all purposes, at a cost of about six dollars per foot. This cost may be indefinitely increased by using finer materials; our estimate is for rough boards and common glass. Heat by a common stove, as above described, or by a brick flue. For this latter, however, a small cellar near one end, cov- 
.ered with a bulk-head door, will be necessary for the furnace; and also a shed for storing coal, and for a potting. room. This may be built on behind at a trifling cost.

It is also advisable to have a gutter along the eaves, to catch the water from the roof. This should communicate with a large hogshead sunk in the ground inside, and thus a supply of water, of the proper temperature, is always :at hand.

A structure of this sort will answer equally well for a cold grapery, or for a peach house, in which cases the plastering may be dispensed with, and the house may be battened instead of shingled, by which the cost would be : somewhat reduced.

A conservatory, communicating with the parlor, is a - beautiful addition to a house, and is easily constructed. We live in the age of bow windows, and by lengthening one of these our conservatory is built. Let the sides and end be of glass; the sides may be stationary or sliding windows; the end, a door opening upon the lawn or garden walk. The roof should have some sliding sashes for ventilation. The width must be that of the bay window; the length may be according to the taste of the owner, but, to look well, should be proportioned to the width. It 
should communicate with the parlor by glass doors, in order to prevent the dampness from entering the house. Heating should be done by a small stove, with hot-water boiler fitted as above described, the pipes to be carried round the house, and hidden by shelves for plants.

The interior arrangements must vary with the taste of the owner. Climbers, such as roses, bignonias, and passion flowers, should be planted in large tubs, or in sunken brick pits, filled with prepared soil.

The stove may be hidden by a staging, or by large plants standing around it; or, if desired and convenient, the heating apparatus might be in the house cellar, and only the pipes, which could be hidden, enter the conservatory.

This conservatory may run south, east, or west; but in any case, wooden shutters, to be put up on cold and windy nights, should be provided for the sides. Double windows may be used, but the plants do not thrive so well as with single glass.

And now, having built our green-house, we must stock it.

Do not, however, be in haste; the green-house wil' fill up fast enough. Let us not run into the error of almost all amateurs, and overstock; let our aim be quality; cot 
quantity; and, to enable us to select, let us look at other green-houses, and gain from the experience of others. Let us visit any green-house in our neighborhood, and carefully examine the collection : in how many shall we find a dozen really beautiful specimen plants? Here and there, now and then, a fine, well-bushed, or trained, well-proportioned plant may be seen; but the mass are tall, longdrawn, ungainly, ugly plants, which, aside from their companions, possess no beauty or symmetry. How, then, do they appear so well? By grouping; each hides the defects of each, and a stage-full of these ugly, ill-grown plants may often present a fine appearance. But this is not the true end to be gained in floriculture; in this way we can never approximate to perfection; the evil grows year by year.

Of what plants are the collections composed? Plants from every region of the globe, all huddled together in a space not large enough generally to grow those of one country to perfection. A small house, some sixty feet long, will be found to contain a collection of camellias, which flower and grow best in a temperature not abore sixty degrees; ericas, which require about fifty degrees of heat; azaleas, which will bear any low, dry temperature; Cape 
plants, which need a different treatment from any of the above; acacias, oranges, geraniums, pclargoniums, tropæolums, fuchsias, begonias, cyclamen, ixias, sparaxis, oxalis, amaryllis, roses, and hundreds of other plants, dissimilar in habits and nature, all requiring a different treatment, each needing its peculiar atmosphere and temperature; and often a few sickly orchids; or other stove plants, with yellow leaves and weak aspect, from want of proper heat, thrust in to fill up the spaces between the larger pots: all these are crowded into one small house. Is it strange that none ever reach perfection? that all are more or less diseased? that the flowers are poor, and the plants sickly? Can we expect it to be otherwise?

None will deny the beauty of a specimen plant, let the kind be what it may; and its superiority over an ill-grown plant, let the latter be ever so rare in variety. The public eye is attracted by symmetrical beauty, and not by novelty in variety. To the common observer a well-grown specimen of the almost forgotten fuchsia globosa is far more beautiful than some new and rare plant, which presents no symmetry of proportion.

We would by no means discourage the taste for new plants; it is a healthy tendency, but may be carried too far. 
If we neglect all our old favorites, or give up well-grown, valuable plants for others of unproved merit, simply because the latter are new, the passion for novelties becomes a disease, and produces bad effects in practice. There is in this, as in all other things, a happy medium, which alone is the safe course: either extreme will lead us into error.

The passion for novelties, or any injurious effects arising therefrom, one would naturally suppose would be confined to amateurs, simply because - if for no other reason - it can only be indulged in by those whose pecuniary means are ample.

But this is not the case: we find our gardeners exerting themselves to meet any demand for new, rare, and expensive plants, to the neglect of our old and well-tried favorites.

All of us can call to mind some flowers, which, once popular, are now hardly to be found in any collection; and yet we are at a loss to give a reason. Let us look at a few cases.

We all remember a pretty little double-flowering brier, which goes by the name of "bridal rose;" it is an exquisite plant, - foliage very delicate, and of a peculiar living green, covering every branch; flowers snowy white, 
rose-shaped, with a green centre, and studding the plant; habit most farorable for symmetrical culture; and yet we may search in vain in our green-houses for this plant, combining so many desirable qualities : it is only to be found grown in old pitchers, and in the windows of the poorer classes, or in some private conservatory, where its beauties are appreciated. Another instance: Can a plant more ornamental at every season than the achænia malvaviscus be found? All the year it is studded with its scarlet blossoms and ornamental white berries; these, contrasted with the green leaves, produce a charming effect; and yet a few years since it xwas impossible to procure a plant. Latterly it has appeared in some gardeners' catalogues; but whether from any demand or an appreciation of its merits it is difficult to say. The writer never saw but one fine specimen of this plant, and that was a picture of beauty, over four feet in height, well busheci, covered with healthy foliage, and the end of each branch crowned with coral flowers, while the berries gemmed the whole plant, white, blush, and red. Such a plant is worth a green-house full of the trash generally cultivated; and all this had been done by careful attention in a parlor, the plant never having been carried to a green-house: if this can be done in house-culture, what 
ought we to expect from those who have every facility for growing plants to advantage?

Instances of this kind might be multiplied, but these must suffice. What has caused this neglect, we are at a loss to say. And another question arises: Can a remedy be found? We think it can. Let our cultivators, our gardeners, our amateurs, estimate a plant by its real beauty, value it for its intrinsic merit, and not by the factitious standards of novelty, or dollars and cents. Suppose you have a greenhouse full of rare plants, but all poor, ill-grown specimens, costly, but not beautiful; your neighbor has a dozen fine specimen plants, in which Nature, assisted by all the appliances of art and care, has developed a perfection of form, a vigor of growth and foliage, a profusion of flower; let these all be common, well-known plants - fuchsias, azaleas, even verbenas, or other soft-wooded plants: which has approached nearer the true end of floriculture, regarding it either as a pleasure or as a science? Surely he who develops to the best advantage the powers of Nature. But we have taken an extreme case; there may be as great beauty, and often is, in the new plants as in the old. Some of the introductions of the last few years possess beauties of which a short time since we never dreamed. Another 
question: Are we any nearer improvement? These plants are the fashion of to-day, and we fully appreciate their beauty; but to-morrow some new taste will develop, and before our new plants; in the ordinary course of nature, have time to grow into good-sized specimens, they are out of date, and are discarded or neglected as old-fashioned. This may seem a severe view, a harsh statement of facts, but it is literally: true.

If we look at plants with the eye of the botanist, the simplest weed becomes invested with the highest interest; and to the botanist the rarer and newer plants are objects of special attention; but his task, or rather pleasure, differs from that of the florist : the botanist would turn away from the most beautiful double flower ever produced, regarding it as a monstrosity. But we are not writing for botanists, with us they are few and far between, - but for gardeners, amateurs, and florists, who esteem a plant rather for its flower, foliage, growth, and other obvious beauties, than for its structural adaptations, be they ever so curious and beautiful.

If our amateurs will grow fewer plants, and grow these few well, - if they will discard the mass of rubbish (for it is nothing else) which cumbers'the stages of their green-houses, 
and grow their plants with plenty of room, light, and air, the evil will be remedied.

They profess to grow plants for their beauty, not from any profit to be derived from them; and yet with this their avowed object, their green-houses seldom present a more respectable appearance than thuse of gardeners who profess nothing.

But it may be said, amateurs need the flowers for their own use, and therefore must grow plants to produce the most bloom. If this is so, let them grow their flowers for cutting in some green-house used for nothing else, and use their conservatories and fine plant-houses for specimen plants.

But there is a fundamental error underlying all this theory; a poorly grown plant does not produce more flowers than one grown with care as a specimen; the former may be sooner drawn into bloom, but the latter affords the greatest profusion.

A constant cutting of the flawers will ruin a specimen plant, unless great care is taken; and this, together with the time taken to perfect the specimen, is another reason why gardeners will not grow specimens.

- But the plant is the object of attraction as much as the 
flower; without it the flowers are not shown to the best advantage, and the perfection of beauty is attained when a perfectly symmetrical plant is seen, healthy in foliage, free from disease, and gemmed with a profusion of bud and blossom.

Let us consider a few of the plants which, now neglected, would, as specimens, be pictures of beauty.

And first, the CAjIELLIA. This plant is by nature of the most symmetrical form, and with little care can be perfectly grown. Contrary to the general opinion, there is no plant which bears pruning better than the Camellia. Let the branches be well pruned out, so as not to interfere; the plants be stocky and well covered with foliage; the roots allowed room enough, and the soil kept sweet and rich; and the specimen is obtained. The common care of removing all but two flower-buds, or eren one, from each shoot, with other minor cares, must not be neglected; but, above all, do not croud your plants; let them have light and air on evcry side, above and below, and keep an even, low tomperature : follow this plan, and you will no longer complain of weak plants, long-drawn, tall specimens with yellow leaves and dropping buds; and you will be surprised at the health and vigor of your plants. From one plant thus 
cared for, you will obtain more bloom than from a dozen camellias as commonly grown.

The DaPhine - a lovely, always grown, but always neglected flower - will make a lovely specimen. Do not spare the knife, for its tendency is to long, leafless branches. You must also begin with a young plant, for to reclaim an old specimen is well nigh hopeless.

In other chapters we propose to give rules for growing specimen plants; in this connection we only mention those peculiarly adapted for green-house culture.

The beauty of Azaleas as specimens cannot be too highly praised; no green-house should be without them; yet a fine specimen is the work of years.

Acacias are only seen to advantage planted out in the green-house borders; being by nature trees, they never make fine specimens in pot culture.

Achænia Malvaviscus, as before observed, makes a lovely specimen, and bears pruning well.

Fuchsias of all kinds show to great advantage, properly grown, - except, perhaps, the white corolla rarieties, which are of too weak a habit to make large plants.

Oranges bear pruning well, and grow to a large size. ErICAs. We read of fine specimens, many feet in diam- 
eter and well bushed. Have we ever seen a specimen erica?

EPACRIs. The same remarks apply.

Keximedas are all well adapted for specimens. Trained on balloon trellises and in full bloom, what can be prettier?

The same may be said of Allamandas, Rhyxcospermuxr, Combretum, Stephanotus, and a host of other climbers.

Chorizema variun also makes a beautiful specimen trained in this way.

All the soft-rwooded climbers are superb objects, grown on large trellises, if the foliage is in good health.

Pelargoriums and Geraxiums, we all know, make superb specimens; also Verbeinas, Hetiotropes, and other plants of the same nature. Hoveas, and plants of kindred nature, are very poor subjects for specimens; but much may be effected by care and patience. The Cape bulbs, such as Ixias, and Sparaxis, are never treated with proper care; they are forced into bloom, and then, instead of allowing: the leaves to ripen well, the plants are thrust out of the way, dried off, and the only wonder is, they ever perfect any bulbs. As it is, the bulbs decrease in size year by year, and at last, being too small to bloom, are cast aside as 
worthless. These remarks apply to all green-house bulbs, except, perhaps, the Cyclamen. We have never seen well grown pots of Cape bulbs, except in a few instances.

Will not some amateur make the growth of bulbs a specialty, and show us what can be done in this almost unexplored region of floriculture? We should say unexplored in this country. In England, much has been done, and great has been the reward.

Orchids make superb specimens, but the growth is slow, and the attention needed immense. The various classes of ferns, mosses, lycopodiums, and other cryptogamous plants, can be very prettily grown.

The vast class of variegated-leaved plants are pictures of beauty if properly grown, and well repay any outlay of care or expense.

Even with our common herbaceous plants, or with annuals, a very pretty effect may be produced.

Thus we have shown that the neglect is not caused by want of subjects upon which to practise.

If we continue to show our green-houses filled with plants which, by their careless growth and sickly aspect, are a disgrace to us, the fault is our own.

Let us give our plants the benefit of our increased knowl- 
edge, — give them air, light, and room to develop their beauties - and we shall soon see that they will not be slow to avail themselves of the liberty. It will then be our care to repress undue luxuriance, or to train into proper shape the wandering branches.

Above all, feed your plants well; they cannot thrive in a poor soil, or draw nourishment from the earth if you do not supply it. Again, adapt the soil to the wants, to the nature of the plant; give sand, peat, or leaf-mould, as the plant requires. Give water as the habits of the plant require, and not promiscuously.

These may seem little matters, but they are vital to the plant, and a want of attention to them is sure to result in vexation and disappointment.

From these hints it will be easy for the most inexperienced to choose what to grow; yet another word of caution may not be misplaced : -

In a green-house, grow only green-house plants - in a stove, only stove plants: do not mix the two, or disappointment will be the result.

The following list will be found useful in choosing plants for the green-house. The culture of each will be given in succeeding chapters, with the best varieties. 
Plants for a Green-House twenty-five feet long.

12 Camellia Japonica,

4 Orange Trees,

1 Mandarin Orange,

1 Lemon,

6 Daphne Odorata,

2 " " Rubra,

4 Diosma Odorata,

1 " Capitata,

4 Erica Caffra Alba (Heath),

4 Erica Caffra Rubra (Heath),

I Cytisus Racemosa (Broom),

6 Heliotropes, in sorts,

2 Cestrum Aurantiacum,

2 Dwarf Acacias,

1 Aloysia Citriodora (Lemon

Verbena),

1 Burchellia Capensis,

1 Coronella Glauca,

2 Stevia,

2 Eupatorium Elegans,

2 Abutilon,

2 Chorizema,
1 Fabiana Imbricata,

Jasminum Odoratissimum and

Multiflorum, (Yellow and

White Jasmine,)

2 Kennedias,

10 Azalea Indica,

6 Fuchsias,

1 Justicia Carnea,

2 Correas,

1 Linum Trigynum,

3 Mahernias,

2 Manettias,

2 Myrtles,

1 Pittosporum Tobira,

1 Sparmannia Africana,

2 Passiflora (for rafters),

1 Olea Fragrans,

1 Tecoma Jasminoides (for rafter),

1 Thea Viridis (Green Tea),

1 Veronica Andersonii, and

Roses.

Add to these a few Verbenas, Cupheas, Salvias, Lobelias, Tropæolum, Calceolarias, Geraniums, and Cinerarias, all of which soft-wooded plants can be raised from seeds or cuttings, and the green-house will be full enough if the plants are of any size. 
We have in this place purposely omitted to mention the many bulbs which may be grown in the green-house, preferring to treat of them in another place.

Any of the above plants may be procured at any wellstocked green-house, and are mostly low priced. The whole collection, if small plants were chosen, could be furnished for about seventy-five dollars.

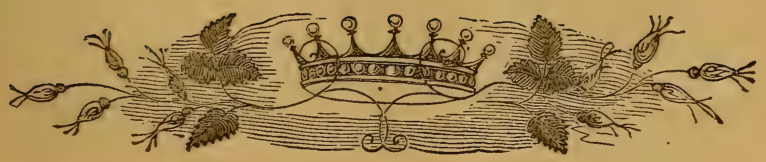




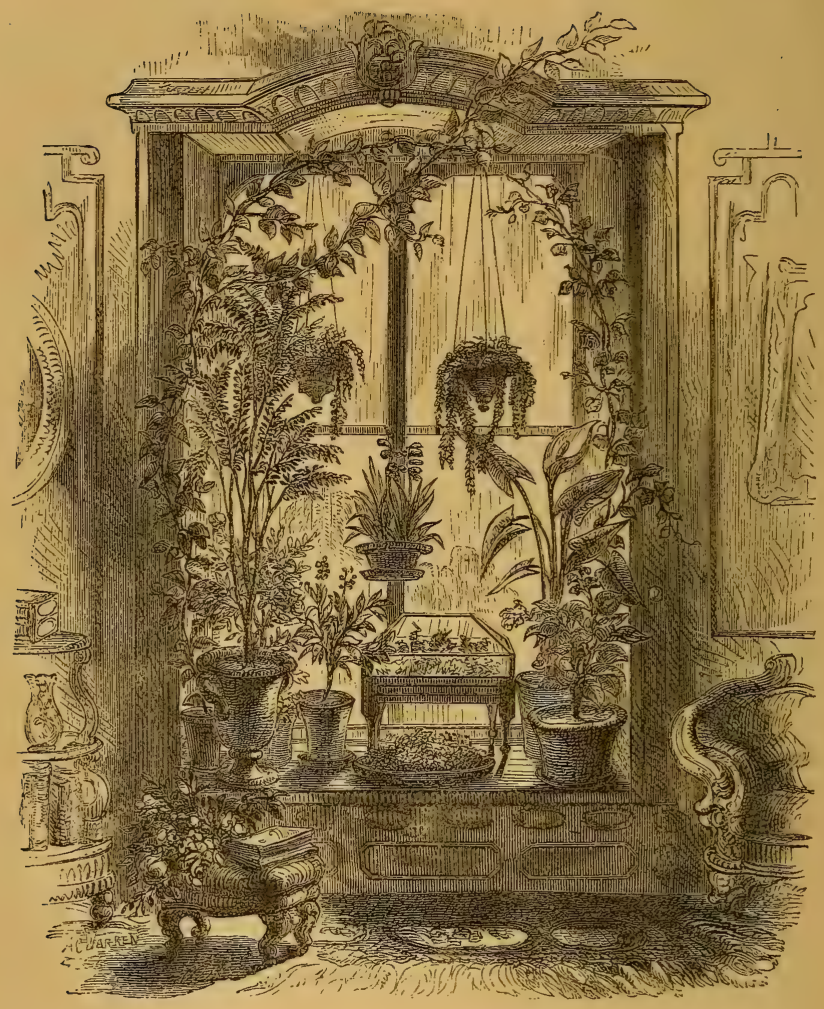

CHAPTER II.

WINDOW GARDENING.

Growth of Plants. - Situation and Exposure.-Heat. - Moisture. - Tem. perature of Room. - Ventilation. - Washing. - Syringing. - Watering. -Choice of Pots. - Window Flower Tables. - Window Shelves. - 
Potting. — Manuring. — Soil. — Peat. - Loam. - Sand. - Leaf Mould. - Manure. - Proportions of Each. - Insects. - Green My. - Mealy Bug. - Seale. - Red Spider. - Pruning.

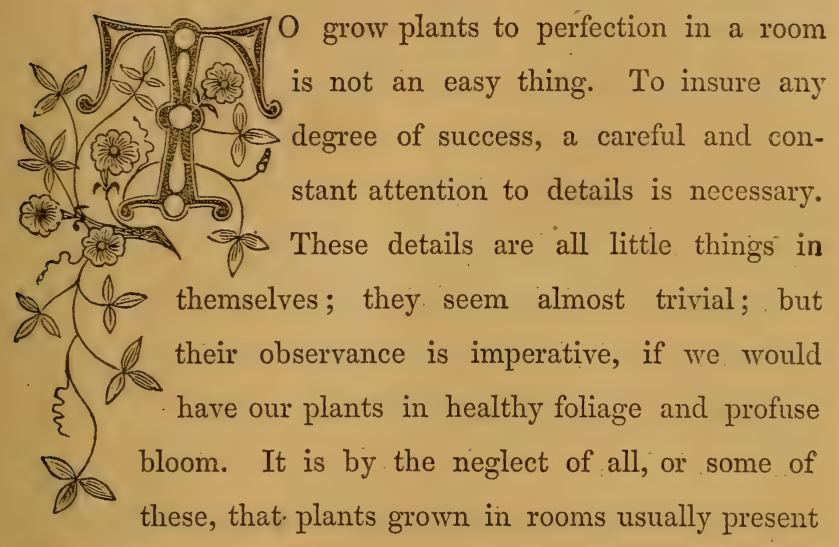
such a diseased, unhealthy appearance.

Any one of us can call to mind some friend, who, as we say, is always successful with flowers; has blossoms when no one else can, and whose plants are models of health and beauty. We laughingly say, the flowers are his friendz; he knows them, and they bloom for him; and so it is, in fact; he knows their peculiarities, attends to their wants, feeds them properly, affords the requisite light and air. Is it then a wonder that for him the grateful flowers put on 
their richest dress of green, and reach out their perfumed blossoms?

But before we give rules for growing window plants, let us look at these little things, which may come under the head of general instructions. And, first, the

\section{Situation.}

We have decided to grow window plants, and we must now choose our window. Let it, if possible, face the east or south; that is, be one which receives the full rays of the morning sun. If we are unfortunate enough not to have such a window, choose the one having the most sun; the afternoon sun is better than none at.all. There are very few plants which will flourish without sunlight, and, as a general rule, the more we can obtain the better. If you have a bay window, looking south, you need ask nothing better.

\section{Heating.}

If possible, choose a room where the temperature at night never falls below forty to forty-five degrees. Let this heat be maintained by an open fire, or by an air-tight stove, on which a large pan of water should be constantly evaporating. A furnace is injurious to plants, by reason 
of its dry heat only; the little gas escaping from our best furnaces is not sufficient to affect plants injuriously. And while speaking of gas, if possible avoid the use of gas light in the room; the unconsumed gas, always given off, is fatal to delicate plants, and hurtful to the most hardy. If you must use gas in the room, arrange glass doors to shut off your plants from the room, or give up window plants, and confine yourself to growth in Wardian cases. If a furnace is your only means of heating, provide for sufficient moisture by constant evaporation. Another objection to a furnace is, that it keeps the room too warm for a healthy growth of the plants.

The cause of so many window plants showing long, white, leafless stalks, with a tuft of leaves on the end, is, too great heat and too little light. Proportion the two, and you obtain a short, stocky, healthy growth. In rooms, this proportion is always unequal. In winter, there are eight hours of sun to sixteen of darkness; we keep the plant at a temperature of sixty to seventy degrees all the twrenty-four. In a green-house, on the contrary, the temperature falls to forty degrees at night, rising, by the heat: of the sun, by day, to a maximum of seventy. 


\section{Ventilation.}

This must not be neglected; it is as essential to the health of the plant as to the human organization. The best method of providing it is to open the top of the window when the sun's rays are hottest on the plants. The quantity of air to be given must be proportioned to the outside temperature. In cold, cloudy days, but little, and often none, should be given. Care must be taken never to allow a direct stream of cold air to blow upon any plant.

\section{WASHING.}

This must be done frequently. A plant breathes like an animal, and not through one mouth, but thousands. $\quad \Lambda \mathrm{s}$ is well known, the plant draws up its food from the soil through the roots, in a liquid form. This food, very much diluted, must be concentrated, and thus assimilated to the plant. We have in the leaves of the plant, a most beautiful arrangement to answer this need. They are filled with "stomata," or breathing pores, which allow exhalation when moisture is freely supplied, and check it when the supply falls off. These little mouths are found on both sides of the leaf in most plants, but usually on the lower side in by far the greater number. They vary in different plants from 
several hundred to more than one hundred and fifty thousand to a square inch of leaf. Now we are careful in our own persons to bathe daily, lest, as we say, the pores of the skin become obstructed; yet we are willing to allow our plants to go unwashed for a whole winter, when the pores are much smaller, more numerous and delicate, than those of the body. The rule is obvious: wash the leaves of the plants, both under and upper sides, at least once a week; if oftener, the better. Use water moderately warm, and if the plants become very dirty, a little weak soap-suds is beneficial. This washing should be carefully done with a soft sponge or cloth in the case of plants with thick, polished leaves, such as camellias, oranges, and daphnes, Where plants have hairy leaves, or the substance is soft, water is best applied with a small syringe, fitted with a very fine "rose." To use this, place the plant on its side in the kitchen sink, syringe it well, turning it from side to side. Let it stand a few minutes for the water to drain off, and return it to its place: it will thank you for its bath by its bright foliage, Never wet the flowers of a plant; water always injures them; nor allow drops of water to stand on any leaves in the sunshine: the rays of the sun form a focus in the drop of water and scorch the leaf. Once a $5 *$ 
month, at least, wash the stem and branches of all the hardwooded plants with a soft sponge dipped in lukewarm water; this prevents the lodgment of insects, and contributes to the health of the plant.

\section{WATERING}

Is one of the most difficult subjects to prescribe by rule, yet there are some rules of general application.

Let it be always done with a watering-pot with a fine rose, such as may be procured at any tinman's. The advantage of this is, it allows the water to fall drop by drop over the whole surface of the soil, whereas, if a pitcher is used, the plants are deluged, or holes made in the earth by the stream of water, and the roots not unfrequently disturbed.

Let it be done regularly; the morning is the best time, and once a day.

The surface of the soil should never be allowed to become perfectly dry, nor should it be sodden with moisture. The temperature of the water used is of vital importance. It should neither be cold nor warm, but just the temperature of the atmosphere of the room. Thus no check, or chill, or undue excitement is given to the roots, both roots and branches being equally warm. 
A good plan is, to set over night a large pan of water among your flowers, then you will be sure of a sufficiency of water of the proper temperature for the morning watering. If this is too much trouble, remember in watering, it is better to have the water too warm than too cold, that is, of a higher rather than a lower temperature than the roots and branches. Now as to the quantity of water. No rule of universal application can be prescribed. What is life to one class of plants is death to another. The amount of water necessary to make a calla lily thrive would kill a cactus or a heath, and yet the drought necessary for the cactus would be death to the heath.

A good rule, however, is never to allow the soil to become dusty or muddy, and with drainage in potting the latter is easily prevented; by regular waterings, the former. Particulars of treatment for different plants will be given when treating of each plant.

Never allow water to stand in the saucers of the pots unless the plants are semi-aquatic.

\section{Pots.}

Choose the common flower-pots, selecting those which are light colored rather than those which are brick red; the 
former are soft baked and are more porous; in these, the plants thrive better.

Discard all glazed, china, glass, or fancy painted pots; they are not porous, and plants seldom thrive in them. There is nothing neater than the common earthen pot, if kept clean. If, however, something more ornamental is desired, choose some of the fancy pots, - and some are very pretty and artistic in design, - and let them be large enough to set the common pot inside.

But there is a very pretty way of fitting up a window which is but little practised; it is, in fact, making the window a flower garden. Build from your window into the room a rounding wooden shelf, say, if the window is large, three feet in diameter from window to outer edge, but at any rate proportioned to the size of the window. On this, place a large box, wood, or earthen ware unglazed, made to conform to the shelf, and in this put your plants, the taller at the back, the smaller in front, and on each side a climber to run over the top of the window, on a neat wire trellis or on strings.

It is desirable to have holes in the bottom of the box to allow superflous water to escape, and to permit this, the shelf should be covered with zinc, which is preferable to 
tin, as it does not rust, and have a low rim all around it, with a little hole to drain off the superfluous water running from the boxes. This is a very pretty way of window gardening, but is only to be practised in a very light room; for in a room with but one window, the plants would all grow to the light, and being planted out, they could not be turned as if in pots. A pretty way to grow low plants, bulbs, and is to fit a box, say eighteen inches wide, and as long as the window, into the window, and then place the taller plants behind in pots. This box could be turned as occasion required, or as the plants grew towards the light, or could even be removed from window to window.

\section{Potting.}

But a few words are necessary. Always fill the lower inch of the pot with broken potsherds to secure drainage. In filling the soil around the plants, press it in firmly and establish the plant well. There is no advantage in loose potting.

In re-potting, pare off as much of the old, sour soil as possible, being careful not to injure the roots, and place the ball of the plant in the centre of the new pot, filling in all around with fresh soil. As a general rule, plants need 
re-potting whenever the roots begin to curl round the inside of the pot, or as gardeners say, "touch the pot." This is easily ascertained by turning the pot down, striking the rim gently against some object by a quick rap, holding the ball of earth and the plant on the palm of the other hand. The plant may thus be taken from the pot and examined, returned again, settled by a smart stroke of the bottom of the pot on the table, and will be none the worse for the inspection. This is also a good way to detect worms in pots, they generally living near the outside of the ball. The operation must, however, be quickly done, or the worm will be too nimble and withdraw into the interior of the ball.

Stirring the surface of the soil is very beneficial, especially for roses, if the roots are not thereby injured. Top dressing is also productive of good effects, particularly with old plants in heavy pots and tubs. It is simply removing the top soil as far down as the upper roots, and refilling the pot with fresh, light, rich soil.

\section{ManUring}

Is not generally needed in pot plants. A mixture of powdered or small bits of charcoal in the soil adds a deeper lustre to the green of the foliage and brilliancy to the color of 
the flowers. Bone shavings produce the same effect on hyacinths.

Liquid manure should be sparingly used, and then very weak.

If guano, a tea-spoonful to a quart of water applied once a week.

Liquid stable manure in about the same proportion, applied as seldom.

\section{SoII.}

In potting window plants rich soil should generally be used. The different kinds of soil are, -

Peat, which is black earth or decomposed vegetable fibre, usually taken from meadows or damp woods. If a mixture of white sand is with it, it becomes more valuable.

Loam, our common garden soil. It may be black or light brown. The best is obtained by taking the turf of old pastures and letting it lay till it all crumbles.

Sand, common, or "silver," such as used by glass makers. It should be free from salt. White beach sand may be freshened by frequent washings.

Leaf mould, the decomposed leaves, being the top soil in old woods. 
Manure, the material of an old hot-bed, well rotted and entirely decomposed; the older the better.

From these five earths all the soil for green-house operations is compounded.

In treating of each plant hereafter we will give its congenial soil.

As a general soil for potting plants, we would say two parts leaf mould, one part manure, one half part loam, one half part peat, one part sand.

\section{INSECTS.}

The only ones troubling house plants are, the green fly, the mealy bug, the scale, and the red spider.

Green fly is to be killed by a smoking with tobacco. Put the plant under a barrel with smoking tobacco; let it remain, say fifteen minutes; then give it a syringing.

Mealy bug is to be searched for and destroyed. Frequent spongings do much to keep down this pest.

Scale is to be treated in the same way. Warm soap-suds are peculiarly distasteful to the creature.

Red spider, which is seldom found on house plants, is nourished by a dry, warm atmosphere. Water is certain death. Keep the foliage syringed and atmosphere moist, and you will have no red spider. 


\section{Pruning}

Is but little required. Should a branch grow out of place or die, it should be neatly cut off; and a judicious pinching does much to regulate the shape of a plant. More will be said on this subject in the chapter on specimen plants. Of course all dead leaves and old blossoms should be cut off at once.

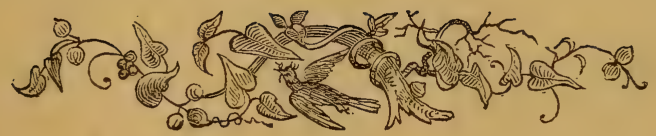

6 


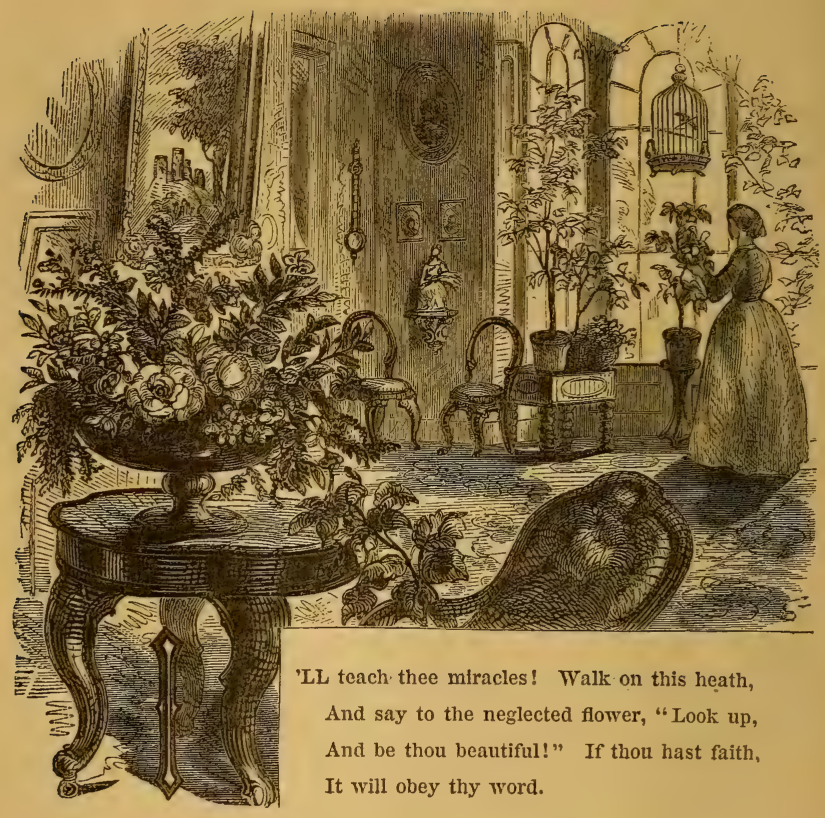

\section{CHAPTER III.}

PLANTS FOR WINDOW GARDENING.

The Camellia : History. - Culture. - Soil. - Temperature. - Potting. - Pruning. - Selection of Varieties. Orange AND Lenon Trees: Culture. - Growth. - Blooming. - Varieties. - Seedlings. - Budding The Daphas: Pruning. - Potting. - Varieties. - Soil. The Azale. 
Description. - Potting. - Culture. - Pruning. - Varieties. The Heath : History. - Soil. - Drainage. - Watering. - Hard and Soft Wooded. - Temperature. - Summer Culture. - Re-potting. - Insects. - Rooting Plants. - Varieties. THE CYCLAMEN : Potting. - Soil. - Growth.Seedlings. - Varieties.

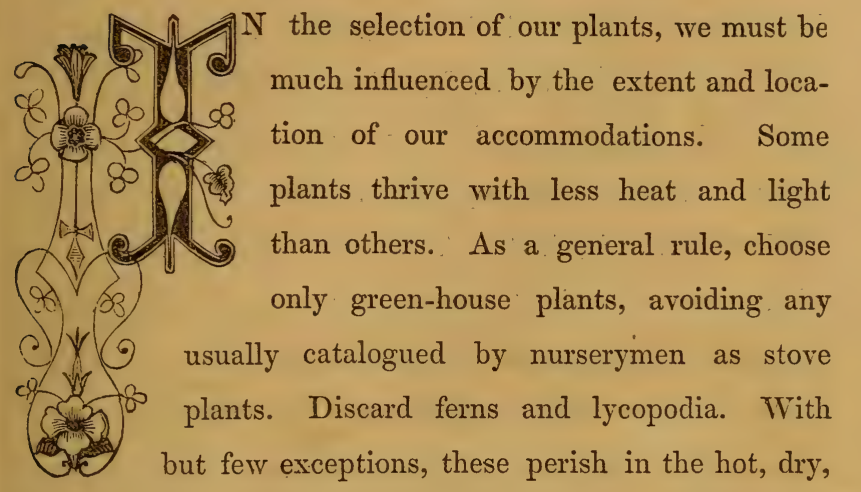
dusty air of our rooms. The Wardian case is their proper place. Remember it is better to grow one plant well than two badly. Because you have roses, geraniums, and daphnes, which do well, it is no reason you should also grow rerbenas, fuchsias, and azaleas; your space is sufficient for the first three only; then be content, and do not crowd your plants.

Now let us first give in detail, with their treatment, a list of plants suitable for window gardening; then select those for peculiar exposures. 


\section{THE CAMELLTA}

The camellia is a native of China or Japan, from whence it was introduced to British gardens about the year 1739 . The name was given in honor of Father Kamel, a Moravian priest, whose name, Latinized, became Camellus.

The plants first introduced were fairly killed by kindness; an error not unfrequently repeated in our day with newly-discovered plants. They were planted in a stove, where the extreme heat soon dried the leaves and parched the plant. We find no further mention of the plant till 1792, when the single red variety (Camellia Japonica) was introduced, and flowered profusely in a common greenhouse; during the next year many plants of this variety were obtained from China; next we find mention of the double red; soon after, the fringed double white, and many varieties too numerous to mention. Strange to say, the single white was not imported till about the year 1820, and even now it is not common, though a showy and freeblooming variety.

The camellia, in its native country, is a shrub or small tree, though Mr. Fortune mentions specimens of the single red as sometimes exceeding twenty feet in height, with 
trunks of proportionate size. This variety is almost hardy, and in the Middle States will often endure the winter; we have known it to survive even our climate, when well protected; all other varieties are more tender, and few will bear any severe frost without injury. Most of the kinds in our green-houses are derived from Camellia Japonica, though other varieties have, we believe, afforded fine seedlings.

\section{Culture.}

The plants should be grown in light loam, or sandy peat and loam, say three parts loam, two parts leaf mould, one part sandy peat; fill the pots one third full of potsherds, to secure drainage, which is indispensable; if the roots of the plant become sodden, particularly during the season of rest, the health of the plant is gone, and years of care may fail to restore its beauty, or remedy the evil caused by a little carelessness in watering. When in a growing state, you can hardly give too much water, and much good may be derived from frequent sprinklings or syringings; this operation, however, must never be performed in sunny weather. One chief care in the culture of camellias is to keep them perfectly clean; dust upon the foliage not only injures the beauty of the plant, but affects its health. The 
plants are injured by too much heat; some hold that no artificial heat should be afforded, unless necessary to keep off the frost; but as we wish our camellias to bloom at a season when there is but little else to ornament the greenhouse, it is advisable to force them moderately.

A safe rule is, never to allow the temperature to fall below forty degrees at night, or rise above sixty-five or seventy degrees during the day. The plants will thus expand the flowers more slowly and naturally, and there will be no complaint of dropping buds, imperfect flowers, and yellow, sickly foliage. One prime mistake in floriculture is the little attention paid to uniformity of temperature; a plant can no more preserve a healthy state when exposed to an atmosphere varying from thirty to one hundred degrees in a few hours, now dry and now surcharged with moisture, than can an animal. The progress of disease may be more gradual, but it is sure to show itself, and, sooner or later, the death of the plant is the result. The plants, when in bloom, should be shaded, as thus the flowers remain in perfection much longer. Give the plants plenty of air at all times, but during the season of growth protect them from chilling draughts, which would cause the young leaves to curl and stunt the plant. During the 
summer, the plants should be placed in a shady, airy situation, out of doors; allow room enough between the plants for free circulation of air; the practice of setting the plants in a mass, under trees, is most objectionable; in the first place, the drip from the branches overhead is injurious, and again, the pots become filled with earthworms, which are often difficult to dislodge.

Another mistake in the culture of camellias is too frequently re-potting; while the plant should not be allowed to become pot-bound, too much room should not be afforded; a vigorous plant will not require re-potting oftener than every three years; on this point there is, however, some difference of opinion. It is a popular error that the wood of a camellia should not be cut; on the contrary, there is scarcely a hard-wooded plant that bears the knife better; the plant is by nature symmetrical in growth, and, by judicious pruning, perfect specimens may easily be obtained.

Pruning should be done after blooming, just as the plants bezin their growth. Not more than one flower bud should be allowed on each terminal shoot, if size and perfection of flower ar 3 required; remove all others before the buds begin to swell; if delayed longer, little advantage is gained. 
The florists' varieties of the camellia are too numerous to mention; the principal colors are red, white, and rose, with all the intermediate shades. The Chinese profess to possess a yellow variety, but we believe it has never been imported; we have seen a variety named "yellow," the flowers being semi-double, and of a dirty white color.

The following are all well-proved kinds, and may easily be procured of any nurseryman. In buying plants, select those of shrubby form, dark green foliage, without any places where leaves have been dropped; look well to see that the plant is free from scale, red spider, or mealy bug; if possible, examine the roots, to ascertain if they are in a healthy state.

White. Alba plena, Candidissima, Myrtifolia alba, Imbricata alba, Fimbriata, and Oleifera.

Rose, Rosy Pink, or Carmine. Saccoi, Henri Farre, Imbricata rubra, Marchioness of Exeter, Binneyii, Fultonii, Fordii, Floyii, Jeffersonii, Landrethii, Myrtifolia, Prattii, Wilderii.

Blush. Lady Hume's blush, Towne's blush, Pomponia.

White, striped with Red or Rose. Feastii, Eclipse, Duchess of Orleans, Mrs. Abby Wilder.

Red, striped or marlied with White. Carswelliana, Chandleri, Donckelaarii, Queen Victoria, Elegans, Elphingstonia.

Crimson. Bealii, Elata, Eximia, Lowii, Palmer's perfection, Sarah Frost, Wardii.

For Seedlings. Waratah, or Anemoneflora, Tricolor, Donckelaarii, Simplex alba, Carnea. 
Could we have but one camellia, we, would choose Double white or Candidissima, for white; for blush, Lady Hume's blush; for crimson, Sarah Frost.

All these are peculiarly adapted for the window.

\section{ORANGE AND LEMON TREES.}

These are favorites for parlor culture, and easily grown. Their treatment is almost identical with that required for the camellia: the same soil, the same temperature, and the same general treatment will produce success in the culture of both.

But they are by no means so clean plants as the camellia, being very subject to scale and mealy bug. The only remedy is constant washing, both of the stem and leaves, with a weak soap-suds warm, and applied with a soft cloth. Grown in large tubs they do well in a parlor if kept sufficiently cool, and in summer succeed well out of doors.

They are thirsty plants and require much water: good drainage is essential. From December to March they will make but little growth; then water moderately. About the first of March growth begins, succeeded by bloom; then give more water. After the young growth becomes hardened, they may be set out of doors if the weather is favor- 
able. A violent wind disfigures the foliage. The young fruit will set in April and May, and will continue green all summer, coloring the next spring, and holding on the tree a long time. At the first approach of frost, the plants should be removed to their winter quarters. The lemon does not bloom and fruit as early as the orange, and is of taller growth and less fitted for the parlor: the blossoms are smaller and purplish outside.

The little dwarf "Otaheite orange" is a very common variety, and is always noticeable for its profusion of fruit. The flowers are not as fine as the other kinds, though plentifully produced. The fruit is sweet, but without flavor.

The Mandarin orange is one of the finest species (dwarf), and producing an abundance of fruit of the most exquisite flavor. Unfortunately it is not common.

There are many other larger growing species, all of which produce a profusion of white flowers, exquisitely fragrant.

Among these, the myrtle leaved is conspicuous for its shining foliage, and the large shaddock for its enormous white flowers. The former is as symmetrical in its growth as the latter is tall and ungainly.

Oranges and lemons raised from seed must attain a large size before they will bloom. The better plan is to graft or 
rather bud the seedling when about a year old. This operation is simple, but is best performed in a green-house, and it is therefore better to employ some neighboring florist to do it. Any variety may be budded on a common seedling stock.

Oranges and lemons will live under neglect, but to grow and flower them to perfection, attention to details, especially of cleanliness, is indispensable.

\section{THE DAPHNE.}

This plant, of which the varieties are numerous, never receives the care and attention its beauty merits. Every green-house contains plants of the well-known Daphne odorata, sometimes called $D$. Indica and vulgarly known as "Daphne odora." It is to this plant we intend more particularly to confine our attention.

It is a green-house evergreen shrub, attaining the height of about four feet, remarkable for its long, dark, glossy, green leaves, and its terminal bunches of fragrant, white flowers. It is one of the few old-fashioned plants which the modern rage for novelties has not driven entirely out of cultivation. It has only been thrust into the corners, and left to make its merits known by its beauty and fragrance. 
It is one of our most popular flowers, and as a window plant is unsurpassed, flourishing and blooming in situations where most plants would dwindle and die.

With gardeners it is no favorite, because, as they say, it is too straggling, and does not form a neat plant. In some respects this assertion is true, for it is impossible to bring into good shape a plant of this variety when once neglected; but by beginning with a young, healthy plant, much may be done, and fine specimens formed. Let it be remembered that the daphne "breaks" easily. Prune the plant to a bare stump, and in a few weeks buds will start from all the younger wood; therefore prune severely; never allow a branch to remain where it is not wanted; let it be as vigorous or luxuriant as it may, and never be afraid of pruning for fear of losing the flowers.

The cultivation of the green-house varieties of this plant is almost identical with that of the camellia; the same temperature will do for both.

The plants should have plenty of pot room, and the pots be well drained.

Potting should generally be done in the fall, about the time the plants are housed, when as much of the old soil should be removed as possible without disturbing the roots. 
The principal varieties are :-

Daphne odorata, the most raluable variety from its season of flowering, which is from December to March, according to the degree of heat given; leaves oblong, lanceolate, smooth; flowers white or pinkish, in terminal heads, produced in great profusion. Introduced from China about A. D.1770. Propagated by cuttings with great ease. It is one of the best parlor plants we know of, and may be obtained at any green-house at a very trifling expense.

$D$. odorata rubra is a superior, and by no means common variety; buds, red; flowers, rosy red, with a porverful spicy fragrance. It is a somewhat stronger grower than the last.

There is also a variety with variegated foliage, which is no less desirable, though rather scarce.

Daphne hybrida is a pretty evergreen shrub, hardy in England, but too tender to endure our winters without protection; flowers purple, produced in terminal heads and in lateral bunches very freely, and possessing an agreeable fragrance. It blooms at all seasons of the year, but especially from January to April.

The soil should be four parts loam, two of leaf mould, and one of sand. 


\section{THE AZALEA.}

The Azalea Indica, or Chinese Azalea, is of Asiatic origin. The varieties are innumerable; but the most common and longest known variety is that from which others are but hybrids, Azalea Indica.

It is a strong growing plant, with long, coarse, evergreen leaves, producing in clusters of three or more, at the end of the branches red flowers marked with dark spots. This plant may be grown in great perfection, and, as well as all the varieties, is admirably adapted for a window plant. The habit is shrubby, and the flowers are produced in great profusion. A. Indica alba has white flowers, and is a fine old variety. A. Indica purpurea is a variety with blossoms of a light purple color; a profuse bloomer, and of rapid growth. There is also a double variety. A. Indica coccinea is bright scarlet. From these all the fine varieties of the green-houses have been produced.

To grow the plants in perfection good drainage is essential. Fill the pot one quarter full of broken potsherds, then fill the soil to within nalf an inch of the top; soil, a dark peat three parts, one part of loam, one half part of silver sand. 
Frequent re-potting conduces to the health of the plants. As a general rule, re-pot when the roots run among the crocks at the bottom of the pot. Do not sift the soil; break it into small pieces.

Frequent syringing is beneficial, but over-watering must be carefully avoided. Give full sunshine to the plant, but lay a little moss over the pot if the sun is very hot, to protect the roots.

Keep the plant about the temperature prescribed for camellias.

As soon as the flowers fall growth begins. Give plenty of air and sun, for on this growth depends the bloom of the next year. It should be short, close, and the flower buds be set at the end of each branch.

Set the plants out of doors in the summer, as prescribed for camellias.

Azaleas may be pruned into any shape. This operation should be performed after the flowers have dropped, or after the plant has made its season's growth.

The Azalea is subject to rottenness of the roots, produced by a sodden soil, the effect of over-watering. The remedy is simple: re-pot the plant, and water moderately. Excessive dryness, the other extreme, produces yellow leaves and a general unhealthy appearance. 
The following rarieties are of proved excellence, and very distinct. All will succeed in the house.

Azalea amoena, a lovely variety; flowers double purple; produced in great profusion in midwinter.

Indica lateritia, salmon; Danielsiana, bright red; Perreyana, scarlet; Murreyana, rose; Indica alba, white; Purpurea, purple; Coccinea, red.

Iveryana, pink and white; Variegata, rose and white; Gledstanesii, white, striped with red.

This list might be increased an hundred fold.

\section{THE ERICA. HEATH.}

All the plants belonging to this genus are of a low, shrubby habit, with fine acicular foliage. None are natives of America. The fine varieties of our green-houses, with the exception of the common Erica Mediterranea, are natives of the Cape of Good Hope, whence the gardener's term, "Cape Heaths."

The erica will not thrive unless the soil is adapted to its peculiar nature; this is often very difficult to learn, and experience must sometimes be the teacher. The soil to obtain is one of a friable nature, full of regetable fibre. We find in an old magazine the best directions we remem- 
ber to hare met in regard to choice of soil. We give them entire for the benefit of our readers:-

"Heaths, like the azalea and rhododendron, make very small, hair-like roots; and where these latter are growing naturally, will be found a good locality to collect soil for the artificial cultivation of the former. This soil will be found full of decaying organic matter. Take up a handful of it, and you will find a mass of thickly grown, fine fibre, feeling like a bunch of moss. Examine it, and you will see that it is chiefly composed of a black debris of leaves and sticks, thickly interwoven with the roots of surrounding vegetation. An inch or two only of the surface shoult be taken; all below that is generally inferior, the organis matter in it being too much decomposed.

"Where this deposit cannot be obtained, a good substitut: will be found in turves from old pasture, cut thin, collected in dry weather, and piled in a heap two or three months before using, so that the regetation in it may be slightly decomposed. Both in its chemical and mechanical properties such a soil is nearly all that can be wished. In preparing it, however, it is better to chop it up rather fine, securing a proper mechanical texture by the admixture of coarse sand, broken charcoal, or even a ferw pebbles, or 
broken potsherds may be used to advantage for keeping the soil open, to allow free admission for atmospheric gases; an essential point to be kept in view in the cultivation of all plants, more particularly those in pots, for they are then entirely dependent on the cultivator for those conditions which they receive in their natural habitats.

"Such a soil as here recommended, kept sufficiently open by any of the above mentioned ingredients, is easily penetrated by air, thereby increasing its temperature and faci ${ }^{i}$ tribing the decomposition of organic matter, during wh.ch process various healthful gases are supplied to plants."

In either of the kinds of soil prepared as directed, heaths wril do well. The great point to obtain is a loose, porous soil; for this reason the soil should always be Ekoken, never sifted.

Another requisite in heath culture, is good drainage; this cannot be too strongly insisted upon; with the best of soil, the plants will suffer if water stagnates around the roots.

Fill the pot one fourth full of crocks, and be careful the hole at the bottom is kept open. Never place the pot in a saucer or vessel of any kind, for all water not absorbed must be allowed to drain off. The pots should be clean 
and free from mould or dirt; cleanliness is a point too much neglected.

In some sections of our country, much difficulty is experienced in growing heaths; the water containing salts in solution which are fatal to the plant, and we know nurserymen who have altogether abandoned their culture. This seems the case in limestone countries, and we have noticed that heaths, of the tender varieties, when watered with "hard" water, grew sickly and soon died. The best plan is to use only rain water, and pursuing this course no difficulty will be experienced. It is a curious fact, that in its native countries, the heath is never found in a soil of which the substratum is lime or chalk. In England, heaths are always grown apart from other plants; with us they occupy the coolest part of the green-house. As a general rule, nothing short of frost is too cold for them, and some varieties will bear several degrees of frost without injury. In the wild state, they are distributed over a vast range of country, which accounts for the different temperatures the varieties require; the degree of cold adapted to each, must be the lesson of experience. Among gardeners, heaths are termed hard-wooded or soft-wooded; the former make only a short growth each season, for example, $E$. Cavendeshii; 
the latter grow a foot or more, as E. Caffra and others. The two kinds require somewhat different treatment; the formcr being far more difficult to manage; they are, however, far more beautiful, some even dazzling from the brilliancy of their flowers. Heaths require plenty of air. If crowded, they are subject to mildew; a disease much more reasily prevented than cured. Air should be given, if possible, every day; but cold draughts should be avoided during the growing season.

Though heaths are often lost during the winter by growing them in too high a temperature, yet the greatest mortality is caused by the heat of summer. With many it is the custom to treat the plants as other hard-wooded plants; to turn them out doors during the summer, under the shade of some tree. The consequence is, the pots are often exposed to the hot sun, the tender fibrous roots become parched, and the plant dies; or else the drip from the trees rots the roots, producing the like result. Our experience has shown the best plan to be a different treatment for the plants according to their age. Early in June, all young plants should be planted out in a bed with a northern exposure; there they will grow luxuriantly during the summer. Before the September frosts, re-pot them with care, 
and winter as old plants. We have found a large bed prepared for rhododendions and azaleas the most favorable place. It is sheltered from the south by a belt of white pines. The soil of prepared peat is suited to the wants of the plant, while the large foliage of the rhododendrons keeps the soil moist by preventing rapid evaporation. For the older plants, we choose a shaded spot, and prepare a bed of coal ashes; slope the bottom to carry off superfluous moisture; plunge the pots in the bed of ashes, and if the bed is exposed to the sun for any length of time, shade by an awning. Be careful not to crowd the plants; a free circulation of air is essential. By this mode, the pots are never exposed to the rays of the sun; the plants receive plenty of light without being burned, and by syringing at evening, and sprinkling (not pouring) water upon the pots and bed, a sufficiency of moisture is secured. Some varieties of the soft-wooded class, such as Caffra rubra and alba, Margaritacea, and others, do best planted out in the full sunshine. The growth becomes short and stout, and the plants are more hardy and less liable to injury. By this course, however, all beauty of foliage is lost, for the plants become of a rusty brown color, which never disappears till the leaves fall.

Re-potting should be done whenever the roots become 
matted or collected at the bottom or sides of the pot; examine to see if they are healthy; if so, give them a larger pot; if not, prune off those which are dead, remove the old soil, and pot in the same size, or smaller, as the case may require.

The custom with gardeners is to pot heaths in the spring, but the grower must be guided by the state of the plant.

Insects give but little trouble, where proper regard is paid to the plants.

Mealy-bug is sometimes found; the best course to pursue, if the plant is badly infested, is to throw it away, for it is almost impossible to remove the insect; if but slightly affected, pick them off, and wash the plant well with warm soap-suds; whale oil soap is preferable. The same rules apply when the plants are troubled with black or brown scale. Erica arborea is particularly subject to attacks of the former, and from the fine, close nature of its foliage, it is very difficult to clean.

We have never known our heaths to be troubled by red spider or by aphis.

In growing ericas, some attention must be paid to pruning, or rather to pinching; the plants should never be allowed to grow tall and spindling; they should be grown 
near the glass, and, by frequent turning, preventea from becoming one-sided. Some varieties are of symmetrical form by nature; others require much care to control the too luxuriant branches.

Heaths strike freely from cuttings. Take the tops of the young shoots, about an inch in length; prepare a pot or pan of heath soil; cover this with silver sand to the depth of half an inch; insert the cuttings about half thcir length, as thickly as you please; cover them with a glass, and frequently wipe the moisture from the inner surface of the glass; keep them slightly moist, and shelter from the direct rays of the sun.

When rooted, pot off the cuttings into small pots filled with heath soil, with the addition of a little more sand than is used for the old plants; as soon as the season permits, plant them out to make growth. In re-potting plants or cuttings, care should be taken never to sink the crown of the root lower than it was before; rather raise than sink it.

There is no plant which makes a greater show, or proves more attractive as a specimen, than the erica. In England, it is grown in the greatest perfection, some of the plants being twelve feet high, and eight feet in thickness. Can a 
more superb object than such a plant be imagined, when in full bloom?

From over five hundred varieties, we cannot be expected to give all that are deserving of cultivation; as before remarked, none are destitute of beauty. The periods of bloom are from January to November; indeed, we may have heaths in bloom every month in the year. The following list contains a select variety in colors :-

White or Light-Flowered. Arborea, Margaritacea, Grandinosa, Boweana, Jasminiflora, Conferta, Vestita alba, Odorata, Ventricosa, Pellucida, Wilmoriana, Caffra alba.

Red Flowers. Gracilis, Ignescens, Mediterranea, Caffra rubra.

Scarlet or Crimson. Ardens, Cerinthoides, Hartnelii, Splendens, Coccinea, Vestita fulgida, Tricolor.

Purple Flowers. Amœna, Mammosa, Melanthera mutabilis, Propendens tubiflora.

Lilac. Baccans, Suavolens.

Yellow. Cavendishii, Depressa, Denticulata.

Green-Flowered. Gelida, Veridiflora, Viridis.

For window culture, the varieties succeeding best are Caffra rubra and alba, Margaritacea, Arborea, and Mediterranea.

We have been thus diffuse in treating of this plant, because it is a general favorite, yet never seen in good condition in the parlor. 
The plant is very hardy, yet impatient of the least neglect. A single day's omission to water, or a drenching, with poor drainage, will kill the plant; yet it will languish for months, and all your care will fail to restore it. If the hair-like roots once become parched or sodden, the plant will die.

We do not recommend it for a window plant, yet its beauty is worth all the care required; and will not some be fired by ambition to make the heath a window plant?

\section{THE CYCLAMEN.}

This pretty flower is too little known. It is a native of Europe and Asia, some varieties being very abundant in Switzerland and Italy, and is to be found in almost every green-house. It is of the easiest culture. Pot about the latter part of Norember, in a rich loam, with a dash of silver sand; an addition of about a spoonful of the old soot from a flue will increase the size and brilliancy of the flowers. It must be well incorporated with the soil. Bits of charcoal, broken fine, serve the same purpose. Place the crown of the bulb just above the surface of the soil. The size of the pot must be determined by the size of the bulb; as a general rule, cyclamen do not require large pots. 
Good drainage is indispensable. Keep the plants cool till the leaves are well grown, always keeping them near the glass. When the flower buds begin to rise on the foot stalks, remove to a sunny shelf, where they will soon show bloom. By shading, the duration of the flowers is prolonged. When the bloom is past, gradually withhold water; the leaves will turn yellow, and the plants should be kept dry, in a state of rest, all summer. Do not allow the plants to ripen seed (which they do freely) unless you desire seedlings, to increase your stock. The seed germinates easily, sown in rich loam, and seedlings bloom the third year. Some find difficulty in preventing the shrivelling of the bulbs during the summer. Our best cultivators, to prevent this, bury the sulbs during the summer in the open border; take them up about the middle of September, when they are found fresh, plump, and in good condition for a start. There is one risk, however, in this method: mice are very fond of the bulbs, and sometimes commit great havoc. There is shown in this plant a curious provision of Nature: no sooner has the flower faded, than the stem begins to curl up, and buries the seed capsule in the ground, at the root of the plant; this is designed to protect the seed from birds, and to sow it in a congenial soil. 
Good-sized, blooming bulbs may be obtained at any green-house, for from fifty cents to one dollar each for the more common varieties. This bulb is particularly adapted for window culture, and will give more flowers, with less trouble, and occupying less space, than any flower we are acquainted with. The more common varieties are C.Persicum, white, tipped with rich, rosy purple; C. Persicum album, pure white; C. punctatum, resembling Persicum. All these flower from January to March. C. Europceum, pinkish purple; C. Europaum album, pure white; $C$. hederafolium, very large, rosy purple, a splendid variety. All these bloom from October to January.

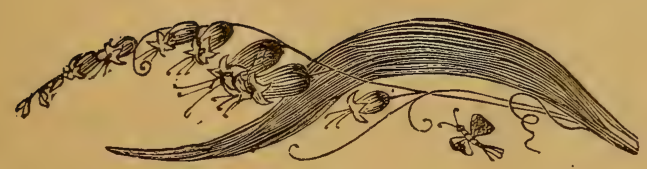




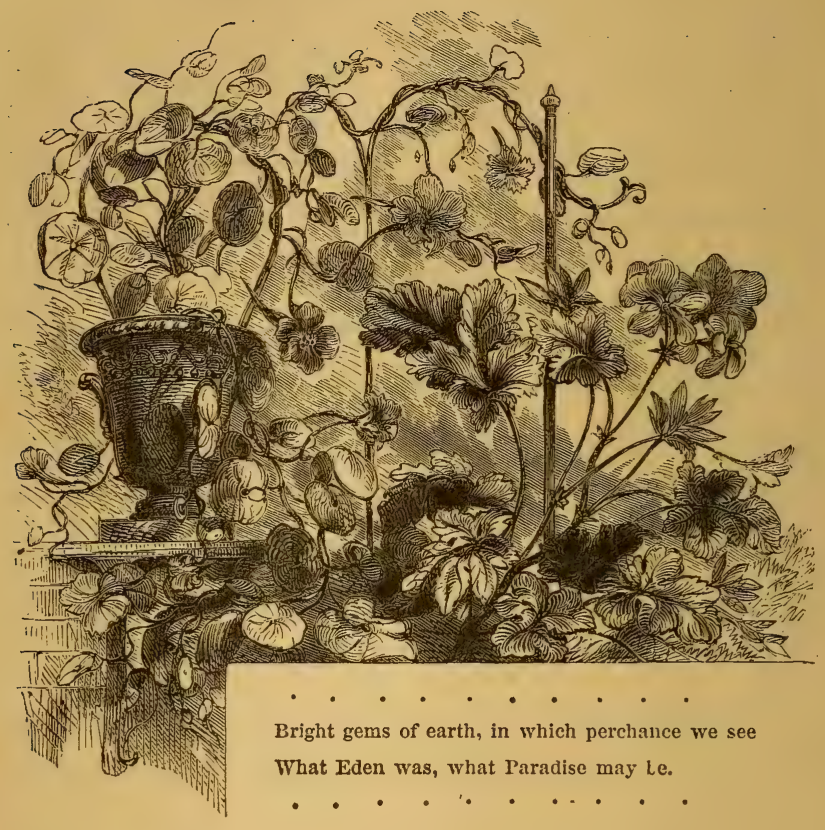

\section{CHAPTER IV.}

\section{PLANTS FOR WINDOW GARDENING.}

The Geraniun. The Pelargoniun : History.-Culture. - Soil. - Potting. - Winter Treatment. - Varieties. THE VErBeNA: History. Culture. - Cuttings. - Summer Culture. - Potting for Winter. - Watering. - Soil. - Seedlings. - Properties of a good Verbena. - WVindow Culture.-Varieties. The Heliotrope: History.-Culture.-Pruning. - Varieties. The SAlvia, or Mexicar SAge: Summer Culture. 
- Winter Culture. - Varieties. The Tropelur, or NAsturtrur : Varieties. - Soil. - Culture. - Varieties of the small Nasturtium. - Window Culture.

\section{THE GERANIUM.}

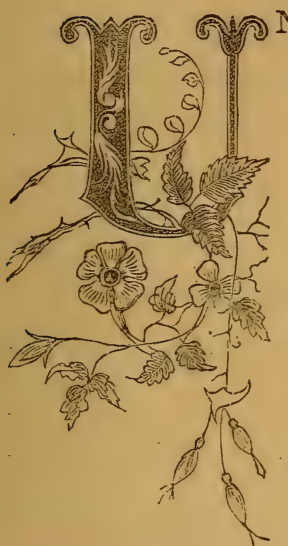
of the plants usually known, in common parlance, as Geraniums, including both those horticulturally and botanically known as such, and Pelargoniums. Between these there are many minute and fanciful distinctions; the principal seems to be, the geranium has no nectary; the pelargonium has a nectary adhering to the peduncle. For window gardening, their treatment must be the same.

For the pelargoniums, we are chiefly indebted to the Cape of Good Hope ; the geranium is found, in some of its varieties, in Asia, Europe, and America; two of the family, our "wild geraniums," being familiar to us all as among the wild flowers of spring.

The scarlet, or horse-shoe geranium, so called from the color of its flowers, and the dark marking of its leaves, is a very common and popular window plant. The rose, oak, $8 *$ 
and nutmeg geraniums are commonly grown for their fragrant leaves, and for their hardiness, as they can endure more hard usage than most plants.

The general fault in geranium culture is, crowding. The plants need light and air on all sides, and unless this is afforded they soon become one-sided, long-drawn, and straggling, with but ferw leaves, and these in a tuft at the end. The blossoms are small and few, and the whole plant presents a picture of regetation under difficulties.

The fine varieties of pelargonium, called "Fancies" by florists, it is useless to attempt to grow to any perfection in the house. They need constant care; and the rules for growing them as specimens, laid down by English florists, are sufficiently confusing and contradictory to involve the amateur in a maze of difficulty.

Light, air, and cleanliness are the three primary rules for growing geraniums. The horse-shoe and high-scented rarieties are not troubled by insects. The pelargoniums (largeflowered geraniums), require constant attention to keep them free from the green fly, which increases upon them with wonderful rapidity, If the weather is warm, and the plants at all affected by the fly, they should be smoked once in ten days, and frequently syringed. Surely the beauty of 
the flowers will compensate for any trouble. To prevent "drawing," that is, the growing of the plants towards the light, all geraniums should be frequently turned, which will give a well-proportioned plant. If the plants grow too tall, pinch out the top; all the axillary buds will then break into lateral branches. Again, if the side branches become too close, prune them out fearlessly. The geranium breaks easily, and you need never be afraid of killing the plant, even if you prune it down to a bare stump.

\section{SoIL.}

Pelargoniums and geraniums require a strong soil; that is, good sound loam, such as will grow melons. The top of a pasture will answer well. Let it be carted home and laid up in a long ridge, so as to expose as large a surface to the air as possible. Keep it clear of weeds, and let it be turned over every little while. To two parts of this loam, add one part of two-year-old cow dung, well turned over. Old hot-bed dung will do nearly, but not quite as well. Then add about one part of river sand and bits of charcoal, mixed. Let all these ingredients be kept in separate heaps till wanted for potting, then mix them in the above proportions, and use them moderately dry. This compost should 
be used to bloom and grow the plants in. For the winter season, use a small quantity of leaf mould instead of dung. Fresh soil is always to be preferred, for old soil is apt to become cloddy and sour.

\section{Potting.}

All being ready, put the drainage in a suitable sized pot. Place first a suitable crock, or a large oyster shell orer the hole; then lay a few large crocks upon that, and smaller upon those, so that the drainage may occupy about three fourths of an inch. Place a thin layer of moss upon the drainage, and upon that a sprinkling of soot or charcoal dust; after that a thin layer of the rougher parts of the compost, and finally a layer of soil. Then turn the plant out of the old pot, pick out the old drainage, and loosen part of the old roots, spreading them over the new soil as much as possible. Then see that the collar of the roots is just below the rim of the pot, and fill in around the ball with the fresh soil, pressing it down gently as it is put in. When the pot is full, give it a smart stroke or two upon the bench to settle the soil; level it neatly, learing it about half an inch below the rim of the pot. This finishes the potting. Then give a good watering of tepid water. 
For four or five weeks, while new roots are running into the fresh soil, they will not need a large supply of water; but when the roots reach the sides of the pots, and the leaves and shoots are advancing in growth, then water will be required in abundance.

They should never be allowed to flag.

After a hot, sunny day, let the plants, in addition to the water at the roots, have a gentle syringing. Exercise discretion, however, on this point.

The geranium is a spring and summer blooming plant. It is very difficult to obtain a flower from December to April; therefore, during the winter it should be kept cool, and moderately dry.

About the first of February re-pot the plants, give more heat, sun, and water, and your plants will bloom profusely in May.

The varieties grown only for their leaves may have more generous culture during the winter months.

\section{VARIETIES.}

Iry-leaved geranium ( $P$. lateripes), is a pretty trailing species, with ivy-shaped leaves and purple flowers in the summer. There is also a variety with white flowers. It is 
a pretty window plant, and always does well. It needs plenty of light, sun, and generous culture.

The varieties of horse-shoe geraniums ( $P$. zonale hybrids), are all good window flowers, and will often bloom in winter. The following are the best old varieties :-

Scarlet. Dazzle, Tom Thumb, Defiance.

Cerise. Cerise unique.

Pink. Rosa mundi.

White. Boule de Neige, Lady Turner.

Variegated Leaved. Flower of the Day, Golden Chain, Alma, Bijou.

These latter varieties need a green-house to develop the rich colors of the foliage, yet they do well as bedding plants in the summer.

$P$. graveolens is the common rose geranium.

\section{THE VERBENA.}

There are few plants which lend more beauty to the flower garden in summer, or enliven the green-house in the winter and early spring months in a greater degree, than the verbena. From the variety of colors, the rapidity of propagation, the little care needed to bloom the plant in perfection, and the abundance of blossoms, it is, and always must remain, a universal favorite. 
In addition to these advantages, the facility with which new varieties are raised from seed, render it a favorite with the amateur; and in no collection do we fail to find the verbena, in some of its many varieties.

It is a difficult task to prescribe the culture of a plant so well known, and which will grow and flourish under such a variety of circumstances, and in such different situations. As every one has grown verbenas, each has his own peculiar mode of treatment, if, indeed, a flower requiring so little care can be said to have peculiar treatment.

In writing of a plant, from which seedlings are produced with such ease, and which sports into such an infinite variety of colors and shades, we cannot be too careful in expressing a decided opinion. Every year new seedlings are "brought out," and latterly the varieties have so multiplied that it is very difficult to choose those really worthy of cultivation : the favorite of this spring may, after a year's trial, be cast aside as worthless, for it may not be found worthy of general cultivation, or better varieties may have been originated.

Our verbena was introduced into England from Buenos Ayres, where it is indigenous, by Mr. Hugh Cumming, an ardent lover of nature, about the year 1825 . 
The first, and for a long time the only variety cultivated, was Verbena melindres, or chancedrifolia; but it now appears lost among the new and superior kinds which have been raised from seed. In form, it has been repeatedly excelled, but its creeping habit and abundance of bloom must always recommend it, though we doubt if at the present lime it can be obtained at any of our green-houses, and probably few of our younger cultivators have erer seen ithis once popular variety. The color is scarlet, and though perhaps equalled, can never be excelled. Many other , earlier varieties might be mentioned, but, although interesting, it would too much extend the limits of this article.

Verbena multifida, with lilac purple flowers, was introduced from Peru; Verbena Tweediana, with rose crimson flowers, from Brazil; and from these, and a few other varieties and seedlings, have sprung all the numerous varieties, many hundred in number, which may be found in extensive collections. The credit of introducing this plant into the United States belongs to Robert Buist, of Philadelphia. About the year 1835, from seed received from Buenos Ayres, he raised the first white, pink, and crimson verbenas. The plant soon became generally known, and was every where a favorite; in the floral world it caused 
quite an excitement, and the original kinds were soon surpassed, in every respect, by newer seminal varieties.

The culture of the verbena is very simple. The plants will bloom with very little care, but to grow them in perfection requires attention; of thousands of plants of any size, scarcely one is a fine specimen. Let us, beginning in early spring, trace the plant, as generally grown, and then see how much a little care might increase its beauty.

About the first of February, cuttings of the young shoots are taken from old plants : in a sandy loam, a few weeks, and sometimes a few days, will suffice to root them; they are then potted off into thumb pots, and, if placed near the glass, will soon show a terminal flower. As soon as the season is sufficiently advanced, these young plants are bedded out, and, in favorable seasons, soon form a conspicuous feature in the flower garden, continuing to bloom till long after the early frosts. About the first or middle of September, the gardener begins to re-pot his plants for winter, and the common practice is to take a runner, which has rooted well at a joint, and, after suitable pruning, to pot it for winter blooming and propagation. Others, again, take up the old roots, while others, by sinking pots in their verbena bed, about midsummer, allowed the runners to root directly 
in the pots; the pots being taken up, and the connection with the mother plant cut, the young plant receives no injury or check. But this mode is very objectionable, for two reasons : first, the loam in the pots is apt to become sour and sodden; and again, earthworms often enter the pots, and prove injurious during the winter. The plants are housed, and, for a long time, produce no flowers, and are any thing but ornamental. Soon after the new year, they begin to grow vigorously, but are allowed to trail carelessly over the staging, or droop from some hanging shelf. No care or attention is bestowed upon them, except to give the daily supply of water.

The days grow towards spring. Cuttings are again taken off; the same process is repeated year after year; and thus one of our loveliest flowers, which, with a little care, might be one of the greatest attractions and ornaments of our green-houses, is never seen in perfection, except in the garden.

That this is the fact, is to be deplored; yet the remedy is simple. By beginning about midsummer, we may have verbenas in bloom as well during the winter as the spring months. About the first of August, or earlier, cuttings should be taken from desirable varieties. In a fortnight 
they will be ready to transplant. Pot them in thumb pots, and re-pot as soon as the roots touch the sides of the pot. Keep them in vigorous growth by affording plenty of light and air, being careful they never suffer from want of water. Pinch off the leading shoots, to cause all axillary buds to break, and in no case allow them to bloom. Train the plant in any form desired, but be careful not to permit it to grow too straggling. When other plants are housed, remove your verbenas to some warm shelf, where they may have the morning sun, and on every favorable day give plenty of air, and fumigate well to destroy green aphis. Your plants will soon be in luxuriant bloom, long before those potted in the common way have shown a bud, and will continue to afford an abundance of flowers until late in the spring. To grow verbenas well in the house in summer is far easier. They may be bloomed in pots of any size, and trained in almost any form, the only requisites being plenty of light and air, careful pruning, and means to destroy aphis and keep off mildew.

One great fault in growing verbenas is the practice of watering too copiously. The plant, as originally found, grows on dry hills; and damp not only produces mildew, but rots the roots, and thus destroys or produces disease in the plant. 
The proper soil for verbenas, is two parts of loam, two of leaf mould, with an admixture of sand, and in this we have found them grow and bloom luxuriantly.

Many verbenas, which for green-house blooming are unsurpassed, are worthless for bedding purposes; the petal of the flower being too thin, or the color fading or changing. Again, some bloom well in winter, others far better in summer; some form large masses and flower well, others are of rambling growth and poor bloomers; some of creeping, others of more upright habit; while a few possess every desirable quality; and in making a selection, all these properties are to be considered.

We have said that seedlings were produced with great ease. The verbena seeds well where the plants have not been too long propagated by cuttings. A long-continued propagation by cuttings seems to diminish the power of the plants to produce seed, and, as a general rule, the further removed a plant is from a seedling, the less the chance of its perfecting good seed. The seeds may be sown in a hotbed or green-house, early in spring, and the plants, when about an inch and a half high, pricked out in the border; it is a good plan to pinch out the leading shoot, as thus the plants branch and become stronger; the plants grow rapidly, and soon show bloom. 
But to raise a seedling is one thing, to raise a fine seedling, a far different. Of many hundred raised in the course of the last few years, by the writer, not more than half a dozen have been worthy of preservation, and only one (and that produced by chance) really a first-class flower.

In raising seed, much may be done to insure its quality by planting fine varieties together, and allowing them to intertwine, then gathering the seed from these plants. No rule can be laid down to obtain any desired color, for the seedlings sport infinitely. We can only approximate towards definite results; thus, if we plant Annie (white) and Robinson's Defiance (red) together, the seedling will be likely to be pink.

The flowers of the verbena are of every color and shade, except light blue, which color has never been obtained. A good yellow verbena has not yet been produced. There is a miserable variety, with a small truss of dirty yellow fl wers. The writer, some years since, by a curious process of watering and fertilization with a white verbena, obtained a seedling, which proved, on blooming, to be of a light straw color; the plant was weak and sickly, and died before cuttings could be taken. Since that time he has tried the experiment often, but never with any successful result. 
The qualities of a first-class verbena, as laid down by florists, are: roundness of flower, without indenture, notch, or serrature; petals thick, flat, bright and smooth; the plant should be compact, with short, strong joints, either distinctly of a shrubby habit, or a close, ground creeper or climber; the trusses of bloom, compact, standing out from the foliage, the flowers meeting, but not crowding each other; the foliage should be short, broad, bright, and enough to hide the stalk; in the eyed and striped varieties, the colors should be well defined and lasting, never running into each other, or changing in the sun.

As a window plant, there is nothing that will give more bloom than a verbena. Let it be trained on a trellis, and give it all the sun possible; the more sun, the more bloom. Pinch the shoots, to prevent its becoming too rambling, and give air enough, and your work is done.

The production of seedlings, as above directed, is a very pretty amusement, and very simple. Seedlings will bloom in three months, from the seed.

It only remains for us to describe some of the best varieties, both old and new. Those called first-class flowers, can be recommended for general culture, while many others, though very distinct and beautiful, are valuable only in a 
large collection, or interesting to the amateur. We have not noticed seedlings, unless they have been proved and shown to be worthy of general culture.

Giant of Battues. Flower and truss large; habit good; foliage large; color dark scarlet, with purplish eye. A good variety.

DrED. Flower medium; habit weak; a good bloomer, but of a dull purplish lake color. Pretty for variety.

Admiral Dundas. Foliage and habit good; color velvety scarlet. Fine.

General Simpson. A magnificent variety; color scarlet, crimson; flower and truss very large; habit very strong; by far the best of its color. No garden should be without it.

Celestial. A strong growing variety, the leaves often two inches across; truss large, forming a fine head; color pink, with darker eye; very fine.

Evenimg Star. Color dark crimson, with well-defined white eye; growth small; very fine in the house, and one of the best of the eyed varieties for the border.

Rosy GEM. A lovely verbena; flower and foliage of medium size; color rosy lake, with light eye; fine in the house, but worthless for open culture. 
Brillitant de Vaise. Growth fine; color crimson scaxlet; a first-class variety; succeeds equally well in the house and garden, though a late bloomer.

Clmax. Light, with dark eye; good.

Chauvieri. Of weak habit; color dazzling crimson, with dark eye; valuable in a collection.

Definance (Robinson's). A fine old variety, always popular, and one of the best for bedding; growth strong; color dazzling red.

Defiance (Kurtz's). Of large, strong growth; color light pink, shading to a dark eye; truss very large and flat; fine.

Etorle de Venus. Similar to the last, but larger and finer.

Axvie. Habit strong; foliage medium; color pure white; truss large, flat, single blooms very large; in some situations in the garden it has been very poor, in others very good; a damp, peaty soil has flowered it in perfection, while in a dry or sandy place the trusses have been small, the growth weak, and the flowers inclined to change to pink. In the green-house, for winter flowering, it is very superior, being a constant bloomer; a well-grown plant will give more bloom than two of any other variety; superior. 
Imperatrice Elizabeth. A pretty little striped variety, which should be in every collection; truss flat and small; foliage cut and fine; habit creeping ; very pretty for a specimen plant, and a free grower in the garden.

Dedham Belle. A good pink, free-flowering variety.

IPHIgene. Purple, with dark eye; a superior old variety.

St. Margaret. An old popular variety; color crimson scarlet; truss and flower good; always a free bloomer, and well worthy of cultivation.

Glory of America. A first-class verbena for the garden; always a mass of bloom; crimson.

Lond RAgLAN (Banks's). Dark crimson, with dark eye ; a fine flower; but the plant is of slow growth, and a poor bloomer.

LoRd Raglan (De Fosse's). Light pearl color; peculiar; good for spring blooming.

Madeline Parfune. Like the last; fine for the garden, but useless in the green-house.

Mrs. Archer Chive. A first-class variety; color rich carmine, shading to dark eye; equally fine for green-house or open culture.

Mrs. Holford. A fine white; growth strong; very 
fine for garden blooming, but very late in the green-house; superior.

Striped Eclipse. An old variety, of very rambling habit, very good, but now little cultivated.

Standard Bearer. Rich plum color, with white eye; a very desirable and beautiful variety.

Vicomptesse Emelyn. Color white, shading to dark; well-defined eye; a free flowerer; by far the finest of its class; does not propagate easily.

JENNY LIND. A pretty white and purple-eyed variety. - Verbenas may be grown to advantage in the garden, either in masses, as single plants, or upon rock-work ; many pretty effects may be produced by a careful arrangement of colors; they are also well adapted for hanging pots and for vases, in which they will bloom profusely.

There is no flower which, if properly grown, will better repay the care required, and none which will show so well with but little attention, and we trust that these few remarks may lead to a more careful cultivation of this beautiful plant.

\section{THE HELIOTROPE.}

This plant is always admired for its fragrance, and will ever be a favorite for window culture. 
It is a native of Peru, and has been in our gardens since the year 1757 .

The details of culture are similar to those prescribed for the verbena; the soil should be strong loam, with a little sand and manure.

The heliotrope is seldom grown as well as it should be. It should have frequent re-pottings, and be allowed to grow large. We have seen them in parlors, in large tubs on wheels, and eight feet high. Such plants are in themselves bouquets of beauty, being always covered with flowers. Train the main stems of the plant to a trellis, and let the branches droop naturally, and as they will gracefully. The plant bears the knife well, and breaks freely, so it can be trained into any shape.

The common variety is $H$. corymbosum, then the oldest, H. Peruvianum; H. Volterianum is a fine dark variety, but not so strong growing.

Florists' catalogues contain many varieties, but the above are the best for general culture.

\section{THE SALVIA.}

This plant is only valuable as a window plant in summer and early autumn. The chief variety cultivated is the Scarlet 
Mexican Sage (S. splendens), introduced from Mexico ahout forty years ago. It is a rank growing shrub, with long, jointed stalks, crowned with rich, scarlet flowers. The best way to grow it is to set the plant in rich soil in the garden in spring. It will grow vigorously. About the last of September pot it (it transplants easily), shade it for a few days, then remove it to a sunny window, where it will delight you with its brilliant blossoms for two months. Then keep it cool until spring, and repeat the operation until the plant becomes so large as to be unmanageable; then spring cuttings must be taken off and rooted.

The proper soil is, three parts loam, one leaf mould, one manure, with a sprinkling of sand.

Salvia patens is an exquisite blue flowered variety. It blooms well in the garden in summer, and the fleshy roots may be preserved like a dahlia through the winter.

There are many other fine varieties.

\section{THE TROPAOLUM.}

This flower, from its earliest discovery and introduction, has been a popular favorite. As year by year newer varieties have been discovered, or finer seedlings raised from old favorites, it has steadily advanced in favor, till now, the 
rich man's choicest green-house and the poor man's garden alike boast some of the varieties of this beautiful plant. In the limits of a short article, like the present, it will be impossible, of course, to give a detailed description, or even to mention all the varieties; many are only desirable in a collection, being of inferior beauty; while others are rare, or of difficult culture, and therefore found only in the greenhouses of amateurs.

The different varieties of tropæolum divide themselves into three distinct classes. First, those with bulbous, or rather tuberous roots, such as Tropcoolum azureum and others. Second, those with large, round leaves, and large showy, often coarse, flowers, as the various varieties of Tropceolum majus. Third, those with small, delicate, regularly-formed flowers, with smaller leaves, and more of climbing rather than trailing habit, such as T. Lobbianum. We are aware that this division is imperfect; that some varieties partake of the characteristics of more than one cliss, and that others are with difficulty included in any of the three; and to any one acquainted with all the different varieties, the difficulty of classification will be at once apparent. We shall, therefore, only attempt this general division; leaving a particular description to be given when 
we treat of each variety. The soil to be used in the culture of the tropæolum is, for the bulbous varieties, leaf-mould and peat, with an admixture of fine sand; for the other classes, an addition of more sand is to be advised, as care must be taken not to enrich the soil too highly, for in a rich soil, with plenty of room to develop the roots, the plants are apt to run all to leaves. This may be prevented in two ways, either by giving a poor soil, or by allowing the roots to become "pot-bound," and nourishing the plant by slight waterings of liquid manure; they generally fail to give satisfaction if the soil is close, heavy, and binding. All the varieties, we believe, are readily propagated by cuttings, and many produce seed in abundance. Some succeed better if allowed to trail on the ground; others are so delicate as to need constant attention and careful training. Some are hardy in England, though to our knowledge none have ever been able to survive our severe winters in the open ground, or protected in frames. All the varieties are of the most rapid growth, and are mostly free flowerers; none are destitute of some beauty, while the greater number are remarkable for the combinations of dazzling colors which they afford. The prevailing color is yellow in its different shades; next, red; then dark; and lastly, a most extraor- 
dinary fact, which puzzled the botanists, a beautiful blue. It had been asserted and argued, with great show of reason, that a flower, of which all the known varieties, or the general types, were of red, yellow, or cognate colors, could, by no possibility, be found related to a plant with blue flowers, or could there be a blue flowering plant in the same class. The discovery of a blue tropæolum, in 1844, completely refuted this theory. In the treatment of the tropæolum, it is essential for the good health of the plants that they should enjoy plenty of light and air ; without this, they cannot fail to become sickly or unsightly from faded leaves and small flowers. A supply of water should be given with the syringe, overhead, occasionally, which will conduce to the vigor of the plant, and destroy the red spider, which sometimes attacks the leaves. The plant, in all its varieties, is remarkably free from disease or insects; we have occasionally had the more delicate varieties troubled by green fly, and by mealy bug, but very little care will prevent this. The chief danger seems to lie in the decaying of the roots by over-watering when in growth, or by not withholding water when they are in a state of rest. These remarks, of course, apply only to the bulbous varieties. Sometimes we have known the roots of the summer-blooming varieties to 
be attacked by the root aphis, but this is unfrequent. The foliage is of too fiery a taste to be subject to the attacks of insects.

With these few remarks we will proceed to the description of the different varieties, noting any peculiarity in the habits of each, or any peculiar mode of culture which may be best adapted to its nature.

The oldest and best known variety is TrOp the common nasturtium of our gardens - a native of Peru, but very early introduced. This occurs in a variety of colors, and under a variety of names. The colors are chiefly red, yellow, very dark, and all the intermediate shades; or, again, red upon yellow in spots, shadings, stripes, or bands, or yellow upon red or dark ground. Scarce two flowers, unless self-colored, will be found alike, and there is no prettier sight than a flower bed filled with this variety, the various colored flowers contrasting finely with the large round leaves. At any seed store, varieties may be obtained; and by a little care in planting the seeds, a beautiful effect may be produced. This species is of the easiest culture, and will grow almost without care; it is well adapted for covering rock-work, or any unsightly spot, producing from the latter part of June until killed by the 
frost, a constant succession of brilliant flowers and ornamental foliage. All the varieties of this species are annual, and are propagated either by seeds, which are freely produced, or by cuttings of half-ripened wood, which root freely in sand.

Tropeolum majus atrosanguineum is only a very fine variety, as its name implies, of the above. It was introduced into England as early as the year 1684. The required soil is light and rich; it flowers freely; increased ${ }^{*}$ by seeds and cuttings.

It would be useless to attempt a description of the varieties of Tropoeolum majus; so constantly do they change, that each year, as newer seedlings are produced, the older are forgotten and lost. All are well worthy of cultivation, and some of the varieties should be in every garden. We have seen a double variety, but it was evidently a mere sport, which was only propagated and preserved as a curiosity in a collection; the colors were confused, and the blossom destitute of beauty.

We pass now to the varieties of Tropceotum minus, being those comprised in our last class, and seemingly only reduced specimens of Tropceolum majus. We have seen it stated that this variety was introduced before Tropceotum 
majus, but we believe the best authorities agree on the latter being the oldest known variety. Be this as it may, both were known in Europe at a very early period. The plants of Tropceolum minus, and its varieties, may always be distinguished from those of Tropcoolum majus, and its varieties, by the leaves; in the former, the nerves of the leaves always end in a point, which is never the case with those of the latter.

- Tropeolum lobbianum, sometimes called $T$. peltophorum. One of the very finest; first collected by Mr. Lobb, in Columbia. A rampant grower, and free flowerer in the green-house; color of flowers, orange scarlet. The temperature of the house to bloom it well, should be kept about fifty degrees; a slight watering of liquid manure should occasionally be given. It does not succeed well with us in the open border; our summers. are too short, and the plants are apt to be nipped by the frost just as they are fully set with flower buds; it strikes freely from cuttings, and produces seed sparingly. Most of our fine, new varieties are probably hybrids between this and the following.

Tropeolum PULChERrimum. Like the last, a rampant grower; color of flowers, bright yellow, with starry rays of orange scarlet at the base of the petal; a free flowerer in the green-house. Culture like the last. 
Tropeolux Suithir. A brilliant red variety, a native of the high mountains of Columbia; treat as T. majus; will bloom well in the open border.

Tropæolum Randir. A very fine seedling of $\mathrm{Mr}$. Joseph Breck's; a very vigorous grower; the writer has, in one summer, had one side of a large green-house covered by a small plant. This variety has the desirable property of blooming equally well as a border plant in the summer and in the green-house in winter. The color of the flower is brilliant yellow; the base of each petal marked with a round black spot; the flowers are often veined with purplish red, sometimes very deeply, and, from a large plant, often dozens of blossoms, all of different shades, may be gathered; this is particularly the case in the green-house; in the border, the colors are more constant. This is probably from its abundant flowers and free habit, the most popular variety of its color, among gardeners for bouquet purposes, and, though of comparatively recent introduction, is very widely disseminated. Propagated by cuttings; produces seed sparingly.

TROPfolUM PERTGRINUM, ADUNCUM, Or CANARIENSE, commonly known as canary-bird flower. A very lovely and popular variety; grows about ter feet high, and blooms well 
if the soil is not too rich. It is commonly cultivated as a summer border plant, but will bloom well in the greenhouse. To this end, plants should be struck during the summer, and grown with plenty of light and air; let the soil be loam, and well rotted manure, with a little sand; do not give the roots too much pot room, and water occasionally with liquid manure. Plants may also be raised from seed, but they flower less freely than those struck from cuttings. This lovely variety is too well known to need description.

We have been thus diffuse in treating of this plant, because it is the best climbing window plant we have. Give it sun, and it will be a mass of bloom all winter. A pretty way is to train it up the side and across the window on strings. Do not, however, give it a very large pot, or it will all run to leaves. It should also have a sandy soil.

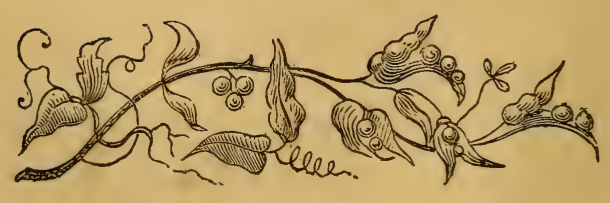




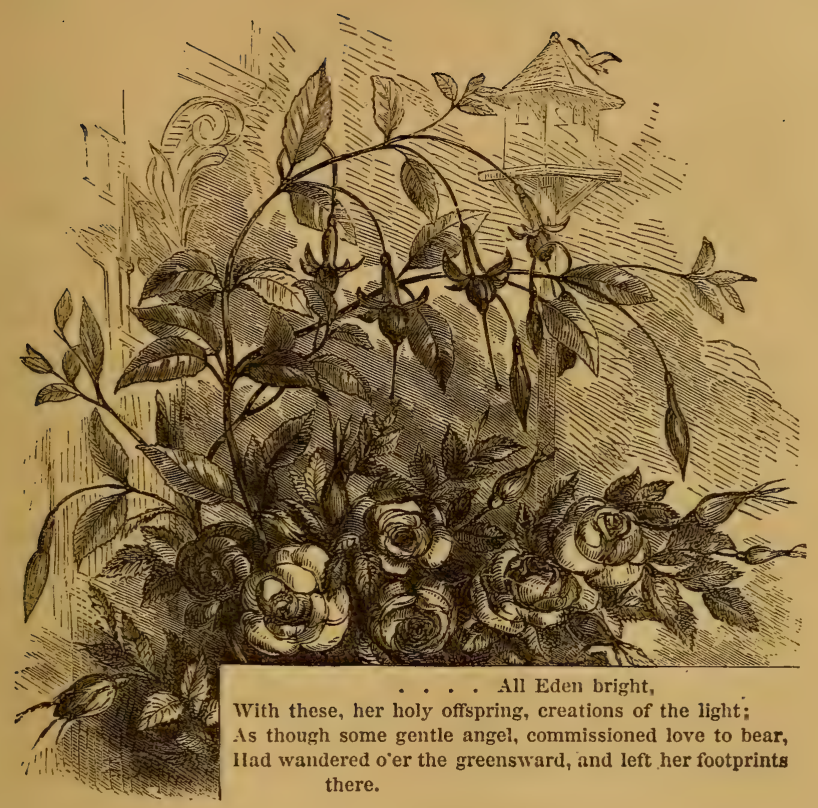

\section{CHAPTER V.}

\section{PLANTS FOR WINDOW GARDENING, CONTINUED.}

Roses. Chrva Rose: History.-Description.-Soil.-Pruning.-Watering. - Varieties. TEA Rose: History. - Culture. - Varieties. Bourbon Roses: History.-Culture.-Varieties. Pisks: Indian Pink. - Carnation._-Difference between Carnation and Picotee.-Classes. - Soil. - Potting. - Care of Flowers. - Culture out of doors. - Prop- 
agation. - Layers. - Pipings. - List of Carnations and Picotees. FuCHSIAS : History. - Growth. - How to direct it. - Wintering. - Soil. Varieties.

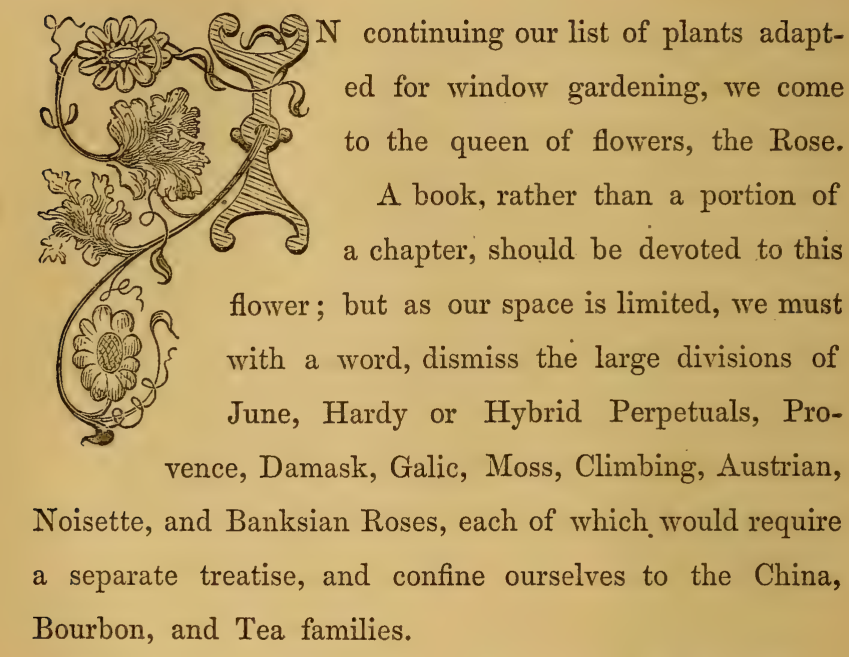

Many of the others are of great value for the greenhouse, some being, in our climate, purely green-house roses, and others being invaluable. for forcing; but none succeed with parlor culture, though many are well known in the garden, and may claim more than a passing mention when we come to the concluding portion of our book, the Flower Garden and Shrubbery. 


\section{CHINA ROSE.}

And, first, the China rose. While treating. of parentage, we may also include the tea rose, which, with the China, comes from the same ancestor, the Rosa Indica and its varieties. From this stock come all the China and teascented roses, which, by skilful hybridization, are now so multiplied that already their name is legion. Properly speaking, the three roses which are the oldest, and may be considered parents of the race, are Rosa Indica, the common Chinese rose, $R$. semperflorens, the crimson or sanguinea rose, and $R$. odorata, the Chinese or sweetscented tea rose.

The China rose and its hybrids are usually stout growing, and sometimes of a close, twiggy habit. With us they will not endure the winter without protection, but south of Baltimore, stand out uninjured.

They are the common rose of window gardening, and are known as "monthly roses." The colors vary from white to deep crimson or red, running through all the shades of blush and pink.

They are often exposed for sale in early spring at the corners of streets and in the market places, every little 
shoot being crowned with a bud or flower. The foliage is generally smooth, glossy, and fine cut, clothing every little twig, and of a lively, fresh appearance.

It will survive almost any treatment, and will live if but a ray of sunlight can reach it. It is the poor man's friend, and clings to him in every vicissitude; yet, while possessing adaptability to circumstances in a remarkable degree, no plant will better repay care and attention. Cleanliness, washing, and syringing are essential to good health; give plenty of light, and it will repay you by abundance of bloom. Though as its common names (daily or monthly rose) imply, it will not bloom every day, yet there will seldom be a day when it will not have a flower or a bud upon it. It will ask you, too, for an occasional smoking; for the green fly is very fond of the delicate juices of its young shoots, and this indeed of all roses.

Do not give it too large a pot. Roses will do well in smaller pots, in proportion to their size, than almost any other plant.

SoIr.

Yet the soil must be rich and well mixed. It should consist of four parts of the richest black loam, or leaf mould, two parts of well-rotted manure, with a slight ad- 
PLANTS FOR WINDOW GARDENING.

mixture of fine sand. This soil should not be sifted, but lumpy; yet well mixed together.

In potting, as much of the old soil as can be taken off without breaking the roots, should be removed, and the plant set just up to the neck or collar, on the new soil; settle the earth well around the plant, and give a gentle watering from the fine rose of a watering pot. Pruning should be done as required; the eyes will break any where; therefore, whenever a branch becomes too long or unsightly, cut it in; there need be no fear of injuring the plant.

If they have been planted out in the garden during the summer, on removal to the house in the autumn they will need a severe pruning. Cut off the young wood to within a few inches of the old wood, and give the plants a little rest, by giving less water and little heat; when you wish them to bloom, bring them into full sunlight, give more heat, and, as soon as the young branches have begun to push, give plenty of water. Every eye will produce a shoot, crowned with one or more buds; after blooming, shorten in the blooming branches about one half; new eyes will push, and a second display of bloom be the result. In watering roses, care must be taken not to render the soil 
cold and sodden; water should never stand round the roots; frequent stirring of the surface of the soil is very beneficial. A few bits of charcoal, broken fine and mixed with the earth, will impart the richest brilliancy to the flowers.

The following list of China roses will be found to include the best old varieties. New hybrids are constantly produced, and all of this class make good window plants. China roses are called also "Bengal" roses.

\section{List of China Roses.}

1. Agrippina, or Cramoisi Superieur. Rich, velvety crimson, very double.

-2. La Superbe. Purple crimson, very double, flowers always opening well.

3. Eels Blush. A profuse bloomer; flowers large and double, resembling a tea rose.

4. Indica, or Common Daily. Dark blush or rose color; free grower and profuse bloomer. This is the common "monthly rose."

5. Indica Alba. A white variety of the last, of more slender growth, but double and free flowering.

6. A dwarf form of R. Indica, called "Fairy Rose," Tom Thumb, Lavorenceana, is a pretty little miniature rose, very double, and about as large as a dime or half dime.

7. Mrs. Bousanquet. Creamy blush, very fine; by some classed as a Bourbon, which it seems to be. It is very distinct from other Chinas.

8. Semperforens, or "Sanguinea." Very double; cupped; rich crimson. Every where grown and appreciated. 
9. Jacksonia. Bright red, very double.

10. Louis Philippe. Dark crimson; globular.

11. Eugene Hardy. White, changing to blush.

12. Eugene Beauharnais. Bright amaranth, very fine form, and fragrant.

There are many others which may be found in florists' catalogues.

For one rose for bloom, choose No. 8 ; for two, Nos. 8 and 3 ; for three, Nos. 8,3 , and 12 ; for four, add No. 4 ; for five, add No. 2 ; for six, No. 9 or 1 .

\section{TEA ROSES.}

The original rose ( $R$. odorata) was only introduced about 1812 , and from this have sprung our many fine varieties. The treatment required is identical with that of the China rose; yet a richer soil, and more heat and light, may be afforded to advantage. The former is easily done by increasing the proportion of manure in potting.

They also need more care, and are not so patient under neglect. For summer bedding in the garden, they are unsurpassed. Usually their growth is more delicate and graceful than that of the China varieties.

The following list includes some of the best varieties, which may be relied upon for window or garden growth. 
They will not bear our winters unprotected. This list may be multiplied fourfold from catalogues:-

1. Adam. Bright pink; large and cupped. .

2. Comte de Paris. Creamy rose; large and fine.

-3. Caroline. Bright, rosy pink or flesh-colored; large and very fine.

4. Gloire de Dijon. Yellow, shaded with salmon and rose; an imImense flower; very full; not always opening well with window culture; iby some, considered a "Bourbon."

5. Clara Sylvain. Pure white; double; very fragrant.

6. Yellow Tea. Pale yellow; long, beautiful bud; very fine.

7. Elise Sauvage. Bright yellow, fading to white; large and fine.

8. Madame Desprez. White; very fragrant.

9. Safrano. Fawn color or saffron; sometimes rosy; not very double, but fine in the bud.

10. Triomphe de Luxembourg. Buff salmon, shading to rose.

-11. Souvenir d'un Ami. Rose and salmon; fine.

12. Goubault Rose. Yellow centre; large and fine.

13. Le Pactole. Lemon yellow; very fine.

14. Bougère. Browzy, rosy lilac; a strong grower. .

15. Odorata. Fine blush, well cupped.

For one rose of this class, for window culture, we should select No. 15; then add No. 9, No. 12 , No. 14 , No. 5, No. 2 , No. 1.

\section{BOURBON ROSES.}

The union of the Damask Perpetual with the China rose has produced the new and distinct race known as Bourbons. They have a peculiar habit and foliage, are free, vigorous growers, and much hardier than the China rose. In the Middle States, they are perfectly hardy, and will 
endure our winters with but slight protection. As bedders, they are unsurpassed, and bloom during the whole summer. They are usually wintered in frames, like the China and tea roses. For window gardening, they are not as suitable as those species, yet their beauty renders them worthy of a permanent place, where space can be given, and for greenhouse and conservatory blooming, they are magnificent.

Their treatment is identical with that of the species above described.

The following are fine varieties:-

Bouquet de Flore. Light, rosy carmine.

Dr. Roque. Purplish crimson.

Gloire de Dijon. See tea roses.

Madame Desprez. See tea roses.

Dupetit Thouars. Bright crimson; very showy.

Leveson Gower. Deep rose; very large.

- Souvenir de la Malmaison. Pale flesh color, very large and fine.

Queen of Bourbons. Fawn-colored blush; a free bloomer.

- Sir Joseph Paxton. Deep rose; very fine.

Paul Joseph. Purplish violet.

Hermosa. Light blush or rose color; very fine form.

George Peabody. Dark, velvety crimson.

-Mrs. Bosanquet. Pale flesh color; good form; very fine.

The most satisfactory method of growing roses is to build a small pit for them. Plant them out in a rich soil, and they will bloom summer and winter. Very little heat 
is required to winter them safely, and the sashes being entirely removed in summer, all the benefit of growth in the open air is obtained. On the approach of frosty nights, the sashes are put on, and the roses bloom all winter.

\section{THE PINK.}

Next to the rose, this is a favorite flower, and as a window plant, does equally well in spring and summer.

We shall at once dismiss the garden, Indian, and florists' or Paisley pinks, and confine ourselves to the carnation and picotee, these being the varieties for window culture.

Yet a word for the double crimson Indian pink. It is a pretty little flower, always in bloom, and only needs light and a rich loam to make it a beautiful window plant.

The best way to procure it is to buy seed; sow it in the spring, in the garden, and on the approach of frost, pot the plants for winter blooming. It may then be easily increased by slips or layering.

The carnation pink is a very old inhabitant of our gardens. It is said to have been introduced into cultivation from Italy or Germany before 1510 .

The question is often asked, What is the difference between a carnation and a picotee? None, botanically; it is 
purely a florist's distinction. The carnation has the marks on its petals, from the centre to the edge, in flakes or stripes of colors, on a white ground. The picotee has a white or yellow ground, the edges of the petals being fringed with various shades of red and purple.

Carnations are divided into five classes, namely: 1. Scarlet Bizarres; 2. Pink or Crimson Bizarres; 3. Scarlet Flakes ; 4. Rose Flakes ; 5. Purple Flakes.

Bizarre is derived from the French, meaning odd or irregular. The flowers in these classes have three colors, which are irregularly placed on each petal. Scarlet Bizarres have that color predominating over the purple or crimson; but the Pink or Crimson Bizarres have more of these colors than the Scarlet. Scarlet Flakes are simple white grounds, with distinct stripes or ribbons of scarlet. Rose and Purple Flakes have these two colors upon a white ground.

Picotees are divided into seven classes: 1. Red, heavyedged; 2. Red, light-edged; 3. Rose, heavy-edged; 4. Rose, light-edged; 5. Purple, heavy-edged; 6. Purple, light-edged; 7. Yellow ground, without any distinction as to the breadth of the edge color.

Pinks, both picotees and carnations, are of little use as house plants until well into the spring; if, however, they 
are grown, they should be kept cool, and rather dry; there is nothing gained by trying to force them. The best method of growing them is in the open border, preserving them in a cold frame through the winter. If grown in pots, they are much more difficult of management. In the open border, they bloom in June, July, and later, and are an indispensable ornament. We do not recommend the pink as a window flower, but have been constrained to include it in our list, as it is a favorite flower.

The rules we give are very full, and apply both to the window, the cold frame, and the garden; they are compiled from English authorities, and possess little claim to originality.

\section{Propagation and General Treatment.}

Soil for Culture in Pots. Get the turf from an upland pasture; take off about three inches thick, and keep it in a heap for a year, to cause the grass roots to decay and mellow the soil; chop it, and turn it over four or five times during the year; it will be in finer condition for use. During this, the worms and grubs, especially wire worms, should be picked out, for it is frequently the case that the soil best adapted to the carnation contains its greatest 
enemy. Before being used, the soil should be passed through a coarse sieve or screen, and the fibre rubbed through with the soil. The soil in which the plants are bloomed, and that in which they are kept in small pots through the winter, should be different, for in the latter they are not required to make much progress, and the less they are excited in autumn and winter the better, provided they make steady progress and preserve their health. This can only be secured by abstaining from the use of stable dung, using pure loam, and such decayed regetable matter as is afforded by the grass naturally growing in loam when the turves are cut. Neither should the loam be too adhesive, but sufficiently porous to allow the water to percolate freely; should it not be so naturally, a little sand may be used to lighten it. In preparing the soil for blooming the plants, take of this loam three parts, well decomposed leaf mould one part, thoroughly rotted cow dung one part (if this cannot be obtained, hot-bed manure, well decomposed, in fact, reduced to a fine, black mould, may be substituted), and of sandy peat, one part. A small portion of old lime rubbish, slightly sifted, will be of service to the plant, mixed among the compost. Being duly mixed, in sufficient quantity, let it be brought under shelter to dry some time before the potting season. 
On receiving the plants from the nursery, if in the fall, they should be potted, as above, in four-inch pots, giving two inches of crocks at the bottom for drainage, and nearly filling the pot with the earth, but highest in the middle, and spreading the roots as much as possible all around alike. The soil is only just to cover the roots, and to be pressed gently to them, and in this state, after watering, to settle the loam about their roots, they should be placed in a common garden frame, upon a hard bottom, into which the waste water, when refreshed, cannot soak, but with a very gentle slope, that any water which runs through the pots may run away. In the winter management, the chief object is, to give all the air they can have in mild weather by taking the lights off; to give them water very seldom, and never till they absolutely want it. If to be grown in pots, they should be re-potted early in twelve-inch pots, two or three plants in a pot, using the soil above directed. Let there be at least three inches drainage. In putting them in those large pots, let the ball of earth be turned out whole, rub off a little of the surface, and, after having filled the large pot high enough with the compost, place the ball so that the collar of the plant, which is just above the surface of the old ball, be within half an inch of the edge 
of the pot; put the soil around it; press it down between the ball and the side, and fill the whole up level with the collar of the plant and the edge of the pot. Let them all be placed in a sheltered spot, and refreshed with water when they require it, which will be more or less frequently, according as the season be dry or wet. Let each pot have a stake in the centre, to which the plants may be closely tied as they rise up for bloom. When they show their buds, remove all but three, and the flowers will be the finer, and not more than one blooming shoot may be left on each plant. When the buds have swollen, and are about to burst, tie a piece of bass matting round the middle, and carefully open the calyx down to the tie, at all the divisions, as the flower can then open all around alike; otherwise, they frequently burst on one side, and it is then difficult to form an even flower. As the petals develop themselves, they should be shaded from the sun and rain, either of which would damage the flowers. Culture in pots is seldom resorted to in this country, unless it be for exhibition purposes; and it is for the benefit of amateurs, who wish to grow them for that purpose, that we have given such minute directions.

Culture in Beds and the Flower Border. This is the 
most common method in this country, culture in pots being attended with more trouble, and occupying more time, than can usually be given.

They succeed admirably in any good garden loam, pro. vided it is well drained; wet or moisture, when over abundant, is very injurious. The soil should be trenched to the depth of eighteen inches in the fall, enriching it at the same time with leaf mould and cow's manure, thoroughly rotted; should the soil be heavy, an addition of refuse charcoal, lime rubbish, or sand, will be beneficial, leaving the surface rough, that the frost of winter may act upon it. In the spring, the beds should be again thoroughly spaded to the depth of one foot, and raked smooth; after which the plants should be turned out of the pots, leaving the ball entire, and planted two feet apart each way. The after treatment may be the same as recommended for pot culture.

Propagation. By layers and pipings, for increasing approved sorts, and by seed for the production of new varieties.

By Layers. The time for performing this operation is when the plants are in full bloom, or a little past. The shoots of the plant, around the bottom, should then be 
brought down to the ground, and, when rooted, separated from their parent. The materials needed for layering are a sharp, small knife, a quantity of notched pegs, and some finely-sifted soil. Choose a dull, cloudy day on which to perform this work; or, if the plants are in pots, they may be layered in any weather. Begin by trimming off the leaves from the bottom of a shoot, leaving the two uppermost on, and entire. Trim off the lower leaves on every shoot before layering one, because, when a layer is tongued, it is easily broken off. When this is done, take hold of the shoot, turn it up, and pass the knife blade through the third joint upward, commencing the cut just below it ; then reach a hooked peg, thrust it into the soil, catching hold, by its hook, of the layer as it descends, and press it gently down to the soil. Do the next in the same manner, and so on until every shoot is layered, then cover them all with the sifted mould, about three quarters of an inch deep, and the process is completed; then give a slight watering, and the layers require no further care, but watering, until they are rooted, which will be in about a month or six weeks. When sufficiently rooted, pot them off into five-inch pots, a pair in each; or, if your space is limited, and the layers small, three may be put into each pot. After they are 
potted, they should be placed under glass, in a cold frame or pit, plenty of air given in mild weather, and shelter from severe frost, when it occurs. Very little water is required sduring the winter months, and the air in the frames should be as dry as possible. Should damp prevail, the plants, some fine day, should be taken out, and a coat of fine, dry coal ashes spread over the surface. The plants should then ibe replaced in the pit.

By Pipings: Carnations may be propagated by this mode, where there is the convenience of a gentle hot-bed. It is, however, not so safe as layering; but when there are more shoots than can be layered, and it is desirable to propagate largely, the superfluous shoots may be piped. Cut off the lower part of the shoot, up to the third joint, trim off the lowest pair of leaves, and pass the knife just through the joint. Prepare a pot, by draining it, and filling it with the compost up to within an inch of the top; fill that inch with silver sand, water it gently to make it firm, and then insert the piping all around it, close to the pot sides; place them in a gentle hot-bed, shading from the sun; watch them daily, and supply water when the sand becomes dry. When they are rooted, which they will show by sending up fresh leaves, pot them in pairs, 
as directed for layers, and treat them in the same manner.

By Seeds. The seeds may be sown, during the spring months, in boxes or pans filled with the same description of soil as before recommended. Let the surface of the soil be made even, and the seed, evenly scattered over it, cover them to the depth of a quarter of an inch with finely sifted mould. If early in the season, the pans may be put in a moderate hot-bed, just to cause the seeds to germinate, but must not be long kept there for fear of weakening and drawing the plants. Without artificial heat, the seeds may be sown in May, placing the pans or boxes in an open, airy part of the garden, but shaded from the sun, at least from ten in the morning till four in the afternoon. Moderate moisture will be indispensable, but if the soil be kept too wet, the plants are liable to damp off, or to be otherwise injured. When the plants have acquired six leaves, and are about two inches high, they should be pricked out in rows six inches apart, keeping them well watered until they have taken fresh root. About the beginning of October, they should be potted for the convenience of wintering. Plant out in the spring, in a bed prepared as before directed. As soon as the blossoms can be seen, all the 
single sorts should be taken up and thrown away, to give the double ones more room to grow. The finer blossoms ought then to be selected for layering or piping.

The following list comprises a few of the varieties:-

$\quad$ Carnations.
Admiral Curzon,
Coriolanus,
General Simpson,
King of Carnations,
Falconbridge,
Acca,
Squire Trow,
Valentine,
Benedict.

\section{Picotees.}

Esther,

Prince Albert, Amy Robsart, Haidee, Ophelia, Princess Royal,

Lamia, Duke of Newcastle, Ganymede.

\section{THE FUCHSIA.}

If by a window plant we mean one which blooms in winter, then the Fuchsia is not a window plant. A few solitary blooms may be produced during the spring, but the summer is its season of glory.

As a pot plant, for summer blooming, it is unsurpassed, being very floriferous, of brilliant foliage, and symmetrical habit. All of our garden varieties are hybrids, from ancestors introduced from South America and Mexico. Strange to say, there is a New Zealand species also. The 
first, $F$. coccinea, was introduced from Chili, just before the year 1800 .

The plant is of the easiest culture; the growth is rapid, and a young spring cutting will make a large plant by autumn. The secret of growing the plant is, never to let it stop growing until you have it of the desired blooming size; keep re-potting, as soon as the roots touch the pot, until you get it into a twelve-inch pot, which is large enough for the window blooming of a fuchsia. Give plenty of light and air; turn the plant frequently, lest it grow one-sided, and fumigate when needed to kill green fly. The best form to grow a young plant is the pyramidal. Train up a leading shoot, and if the plant is supplied with pot room and plenty of light, and has not heat enough to draw it out weak, it will form side shoots in sufficient abundance to produce a handsome outline, the branches being allowed to take their own pendent form. The plant may also be prettily grown on a flat trellis. The best place for a fuchsia in winter is a dry cellar, free from frost, where they should be kept nearly dry. About the first of March prune back all the side shoots, and leave only the upright stem; prune in the roots also, and re-pot them in as small a pot as will hold the roots; as the eyes break, 
thin out those which are not needed, leaving enough to give plenty of side branches. Re-pot, and treat as above directed.

\section{SoIr.}

One part of peat, one of loam, and one of leaf mould will grow them well; thoroughly mix the component parts, and break it rather fine; be careful to secure good drainage.

\section{VARIETIES.}

Every spring gives us a host of new varieties, most of which are discarded in a few years. The white corollaed varieties are generally of weak growth, and not adapted for culture out of the green-house. Those with a double corolla we do not admire; the multiplication of floral leaves detracts much from the simple beauty of the flower; they are, however, valuable in a collection, and rery showy.

Fuchsia coccinea is a pretty species, with purple and white sepals and corolla.

Fuchsia serratifolia, a species with scarlet tube, tipped with green, blooming in winter.

There are some twenty other species, which are beautiful in a green-house, but ralueless for window growth.

The following hybrid varieties are all fine:- 
Venus de Iredicis. Tube white, sepals blush white, corolla deep blue; fine habit.

Etoile du Nord. Bright scarlet sepals and tube; corolla black violet. with short, reflexed sepals.

Souvenir de Chiswick. Tube and sepals rosy, crimson, violet; corolla fine.

Ajax. A fine, dark variety.

Empress Eugenie. Crimson sepals, white corolla.

England's Glory. Fine white; scarlet corolla.

Globosa. Scarlet; purple corolla.

Glory. Crimson; violet corolla.

Lady of the Lake. Crimson blush; white corolla.

Mrs. Story. Scarlet sepals; white corolla.

Wonderful. Scarlet tube and sepals; violet corolla.

Queen Victoria, La Crinoline, Omar Pasha, Nil Desperandum, Duchess of Lancaster, Climax, Guiding Star, Rose of Castile, Roi des Blancs, Prince Fredieric William, are all fine varieties.

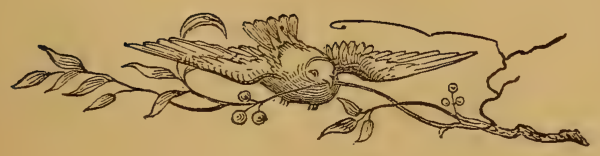




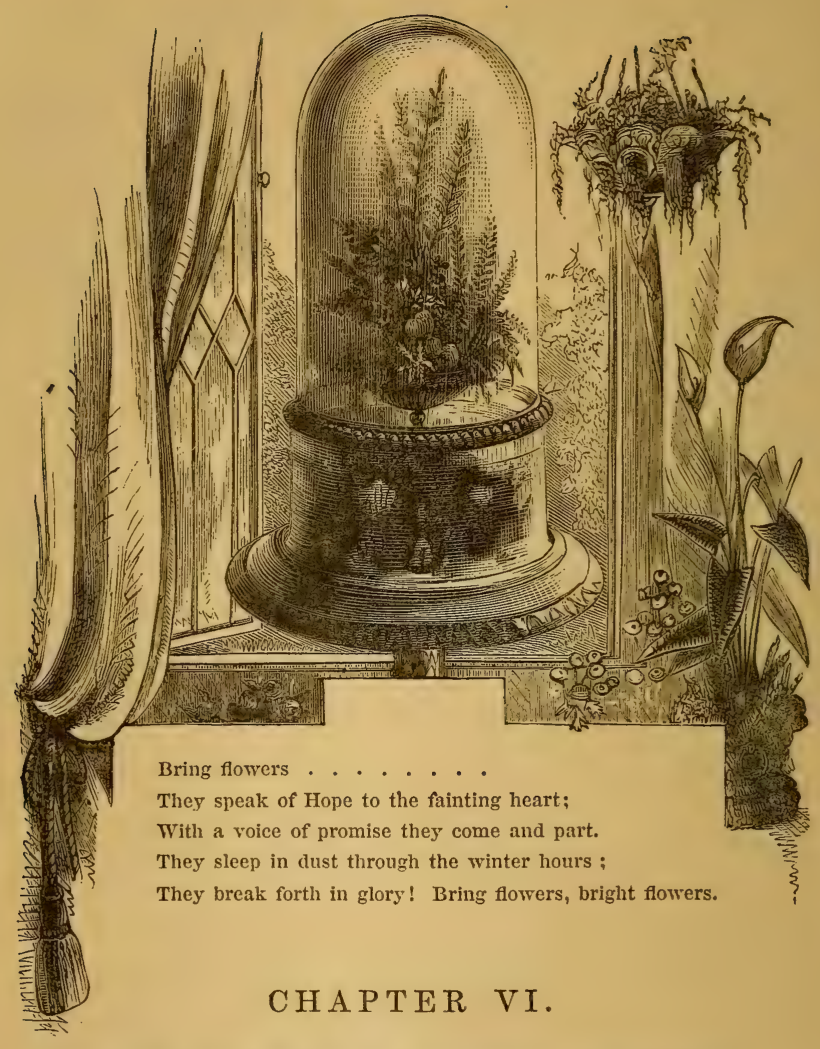

PLANTS FOR WINDOW GARDENING, CONTINUED.

Mrrtle: History. - Soil. - Culture.-Varieties. Achaxil: Ease ut growing.-Soil. AButrlox: Culture.-Soil.-Varieties. ThuxberGIA : Sowing. - Training. - Insects. - Soil. - Varieties. AlorsiA, OR Lexon VerbexA : Culture. - Soil. - Watering. CALlA: Resting.Blooming. - Soil. CupheA : Culture.-Potting.-Soil. CACtus: Di, visions of the Family. - Cereus : Summer Treatment. - Pruning. - Wa 
tering. - Varieties of Cereus. - Epiphyllum : Soil. - Varieties. HxDrANGEA : Culture.-Soil. - Effect of Iron. AGAPANTHUS: Soil. - Win. tering. - Watering. - Varieties. OLEANder: Flowering. - Soil. - Varieties. Pitrosporum: Varieties. - Soil. JAsuine: Soil.-Culture. - Water. - Varieties. Calceolaria: Sowing. - After Culture. - Soil. Mahernia: Description. - Soil. - Varieties. Prinula : Sowing.Treatment.-Soil.-Description. Solanum: A Parlor Ornament.-

Culture. - Soil. LAURestinus: Description. - Washing. Hoya: Description.-Flowering. - Watering. Chrysunthemuss: Culture. - Watering. - Soil. - Varieties. BEgonIA : Varieties. - Situation. Watering. - Soil.

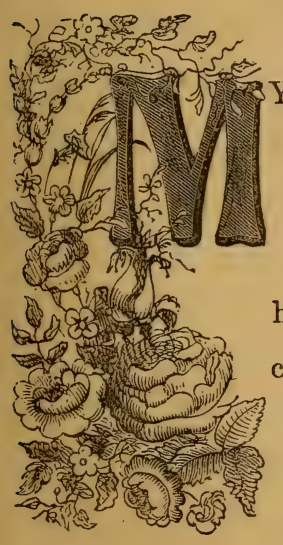

\section{THE MYRTLE.}

YRTLES are natives of Europe, New Holland, and China. They are hardwooded, evergreen shrubs, possessing a peculiar, agreeable fragrance, and have always been favorites for parlor culture.

The soil should be three parts loam; with one part of sand and one of leaf mould.

They do not require very large pots, and flourish well in almost any situation.

They require moderate washing, and watering, and plenty of light and air during the growing season, which is in summer, when they should be put out of doors in a shady place, 
yet not under the drip of trees. The flowers are usually. white, and produced in profusion in midsummer. $I I$. communis is the common plant of our parlors, of which there are many varieties, with small and large leaves, variegated foliage, and flowers single or double.

MI. tenuifolia is a New Holland species; a fine plant for parlor culture.

M. tomentosa is a fine Chinese species, with purple flowers changing to white, so that flowers of many shades are seen at once on the same plant. It should be more generally grown, being equally hardy, except it is impatient of exposure to the hot sun.

\section{ACH ENIA.}

A. malvaviscus is a beautiful parlor plant, symmetrical in growth, and producing its brilliant, scarlet flowers in profusion at the end of every branch. These flowers are succeeded by white berries, changing to bright red, which alone would make the plant ornamental did it not always display a profusion of bloom.

The best way to grow the plant is as a pyramid, as thus the flowers and fruit show to great advantage. Give plenty of sun and light, turning the plant frequently. It is not 
subject to the attacks of insects. Soil, two parts loam, two leaf mould, with a slight admixture of sand.

\section{ABUTILON.}

This is a race of shrubby, green-house plants, well adapted for the parlor.

They are free growers, of upright habit, and unless judiciously pruned, will soon outgrow their quarters. They are natives of South America and New Holland.

The proper soil is, two parts loam, two of leaf mould, and one of sand. If the soil is too rich, the growth will be too rapid for the full development of the side branches. Keep the plant moderately moist. The varieties for parlor culture are, -

$A$. venosum, with large yellow flowers with red veins; $A$. Bedfordianum, flowers much of the same character.

A. striatum, one of our prettiest window plants; always in bloom, and beautiful from its profusion of pendulous, reined, red and yellow blossoms all winter.

There are many other varieties, some with white, others with red flowers, but they are not recommended for house plants. 


\section{THUNBERGIA.}

These pretty plants are usually grown as annuals with us, for summer decoration in the flower garden, but they also make fine window plants. For this purpose, sow the seed in August in pots; as the plants grow, transplant one to each pot, and train the slender shoots on a neat trellis. Give plenty of sun, and syringe very often, for the plants are very subject to attacks of red spider. They will show ibloom about the middle of January, and produce a profusion iduring the winter and spring months. The plants will show ibud very early, but if they are allowed to bloom, growth will stop; therefore it is best to pick off all the flower buds until the plant is of the required size, when they may be allowed to open.

Cuttings root very freely in sand, under a bell glass. The soil should be, one part turfy loam, one part peat, one part well-rotted manure. Water moderately.

The varieties are, -

T. alata, buff yellow, with a black centre; $T$. alata aurantia, deep orange, with black centre; T. alata alba, white, with black centre.

There are also some superb hot-house species. 
PLANTS FOR WINDOW GARDENING.

\section{ALOYSIA, OR LEMON VERBENA.}

A half-hardy deciduous shrub, from Chili; the only species is A. citriodora, commonly called Lemon Verbena. It is valuable only for the fragrance of the leaves, the flowers being small, whitish lilac, and of little beauty. As a winter plant it is of no value, as it needs a season of rest, which must be given it in a cellar free from frost.

The best treatment is, to plant it out in spring in the flower border, where it will make vigorous growth. In the fall, before the first frost, remove the plant with a ball of earth to the cellar. In spring, trim the plant into a neat shape, and re-plant it. If grown in pots, the proper soil is, two parts of loam,'two of leaf mould, and a slight mixture of sand. TWhile the plants are growing, give plenty of water, but withhold it entirely during the winter.

\section{CALLA.}

The only plant of this genus, worthy of cultivation, is the well-known Calla Lily (Richardia Athiopica). It is too familiar to our readers to need description. To bloom the plants well, they should have a season of rest, which may be regulated so as to have blonm at any season, if we have sev- 
eral plants. They naturally rest after the blooming season. When they again begin to grow, re-pot them; if a plant with a single stem is required, remove all suckers, otherwise they will do no harm to remain; but the plant requiring frequent re-pottings, will soon become so large as to be unmanageable.

The foliage is peculiarly fine, and the plant is worth growing for this alone.

If bloom is particularly desired, the best way is to plant some six or eight roots in the half of an oil cask. Paint it green, and put on two iron handles; you thus have a very cheap, pretty, serviceable, and durable tub. Fill this with the richest loam, and set the plants, the largest in the middle, the smaller around the sides, and set the tub on the piazza or in a grass plat. The plants will bloom during the summer very freely, and may be wintered in a light cellar without difficulty.

The proper soil is richest loam and peat well mixed. When growing, you cannot give the plants too much water. In the window, if the plants are set in a saucer kept constantly filled with water, they will be the better for it. In summer, the plant will grow well, and flower profusely out of doors in a tank. 


\section{CUPHEA.}

The only plant of this family, desirable for a window plant, is the little Mexican C. ignea or platycentra. This is a sparkling little gem of a plant, always in bloom. Plant it in the flower border in summer, re-pot in autumn, and all winter it will gladden you by a profusion of its bright scarlet tubes tipped with a ring of black and white. The plant never grows above a foot in height, and is just suited for the window. Soil, about three parts loam, one each of sand and manure. Water freely, but do not allow the soil to become sodden.

\section{CACTUS.}

There are seven families of Cacti, containing each a great number of species. Those chiefly grown as parlor plants come under the families Cereus and Epiphyllum. The former family is a native of all dry, tropical regions of the western continent.

The soil most suitable is, two parts peat, one part broken potsherds, broken coarse, one part loam or old mortar rubbish, and one part manure; mix these well together and secure good drainage.

During the summer, the plants should stand out of doors 
in a sheltered place, from the time they have done flowering until September. Then remove them to the house, all parts of shoots having no bloom buds (they are easily seen along the leaves) being cut back to just beyond the buds. The plants should be confined to six or eight strong stems; while these are in good health, the growth of shoots from the roots is not to be encouraged.

Give the plants no water from September until February; while in growth, water moderately. They bloom from May to August.

Some of the varieties are, -

C. Speciosissimus. Crimson and purple flowers.

C. Flagelliformis. Rose flowers. This variety should be allowed to droop, and not be pruned.

C. Grandiflorus is the night-blooming Cereus; flowers yellowisb white. This variety will not bloom until it is old.

C. Maynatdi. Deep orange red flowers.

C. Triangularis. Cream color; immense flower.

All varieties will do well as window plants. The first is the best for general culture.

We now come to the latter family, Epiphyllum, all natives of tropical America. This branch of the Cactus family is distinguished by flat shoots, and leaves without spines. The soil and treatment is identical with that of the Cereus. The best varieties are, - 
E. Akermanni. Fine scarlet flower.

E. Jenkinsonii. Fine šearlet flower.

E. Speciosum. Rosy pink flower.

E. Alatum. White flower.

E. Truncatum, and its varieties, with scarlet, rosy, red, violet, and white flowers.

All these latter varieties are drooping, and to show to advantage, should be grafted on some of their tall-growing Cereus relations. C. speciosissimus makes the best stock.

\section{HYDRANGEA.}

This is only a summer plant, but an old favorite. One requisite for its successful culture is shade; if grown in the sun, the leaves become browned and the plant does poorly. With us, it is not hardy out doors, so it must be grown in a tub, and wintered in the cellar. The flowers are produced on the shoots of the previous year. It requires to be well grown to flower profusely, and the flowers from young plants are larger than those on plants three or four years old.

While growing, the plants should have a good supply of water.

Soil, one part loam, one part manure, one part peat. The color of the flowers is pink, but if iron filings be mixed with the earth they will become blue. 
Besides the well known pink variety ( $H$. hortensis), there are many others; of these, H. japonica, with blue and white flowers, is desirable.

\section{AGAPANTHUS,}

Or African Lily. A showy plant for summer blooming, and too well known to need description. Soil, two parts loa:2, one part manure, one part leaf mould. Well grown it is a noble plant, but will bear much ill-usage. Treated as recommended for the calla lily, and planted in a tub, it forms a fine plant.

Winter in a dry, light cellar, and water occasionally. Water freely while growing.

There is a white variety, and one with variegated foliage; both desirable; a native of the Cape of Good Hope.

\section{OLEANDER.}

A very showy, but much neglected plant; too well known to need description. To bloom them in perfection, they need a stove, and yet do well in the parlor and out of doors.

Their season for blooming is July, yet that may be changed, and bloom produced at any season. They flower freely when scarcely a foot high, but will grow to the height 
oi ten or fifteen feet, forming splendid trees covered with rose-colored, white, or variegated flowers.

Give them plenty of pot room in soil, two parts loam, two parts peat, one part well-rotted manure. Being subject to white scale, frequent washings are desirable.

They may be wintered in a light cellar, and then should be but little watered; during the growing and blooming seasons, water should be abundantly supplied.

The principal varieties are double rose (Nereum oleander splendens), striata pleno, with double striped flowers, purpurea, dark red, and as many as fifty named varieties, all good.

\section{PITTOSPORUM.}

This is an old-fashioned plant, a favorite for its fragrant flowers rather than for any beauty of foliage or blossom; the former is dull green, the latter dirty white.

The common variety (P. Tobira) is a native of New South Wales, and in England is a hardy wall plant; with us it is a parlor plant, blooming from February to May. Soil, three parts loam, with one each of leaf mould, sand, and manure.

Water freely while in bloom and growth. During the 
summer, set the plant in a sheltered situation out of doors.

The leaves need frequent washings, to keep them free from dust.

This plant will thrive with very little sun.

\section{JASMINE.}

A family of favorite climbing shrubs, and very pretty for window culture, alike desirable for their neat foliage and fragrant flowers. The flowers are white or yellow, and produced from February to June, or later.

The soil should be equal parts of loam and peat, with a slight admixture of sand. The only insect attacking them is scale, which a little care in washing will soon remove. With common room culture, they grow to a large size and make superb plants.

Water should be rather freely given. They should be trained on neat trellises, and the branches allowed to droop. The most desirable varieties are, -

J. Azoricum. White flowers in summer.

J. Odoratissimum. Yellow flowers in spring.

J. Multiflorum. White flowers in spring.

$J$. Nulliforum. Yellow flowers in spring. 


\section{CALCEOLARIA.}

The best way to grow this pretty plant is by raising seedlings. Sow seeds in August, in light, rich loam; transplant the young plants to separate pots; pinch out the centre of the plant, and continue to do so until the plant is of the required blooming size. As the roots of the plant touch the pot, re-pot into a size larger. Then the flower stems push up, tie them neatly to sticks. Be careful in watering not to give too much, or your plants will damp off. Give all the sun and air possible, and keep the plants as close to the glass as you can.

The proper soil is three parts light, rich loam, one of fine peat, one of sand.

The shrubby varieties are seldom grown as window. plants, but are reserved for the flower garden. Under the treatment given above, they grow and bloom well.

\section{MAHERNIA.}

This is a lovely flower and a general favorite, always blooming, and always attractive with its fragrant yellow bells.

Its tendency is to grow straggling, therefore it is best to 
select a plant with a straight stem. Tie up the main stem as it grows, and by continued pinching restrain the too luxuriant growth

$M$. odorata is the variety chiefly grown. $M$. Hector and Diana are pretty orange and pink varieties.

Soil, four parts loam, one of sand, one of manure. Keep the plants moist, but not wet, and give as much sun as possible. In bloom from February to May.

\section{CHINESE PRIMROSE.}

Both the single and double varieties of this plant are pretty for window gardening. Sow the seed in July, in a fine soil, as directed for calceolarias, and treat the plant the same, except the pinching. By January, nice little blooming plants will be formed; give them sun and air and do not allow them to over-bloom, as they are apt to do.

After bloom is over, set them out of doors (about June), and on no account allow them to bloom during the summer. Grow them well until autumn, then re-pot in blooming pots, and by Christmas they will begin to show flower, and keep up a succession until spring.

Soil, one part turfy loam, one part well decomposed cow dung, one part peat, and one part sand. 
Be sure the pots are well drained, and never keep the plants very wet. The colors are red, rosy, lilac, white, striped, and mottled, with fringed. and plain edges.

\section{SOLANUM.}

The only plant of this useful family, suitable for room decoration on account of its flowers, is the Solanum jasminoides, a pretty climber, with dark green foliage, and white potato-like flowers, in large clusters.

It is useful to climb around a window or to cover a trellis. It is a rampant grower, subject to no disease or insect attacks, and with sun and air, if potted in a soil of rich loam, will take care of itself, and bloom all winter.

\section{SOLANUM PSEUDOCAPSICUM.}

This plant is the common Jerusalem Cherry. It was introduced from Maderia about the year 1596. For a showy plant, in the parlor or green-house, it has no equal, being studded with bright, red berries, about the size of a cherry, during the whole winter. A plant now before us, only two years old, is two feet high, three feet through, and bending down beneath the weight of fruit. The flowers are produced in June, and are inconspicuous. Sow the 
seeds in a pot in April; as soon as the weather becomes warm, transplant to a rich, sunny border; the plants will grow rapidly, and probably be in fruit the next winter; pot the plants before the frost, and winter in room.

There is a more dwarf-growing species ( $S$. capiastricum), with orange berries, which is also very ornamental.

A strong loam is the proper soil for all plants of this family.

\section{THE LAURESTINUS.}

This plant, hardy in England, is with us a winterblooming parlor ornament. It is a free-growing, freeblooming evergreen, and will bear much hard usage. If cared for, however, it will repay the attention. The flowers are small, white, and in large, flattened panicles, expanding from February to May.

The proper soil is a mixture of four parts loam, with one each of sand, leaf mould, and manure. The pots should be large, and the plants be freely watered. Dust collecting on the foliage injures the beauty and health of this plant, therefore frequent washings are desirable. There are many varieties, some of which, as the snow-ball (Tiburnum opulus), are hardy shrubs. 
HOYA, OR WAX PLANT.

A showy genus of stove climbers, of which one, Hoya carnosa, succeeds well with parlor culture. It is a climbing shrub, the leaves dark green and fleshy; the flowers are of a peculiar waxy appearance, produced in umbels, whitish, with rose-colored centre, in which hangs a drop of limpid honey.

Give the plant a large pot, and a compost of peat and loam in equal parts, securing good drainage. Give as much sunlight and heat as possible. The old bloom stalks should not be removed, as they put out flowers year after year. Much water is not needed, especially when the plant is not growing. This beautiful plant is a native of tropical Asia, and is one of the few stove plants that will adapt themselves to parlor culture.

\section{CHRYSANTHEMUMS.}

These plants are favorites for autumn blooming, and quite a treatise might be written on their cultivation, since they have become florists' flowers. A few hints must, however, suffice.

The best way to obtain a fine specimen is, to set out in 
the garden in the early spring a small plant; give it constant attention during the summer, and pinch out the shoots so as to make lateral branches. About the first of September let it set for bloom, and on the approach of frost, pot it and remove it to the parlor. It will bloom for two months or more. Then dry it off for the winter in the cellar, and by the spring it will furnish you with plenty of young plants. Water should be liberally supplied. The smallflowered, Pompon, varieties are very desirable; the larger flowers are best seen in the garden.

The proper soil is loam and well-rotted manure, with a little silver sand. Waterings of liquid manure are very beneficial as the plants are showing bloom. The following will be found to be fine kinds : -

Pompone.

Andromeda. Cream color.

Nellie. Creamy pink. -

Miranda. Bright rose.

Christiana. Canary yellow.

Mrs. Dix. Blush.
Riquiqui. Violet plum. Lady Mayoress. White. Salamon. Rosy carmine. Canary Bird. Yellow. Miss Talford. White.

\section{Large-Flowered Varieties.}

Alarm. Crimson.

Little Harry. Golden amber.

Cassy. Orange and buff.

Hermine. Silver white.

Pearl. Pearly white.
Prince Albert. Crimson red.

King of Yellows. Yellow.

Vesta. White.

Annie Salter. Canary yellow.

Queen of England. Blush. 
PLANTS FOR WINDOW GARDENING.

\section{BEGONIA.}

The only two species of this ornamental stove plant that do well in the parlor, are $B$. incarnata, and fuchsioides. The former is an evergreen shrub, with thick, fleshy stems, and large, drooping clusters of pink flowers in winter. It shows to great advantage if well cared for, and is one of the best window plants. The latter is often called "coral drop," and resembling the former somewhat in habit, produces at all seasons, but chiefly in summer, its pretty, drooping, coral flowers.

Both species require the warmest possible situation, and plenty of light and sun. They are impatient of much water, but the plants should hever be allowed to droop. Good drainage is indispensable. The whole family thrive in a compost of one half loam, one half leaf mould, with a slight portion of sand.

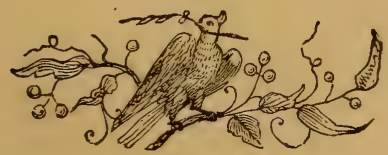




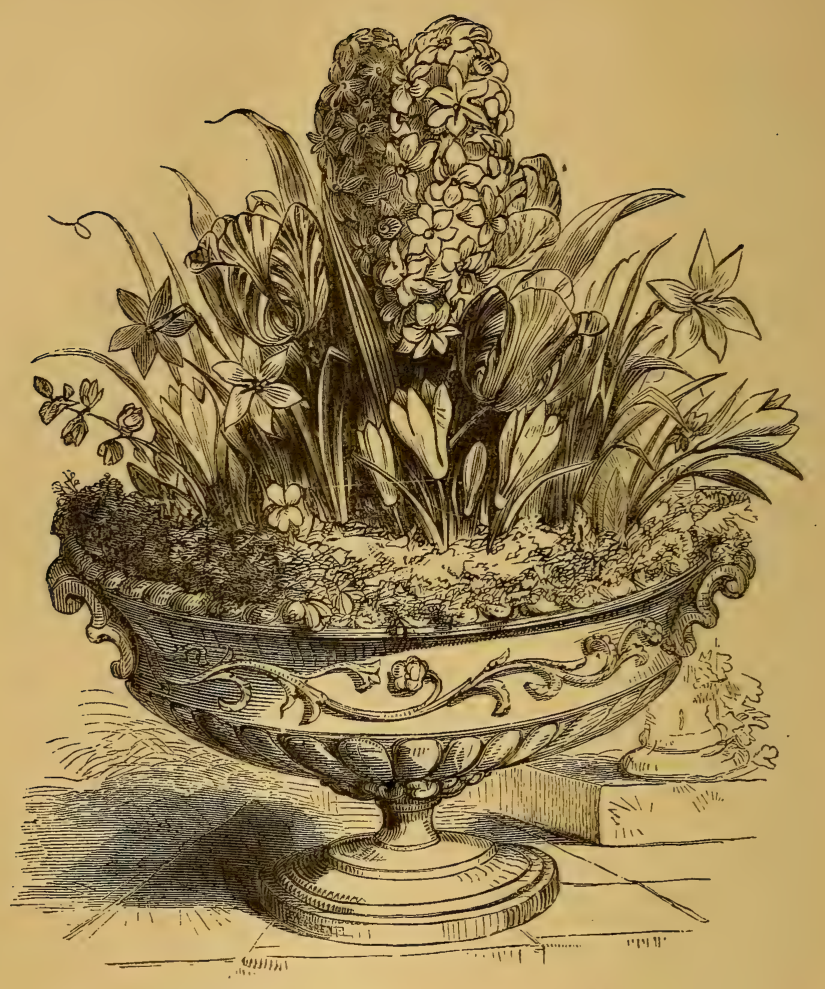

\section{CHAPTER VII.}

\section{CAPE BULBS.}

THE IXIA: Soil. - Potting. - Drying off. - seedlings. - Species. - Var1eties. The Oxalis: Culture.-Soil.-Species. The Babiaxa: Description. - Culture.-Red Spider. - Species. The Hæiraxrhus: 
Description. - Culture. - Species. The AyaryluIs: Description.Soil. - Species. The Lachenalia : Soil. - Potting. - Foliage. - Species. The Sparaxis: Description. - Culture. - Species. - Watering. The AvomathecA : Description. - Planting. - Resting. - Seedlings. Species. The Tritonia: Culture.-Species. The Homeria: Soil. - Culture. - Flowering. - Species. The Nerine: Culture. - Soil. Species.

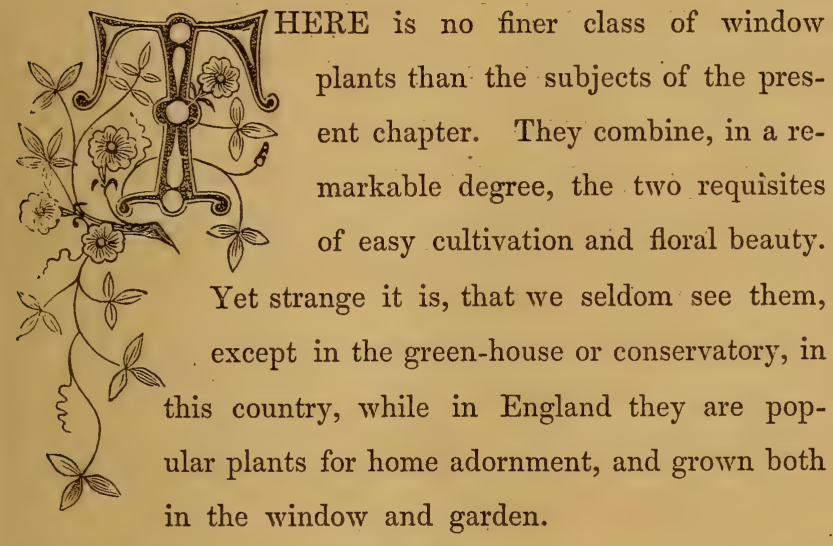

Now, the inclemency of our climate debars us from blooming these floral gems in the garden; but, as a compensation, our winter suns bring them to perfection at a season when the earth is locked with frost, and out-door gardening is entirely prevented.

They are mostly natives of Southern Africa, in the region of the Cape of Good Hope; whence their horticultural name, Cape Bulbs. From the nature of the climate 
of that region, it is obvious that the buibs must have a season of rest. The year is there divided into two portions, the dry and rainy seasons; during the one, the earth is saturated with moisture; during the other, parched with drought.

The general rule of culture is evident. When the plants start into growth, give plenty of water and sun; keep them vigorously growing until after the flowers have faded; then dry them off gradually, by watering less and less, till the foliage withers; then place them in a dry, airy place, without removing them from the pots, until the season of growth. The soil should be sandy loam, for almost all the species. Never allow water to stand round the roots.

The time for potting is from October to December; they will flower from February to April; let them dry off from March to June, and rest till October. These are but general rules; special cultural directions will be given when we treat of each species. We have only described a few of those best adapted for the house. There are moro than a hundred species, and countless varieties. To those who would see their beauty, and are unable to grow them, we would recommend Mrs. Loudon's book on Bulbous Plants, where most of them are described, and colored illustrations of many of the finest given. 
CAPE BULBS.

\section{THE IXIA.}

These are all bulbs of easy growth, and remarkable for the brilliancy of their flowers. About the latter part of November, or earlier if the bulbs begin to grow, they should be shaken from the soil in the pots, and planted anew, in a compost made of one part sandy loam and one part peaty earth, with a little well-decomposed dung, in new, clean pots; fill the pots about an inch deep with small crocks to secure good drainage, as the plants never thrive if the earth around the roots become sodden. Place the pots in a cool place till the plants begin to grow, when they should be placed in a strong light on a shelf close to the window. As a general rule, all bulbs should be grown as close to the glass as possible, as thus the leaves are shorter and of a better color, and the plants never become drawn, weak, and sickly. Do not attempt to force these plants; they do not bear it well, and are deficient in size and number of flowers. The temperature sufficient to grow them is about forty degrees at night, to sixty by day.

Five or six bulbs in a ten-inch pot, are quite sufficient, but never mix the varieties; the bulbs in a dry state are very similar, therefore each pot should be labelled distinctly, 
if confusion in potting would be avoided. These plants, in England, are often grown in frames, or in the open border. In our climate, the green-house is their proper place, as they are killed by the least frost. By the latter part of January the flower stalks will begin to appear; as they are very slender, they should be secured to neat stakes. Soon after blooming, the leaves begin to turn yellow, and the plants indicate a desire to rest. Unless it is desirable to ripen seed, the plants should be allowed to dry off gradually, and the pots then placed on a dry place, secure from mice, until the next autumn. Seedlings may be easily raised.' Sow the seeds thinly, about the first of October, in the same soil used for the bulbs; allow the seedlings to remain in the pan one year; then transplant and treat as old bulbs; they will bloom the third year, if well cared for. The most usual mode of propagation is by offsets, which are freely produced; the old bulb dies each year, giving birth to new bulbs and a host of offsets; separate these before potting, and they will soon make flowering plants. Most of the varieties do well in the parlor window, and we can recommend them as both pretty and showy, though we believe none are fragrant. We have only space to describe a few out of some thirty varieties. 
Ixia Viridifora. A most lovely species; leaves very slender; flower spike very long, producing from ten to thirty flowers. Words cannot describe the beauty of the flower; the petals are of a peculiar vivid green; the base of each black ; stamens large and yellow; the contrast is most marked; a very free bloomer, of the easiest culture. Introduced from the Cape about the year 1780 .

Ixia Crocata, or, more properly, Tritonia Crocata. Flowers orange yellow, in great profusion. A fine variety for window culture.

Ixia Conchiflora. A strikingly beautiful variety, with long, buffcolored flowers.

Ixia Conica. Flowers orange; very pretty.

Ixia Crateroides. Flowers dark yellow.

Ixia Alba Oculata. Color white, shading to yellow, with a dark chocolate eye; exterior of petals pink, yellow and white. A very fine variety.

Ixia Crispa. Flowers blue.

Ixia Erecta. Flowers white or flesh color.

Ixia Squalida. Flowers rosy lilac.

Ixia Kermisiana. Flowers vermilion.

Ixia Leucantha. Flowers white.

Ixia Capitata. Flowers white and black.

\section{The following are varieties :-}

I. Theseus. Rosy pink, shading to a deep purple or lake eye.

I. Aulica. Exterior of petals purple; interior almost white, shading to purple at the tips; eye dark purple.

I. Plutus. Exterior of petals orange, with red strip down centre of the outer; inner petals, and interior of all, bright orange; eye almost black.

I. Pallas. Only differing from last described in being straw, or cream color, instead of orange. 
These varieties resemble in growth Ixia viridiflora, are tall growers, with narrow leaves. They are very fine, and well worthy of general cultivation. There are also many newer varieties advertised in English catalogues.

An outlay of a few dollars will procure all these, and many other fine varieties, from England. The best way to procure a good stock is to import a collection. There are many new seedlings which are very beautiful. This plant will well repay the little trouble required to grow it in perfection.

\section{THE OXALIS.}

A very beautiful winter and spring flowering bulb. The varieties are very numerous, and are all indigenous to the Cape of Good Hope and America.

The details of culture for the New Holland species are identical with those given for the ixia; we need not, therefore, repeat them; any varieties requiring peculiar treatment we will notice as we proceed. The soil should be sandy peat and leaf mould, and the pots should always be well drained. These plants are not universally bulbous, some having fleshy, tuberous roots, and it is evident the same treatment will not do for all. Some varieties produce their bulbs in a curious manner; the original bulb sends 
down a long, radicle fibre, which in time forms the new bulb, and the old bulb dies.

\section{We have space but to note a few varieties. .}

Oxalis Hirta, O. Flabelifolia, O. Elongata, and $O$. Amœna require to be potted in August or September.

Oxalis Boweana. One of the best, producing large clusters of bright, rosy red flowers during the whole fall. Should be potted in September. Native of the Cape of Good Hope.

Oxalis Floribunda. A variety with short, fleshy stems, just serving to elevate the dense tuft of leaves and blossoms above the soil. Should be allowed to dry off during the winter, and bedded out in summer, when it will bloom profusely for about four months. A native of Chili. Flowers rosy pink.

Oxalis Carnosa will do well with the same treatment.

Oxalis Caprina. Two varieties, the single and double; the former is preferable, and the freer bloomer. Flowers, yellow and fragrant, produced most luxuriantly all winter. Pot in October. This variety does finely under window culture.

Oxalis Deppii. A summer-blooming variety, with fine, lilac rose flowers. Does well bedded out. A native of Mexico. The fleshy taproots of this variety are sometimes used as an esculent.

Oxalis Versicolor. A lovely variety; flowers white, with yellow eye, rosy pink, or crimson outside; whether the flowers are expanded (which they only are in sunny weather) or in the bud, they are equally orna$\mathrm{mr}$ ntal. Plant, in October, six to eight large bulbs (the largest do not $r$ xceed a pea in size) in a five-inch pot; suspend the pot; the plants droop orer the side, and are a mass of bloom from January to April. Native of the Cape.

Oxalis Luxula, and $O$. Luxula Alba, are pretty varieties, to be potted in September, and blooming freely during the winter. Flowers pink and white respectively. 
Oxalis Alba, Multiflora, Cuprea, Elegans, Palmata, Hirtella, Lasian$d r a$, and Speciosa, are all pretty varieties, worthy of cultivation.

\section{THE BABIANA.}

This is a very handsome genus of Cape bulbs, with hairy plaited leaves, and brilliant flowers.

They are natives of arid plains, and during their growing season will bear much wet, and when dry will not be injured by great heat. In their native haunts the ground often becomes powdery, and the bulbs lie exposed to the fierce rays of the sun.

The general treatment prescribed for ixias will suit them well. The soil should be kept open by sufficient sand, yet should be rich, say two parts sandy loam, and one part black leaf mould.

These plants are very subject to attacks of the red spider, for which constant syringing is the remedy. It is to be remembered that in this "an ounce of prevention is worth a pound of cure," for when the red spider once makes a home in the hairy leaves it is very difficult to dislodge him. Seedlings are easily raised, and flower the third year. The following, from some twenty species, are the best:-

Babiana Rubro Cyanea. A very handsome plant. Flower very brilliant; colors dark blue and dazzling crimson; leaves broad, covered 
with hairy down; flowers of long duration, if not exposed to too strong a light. A pot of this bulb, in full bloom, is one of the most splendid ornaments of the parlor. This beautiful bulb may be procured in this country, but not in any quantity. It is often imported under the name of Anomatheca Azurea.

B. Villosa. A fine species, with dazzling crimson flowers, produced in great profusion. In spite of its name (Villosa), the species is less hairy than others.

B. Stricta. Produces lilac and white flowers very plentifully, and continues in bloom a long time. The colors are very bright and distinct.

$B$. Angustifolia is a pretty dwarf species, with brilliant bluish-pink flowers, which are slightly fragrant.

B. Sulphurea. A fine species, with cream-colored flowers.

B. Plicata, with violet blue flowers.

B. Disticha produces white and purple flowers, of an exquisite hyacinthine fragrance.

B. Sambucina has rich, purple, fragrant flowers.

\section{THE HAMANTHUS.}

This bulb, commonly called Blood Flower, is not uncommon, but is grown more for its oddity than its beauty.

The bulb is very large, often a foot in circumference. About the first of September, it pushes forth a flower stem an inch thick, crowned by a large bud, which, opening, discloses a multitude of crowded flowers, of no beauty. These soon fade, and the bulb then produces two immense leaves, which often grow eighteen inches long and six inches wide, hanging down, one on each side of the pot. These wither; 
the bulb goes to rest, to repeat the process the next year. When the flower bud begins to push, or just before, say about the last of August, the bulb should be re-potted in two parts rich leaf mould, one part sand; give plenty of sun and water as long as the leaf continues to grow, then dry off gradually. There are few persons, having friends at the Cape, who have not received bulbs of this plant, and it is quite common. There are many species; the most showy are $H$. insignis, with red flowers, and a variety with yellow flowers.

\section{THE AMARYLLIS.}

This is an immense family of fine flowering bulbs, in regard to which great botanical confusion exists, and from which several families have been separated. They are all strong growing plants, requiring liberal treatment to insure good bloom. The flowers are of many colors, produced in great profusion, and will well repay the care required. The soil should be richest leaf mould and loam, with a little fine sand. Good drainage is important. The pots should be large, as the roots are very strong and require much room. The species differ so much in their habits no general cultural rules can be given. 
As window plants, they do admirably, one species, $A$. (Vallota) purpurea, being found in every cottage window.

A. belladonna is the always admired belladonna lily. Two things are necessary for its flowering: a vigorous growth of the leaves, and entire rest from midsummer until the flowering season in September. The bulbs are very large. Plant in August, in good sized pots; if your bulb is in good condition, about the middle of September the flower stem will appear, and will develop from four to ten large pink and white lily-shaped flowers, on a stem eighteen inches high. As soon as the flower fades, the leaves will appear in profusion; give plenty of water, light, and air, for on the growth of these depends your next year's bloom. The leaves will continue to grow until the next spring; then the bulb should be allowed to dry off, and absolute rest be given until the time for re-potting.

Thus treated, not one bulb in a hundred will fail to flower regularly.

A. blanda, a fine species with an enormous bulb, and flower buds four inches long; the flower stalk is three feet high. Treatment identical with the above.

A. (Hippeastrum) aulica, a species with a large bulb, and dark crimson flowers, marked with green and black. 
Soil, the same as above. A peculiarity of this species is, it should never be allowed to dry off.

During its season of rest, which is from August to December, water should be sparingly given, but never wholly withheld. The leaves are long, and of a dark, shining green, rising from the crown of the bulb and drooping slightly at the end. The flowers are two in number, produced on a stout stalk, which pushes from the side of the bulb; frequently strong bulbs will give two or three spikes. After blooming, grow the leaves well. This bulb scarcely ever fails to bloom, and the flowers continue in perfection a long time.

A. (Hippeastrum) vittata is a magnificent species, with white flowers striped with bright rose. In the house, it flowers from April to June. It requires a season of rest just before flowering, and a soil similar to A. belladonna.

A. (Hippeastrum) psittacina resembles $A$. aulica, but has six or more flowers in an umbel. The treatment is the same as $A$. vittata.

There are many varieties of these last three, the garden hybrids already numbering hundreds. All do well as parlor plants.

A. (Vallota) purpurea requires much the same treatment 
as $A$. aulica; it should never be allowed to wholly rest. The soil should be, one part turfy peat, one rich leaf mould, one fine sand. Its flowering season is in summer, from July to October. It produces offsets abundantly, which should be removed and potted separately. A large bulb will often throw three or four spikes of eight to ten rich scarlet flowers.

A lovely plant, and very common.

A. (Sprekelia) formosissima. This is the well-known Jacobean lily, so commonly sold as a summer bulb in the spring. The bulbs should be potted in equal parts of loam, well-rotted manure, and sand. The flowers are of peculiar shape, of richest crimson, produced in June, and followed by the leaves.

It may be grown as a pot plant, or in the garden (taking it up in winter), or in water (as a hyacinth), or hung up in a room, wrapped in wet moss.

By growing the leaves well, the bulbs will bloom for years.

\section{THE LACHENALIA.}

These are pretty little bulbs, requiring a rough, peaty, and sandy soil. The bulbs are small, but a pot filled with the foliage and flower makes a pretty show. The plants are 
impatient of water, but after starting into growth should never be allowed to become parched. Pot in October, and they will bloom from January to February. The foliage is prettily variegated with black; the flowers are produced in upright spikes, and are pendulous, high-colored tubes.

L. pendula is our most common species, with yellow and red flowers.

L. fragrans. Flowers white and red.

L. quadricolor. Flowers yellow, red, and purple.

There are many species with pink, purple, red, yellow, and blue flowers, all of easiest culture, and all pretty window plants.

They should be grown as near to the glass as possible.

\section{THE SPARAXIS.}

This is a genus of splendid flowering plants which have been separated from ixia, to which they are nearly allied, and which in growth, foliage, and flower they much resemble.

Their treatment is in every way identical with that prescribed for the ixia.

The flowers are usually more brilliant and variegated in color than those of the ixia. 
Sparaxis tricolor produces flowers of extraordinary beauty; they are yellow, bordered with rich, velvety purple, and this again bordered with brilliant orange.

It does not bloom until well into the spring. Water should be moderately given during growth, and plentifully during the flowering season. Its period of rest is from June to October.

$S$. versicolor, a species much resembling the last, the ground color being crimson instead of orange. The same treatment is required.

S. blanda has pink and white flowers with a yellow centre.

S. grandiflora has dark, reddish purple flowers.

$S$. pendula is quite distinct from the above. It requires more water, being a native of wet places. The flowers are drooping, and purple. It is a tall-growing, very handsome species.

All the sparaxis require rather more sand than the ixias, and will not bear over-watering.

\section{THE ANOMATHECA.}

This is a beautiful little bulb, of only two species, one with pink, the other with scarlet flowers. The bulbs are 
small, and should be planted thickly in the pot. Soil, rich loam and leaf mould, in equal parts. Plant the bulbs in January; the leaves will soon make their appearance, followed by the flowers in May; the plants will continue in bloom the whole summer, and be gems of beauty. Let them rest from September to January. Seed is plentifully produced, germinates freely, and seedlings will bloom the second year.

There is no flower that will make so much show in a small space as $A$. cruenta. Water moderately; drain the pots well. The only species are, -

A. juncea, with reedy leaves and pink flowers.

A. cruenta, with scarlet flowers and large leaves.

\section{THE TRITONIA.}

The plants composing this genus are closely allied to ixia and sparaxis. In form, they vary greatly one from the other, some being funnel-shaped, others salver-shaped, like ixia, others bell-shaped.

The culture prescribed for the ixia will do for them, and all are well adapted for pot culture in the green-house, yet few would succeed in the window.

T. (Ixia) squalida has fine, rosy flowers; T. rosea has 
delicate pink flowers; $T$. miniata fine orange-colored flowers; T. (Ixia) crocata, a very showy orange-flowered species, very easily grown, and quite common.

All the above much resemble the ixia in form of the flowers, and do well as window plants.

\section{THE - HOMERIA.}

A race of fine flowering bulbs, of easy growth. The flowers are showy, produced in profusion for a long time.

The proper soil is equal parts of loam, leaf mould, and sand.

The bulbs should be treated like ixias as to potting, watering, and rest. They flower from April to June. The principal species are, -

Homeria lineata, leaves very long and stiff, marked with white and green lines; bulb small; flower stem about one and a half feet long, producing from spathes single flowers of a copper color, in shape very like those of Tritonia crocata; single blooms transient, but many are produced in succession, and the plants are thus in flower for a long time. Blooms in the house about the middle of April. A showy plant. The flower has a disagreeable smell; perfects seeds in abundance. A number of bulbs should be planted 
in a pot to produce a fine effect; and as the roots grow, the plants should be re-potted (taking care not to break the ball of earth, and to disturb the roots as little as possible), for the growth of the roots is so strong as often to break the pot if it is not large enough for their development.

H. spicata, a beautiful plant, producing an abundance of yellow and red flowers.

H. collina, having orange scarlet flowers.

\section{THE NERINE.}

The treatment of these beautiful bulbs is identically that required for the Belladonna Lily. Thus cared for, the flowers will be plentifully produced, and by their brilliancy and beauty repay for the care afforded.

The soil should be rich loam, peat, and sand, in equal proportions, and water should be plentifully supplied during flowering and growth.

$N$. curvifolia is a fine species, with glittering, scarlet flowers.

$N$. coruscans has large umbels of shining, salmon-colored flowers, and is our most common species.

$\Lambda^{\top}$. sarnensis is the far-famed Guernsey Lily. 
The two former make fine plants for the parlor, producing their umbels of showy flowers in September or October, before the leaves. The flower of both species have a peculiar lustre, and glitter like jewels in the sun.

All these bulbs may be procured of any large dealer at 2. trifling cost. They are admirably fitted for growing close to the glass, and do well in long boxes set into the window.

They are hardy, and will bear ill-treatment; the primal rule is, grow the leaves well, dry off the plants gradually, and you will be sure of a profusion of fine bloom.

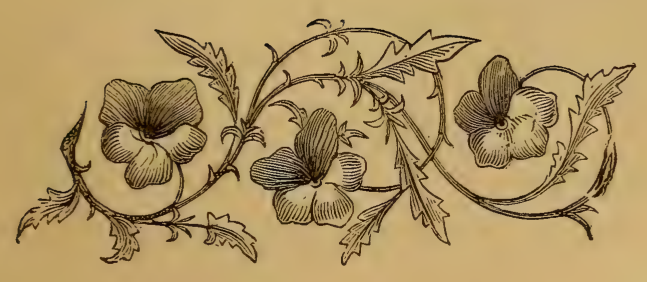




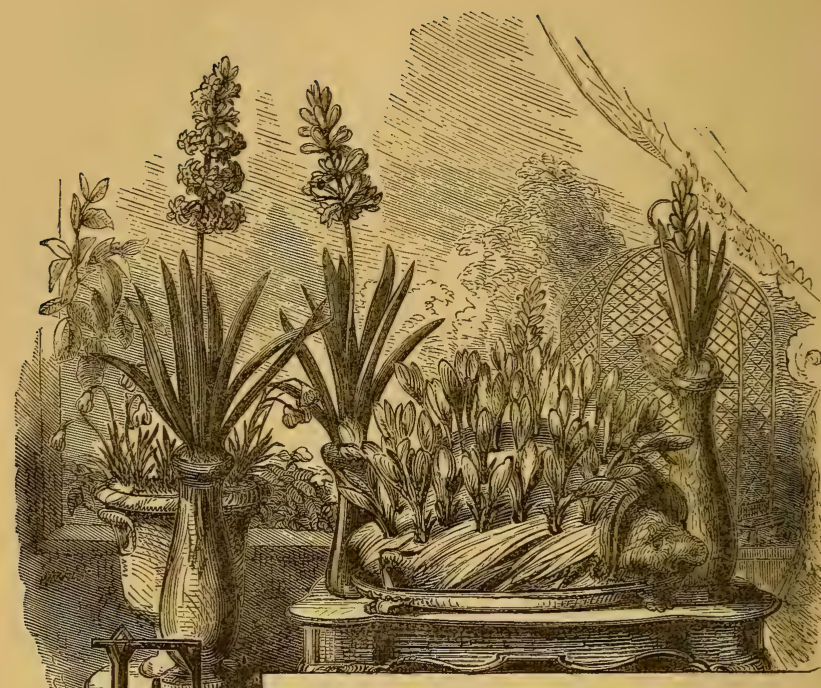

LOWERS, scattered unrestrained and free, O'er hill and dale and woodland sod, That man, where'er he walks, may see, In every step, the hand of God.

\section{CHAPTER VIII:}

\section{DUTCH BULBS.}

[HE HYACINTH : History.-Season for Planting. - Modes of Growth. In Pots. - Offsets. - Water. - Drying off. - Increasing Brilliancy of the Flowers. - In Sand. - In Moss. - In Frame. - In Glasses. - Choice of Bulbs. - Varieties. THE TUliP: Species. - Classes. - Seedlings. - Varicties. - Soil. The Crocus: Description. - Soil. - Varieties. THE 
DUTCH BULBS.

Sxowdrop: Scil.-Species. THE IRïS: Soil.- i Tatering.-Modes of Growth. - Species. THE Jorquil: Culture.-Soil. THE NARcrssus: Soil. - Modes of Growing. - Species and Varieties.

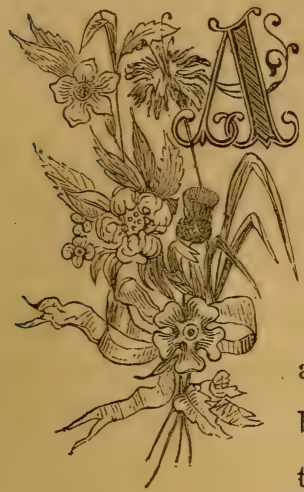

VARIETY of bulbs receive the general name of Dutch Bulbs, because they are extensively grown in Holland, and are chiefly exported thence. They are among the most popular parlor plants, and are desirable, both from their beautiful and fragrant flowers and their easy culture. They are all

winter bloomers, with proper management producing a succession of bloom from January to April.

They will succeed with but little care, the requisites for success being procurable by all; requiring but little space, they can be grown in the smallest window, while their cheapness places them within the reach of all. Are any, then, excusable for not growing flowers? Is not the reward more than a compensation for the trouble? And who is so unmindful of the beauty of flowers as not to wish to have them around him?

The general treatment suitable for these bulbs does not 
differ materially from that prescribed for Cape Bulbs, in the last chapter.

These bulbs being winter bloomers, are at rest in summer, therefore their period of growth is from October and December to February and May.

They possess one advantage over the Cape Bulbs, that of succeeding perfectly in the open border, being hardy enough to endure our winters; but their treatment in open culture will more appropriately fall under a later chapter.

The soil for their growth in the house should be one part very rich, well-rotted manure, one part rich loam, one half part sand. They are thirsty plants, and require to be liberally supplied with water. They are subject to no insects, except occasionally green fly, which is easily removed by smoking.

\section{THE HYACINTH.}

All the innumerable varieties of this bulb are seedlings and hybrids from the Oriental Hyacinth (H. Orientalis), a native of the Levant, and introduced to cultivation about the year 1590. Ever since that time it has, in some of its many varieties, been a popular plant; it is, in fact, one of the flowers of the olden time, and claims a prominent place in floral poesy and simile. 
But even the gorgeous varieties of this species are exceeded in beauty and brilliancy of color by the little blue Amethyst Hyacinth of Europe. The color of this azure gem cannot be described. It is the most pellucid amethystine blue. The flower is small and drooping, and exquisitely fragrant. This little bulb is perfectly hardy, and should be more common in our gardens. In growing the hyacinth for winter bloom, a succession may be maintained by planting a few bulbs every week, from November or earlier, until Christmas. Those first planted will bloom soon after New Year's, and a continuous bloom may be had until the flowers bloom in April in the open air.

There are, also, many modes of growth.

\section{Is Pots.}

A deep pot grows the bulbs far better than a shallow one. These are called bulb pots, and may be procured at about the cost of common pots. Fill in an inch of potsherds, then a few small pieces of charcoal. Prepare a compost of rich yellow turfy loam, one part; well-decomposed cow manure, one part; coarse, clean sand, one half part. Fill the pots with this, and pot the bulbs, leaving the crown about half an inch above the surface of the soil; 
press the earth around the bulb, and settle all by a good watering. Then set the pots away in a warm, dark place, keeping the soil moderately damp until the pot is filled with roots, which may be ascertained by turning out the plant, as directed in a previous chapter. Then bring the plant to the light. The shoot will probably be an inch high, and pure white, but in a few days it will become green, and grow with great rapidity; the flower spike will soon show, and with plenty of light and heat, a few weeks will suffice to give a fine display of bloom.

Offsets should be removed as soon as they appear, by running the thumb nail down the side of the bulb, and pressing them off; if large enough to flower, or of fine varieties, they should be set in small pots, where they will soon make roots, and in time form fine blooming bulbs.

Water very liberally after the bulbs are brought to the light.

As soon as the flowers fade, and the tips of the leaves begin to turn yellow, water should be gradually withheld, and the bulbs thus dried off. When dry, the earth should be carefully shaken off, and the dry bulb put away for the next autumn's planting.

This is, however, seldom done, the bulbs being so cheap 
"it is too much trouble;" so, after flowering, they are usually thrown away or rapidly dried, and in the spring set out in the flower garden, where they produce weak bloom for years. If small bits of powdered charcoal be mixed with the earth, it imparts great depth and brilliancy of color to the flowers, and a dark, rich green to the foliage. Bone shaving's or horn scrapings assist a full development of foliage and flower. If the plants are watered once a fortnight with a very weak solution of glue, or a few drops of hartshorn added to the water, the same effect will be produced.

\section{IN SAND.}

The bulbs may be grown in pure sand. Silver sand is the best, but common house sand will do if well washed, to free it from salt.

Plant and treat as directed above. The bulbs should, however, be transplanted to earth after blooming, and dried off gradually. A pretty effect is produced by covering the sand with moss.

\section{IN Moss.}

Plant and treat as directed above, and after blooming 16 * 
transplant to earth, if desirable to plant the bulbs another season. Water very freely.

\section{Cold Frame.}

A good way, if one intends to grow many of these bulbs, is to have a cold frame and sash. Let it be set on a good hard gravel bottom, or some well-drained place; then set all your pots in the frame, placing over each bulb a small pot inverted. Fill in all around the pots, and half cover the small pot with tan or fine coal ashes. Cover up your frame, and unless the plants, by becoming dry, need a watering, you have nothing more to do. Suppose this is done by the first of October, they will be sufficiently forward to bring into the house about the middle of November. But as frost will not hurt them while covered up in the bed, bring in a few as wanted, and thus maintain a succession of bloom. This treatment does admirably for all Dutch bulbs. The frame is small, and could be put in any back yard. It need not be light, nor is a glass sash essential; a board cover will do. The object of the small pot is to keep the ashes, and, tan, away from the bulb. 


\section{IN WATER.}

When hyacinths are to be grown in water, choose the darkest-colored glasses. It is a good plan to keep the bulbs for a few weeks in damp moss, to encourage the growth of roots. Place them in the glasses about the last of November, or later; the water should just touch the base of the bulb. Keep them in a warm, dark place until the glass is half full of roots. Rain water should be used, and changed once a fortnight; any loss by evaporation should be supplied. Care must be taken not to use the water too cold; that filled in, both in changing and refilling, should be the same temperature as that in which the bulb is growing.

A few drops of hartshorn, supplied when the water is changed, help the growth. After blooming, the bulbs should at once be re-potted in earth, if the bulb is valuable. If by any neglect the roots become coated with green slime, they may be carefully washed in lukewarm water.

\section{Chotce of Bulbs.}

The bulb should be hard and solid, and its base sound. Size is no criterion, some of the finest kinds being always 
large, and others always small. Nor can any rule be given as to shape, some being quite conical at all times, and others spherical or flat. Avoid those bulbs which have the appearance of throwing out many offsets, as they will be sure to weaken the parents. As a general rule, choose medium-sized, firm, hard, heavy bulbs. If you wish fine flower, never buy auction bulbs; they are but the refuse of Holland florists, shipped here to sell at best prices. Good bulbs, of fine named kinds, can be procured of seedsmen for three dollars a dozen. Auction bulbs will do for general effect out of doors, but they never give fine flowers.

Hyacinths may be prettily grown in large pots, boxes, or pans. A small hollow table, made to receive a large pan of hyacinths, is a pretty ornament of a parlor.

\section{VARIETIES.}

Single varieties usually bloom better than double in the window, and are, therefore, to be preferred. We give a list of both.

Double Red.

Acteur,

Grootverst,

Bouquet Tendre,

Hecla,
Josephine, Panorama, Rex Rubrorum, Sans Souci. 
DUTCH BULBS.

Double White.

A la Mode,

Miss Kitty,

Anna Maria,

Gloria Florum,
Triomphe Blandina,

Sultan Achmet,

Grand Monarque de France,

Violette Superbe.

Double Blue.

- Buonaparte,

Argus,

La Majestueuse,

Grand Vedette,
Orondatus,

Enroye,

Laurens Koster,

Lord Wellington.

\section{Double Yellow.}

Bouquet d'Orange,

Gloria Florum,

Heroine,

Ophir,

Single Blue.

Amicus,

Baron Van Tuyll,

Argus,

Emilius,

Single Red.

Amy,

Mars,

Charles Dickens,

Porcelain Sceptre,
Louis d'Or,

Duc de Berry d'Or.

Crosus,

Goethe.

L'Amie du Cœur,

Robert Peel,

Orondatus,

Prince Albert.

Grand Vedette, Mrs. Beecher Stowe,

Cosmos,

Homerus. 
Single White.

Blandine,

Victoria Regina,

Voltaire,

Elfrida,

Alida Jacoba, Fleur d'Or, Lion d'Or, Soleil d'Or,
Mont Blanc, Paix de l'Europe, Anna Paulowna, General Cavaignac.

Single Yellow.

Heroine, Aurora, Victor Hugo, Prince of Orange.

\section{THE TULIP.}

Probably no flower has been so much the object of commercial speculation as the Tulip. There was a time when a single root, of a fine variety, was held at a far higher price than its weight in gold. To such an extent did the mania increase, that houses, farms, and all species of property were bargained for a bed of tulips; and all kinds of absurdities were committed, which are well detailed in the story of the "Tulip Mania," in the History of Popular Delusions.

The many varieties of garden tulips are all derived from Tulipa Gesneriana (except the Early Duc Van Thol, the Double Inodorous, varieties of the T. oculus solis, and the Parrot Tulips, which are produced by a cross between $T$. 
cornuta and sylvestris). It (T. Gesneriana) was brought to Europe from Persia, more than three hundred years ago, and was cultivated at Constantinople. Thence it was -disseminated through Europe, under the name of Turkey Tulip, and was first botanically described by Gesner, a Swiss botanist, in honor of whom it was named by Linnæus.

The commercial speculation in tulips reached its height about the beginning of the eighteenth century, as we learn from Loudon; since then it has declined; but still large prices are often paid for new or fine varieties.

Tulips are chiefly raised for the market in Holland, though in England much attention is paid to them as florists' flowers.

Tulips are divided into three classes : Bizards, or Bizarres, having a yellow ground, broken with purple or red; Rose, which have a white ground, broken with cherry color; Byblœmens, which are white, broken with purple. These classes are subdivided into flamed and feathered, the former being those which are somewhat striped, the latter those which are only broadly marked on the edge.

We abridge from Loudon, some facts of interest concerning this flower:-

"The mode of raising tulips from seed, practised in 
England, was till lately a very strange one, and quite unworthy of the advanced state of science at the present day. The seed was saved from the unbroken flowers, or breeders, as they were termed, and consequently the young plants were always self-colored. To make them break, that is, to vary their colors, the strangest methods were resorted to: sometimes they were planted for one season in a hot-bed, and the next in the poorest soil that could be procured; and sometimes they were remored to. a distant county, twenty or thirty miles from where they were first grown, and then brought back again. But, in spite of all the care bestowed upon them, they were generally from seven to ten or twelve years before they showed any symptoms of rariegation, and some never did at all. A more rational method is now pursued, and the seeds of the handsomest tulips being saved, showy flowers are frequently produced the second year, and bulbs of three years old often produce flowers fit for winning prizes."

The only species of tulip grown in the parlor are $T$. oculis solis, with red flowers and a dark eye, and T. suavolens, commonly called Duc Van Thol, with scarlet and yellow blossoms. These are both dwarf early species, and make a dazzling, though transient show. They may 
be brought into bloom in December, and a succession may be obtained, as directed for hyacinths. The proper soil is one part well decomposed horse dung, one part rich loam, one part sand.

\section{THE CROCUS.}

A beautiful race, of about twenty species of hardy bulbs, some blooming in spring, others in autumn; natives of the south of Europe and Eastern Asia; some species grow wild in England.

Our garden varieties, with the exception of the large yellow and the Scotch Crocus, are mostly hybrids.

For blooming in the house the crocus is only valuable as an early flower, its blooms being fugitive. A few, however, planted with other bulbs, produce a pretty effect.

The soil should be one part loam, one part sand, and water should be sparingly given. Otherwise treat as hyacinths.

\section{Varieties.}

Sir Walter Scott. Variegated. Grootverst. White.

David Rizzio. Blue.

Scotch. Yellow.

I.a Majestueuse. White and violet.

Caroline. White.
Othello. Very dark purple.

Large Yellow.

Grand Lilas. Lilac,

Albion. Violet.

- Queen Victoria. White. 


\section{THE SNOWDROP.}

Well known dwarf, hardy, and pretty bulbs. They succeed well in the house, but a large number must be planted in a pot to make a display.

Soil, loam and sand.

There are two varieties, single and double; the former is the prettier.

The large Crimean Snowdrop (Galanthus plicatus) is very pretty, but not common.

\section{THE IRIS.}

There are a few species of the bulbous Iris which do well under pot culture. The varieties of English Iris ( $I$. xiphioides) are tall growers, and are awkward parlor plants.

The soil required is a sandy loam; and, while showing bud and flower, the plants should be freely supplied with water. Treat otherwise the same as a hyacinth. The bulbs may be grown very prettily in glasses, similar to hyacinths.

The species usually grown are,- 
Iris Xiphium, the Spanish Iris. With showy flowers of purple yellow, and their shades. Grows about eighteen inches high. Flowers late in the spring.

Iris Xiphioides, the English Iris. With tall stems, and large, showy flowers, somewhat resembling the last.

Iris Persica, or Perszan Iris. A little gem. Very dwarf. Well adapted for forcing. Flowers vary from delicate to deep blue. Soil very sandy. Requires plenty of water. Does well under pot culture, in loam, sand, or moss, or in water.

\section{THE JONQUIL.}

This plant is a species of Narcissus ( $N$. jonquilla) and is a native of Spain. There are two varieties, the single and double, both valuable for parlor plants. They bear forcing well, always bloom, and their flowers are delightfully fragrant.

They should be treated as hyacinths, only two or thrce bulbs may be planted in a pot. The soil should be rich loam and leaf mould, with a little sand. There is no bulb of easier growth; they may be bloomed any month; flowers yellow.

There are florists' varieties. 


\section{THE NARCISSUS.}

This is a large family of hardy bulbs, of easiest culture.

The principal varieties worthy of house cultivation are those known as the Roman and Polyanthus Narcissus.

Great quantities of these are annually imported from Holland. They require, in every respect, the same treatment as the hyacinth, and will do well in any light, rich soil, or may be bloomed in glasses, in which case the water must be changed once a week.

The bulbs are large, and strong growers; they have grassy or leek-like leaves; the flower stem comes up in the centre, and, from a sheath at the top, bursts at one side the bunch of flowers, which are white or yellow, with orange, white, or yellow cups. They are rery fragrant, and continue in perfection a long time. The pots should be large, as the roots are numerous and strong. Give plenty of water during the growing and flowering season.

The Roman Narcissus is esteemed for its early flowering; it is usually in bloom about Christmas. The single varicty is yellowish white; the double, cream color. The 
paper-white Narcissus (N. papyraceus) produces very pretty pure white flowers.

The following are varieties of the Polyanthus Narcissus :-

Bazelman Major. White and yellow.

Grand Monarque. White and citron.

Grand Primo. White and citron.

Grand Prince. White and lemon.

Soleil d'Or. Yellow and orange.

17 *

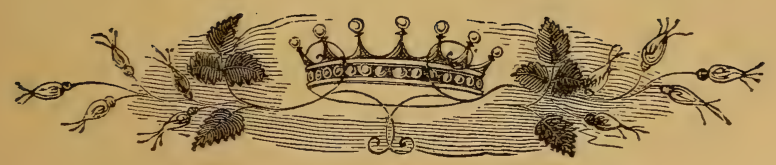




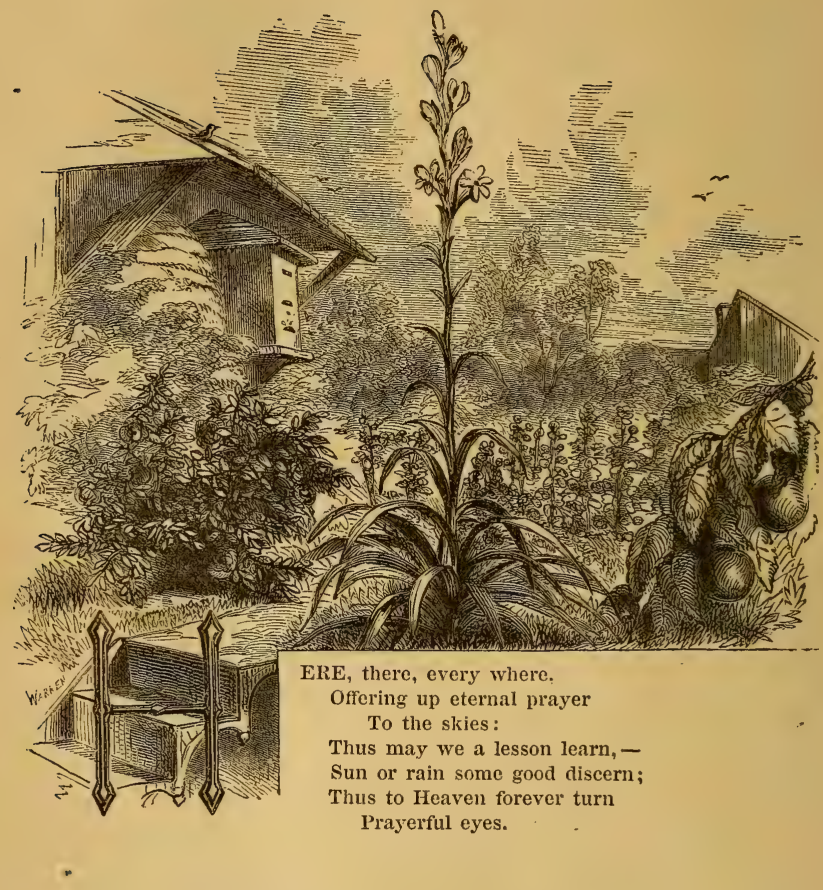

\section{CHAPTER IX.}

\section{THE CULTURE OF THE TUBE ROSE.}

History. - Causes of Failure.-Potting. - Manure. - Selection and Preparation of Bulbs.-Treatment of Flower.-Planting for Succession. - Single and Double Varieties. 


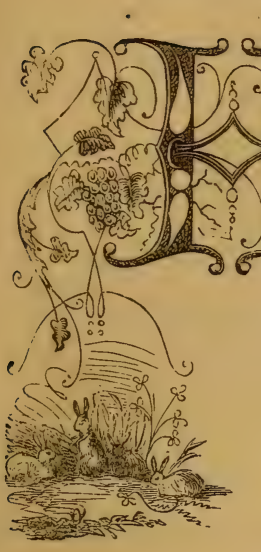

OTV can I bloom my Tube Roses? They grow well, they produce abundance of foliage, healthy as could be desired, but no flowers. Yet their culture is very easy. They will bloom freely with but little care; yet you must learn how to do it; and this secret was communicated to us a few years since by an ardent lover of this beautiful flower, who proved it by showing us spikes of bloom with from twenty to thirty flowers. The tube rose is a native of the East Indies, and was introduced about the year 1630. It has since been in general cultivation, and is now grown in all warm climates as an out-door plant; with us it will not stand the winter. Our dried roots are annually imported from Italy, where they ripen their bulbs in the open air.

The great want of success in growing this plant is caused by too poor a soil, too little water, and too little heat at the root; the plant would probably bloom were the latter need supplied, but we are not content to merely bloom a plant, but must bloom it well.

A hot-bed is necessary : it may be of the simplest kind, 
the heating material being a few wheelbarrow loads of dung. How to best make the hot-bed we will describe in a future chapter.

Now suppose the heat is up in the hot-bed, and we have selected tubers as soon as opened by the importer, thus securing the strongest and best-grown roots, known by the size, and firmness even to the top, and the absence of offsets or their marks, being sure that there is no old blossom stalk, evidence of exhaustion. Time, about the first of April ; prepare seven-inch pots, with the usual drainage; we prefer charcoal to any thing else; over this place about four inches of old, dry cow manure, picked up in the pasture, and preserved for future use (the older the better), broken fine, but not sifted.

Then fill the pot nearly full of a compost of nearly equal parts of sand, loam, peat, and last year's hot-bed, with a slight admixture of charcoal dust; then prepare the roots by removing the outer scale or coating, so as to detect embryo offsets. These carefully remove with a knife, or the thumb nail, so as to lessen future operations of that kind. This done, plunge them in the compost, just corering them from sight, and then fill the pot with spent bark or tan, and plunge the pot to the rim in the tan, which, by 
the way, we deem the very best material in which to plunge pots in the hot-bed, retaining well the heat and moisture, and, withal, pleasant to work in. Soon, they begin to strike root, and the foliage to show its tips; then give slight waterings, until indications of "spindling" appear; then increase the water so much as to solve, to some extent, the broken manure, and thereby allow of consolidation, by firm pressure upon the top surface; watch closely for offsets, and, as they appear, split them off by inserting the thumb between them and the parent, thus keeping the strength where it is wanted. The best practice is to retain them in the pots, and keep the pots together in the hotbed, unless they become so tall as to interfere with the sashes. Keeping them in pots is preferable to turning them out, not only because thus the supply of water can be controlled, but because they can be moved at pleasure. When blossoms begin to appear, remove them to an arbor, or any sheltered place, to secure shade to some extent, and thus preserve the natural delicacy of the flowers. On the approach of frosty weather, they can be housed without the shock they would suffer from "lifting and potting." If kept neatly tied to rods, they are not unacceptable in tho parlor. 
By a succession of plantings, a long season of bloom is secured. By planting on the eighth and twenty-fifth of April, and the twelfth of May, one may have an uninterrupted season of bloom from the twentieth of July to the tenth of November.

Who shall say the end does not warrant the means? Is any one unwilling to devote the amount of labor to the culture of so delightful an exotic? Truly there is no flower which, with little trouble, will yield so large a return of beauty and fragrance. The bulbs generally sold in the seed stores are the double-flowered variety. That with single flowers is far more beautiful and equally fragrant; it is not so tall a grower, and its foliage is more graceful; it is, however, far from common.

After the bulbs have flowered, it is the best course to throw them away, procuring fresh each spring. Our climate is too uncertain to insure a proper ripening of the bulb.

Offsets bloom the third year.

The price of the bulbs in the seed stores is a dollar and a half a dozen; they may, however, be imported for two dollars and forty cents per hundred, costing, with charges, about three cents each. 

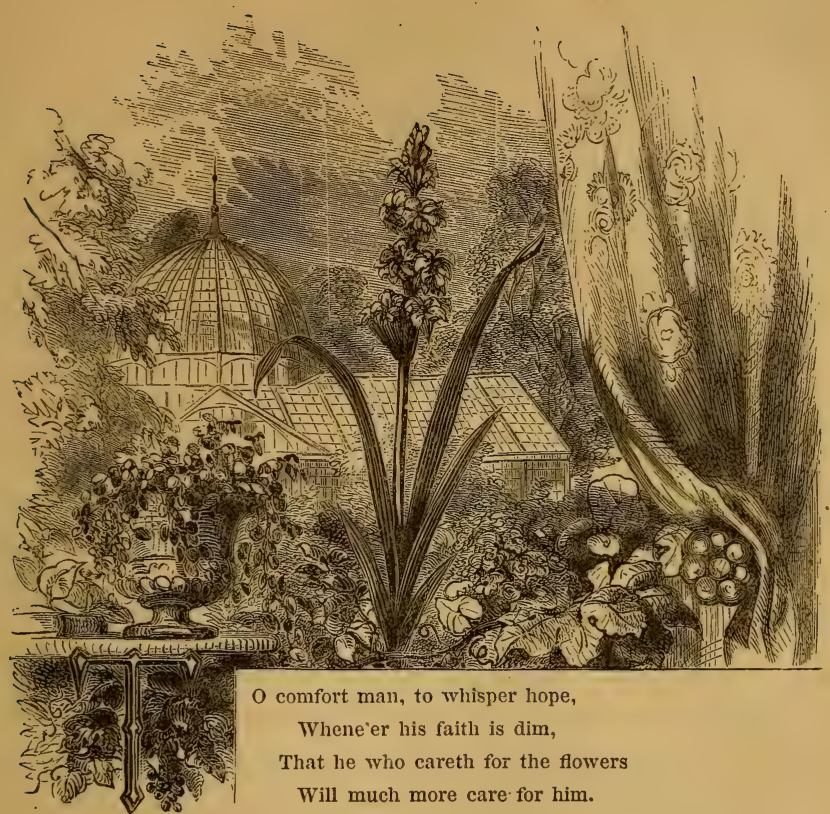

O comfort man, to whisper hope,

Wheneer his faith is dim,

That he who careth for the flowers

Will much more care for him.

\section{CHAPTER X.}

\section{THE GLADIOLUS AND ITS CULTURE.}

$$
\text { History. - Species. - Culture. - Varieties. }
$$

There is no bulb which has so rapidi ${ }_{j}^{j}$ grown into favor, or so much improved by hybridization, as the Gladiolus. A féw years since, it was comparatively rare; we had a few varieties, but they were little noticed, and excited little 
attention. But the results of the last few years, since it has received more careful culture, and since the fine new varieties have been introduced, have been wonderful; and at the present time there is probably no one class of plants which promises better for the future, not only in Europe but also in this country, than the Gladiolus.

There are three species of gladiolus (G. Byzantinus, communis, and roseus), which are tolerably hardy, and if once planted in the open borders will flower well year after year, requiring little attention. Bulbs of these varieties should be planted in November, and need no protection. Perhaps, however, it is better to throw some loose litter over the bed, as Roseus is often winter-killed. Plant the bulbs in little clumps, four or five together; they will flower finely the next spring, and need no further care. The bulb must, however, be planted deep enough to protact it from severe frosts, and to prevent its being thrown out of the ground.

G. Cardinalis was first introduced into this country about the year 1835 ; it was for a time very rare, but can now be easily procured. It is a native of the Cape of Good Hope, and in England receives the same attention and culture as the rest of the so-called "Cape bulbs ;" but 
we must give a different treatment to grow it in perfection out of doors. As a pot plant it is of the easiest culture light and air are essential; care must also be taken to keep off the red spider, which infests all plants of this class. The soil in which it thrives most is a compost of about three parts of sandy loam to one of leaf mould; do not pulverize the earth, as it is apt to become sodden by watering, and thus prevent a free development of the roots. The plants intended for the border should be started in pots in the house, for our season is scarcely long enough for their full development and the proper ripening of the bulb. Keep them in a cool place until the end of May, when they may he turned into a border of prepared soil; they will soon show bloom, for in their native climate they are of rapid growth. As soon as the leaves decay, take up the bulbs and dry them; moisture or frost are fatal, so care must be exercised. Keep in the dry state till the bulbs show signs of activity, when they must be immediately planted, for attempting to retard their growth in a dry state greatly injures the bulb.

The color of $G$. Cardinalis is scarlet and white. It is a beautiful species, but of very weak growth, and is not pop- 
ular, being entirely cast into the shade by larger, strongergrowing species.

Gladiolus Racemosus. Beautiful rose, marked with white and carmine. The bulbs are much smaller than those of the varieties to be described, but some of the beautiful hybrids are well worthy of cultivation. The treatment given above for Cardinalis will do well for all the varieties of Racemosus, though, if strong bulbs are procured, they will bloom well if planted in the open border about the last of May. The growth is far stronger than that of Cardinalis, and some of the hybrid varieties are very beautiful. We annex a list of a few of the most desirable, but doubt whether they can be procured in any quantity in this country :-

Gladiolus Racemosus Formosisstmus. Magnificent scarlet.

Queen Victorta. Red, with white and carmine border.

Oscar. Brilliant scarlet, spotted with white; choice.

LoRd Grey. Vermilion, spotted with violet and white.

Lord Patmerston. Vermilion, distinct carmine spots, violet and white.

Lord John Russetc. Clear vermilion, large, bordered with lake and carmine; choice. 
WrlmeLarus. Vermilion, bright, spotted with white and violet.

Gladiolus Psittacinus. Originally called Natalensis, from Natal, its native country, was but a few years since one of our most popular and admired species. Its colors are yellow, red, and green, and it blooms profusely in the open border with little care; it will flourish in almost any soil, and instances have been known of its surviving our winters. Plant in May, and take up after the leaves have been killed by the frost. This once generally admired species is now little esteemed in comparison with $G$. gandavensis and its hybrids, but, nevertheless, is well worthy a place in the garden, as its bulbs increase rapidly, and are of the simplest culture; seeds are also produced in profusion, and seedlings flower the third year.

Gladrolus Floribundus, or (from the position of its flowers) Oppositiflonus. A most beautiful variety; color, shaded rose, pink, or white. The flowers are very delicate, and produced in long, crowded spikes. The growth is stronger than any of the species we have previously described, except Natalensis, and the bulb smaller, and does not increase so readily. Cultivate as directed for G. Natalensis, though, if a rich soil is given, the flowers are larger 
and the spikes more numerous. One of the most beautiful features of our garden this last summer have been two large beds of this species and G. Gandavensis.

Gladiolus Gaxdavensis. A very striking species; color, superb orange and yellow. This variety was raised as a seedling by Van Houtte, and derives its name from the town of Gand (Ghent). It is stated to be a hybrid between Cardinalis and Psittacinus ; but Rev. Mr. Herbert, of Spofforth, England, probably the best authority on bulbous plants, very much doubted the truth of this assertion. For a long time he experimented, crossing those two varieties, but was never able to obtain any seedlings. At the present time it would be useless to revive this question or attempt its discussion; it might, however, be interesting to know the truth, for ccrtain it is to this species we owe all the magnificent varieties we shall soon describe, and many more none the less beautiful.

The culture of Gandavensis is very easy : prepare a wellmanured bed; plant the bulbs three fourths of a foot apart each way, and two inches deep; stake carefully, and the bloom will be magnificent; give them the full benefit of the sun, for, if shaded, they do not succeed. A single bulb will often give two or three stems of bloom, and a succes- 
sion of flowers will be produced for two months. In winter keep the bulbs from frost. Seed is freely produced, and hybridization between this and other varieties easily effected. The growth of this species and its hybrids is very vigorous; the plants require staking, otherwise they are liable to be broken by the wind.

\section{Propagation of the Gladiolus by Seed.}

The Gladiolus may be propagated by seed; the sowing should be in the fall, as soon as the seeds are gathered, or during the months of January and February, March and April, in a peaty soil, in a frame covered with glass to exclude the frost, or in pots or pans well drained, and filled with fresh peat; the seeds should be scarcely covered. The pots in which the seeds are sown should be placed in the green-house or in a frame.

When the plants appear, and the rays of the sun are too strong, shade them; place them in large pans, and give them air, in order to make them strong. When, in the month of May, the weather is fine and settled, remove the frames which sheltered the seed in the open borders, or repot, and place the pots of young plants in the open ground, so that the first year they may make the greatest possible 
growth. When the leaves begin to grow yellow, take up, with care, the small bulbs, and preserve them in a dry, secure place. The next spring plant them again in the open border, at a distance proportioned to their strength. The care to be given during the winter is the same as that which old bulbs require. The third year the greater part of them will show bloom.

The following is a list of fine varieties of this species, with colors. Most of them may be obtained for about three to four dollars per dozen.

Mrs. Haquin. Light straw color, marked with rosy purple.

Pline. Cherry, marbled with darker shades.

Eugene Domage. Dark, velvety red, with white markings.

Helene. Pink and salmon; yellowish marking.

Rebecca. White, blotched with pink.

Mon. Vinchon. Rosy cherry.

Aristotle. Rose, marbled with rosy red.

Calendulaceus. Brilliant salmon yellow.

Jeanne d'Arc. Pure white; rose-tipped petals.

Egerie. Rosy pink, marbled with rosy red.

Ninon d' L'Enclos. Rosy pink, shading to white.

Don Juan. Deep red, with faint white lines.

Vesta. Pure white, with purple lines.

Brenchleyensis. Deep, blazing scarlet.

Daphne. Rose, marked with scarlet.

Pluton. Clear red, shading to pure white.

Isoline. White, shading to pink. 
Madame de Vatry. White or straw color.

Clemence. White, stained with currant.

Archimedes. Rosy red.

Celine. Rosy white, with amaranthine lines.

Ophir. Straw color, mottled with purple.

Janire. Cherry, with white.

Lelia. Pink, with white shadings.

Princess Clothilde: Rose, with cherry markings.

Le Poussin. Bright cherry and pure white.

La Quintanie. Peach cherry.

Rembrandt. Vivid scarlet.

Raphael. Deep cherry, lighted with white.

Calypso. Pink and flesh-colored.

Imperatrice, or Empress. White, marked with pale pini.

Premice de Mont Rouge. Dark scarlet.

Berenice. Salmon pink.

Penelope. Rosy white.

Fanny Rouget. Carmine and flesh color.

Goliah. Rosy cherry.

Sulphureus. Sulphur yellow.

Napoleon III. Vivid scarlet; white centre.

Velleda. Bright pink.

Hebe. Clear rose.

Vulcain. Dark, lustrous scarlet.

Count de Morny. Deep cherry crimson, white lines.

Nemesis. Cherry, clouded with white.

Lord Campbell. Splendid yellow.

Surprise. Clear, currant red.

The above list may seem large, but the difficulty is what to reject; it might easily be doubled, and yet all be splendid varieties. 
For a dozen choice varieties choose Surprise, Lord Campbell, Vulcain, Pluton, Celine, Ophir, La Quintanie, Raphael, Rembrandt, Isoline, Jeanne d'Arc, Princess Clothilde, and Count de Morny. For the same number of cheaper sorts : Penelope, Goliah, Aristotle, Empress, Janire, Nemesis, Hebe, Fanny Rouget, Sulphureus, Archimedes; Vesta, Don Juan.

The following should be in every collection, however small: Count de Morny, La Poussin, Brenchleyensis, Vesta, Penolope, Hebe, Pluton, Calypso, Vulcain, Madame de Vatry.

New varieties are yearly produced, and there are many promising American seedlings.

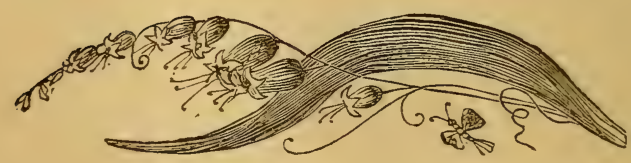




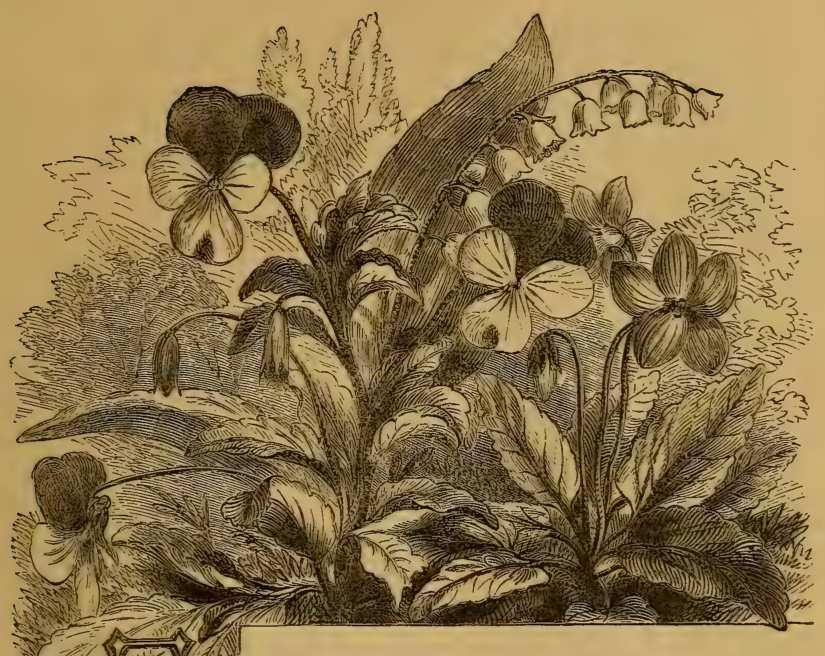

RESH beanty all around our paths,

If but our watchful eyes

Would trace it, 'mid familiar things, And through their lowly guise.

\section{CHAPTER XI.}

HOW TO FORCE FLOWERS TO BLOOM IN WINTER.

Tiolets. - Polyanthus. - DAIsies. - PANsies. - Lily of the VALley. - Hepatica. - Flowering Shrubs. 


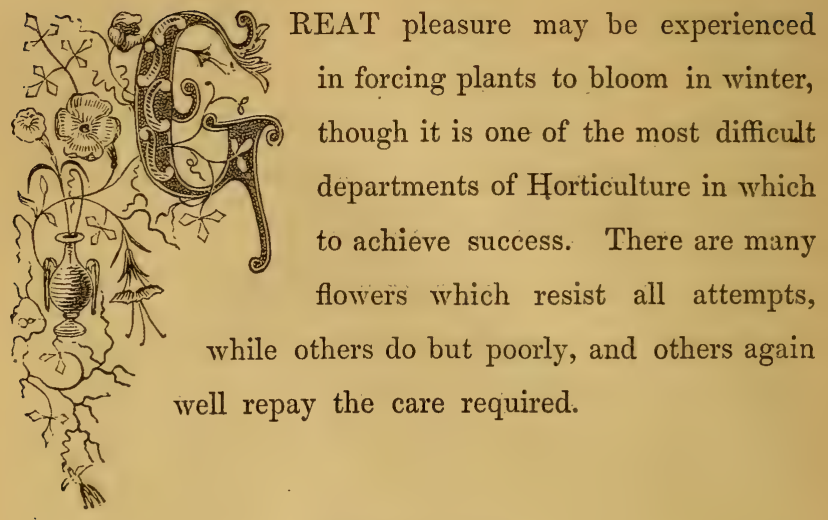

\section{THE VIOLET.}

This little spring flower, always a favorite, from its grace and delicate fragrance, can be bloomed successfully during the winter months, and this with but little expense.

Let the season be the last of August; procure a frame of rough plank, about four feet long by three wide, and sloping from one foot to eighteen inches in height. On each side, from top to bottom, nail two narrow strips of wood, letting them stand about an inch above the top of the frame. Fit on to the frame, so as to slide betrreen the strips, a glass sash; the cost of the whole will be about three dollars. If our violets have been properly divided in the spring, and planted out in a rich, loamy, damp spot, we 
have now plenty. of plants, each about six inches in diameter. If we do not have them, they can be obtained of any florist for about a dollar a dozen.

Prepare a bed the size of your frame, of rich, decomposed manure and leaf mould, and plant the violets in clumps, as many as the bed will hold, about six inches between each clump. This bed may be below the surface of the surrounding soil, or on a level. Allow the plants to grow in the bed thus prepared until about the first of November, when the nights get frosty; then put your frame over the bed; fill in over the plants with dry leaves, and put on the sash. The bed should be in a place where no standing water will settle in winter; and, in the preparation, if the soil be naturally wet, it may be better to fill in a few inches of the bottom with small stones, to secure drainage. The earth should be banked up around the frame before the ground freezes, as thus the inside of the bed will be warmer. Care should be taken that the frame is tight and well banked, or you may have provided a winter domicil for field mice, to the destruction of your riolets. About a week before the violets are wanted, open the frame, remove the leaves, and expose the plants to full light. The bed should face the south - that 
is, the inclination of the frame should be in that direction.

Have some straw mats, board shutters, or other warm covering (the mats are the best), with which to cover the frame at night, and on cold, stormy days.

This mat should be removed on pleasant days, unless very cold — for the more light the better flowers - and on warm, cloudy days. Guard against frost, and on very cold days the beds should not be uncovered; it is necessary to preserve the heat as much as possible, as our only reliance is on that obtained from the sun.

The violets, in planting, should be about four inches from the glass; if the beds are deeper; your bloom will not be so early, though the flowers, by being drawn, will have longer stems.

With good weather, the flowers will begin to open from three days to a week after being uncovered. Erery sunny day they will come forward wonderfully, and with a few frames, there need not be a day, from January to May, when you cannot gather a bunch of violets. The plants will require but little water, unless the earth becomes dried by the heat of the sun; if kept too wet, the plants will mould and rot. When the spring opens, and the plants have done 
blooming, take them up, divide them, - every piece with a root will make a plant, - and set them in a damp, sheltered spot in the garden, to make plants for the next autumn. Put away the frame and sash in a dry place, for future use.

A good plan is to have the beds laid in masonry; then they are permanent, and require only to be filled in with compost and planted.

A wooden frame will, however, with care, last from three to five years.

The best varieties to plant are, -

The Single English. This is very early and fragrant, and an abuindant bloomer.

The Double English. Dark blue.

The Double ENglish White is pretty, but forces badly, usually having a green centre.

The Double Light Blue, called the Neapolitan Violet.

It is not well to mix the varieties in the same bed, as they come to perfection at different times.

\section{THE PÖLYANTHUS.}

This variety of the Primrose, commonly called Cowslip, may be bloomed in the same way as violets. 
The plants thrive best in a heavy, loamy soil. A good way to grow them is to plant them in pots, and set the pots in a cold frame, as above described, filling in all around the pots with fine coal ashes, and covering with leaves, as above directed. They can then be forced into bloom in the frame, or the pots, when wanted, be removed to the green-house or conservatory. They are impatient of damp, therefore give little water.

The best way to procure a stock, unless one wishes finenamed florists' varieties, is to sow the seed in spring, in fine soil, and prick the plants out during the summer; then pot about the first of September.

The plants bloom in the frame from March to May.

Fine named varieties may be procured of florists.

\section{THE DAISY.}

These pretty little plants may be grown as Polyanthus, and will give a profusion of flower in spring.

There are many varieties, — red, white, variegated, pink, with single, double, and quilled flowers, and with green and variegated leaves. A common garden loam suits them well; water but little until the plants begin to grow. 


\section{THE PANSY.}

This pretty species of Violet is seldom grown in this country in perfection. Our climate is too dry, our summer suns too hot, and the flowers grow small, and we never see the fine, large flowers which English florists are so proud of. In spring and autumn we get large pansies, but all through the summer the flowers are sure to be small.

Our winters are often very severe on this flower, and it is no uncommon thing to have the whole bed winter-killed. They succeed best when covered with snow during the whole winter.

In a frame, however, these flowers may be successifully cultivated.

The seed should be sown in July or August, and tho plants pricked out into a bed in a mivist sheltered spot in the flower garden. About the middle of October, when the plants have become sizable, pot them, one in a pot, and treat them as directed for polyanthus.

They will bloom from the middle of April all through the summer.

The soil should be a rich loam.

Only water when th: stants become dry, and then 
only in sunny weather, as the plants are liable to damp off.

The only insect attacking the pansy is the green fly, which is easily removed by fumigation.

The fine varieties may be propagated by cuttings of the young shoots, which root freely in sandy loam, under a bell :glass.

\section{THE LILY OF THE VALLEY.}

The Convallaria majalis, or Lily of the Valley, is now an old inhabitant of our gardens, and still very generally admired, on account of the delicious fragrance of its beautiful bell-shaped flowers. As a companion to the crocus, snowdrops, hyacinths, and other early flowering bulbs, it well merits every attention. To have it in flower about Christmas, the tubers should be taken up from the garden about the middle of November, or at latest the third week. The tubers should not be less than three years old; if more, all the better. The little tubers of the Lily of the Valley are of two kinds, those with sharppointed buds, and those with thick, blunt buds. The former produce leaves only, the latter flowers.

Now, in choosing for forcing, take the bluntest and fullest buds you can find, for it is important every bud 
should give a flower. Previous to potting, it will be necessary to decide how they are afterwards to be disposed of when in flower; they may be placed in fancy wire or wicker baskets, or in ornamental vases.

If it is intended to remove the tubers when in flower, wrap a little bit of moss round each, and then pack them away, as closely as possible, in pots, or what is still better, long boxes, previously filled with any light, porous soil, the tubers inserted just deep enough in the soil to slightly cover the crowns. Over all, place a good thick layer of moss; it assists in keeping the soil and tubers moist; and lastly, pots or boxes, of the same dimensions as those the tubers are planted in, are inverted and placed over them, so as to keep all dark, as darkness is essential to success. The boxes are then removed to a warm place, where they can be supplied with a little bottom heat (a pit or the cooler end of the green-house flue will do), which must be gentle at first, but may be gradually increased as the plants show symptoms of active growth. Thus, in three or four weeks, more or less, according to the treatment they have received, they will be abundantly furnished with their exquisitely scented flowers. They may then be removed with the greatest facility, on account of the 
moss in which each tuber is enveloped, and transferred to the vases or baskets. If they are intended to remain in flower where planted, the moss may be dispensed with, but otherwise the treatment is the same.

The plants should be kept in the dark until they begin to show flower, which will be when the spikes are about six inches long. The boxes or pots may then be removed, and the plants gradually inured to the sunlight, when the leaves will become a beautiful green.

Occasional waterings with tepid water are to be given, as the plants when once fairly started into growth must on no account be allowed to become dry.

Other plants of the nature of the Lily of the Valley, such as the various species of Convallaria, Dielytra, Uvularia, Sanguinaria or Bloodroot, may be forced by similar treatment.

\section{HEPATICA.}

The different varieties of Hepatica (Squirrel Cups) may be forced as directed for Polyanthus. Some of the double varieties, with their lovely red and blue flowers, beautifully imbricated, are among the most desirable flowers for forcing, a pot of any of them being a mass of bloom for 
several weeks. They are also among the earliest spring flowers in the open border.

Soil, rich loam and leaf mould.

Any of our hardy flowering shrubs may be forced for the conservatory with very little trouble. Late in the autumn, before the ground freezes, take up plants of the desired kinds with a ball of earth, and either pot them, or set them away in a cool, dry cellar.

When wanted for flower, bring them into the light and heat of the conservatory, potting those put into the cellar; water freely, and in a few weeks they will be a mass of bloom.

The most suitable plants for this purpose are the early blooming spring shrubs, such as Weigela rosea, Deutria gracilis, Spirea prunifolia, \&c.

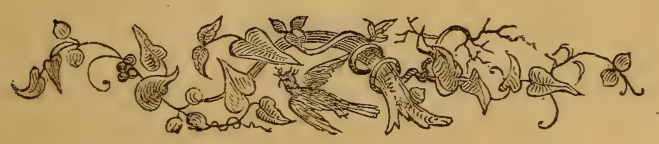




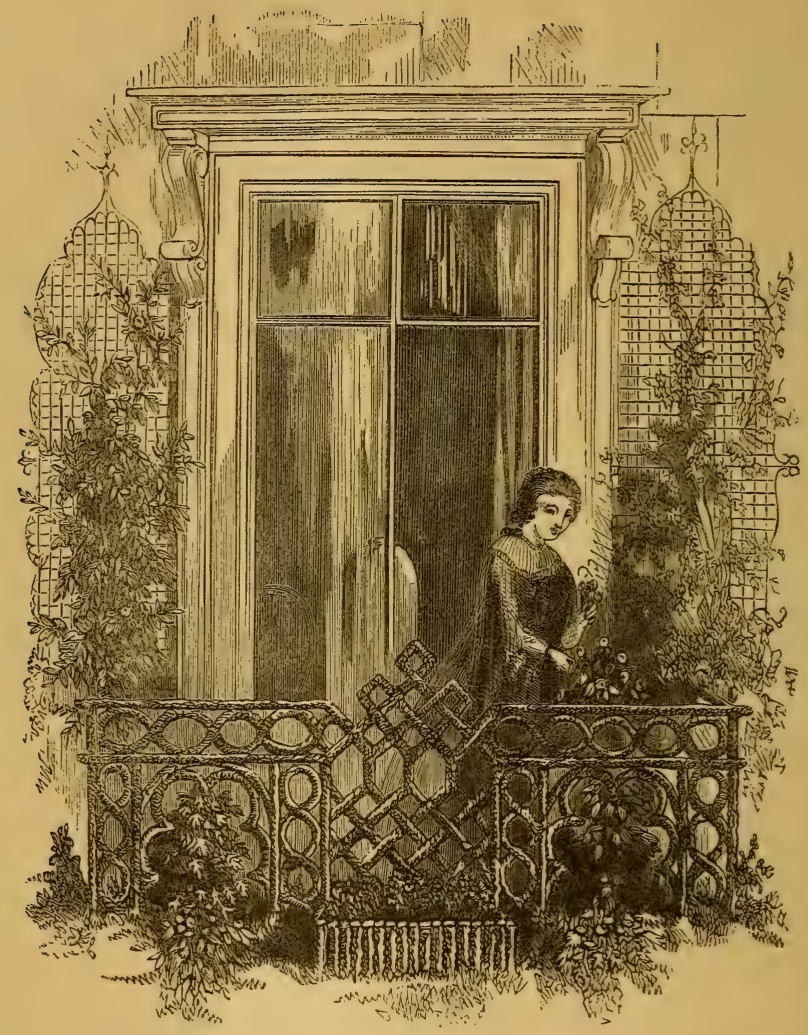

CHAPIER XII.

BALCONY GARDENING.

Situation. - Arrangement. - What to plant. CoBEA ScAxdexs : Autumn Treatment. 


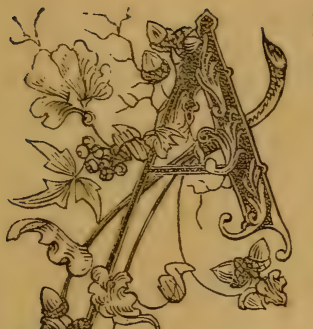

PLEASANT summer pastime, in our climate, is balcony gardenirg. In England, very pretty winter gardens are fitted up in the balconies by a collection of fine evergreens, such as variegated Hollies, Laurestinus, and Acuba Japonica, but none of these withstand our winter.

In England, they never have such burning sun and such icy cold as we experience; such sudden changes of temperature as occur in our climate are unknown, and many of the inhabitants of our green-houses are there hardy plants. It is not the winter's cold which kills many of our plants, it is the sun. The plant is frozen hard by a zero night; at morning, the sun comes out warm, and, while the air around may be cold, the plant is thawed; at night, it is again frozen; then thawed. Is it strange the plant dies? Therefore it is that many plants will grow and thrive on the north side of your house, which, on the south, are winter-killed. The remedy is simple: protect from the winter's sun, and your plants will not be winter-killed.

In this climate a pretty display of green may be kept up 
on a balcony in winter, by a lot of small, hardy evergreens, such as white and pitch pine, hemlock, and spruce; but even these, on a sunny exposure, grow dingy and suffer; therefore we say, balcony gardening must be a summer pastime.

The balcony should face the south or east, so as to obtain the morning sun; there are few flowers which succeed in the shade.

Now, we may either grow our plants in pots, or fit up the balcony with neat boxes; but in either case the outside of them must not be exposed to the direct rays of the sun; it would heat and parch the earth so nothing would succeed. A good way to prevent this is to make a board lining round the inside, and fill a space of three inches with straw, tan, or moss, between the outside and your boxes. Fill your boxes with a rich soil, composed of one part loam, two parts leaf mould, two parts decomposed manure. Put an inch of "crocks," or broken pots, in the bottom, to secure drainage, and have a few augur holes in the bottom of each box to allow the surplus water to drain off. Now, the boxes being all prepared, and the season the first of May, what shall be planted?

Yet first, do not plant too much; you have only a balcony, 
not an acre lot, therefore be content with a few good plants, remembering that by trying to grow many you will succeed with none; each plant will crowd its right and left hand neighbor, and all will become drawn and weak.

If your balcony is small, do not attempt to grow shrubs, but be content with climbers for the sides, a few hardy herbaceous plants, and annuals. If you have plenty of room, grow as much as you can without crowding.

Now, as we said, let the season be the first of May, and supposing we have a sizable balcony, all fitted with boxes filled with prepared soil, what shall we plant?

First, a Weigela rosea, - one of those beautiful exotic shrubs introduced from China, and bearing, in June, lovely bunches of pink flowers changing to white. Let us set this in one outside corner, and on the other side, to match it, plant a Spirea prunifolia, a beautiful species, which, about the middle of May, puts on an emerald jacket, and buttons it with innumerable silver white buttons. Let us now select climbers to grow up over the window, to be planted at each side, close to the wall of the house. We need something that will endure the hottest sun without injury, for our wall is of brick, and a July sun against a brick wall is very often scorching. It will be too hot for honeysuckles 
or woody-climbers, unless we shade them for several years, until they get well established, and can cover the walls with their leaves. Morning Glories would suffer, and Nasturtiums be dried up by the heat. We must have a stove climber, or certainly one which will endure great heat, and there is just the plant we need, and very common too, one withal with which the common complaint is it does not flower. We can, however, flower it, and if the season be long, ripen seed, for we have what it needs, heat.

Let us, then, get two or more plants of the climbing Cobea ( $C$. scandens). It is better to buy plants than raise seedlings; you thereby gain a month. The plant is a rank grower, with stout, herbaceous stems, and fine thick foliage, and produces large, purple bell, or rather cupped flowers, all summer. These flowers are very showy, and with plenty of heat color finely. Set the plants in a rich soil, and be sure they have plenty of water; they are rapid growers, and will, in luxuriance, almost equal the famous bean stalk of the fairy tale.

A trellis must be provided; those of small wire are the best. Place it where you will, the cobea will follow, for the plant grows twenty feet in a season. There it will bloom and hang with long festoons of foliage, gay with 
purple blossoms and fantastic seeds. But give plenty of water; it is a thirsty plant, and in a situation like ours will drink largely. The first frost will, however, turn it black, so if we want the permanent climbers, the cobea will prove a good nurse for them. Plant them with the cobea; it will shelter them, but be careful not to let it kill them by its exhausting the soil, filling the box with roots, or twining around them.

Now, we need climbers for the sides of our balcony, and they should be planted close to the outside of our box, and here we have a large list to choose from. Maurandia Barclayana, with blue, foxglove shaped flowers, is a little gem of a twiner; then there is $\mathbf{M}$. rosea, with pink, and $\mathbf{M}$. alba, with white flowers. These should be raised from cuttings, or plants purchased. Seedlings do not bloom till late, and we wish flowers all summer.

Then we have the large family of Nasturtiums, both the large and small flowered varieties; these all do well; then scarlet beans, morning glories, the pretty little cypress vine, the canary bird flower (Tropceolum aduncum), sweet peas, and that pretty vine commonly known as Madeira vine, which comes from tuberous roots, which may be any where procured. 
In fine, any of our annual garden climbers, or the more tender green-house summer bloomers, such as Loasa, Calampelis, Physianthus, and a host of others, will succeed. To fill our boxes we have now a host of annuals, biennials, and herbaceous plants to choose from; and here we are at fault. To give a list of all pretty and desirable, would exceed the limits of this work, and tastes and fancies differ so much that to select is difficult. Mignonette, Indian Pinks, Sweet Allyssum, Drummond's Annual Phlox, and Nemophila, will please all. These from seed. For bedding plants, Verbenas and Heliotropes, and if you have room, a scarlet Salvia. For herbaceous plants, a Larkspur ( $D$. formosum is the best), Dielytra, and for early spring some clumps of dwarf Iris, and a plant of Bloodroot.

We must find room for a few of the fine hybrid Gladiolus; if we can have but two, let us choose Penelope and Brenchleyensis for vigorous growth and fine contrasts of color. Then a half dozen of the gay Tiger flower, of the two species, red and yellow, (T. pavonia and conchiflora) will occupy but little space, and make a fine show.

Now, with one third of the plants we have mentioned, the largest balcony would be overstocked, and with a judicious selection all will be gay until the frost kills out-door flowers. 
Then prepare for winter; dig over the boxes, pulling up roots of dead plants, being careful not to disturb perennials. And plant a dozen good hyacinths, fifty crocus, a few jonquils, and a hundred snow-drops, for early bloom the next spring. When severe frosts come, cover half a foot of coarse manure over your boxes, laying down under its protection your hardy climbers, such as honeysuckles, clematis, trumpet flowers, and wistaria, if you have them, or else mat them up carefully in straw or old bass mats.

Now you have only to enjoy your flowers in the memory of the past summer, or in anticipations for the future, unless, with us, you would have flowers in winter, and will devote an hour each day to window gardening, or study with us, in the next chapter, the Wardian Case.

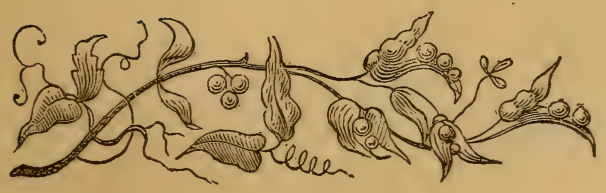



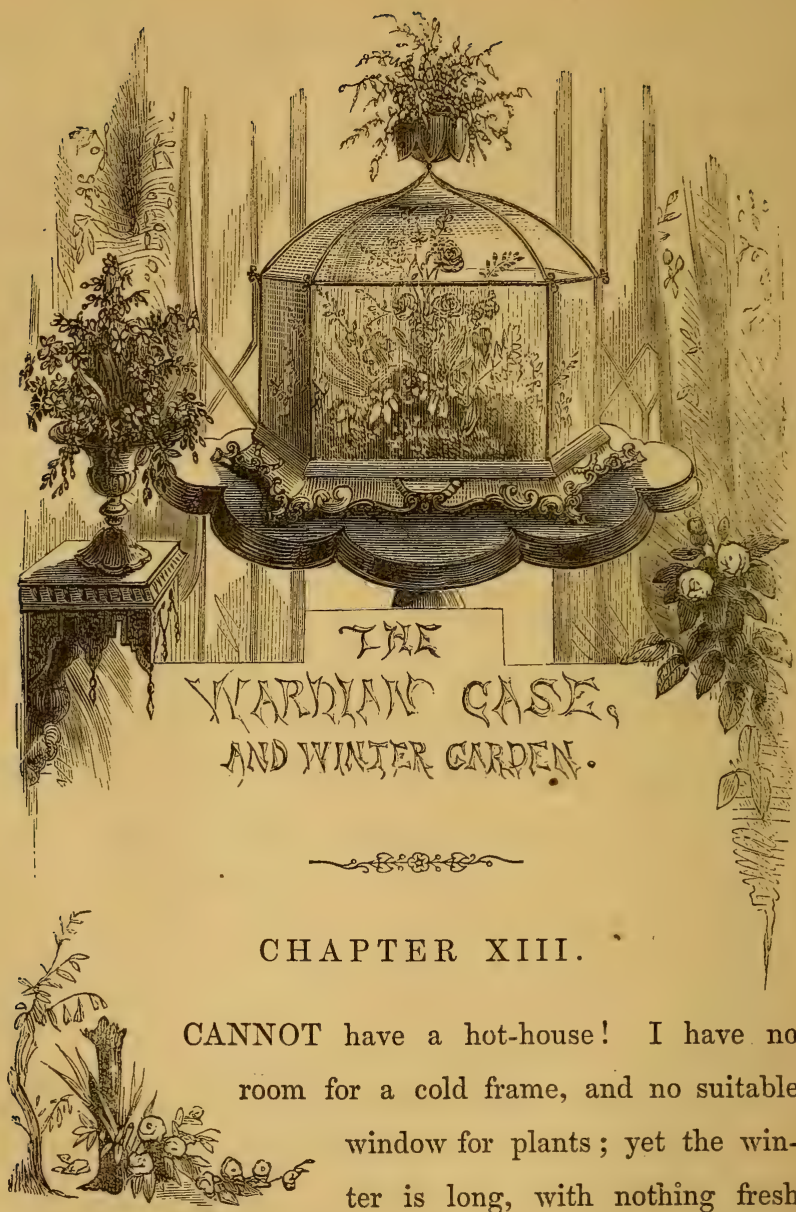

window for plants; yet the winter is long, with nothing fresh and green to cheer me. Is there no way I can grow flowers?" exclaims some one, almost in despair. 
Patience a while, my friend; this chapter is for your benefit.

Flowers are so universally loved, and accepted every where as necessities of the moral life, that whatever can be done to render their cultivation easy, and to bring them to perfection in the vicinity of, or within the household, must be regarded as a benefaction.

But in the midst of the smoke and dust of the city there is but one way to have real verdure, in the freshness of its original strength and life, and that is, by the culture of it in Wardian cases.

Not only may many ornamental plants be thus preserved in full beauty in the midst of a dry, dusty atmosphere, but the rarer and more delicate forms of vegetation, which refuse the tenderest care under ordinary circumstances, readily submit to domestication, and manifest high development of beauty in these cases, if the requirements of their constitutions are severally fulfilled.

It was in the year 1829 that Mr. Ward placed the chrysalis of a sphinx in some mould, in a glass bottle, covered with a lid, in order to obtain a perfect specimen of the insect. After a time, a speck or two of vegetation sppeared on the surface of the mould, and to his surprise 20 * 
turned out to be a fern and a grass. His interest was awakened; he placed the bottle in a favorable situation, and found that the plants continued to grow, and maintain a healthy appearance. On questioning himself about the matter, the answers readily presented themselves, inasmuch as air, light, moisture, and the other requirements of the plants, were contained within the bottle. This was the first Wardian case.

The experiment was extended; the case was shown to be self-supporting, and admirably adapted to some kinds of plants. Further experiment showed that while the Wardian case, as an air-tight structure, was in many cases a success, yet for a great proportion of plants a change of air is necessary, and thus at the present time the Wardian case is simply a green-house on a small scale, ventilation and heat being provided according to the requirements of the plants grown.

In a close case some ferns will live and flourish; others will maintain their beauty for a time, and then perish.

In a close case it is impossible to raise flowering plants of any kind, and whatever may be grown in such a structure will be more or less drawn, spindling, and sickly. The glass will usually be in a semi-opaque condition, from excessive condensation of moisture. 
Let us, however, regard ventilation as a necessity. The Wardian case becomes a miniature green-house, and we can grow almost any thing. Before, we were confined to ferns, because of all plants they bear a damp imprisonment with wonderful patience; but now the field is open for the introduction of flowers of the choicest kinds, and by applying heat, the working department of plant propagation may be carried on in-doors with success. In the design of an oblong, rectangular case, graceful outlines may be attained by the adoption of the following proportions:

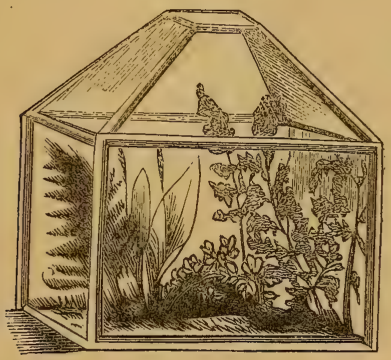

First, determine the general dimensions of your case ; then, whatever is to be its length, let the width be nearly one half. If from right to left it is to measure thirty-two inches, let its breadth from back to front be fourteen or fifteen. The height of the glass sides should be the same 
as the breadth of the case. Then to roof, it, let the summit of the roof be formed of four sloping sides, surmounted by a flat top; and let the flat top be as much above the edges of the four sides as half the height of those sides; then you will have an angular object, possessing as much grace as can be infused into the simple rectangular design. One side of the top should be fixed on hinges, so as to give occasional ventilation. The material for the frame may be metal or wood.

Now, it will be better to have a stand made expressly for it, with four legs, and an elliptical arch of fretted work, to break the monotony of straight lines. The stand may be varied very much to suit individual taste; light work is more suitable than heavy carving. Of course, the principles of art may be applied to glass structures in many ways, so as to insure grace of outline.

The above has only been given by way of example; every variation may be adopted, but it may be remarked that imitations of villas, temples, with many corners, and fancy convolutions, or any intricate design that may be adopted for a Wardian case, is more likely to produce puerility than grace. Let the form be simple, and the proportions symmetrical, and you will not hereafter fail to be pleased with your work. 
An ingenious mind will suggest numerous designs for the purpose, and of these, built structures are always preferable to the mere glass dome or bell, as they can be ventilated and arranged with greater ease.

In England, Wardian cases are often built in windows, by removing a portion of the lower sash, and building into the room of the required size, with the top flat, sloping, or domed, as fancy may suggest. In our climate this would seldom be practicable, for our winters would chill the plants; it might do, however, for eight months in the year.

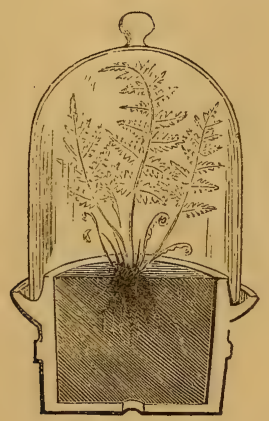

The simple fern glass makes a cheap Wardian case; it is merely a common glass dish, with a rim, into which is fitted a glass dome or bell. It answers well for 
ferns, but not for flowering plants, as the atmosphere is too close. Unless the pan is porous, proper drainage must be secured, and water must be sparingly given, as it can only, if in too great a quantity, be got rid of by evaporation, during which process the plant may be injured. The ferns best adapted to these cases are those that love shade, moisture, and a close air, but even with these a little ventilation should be given to prevent damping off.

A flower pot, with a rim to receive a hand-glass, makes a nice little Wardian case; these could be obtained at any potter's, could be made shallow, and

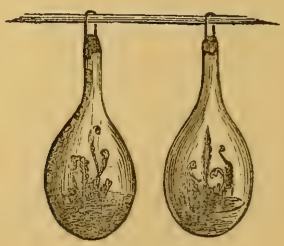

are inexpensive. The common Florence flasks, in which salad oil is imported, make rery pretty little cases for the culture of delicate forms of vegetation. A good way is, to suspend a row of them along a shady window; in some, grow terrestrial plants, in others, delicate water 
plants. They may be half filled with soil, and the seed sown. The daily growth may thus be watched, and very many interesting lessons learned. The flasks should be covered with a piece of oiled silk, so arranged that it can be removed for supplies of air and water. The only matter of importance in the management is, to keep the rays of the sun off, or only to allow them to shine very faintly, for a single hour's exposure to a hot sun would bring destruction on the whole.

It has been recommended that all Wardian cases should have a double bottom, to insure sufficient drainage, as the evil most frequently experienced is sodden roots, caused by standing water. This, though a good arrangement, is by no means necessary. The proper drainage may be secured by broken potsherds and charcoal, laid along the bottom to the depth of an inch. The water will, of course, drain into this, and may be drawn off by a little stop-cock under the case, and hidden by one of the legs.

The depth of soil should not be greater than nine inches; too great depth will give a damp, heavy soil, which will be uncongenial to the roots.

It is also advisable to make arrangements for a com- 
plete change of the plants at any time. It is, therefore, not advisable to plant your case by filling earth directly into the table; unless, indeed, you grow your plants in pots, and plunge them in the soil, so that they may be frequently renewed. The best plan is to have -zinc pans, one or more, according to the size of your case, fitted closely to the inside of the case; these may be planted and changed from time to time. One may have two sets, which can be renewed at a neighboring green-house, and thus a perpetual display of floral beauty may be obtained.

However skilfully managed, a change of vegetation in the case may now and then be desirable, and it is easily effected by means of duplicate pots or pans.

The frame of a Wardian case may be wood or metal; wood is least likely to be affected by sudden changes of temperature; metal is less liable to decay.

The frame of our largest case is of bronze, but probably the best metal is galvanized iron.

The pans should be of zinc or galvanized iron.

The advantages of the Wardian case may thus be summed up :-

You may grow in them many plants which a single day 
of parlor culture would greatly injure or destroy, since they are impatient of - a dry heat. Delicate ferns and lycopodia are at once destroyed by the dry atmosphere of our parlors, but develop, in full beauty, in a Wardian case.

Again, you may succeed with them if you have but little sun. This must recommend them to residents of cities, where the sun often gives but little light in the parlors, being shut off by high walls, and where window plants become weak and blanched, or are longdrawn, ugly specimens, with weak, sickly blossoms.

Another feature of a Wardian case, which is a source of unfailing delight. All well know that a winter bouquet, as procured from a florist, in a few hours loses its freshness and beauty, and a few days are sufficient to convert it into a dry, unsightly mass. If the bouquet be placed inside a Wardian case it will preserve its freshness for a long time. It is better, however, to arrange the flowers in a shallow dish of water, taking care the petals do not touch the water, as thus they would soon mould; if the stems are inserted in a dish of wet sand, or merely in the earth of the case, it will answer every purpose. Our only care with camellias is to place them on the surface 
of the soil. The water in the dish does not become foul unless the flowers begin to decay; shculd this be the case, a little powảered charcoal will at once arrest the tendency.

We have found many flowers to last very long in perfection. Thus, camellias, two weeks; azaleas, from two to four weeks; daphne, ten days; allamanda, four days; the scarlet bracts of poinsettia, six weeks; heath, from one to three weeks; roses, five days; diosma (the green sprigs), four weeks; chorizema, one week; cyclamen, three weeks; mahernia, eight days; cinerarias, two weeks; calceolarias, one week; pinks, ten days; heliotropes, and other thin-petalled flowers, three to six days; geraniums, from six to ten days; orchids, such as Cattleya and Oncidium, from six to ten days. Care must be taken not to have the case so damp as to cause mould to collect on the flowers; experience will be the best teacher in this respect.

A very șimple case may be constructed by procuring a shallow, round, glass dish, about two feet in diameter; set in this a glass dish two sizes smaller, and about three or four inches deep; fill the outer dish with water, the inner with earth, and plant your ferns. Procure a 
hemisphere of glass, large enough to cover the smaller dish, and to rest its rim on the water of the larger. The water prevents the admission of air, and the only care is to see that it never entirely eraporates from the outer dish. Your case is done; and with a little ventilation, your plants will grow with a vigor and freshness unknown to you before. These common cases may be made of any size, and any clear glass will do as a cover. The lower dishes may be common stone ware, and the cover one of the glasses used by confectioners to cover cake, or what is better, a common plain or tubulated receiver, which may be procured at any glass house, or of any dealer in chemical ware.

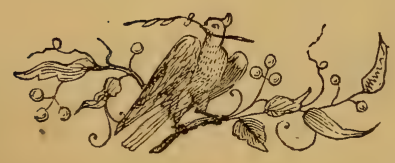




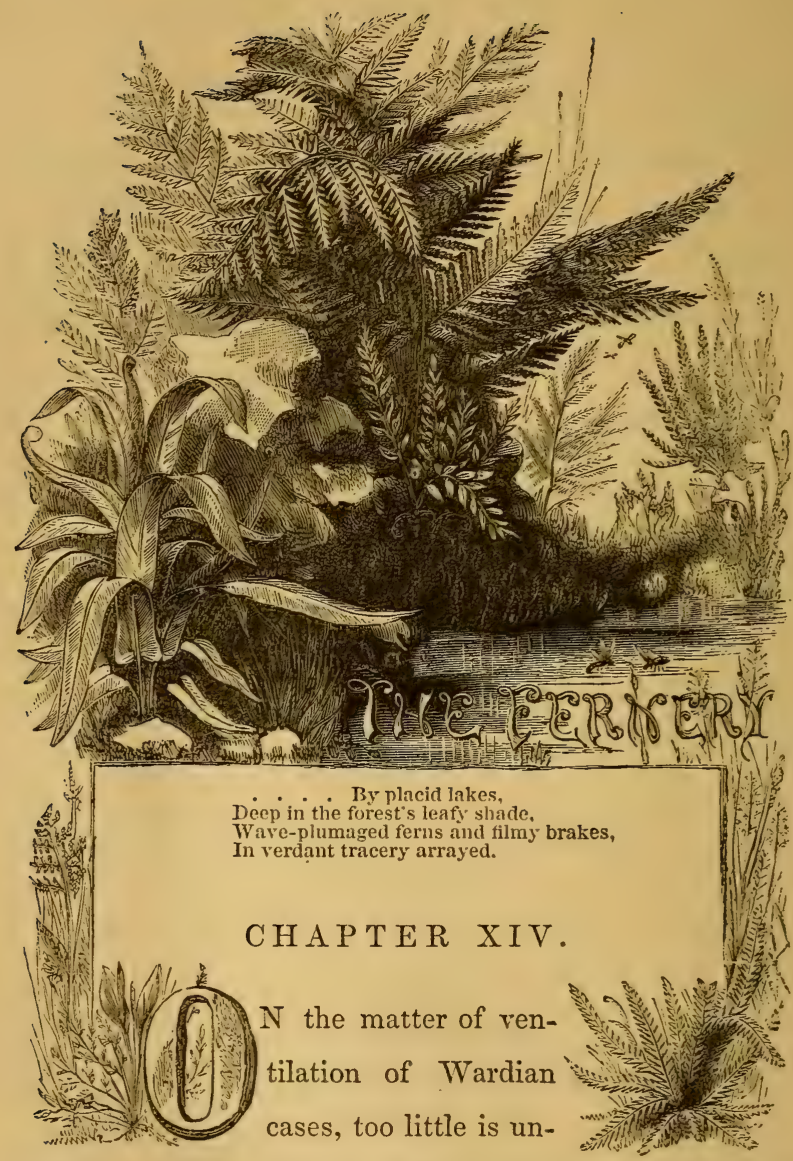

derstood. Ferns, and a few kindred plants, may be grown in air-tight cases, but there is no objection to occasionally admitting air to a Wardian case. 
STOCKING AND MANAGING WARDIAN CASES. 245

The principal care necessary is to see that the case does not suffer from want of water. The moment the door is opened, or the glass raised, the moisture, which was suspended in the air, or condensed on the sides of the case, flies off, and an equalization of temperature begins between the air in the case and that in the room. That in the case soon parts with its moisture, and becomes dry and unfit to sustain the plants in health and beauty, unless the earth in the case is again watered. When too much water has been given (which is readily seen by the glass always remaining clouded), opening the door and admitting external air is necessary to the health of the plants. In this matter, experience will be the best teacher. Few cases are perfectly air tight, and usually enough air will be admitted through cracks and ill-fitting shades, for the health of ferns and lycopodia. The advantage of such cases is, that they are sufficiently close to exclude dust and noxious gases, yet admit of ventilation at times favorable for the operation.

For cases made on the ordinary principle, that is, as close as ordinary workmanship will make them, the best plants are ferns and lycopodia, because these naturally love a close, moist atmosphere, and whatever facilities the case may 
afford for the admission of atmospheric influences, such flowerless plants need less ventilation than most other kinds; and even in the case of flowering plants, those which prefer moisture and partial shade are the most suitable.

Of course different ferns and plants require different culture, but most will thrive under one general system. The soil should be one part peat, one part leaf mould, one half part silver sand; small bits of charcoal should be mixed in. The soil should be broken, not sifted, and should be of such a consistency that when wet it should be crumbly, and not pasty. The materials should be well mixed by hand.

We have also grown ferns successfully in a soil composed of one part peat, one part sphagnum moss, chopped fine, and one part silver sand.

The planting of the case may be varied to meet the taste and fancy. The primary object is to secure perfect drainage; and for ferns, an admixture of broken potsherds with the soil permits a freer circulation of air around the roots, which conduces much to a healthy growth.

If your case is large, and sufficiently high, a miniature 
rockery may be formed, with some graceful fern occupying the top, and the smaller kinds clustered at the base. In a small case it is, however, not advisable to attempt any such effect, but to plant in rows or clumps.

Care must be taken not to crowd the plants, nothing is gained by it.

Having selected our plants, place them firmly in the position they are to occupy; cut off all damaged and decaying fronds, being careful not to injure any young shoots. Level or elevate the surface of the soil, covering or picking out any protruding lumps. If the plants are in pots, sunk in the soil, draw the earth over the rim of the pot, so as to hide it, being careful not to thereby bury the plant too deep.

Now, as to watering; Ferns love shade and moisture, but this is no reason they should be shut up in darkness, or drenched with water, as is too often the case. As soon as the case is planted, give a slight watering with a finerosed watering pot, to settle the soil.

Shade the case for a few days, giving free ventilation until the plants are established; if the case is open for a few hours each day it will be sufficient. Water thus whenever the soil seems to need it, which is easily known 
by the appearance of the plants; the great danger is in giving too much moisture; the soil then becomes sodden, the young fronds decay, and the older fronds collect mould. The soil should at all times be moist, but never wet.

As to general ventilation, when the plants are fully established: The requirements of different plants are so various that no rule of universal application can be given; flowering plants need the most, ferns and lycopodia the least.

Light is essential, and a few hours of gentle sunlight are beneficial. The direct rays of a hot sun should be aroided. When the sun is on the case keep it closed, unless the soil has become too wet. Of course dead leaves must be removed, and all kept clean.

Let us now consider the adaptation of the Wardian case to flowering plants. And we must frankly state that the case does far better for the exhibition and preservation of flowering plants than for their growth.

If you have a green-house, bring the plants forward there; as soon as in bloom remove them to the case, sinking the pots in the soil, and they will remain a long time in perfection.

In the selection of plants those with variegated foliage are to be preferred, as they are gay at all times. 
Gloxineas and achimenes grow and flower well, and are very beautiful ornaments; these we cannot otherwise grow in our parlors.

Roses, pansies, and begonias thrive well, and bloom profusely.

The grand point in the selection of plants is, to grow only those together which have the same requirements of light and moisture. Thus ferns and verbenas would never succeed in the same case; the moisture necessary for the former would be death to the latter.

A very pretty stock of plants may be obtained from our own woods. All our pretty mosses and ferns, and most of our early spring flowers, thrive admirably. They should, however, have a case to themselves, as they do not thrive in company with rare exotics. These plants must be carefully taken up, and all sods shaken off, preserving of course as much of the earth around the root as possible.

The objection to transplanting sods with roots of choice plants in them to a Wardian case is, you of necessity get strong roots of rank grass, which grow so rapidly as to hide your ferns and mosses, and are also too apt to introduce slugs and worms, which destroy your rarer plants. We once lost a fine Maranta by a slug which we introduced in 
some moss; but probably the fellow was unused to such luxurions living, for after searching for him in rain for several days (his depredations still continuing), we found him one morning dead under a half eaten leaf; his appetite had destroyed him.

Our native orchids, the Arethusa, Pogonia, Cymbidium, and Orchis do well. The Trillium, so shy of cultivation, deigns to live and bloom, and many of our meadow and swamp plants thrive as if in their native haunts.

And now for the selection of plants.

$$
\text { Flowering Plants. }
$$

Gloxinea Rosea Mrutabilis. Rosy white.

“ Cartonii. Pink, white lines.

“ Annulata Superba. Blue, white throat.

" Grandis. Cream color, plum throat.

" IVilsonii. Pink and white.

" Heliodorus. Blue and white.

"Alba Sanguinea. White, rich, carmine throat.

" Alba Grancliforc. Pure white.

“ MIaria Van Houtte. White and pink lemon throat.

“ Sir Hugo. Violet purple.

“ Carlo Maratti. Violet, blue, and white.

" Guido Reni. White, crimson centre.

Achimenes Grandiflora. Rosy purple, white centre.

" Longifora. Deep blue.

" " Alba. Pure white.

“ Picta. Yellow, spotted with scarlet.

" Ambrose Verschaffelt. White, marked with purple.

“ Parsonsii. Salmon crimson, orange centre. 


\section{STOCKING AND MANAGING WARDIAN CASES. $2 \tilde{j}$}

Achimenes Meteor. Brilliant crimson.

Edmund Bosseir. White and blue.

\section{Plants with Variegated Foliage.}

Begonia Rex,

“ Sir Colin Camphell,

" Argentea Superba,

"Queen Victoria,

" Makoy's Victoria,

"Funkii,

" Duchesse de Brabant,

"Margareticea,

"Picta,

Plectranthus Concolor Pictus,

Caladium Pacile,

" Marmoratum,

“ Argyrites,
Caladium Chantinii,

“ Hastatum,

"Bicolor,

Croton Pictum,

Dracena Ferrea,

"Terminalis,

Dieffenbachia Picta,

Gesneria Zebrina,

Maranta Regalis,

"Fasciata,

" Alba Lineata,

Tradescantia Discolor.

Tall Ferns.

Polypodium Aureum,

Pteris Argyrea,

Davillia Canaricnsis,

Polypodium Appendiculatum,

Grymnogramma Sulphurea,

Gymnogramma Chrysophylla

(Golden Fern),
Gymnogramma Peruviana, (Silver Fern),

Myriopteris Elegans,

Nephrodium Molle, [bosum), " " (var. Corym-

Nephrolepis Davilleoides,

Blechnum Pectinatum.

Dwarf Ferns.

Pteris Hastata,

Polypodium Vulgare,

Asplenium Adiantum Nigrum,

Asplenium Trichomanes,

Adiantum Cuneatum,

"Concinnum,

“ Affine,
Blechnum Gracile,

Lomarea Nuda, Asplenium Belangeri,

Davillia Bullata, Hypolepis Repens,

Pteris Tricolor. 
Lycopodia, or Selaginella.

Apoda,

Denticultum,

Densa,

Wildenovii,

Paradoxica,

Stonolifera,

Schotii,

Lepidophyllum,
Argenteum,

Delicatissimum,

Africanum,

Microphylla,

Lobbii,

Casium,

Atroviridis.

Climbing Ferns, \&c.

Lygodium Scandens,

Lycopodium Casium Avboreum.

Plants for Baskets.

Tradescantia Zebrina,

Hoya Bella,

Aschynanthus Boschianus,

"Zebrinus,

“ Pulchra,
Pothos Argyrea,

Torrenia Asiatica,

Linaria Cymbalarea,

Ficus Repens.

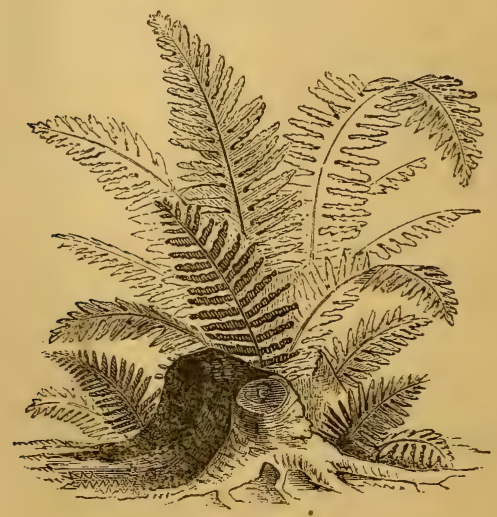




\section{CHAPTER XV.}

HANGING BASKETS AND SUITABLE PLANTS, AND TREAT-

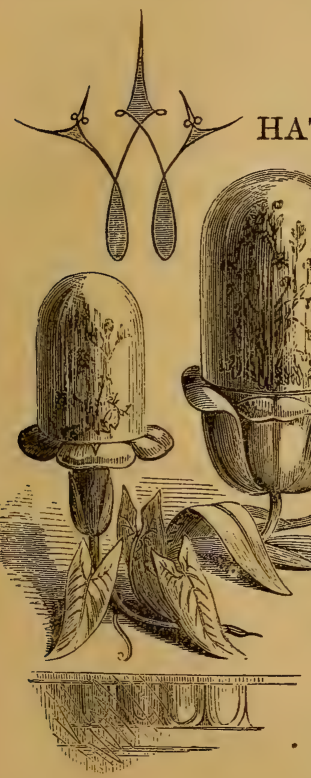

MENT OF IVY.

HAT a pretty amusement is the growth of plants in hanging baskets or pots ! It is very popular, and deservedly so. The beauty of the baskets, now fashioned in so many artistic designs, is almost sufficient to inspire a love of horticulture, if only for the sake of growing the plant in so pretty a pot. Yet we cannot urge the growth of plants in these baskets; a porous pot is essential to the health of a plant, and most of these baskets are china, or glazed or painted.

Yet they may be used by setting the pot containing the 
plant inside of them. Another objection is, that having no outlet for the escape of the water, it collects in the bottom, and, unless there is very ample drainage, which is seldom the case, the roots are rotting in water while the surface is dry.

Potting in these vases is very simple. If the plant must be in the vase or basket, fill half full of broken potsherds; on these place a thin layer of moss, and fill up with prepared soil; shade the plant for a few days until well established, then hang it in the window, and water slightly every morning with a fine-rosed watering-pot; as the plant grows, dispose the branches to fall gracefully over the pot.

The plants most suitable for baskets are, -

The Common Perrininkle (Vinca Major and Minor), and the pretty variety with variegated leaves. This is an evergreen, and produces its pretty blue flowers in spring and early summer. There is also a white-flowered and a double variety.

Lysmachia Mummularia (Money Wort). A pretty little trailing plant, with dark, glossy leaves, and a profusion of dark yellow flowers in June. This plant should be in a shady window.

Linaria Crmbatarta (Coliseum Ivy). A little gem 
of a plant, and thriving well in the parlor. Leaves small; ivy-shaped flowers, like a little snap-dragon, purple and white. Should be kept rather moist.

Tradescantia Zebriva. A rapid growing plant, with greenish purple leaves, with lighter markings on the upper side, and dark purple below; flowers small light pink.

Cereus Flageldiformis. - A pretty species of cactus, with pink flowers in summer, and long, pendulous leaves, with close spines.

Lobelia Gracilis and Erinus. These, and many others of the family, are pretty, graceful plants, producing blue or white flowers. Sow the seed in early spring, and plants will bloom in June, and continue in blossom all summer.

Nemophila. A class of pretty annuals, with blue, white, and spotted flowers. Treat as lobelia.

Tropæolum (Nasturtium). The various small-flowered kinds do well, and are gay with flowers, if the pot is large enough, and the soil not too rich.

Solanum JasminoIdes. This pretty plant, previously described, does well in a large basket.

Saxifraga Sarmentosa (Chinese Saxifrage). Very 
pretty and common, producing long, hanging runners, with new plants growing out every few inches. 'The flower is white, produced on a tall spike, from the centre of the old plant. It is not showy, and the bud, when young, should be cut off, as the plant dies after blooming. Give plenty of wwater.

Convolvulus Mauritanicus. A beautiful, new Morn:ing Glory, with pink and blue flowers, with a white star in :the centre.

Pelargonium Lateripes (Ivy-leaved Geranium). Makes :an excellent plant for a basket, and will do well with little care; the variegated-leaved variety is very fine.

Disandra Prostrata. A pretty, free-growing plant, with long, slender stems, clothed with roundish leaves, and bearing small, yellow flowers, of no particular beauty; cultivated more for its freedom of growth than for its flowers. Grows in any light, loamy soil.

One of the most serviceable trailers is the plant commonly known as German Ivy (Senecio Scandens); it is of most rapid growth, with light green leaves, studded with pellucid dots, and never troubled by insects. As a screen for a window, or covering for a wall, it is most valuable. It is easily propagated, every joint root- 
ing if placed in the earth. The flowers are strawcolored, and often produced in greatest profusion. The plant is a native of the Cape of Good Hope, and has been introduced many years. It is admirably adapted for baskets.

\section{IVY.}

This plant, in some of its varieties, is probably the most popular ornament of the parlor. The ease of culture, its beautiful foliage, its rapid growth, and evergreen character, all combine to make it a favorite.

The soil should be a rich loam; the richer the soil the more rapid will be the growth. Yet avoid stimulating manures.

Slips root readily, taken off at any leaf joint, and placed either in earth or water; in the latter they will soon throw out roots, and may then be transferred to pots.

The only precaution to be taken in growing ivy is to keep it from frost while in growth; and if frozen, to keep the sun away from it, thawing it out with cold water.

In summer the plants may be set out of doors, and will make vigorous growth.

There are many species, of which the most common is 
Hedera Helix, the common twining ivy, a native of Europe, of which there are many varieties. The leaves of these varieties vary very much, and many distinctions have been founded on these variations. There are two very beautiful kinds, the silver and golden, the foliage being beautifully variegated with white and gold. The following cuts will

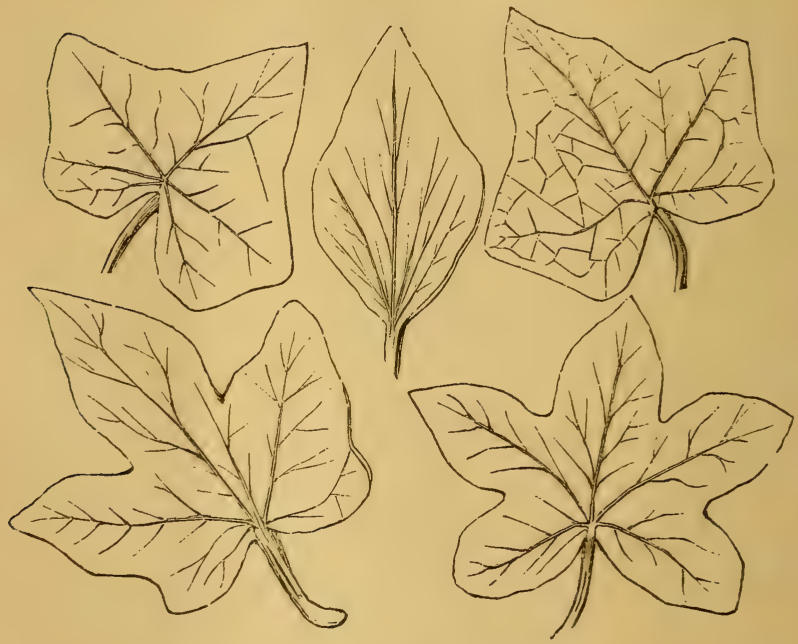

show how these differ in foliage, all being taken from living leaves, though some are necessarily reduced in size to accommodate them to our pages.

The Tree or Aborescent Iry is merely a form of the com- 
mon variety, which is shown by its returning to the primal form not unfrequently. The leaves are entire, and the plant often retains its arborescent form for years.

H. Rcegneriana is a variety with large, heart-shaped leaves, which is much esteemed.

H. $h$. digitata, the palmate or hand-shaped Ivy is a
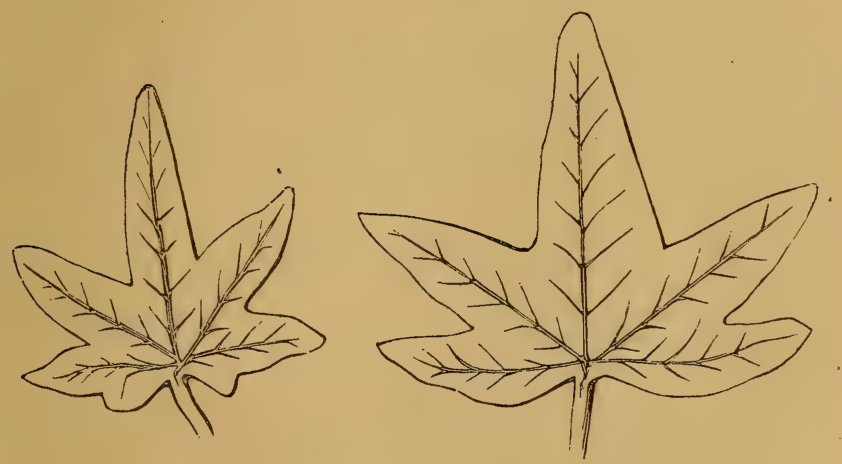

pretty variety, of rapid growth; the leaves are small, dark, and veined. This is often called, erroneously, the Irish Ivy.

H. Canariensis is the Irish, or Giant Iry; the leaves are five-lobed, and larger than those of the common iry.

Almost all the varieties of nurserymens' catalogues are merely forms of these, with peculiar foliage. 
The Golden Ivy is a splendid plant; when the young leaves come out it resembles a mass of yellow flowers.

Ivies are grown in hanging baskets, around windows, made to trail around picture frames and looking glasses; indeed, they may be made decorative in the highest degree.

The plants should always be well supplied with water, though it should never be allowed to stand at the roots. Large plants of the common varieties may be procured for fifty cents. The ornamental foliaged varieties are somewhat dearer.

If you have ivy growing out of doors (and it will thrive if you keep the winter's sun away from it), a pretty effect may be produced by cutting large branches, and keeping them in rases of rain water. They will grow well all winter, and planted in spring make nice plants for autumn.

The plant commonly known as German Iry is not an iry; the botanical name is Senecio Scandens. It is deservedly popular, from its rapid growth and its freedom from insects. We have, in a former paragraph, treated of it more fully.

The Coliseum Iry is a species of Snap-dragon, as may be seen from an examination of the flowers, and a very pretty 
plant it is; botanically it is Linaria Cymbalaria, and is mentioned more fully in the early part of this chapter.

Five-leaved Ivy is the Virginia Creeper or Woodbine (Ampelopsis Virginica); a native of our woods.

The Poison Ivy is Rhus Radicans or Rhus Toxicodendron, and not of the same family as any of the above.

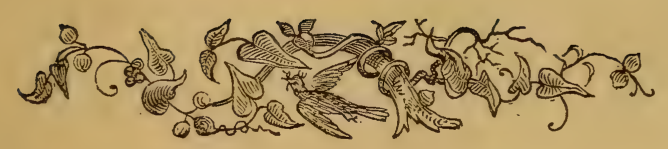




\section{CHAPTER XVI.}

\section{THE WALTONIAN CASE.}

Definition. - Form. - Construction. - Capacity. - Heating. - Lamp. - Cil.

- Gas. - Pots. - Sand Bottom. - Description of Case. - Various Sizes.

- Advantages over Hot-bed. - How to make a Cutting.-Waltonian Principle applied to Wardian Case.

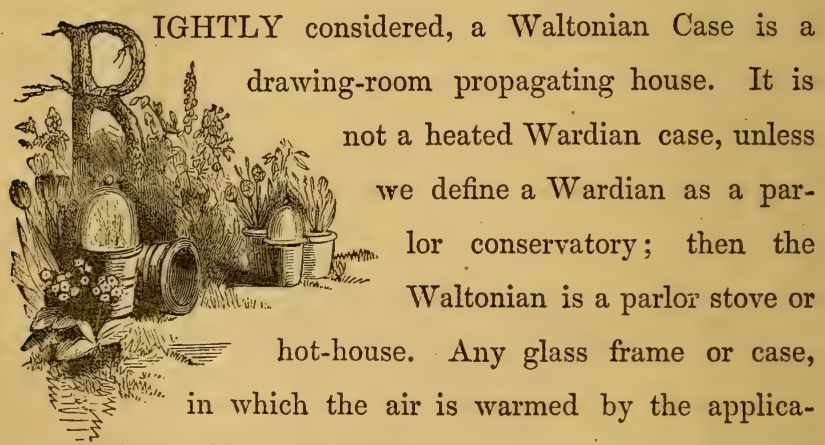
tion of heat, either directly from a lamp, or by means of hot water, would be a Waltonian case.

The first invention of $\mathrm{Mr}$. Walton, from whom the case is named, was placing a tin case, filled with hot water, inside a wooden box, covered with a glass. The air inside 
was kept close and warm, but there was not power enough to raise temperature very much, nor sufficient to root cuttings. Bottom heat, which is one of the features of the Waltonian case, was at first entirely wanting.

By much experimenting many changes were made and improvements introduced, until now the Waltonian case is the best method an amateur can use to supply himself with bedding plants. It is a hot-bed, without the dirt and inconvenience; an ornament instead of an unsightly object; inexpensive, and yet accomplishing wonders ; an indispensable aid to the amateur florist.

As far as we know, these pretty little cases are not made in this country; they may, however, be imported for about ten dollars each, and expense of freight and exchange. We trust, however, in our description to be sufficiently intelligible to render their construction an easy matter.

We can, however, lay no claim to originality in this chapter; we have but collected all the best information on the subject.

Now that the best form, the best measurements, and the exact details of construction have been determined by experiment, no one, however previously ignorant of ordinary gardening operations, need find it difficult to produce an 
abundance of stock for the garden, the green-house, or the window ; for it may be a hot-house, an intermediate-house, or a cold pit, just as you please, by a very simple regulation.

The Waltonian case is fashioned in the style of a garden frame, the frame-work being of wood, with side and top lights, a boiler and lamp for supplying heat, and a tray of sand, on which the pots are placed.

To give the reader an idea of the appearance of the case, we will at once refer to the figure of one of simplest construction, which we propose to describe particularly.

The frame-work is of wood, and may be either plain deal, or any ornamental wood with elegant mouldings. The front and the two ends are fitted with glass, the back is wholly of wood, and on the top are two lights, laid on loosely. There is room inside for thirty-two four inch pots, in four rows of eight each, and these pots stand on a thin layer of silver sand, kept constantly damp, and heated by the boiler immediately beneath it. The lamp in front is a common tin one, burning colza oil. (This oil is much used in Europe ; it is a very fine oil, burning without smoke, and is pressed from rape seed (Brassica oleracea); 
with us the heat may be from a gas jet, a spirit, or fluid lamp.) And the cost of working would be about fifty cents a week.

The time the lamp will burn must depend upon the size and the care used in trimming; and to keep it burning

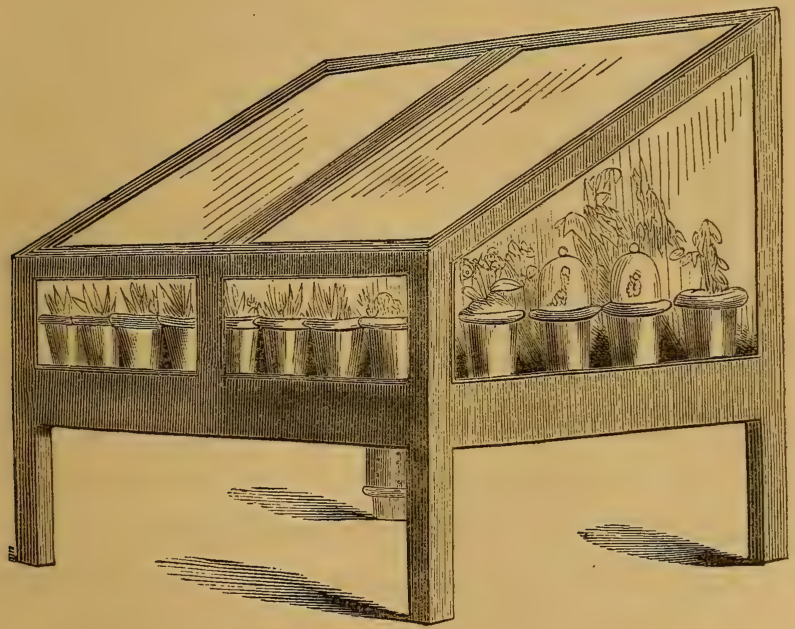

FIG. 1.

constantly would require but little care. Having glanced at it so far, let us now take the case to pieces. The top lights lift off, without troubling with hinges, hooks, or attachments of any kind. They are simple squares of 
glass let into a zinc belding, and with a ring by which to lift them. This plan allows them to be shifted, to give air to any extent necessary. Having removed these, we find the pots standing on clear, damp sand. When the pots are removed it is an easy matter to lift out the whole of the heating apparatus, by means of the two handles attached to the zinc tray, and its appearance is that in Figure 2.

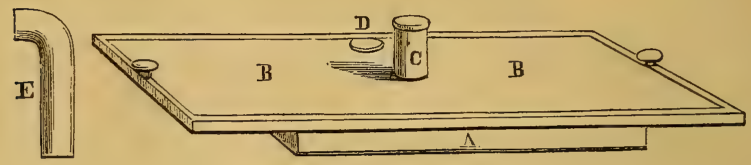

FIG. 2.

The upper tray B B is an inch deep, and in this, sand an inch deep is carefully spread over. Attached to it is the boiler $\mathrm{A}$, which is in reality double, one portion enabling the hot air and the smoke of the lamp to circulate round the tank, and escape by means of the flue $\mathrm{D}$, to which the funnel $\mathrm{E}$ is attached when in operation. The tank itself being filled by means of the vapor tube $\mathrm{C}$, on which a cap fits to prevent any excessive escape of steam. The boiler holds about two quarts of water.

If we turn the tray upside down, we have the appearance presented by Figure 3, where $\mathrm{F}$ is the boiler, and $\mathrm{G}$ the 
entrance to the hot-air chamber, into which the flame of the lamp enters when the case is at work.

Replacing the tray, it will be seen that the hole in the boiler fits over the box that contains the lamp.

The flame of the lamp plays upon the inside tank, and the smoke escapes by means of the flue $G$, which conducts it out through the back of the case, quite away from the plants. Practically speaking, there is but very little smoke.

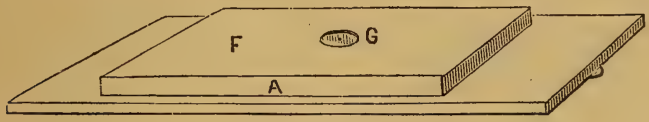

FIG. 3.

The exact measurements of these several parts are in the case above figured. Length of tray B B, thirty-four and one-half inches; breadth, seventeen inches. As the pots stand inside the tray, and the latter fits the frame, there is, therefore, a working space for plants of five hundred and sixty square inches. Depth of the boiler A, two inches. The entire case measures outside, along the front, thirty-six inches and a half; from back to front, eighteen inches and a half, When placed at a window, or in a green-house, light is admitted only at the top, but the case might be made with lights at the back, and additional light would be 
obtained; but as the chief use of the Waltonian case is to raise seeds and strike cuttings, a partial admission of light is usually sufficient.

The Waltonian case may be made of larger or smaller size. The following figure shows a case of larger size, made on the close principle, by which all is entirely hidden. $X$ shows the door for the introduction of the lamp.

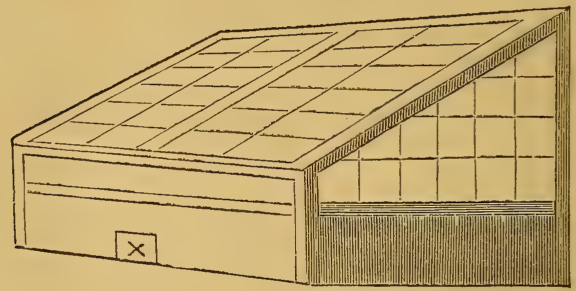

FIG. 4 .

The interior arrangement of the case may appear somewhat complicated, especially the arrangement of the double boiler. We therefore give the accompanying illustration, showing the interior workings.

$A$ represents the boiler; $B$, the steam chimney, opening into the middle of the case, through the zinc tray; $C C C$, the zinc tray; $D D D$, outer cover to boiler, through which the heat is conveyed from the lamp round the boiler, and 
the smoke out through $E ; F$, lamp for heating boiler; $H$, tap to draw off water.

The heat for a Waltonian case should be about seventy degrees; when the sun will raise this heat, the lamp may be dispensed with. In managing the case, it is important the sand should be kept constantly moist, or the heat will

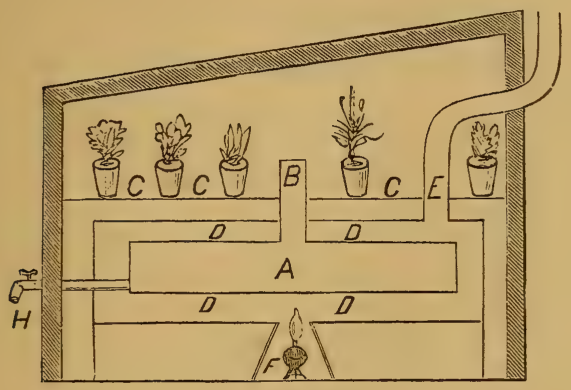

FIG. 5 .

not rise freely; any excessive moisture may, however, lead. to damping off.

It is a good plan to sprinkle a little silver sand over the surface of the pots containing the cuttings; it is a great safeguard against damping off. It is also important to sow the seeds in small pots - the smaller the pots the greater the safety. 
Those that require the greatest amount of neat must be placed towards the centre, immediately over the lamp.

Watering must be regularly attended to, and the water must be of the same temperature as the air in the case. It is well to water them with a fine-rosed watering-pot, as thus the plants and sand are both moistened; any superfluous moisture may be removed by rentilation.

It is really surprising what an amount of work may be done by a Waltonian case. In it plants, seeds, and cuttings may be so started that they may safely be hardened off for the green-house or the window.

It has many advantages over a common hot-bed. In the first place we are certain of heat, and can regulate the temperature from any point up to nearly ninety degrees, the ordinary temperature being from seventy to eighty degrees.

It requires an experienced hand to make up a hot-bed with dung, that shall give a steady heat for any length of time; and with the most experienced the accidents of damping off, burning up, and failure of heat, are not uncommon; but here we have simply to fill the boiler, light the lamp, and then keep the case as close and damp as we please, or give light and air, as circumstances require. There is no 
soiling of hands, wetting of feet, or anxiety about frost and mats; and the most serious part of garden economy is brought within a lady's reach and the merest beginner's unripe judgment.

The small size of the case may seem to be against it, but it will perform such an amount of work, when well managed, as to meet the wants of most amateurs.

Geraniums, Fuchsias, and Calceolarias, may be rooted safely, and in quantities sufficient for ordinary wants.

"Hardening off" the plants is simply removing them from the heated centre to the borders of the case, as they become well rooted, and thence to a cooler frame, or gradually to the window.

The cuttings, if more than one in a pot, may be transplanted to separate pots in the usual manner.

In all other respects there is no difference in the management of seeds and cuttings in a Waltonian case from that employed in a common hot-bed.

And now to make a cutting. Usually it is very simple. Take off a portion of the partially ripened wood (if too soft or young it will damp off, if too hard or old it will not put forth roots); cut it horizontally, or slaning downwards, at a joint, or just below a leaf; it being for verbenas, 
fuchsias, and heliotropes, from an inch to two inches long. Plant it half its length in silver sand and loam, along the sides of the pot, and put the pot in your case.

As a rule, take all cuttings of soft-wooded plants at a joint.

Some hard-wooded plants, such as Heaths, and Epacris. are rooted from tips of young shoots, in sand, with no bottom heat. Gloxineas, and Begonias, are rooted from leaves. Place the leaves in silver sand, keeping it moist, and pressing them close on to the sand. A plant will always spring from the junction of the leaf and stem, and frequently every nerve will produce a plant.

The Waltonian principle may be applied to the Wardian case, and thus many rare hot-house plants may be grown in the parlor.

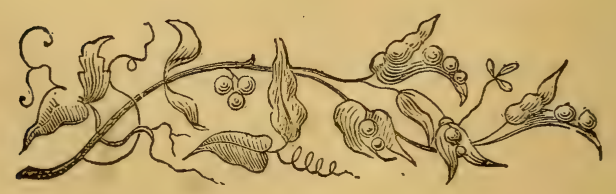




\section{CHAPTER XVII.}

\section{THE AQUARIUM AND WATER PLANTS.}

Proportion of Animal and Vegetable Life.-Form.-Construction.-Dimensions. - Situation. - Oxygenation. - Sunshine. - Planting. - Plants suitable for the Parlor Aquarium. - Limnocharis Humboldtii. - Procuring Plants. - General Directions.

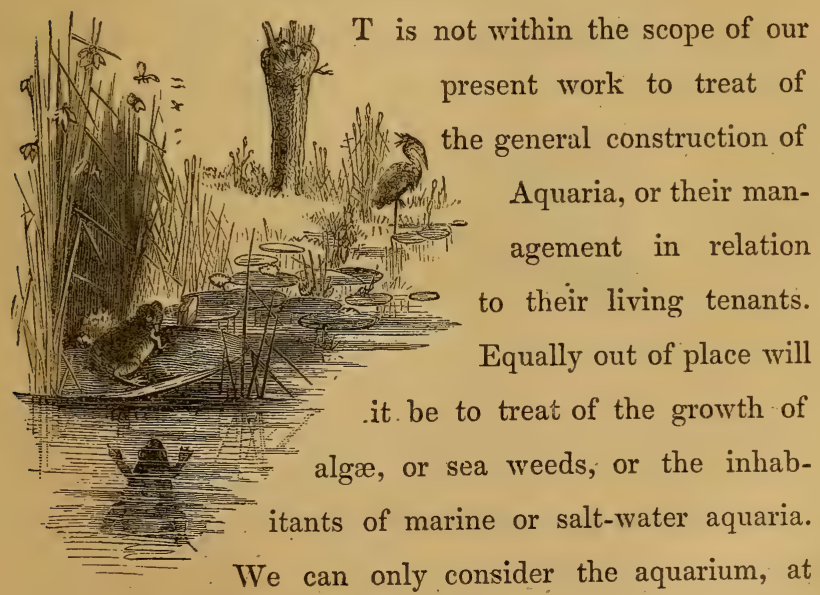
present, as a means of growing in perfection, in the parlor, meadow and water plants, leaving for others the pleasing duty of describing animate life in connection therewith. 
It is well, however, to understand that no aquarium does well unless stocked with some forms of both animal and vegetable life. The goodness of the Creator has, in Nature, proportioned the one to the other, each consuming what is injurious to the other, and both together working with that admirable adaptation which ever characterizes the works of God.

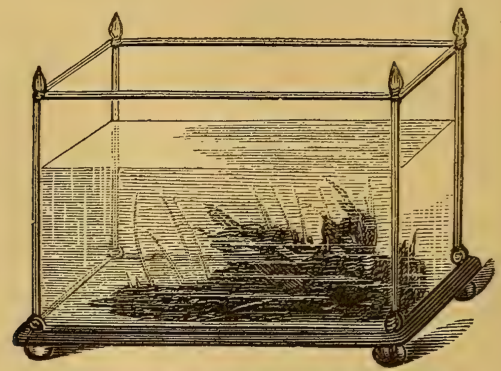

FIG. 1.

We must, in our imitation of the great provisions of Nature, in an humble way, provide as she provides, and so proportion our animal and vegetable life as to give health and beauty to both. For this reason a few of the smaller fish, and a quantity of snails, should always be introduced into our aquarium, to preserve the proper balance by con- suming surplus vegetation. 
The best vessel for an aquarium is, doubtless, a tank of a rectangular form, constructed of glass, with a slate bottom, and mounted on a stand made for the purpose.

The simpler the outline the better, because, where we have but a few broad sheets of glass, the view is less obstructed, and light, the great essential of success, can penetrate to every exposed part of the collection.

In Figure 1, the dimensions are as follows: Back and front, three feet; ends, one foot four inches; depth, one foot six inches. The bottom is of slate, and the four sides are of plate glass. Four turned wooden pillars unite the four sides, and four similar pieces bind the whole along the top edge.

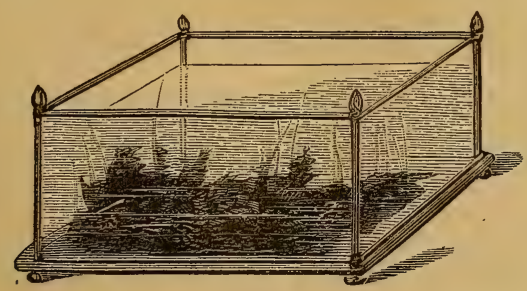

FIG. 2.

If shallower water is required, a square tank, say two feet four by two feet four, and one foot deep, would be suitable, as shown in Figure 2. 
The weight of these tanks, when filled with water, is very great, therefore strength is a matter for consideration. The joints must be strong to resist internal pressure, and the table firm enough to bear the weight. The slate bottom and ends must have suitable grooves to receive the glass, which should be heavy plate or very thick crown.

White lead putty may be used; there are, however, many kinds of water-proof cement equally good.

The most elegant outline of straight lines and right angles will be attained by giving the tank the form of the double cube, in which the length is exactly double that of the width, the width and depth being equal.

A window is the proper place for the aquarium. An abundance of light promotes the growth of the plants, and secures that succession of tiny globules which the vegetation sends up from the bottom, and which in the sunlight rise rapidly to the surface. This is one of the prettiest features of an aquarium. These bubbles, which ascend from some plants in continuous streams, are globules of oxygen, and are produced by the plants which decompose the water into its elements, retaining the hydrogen for their own growth, and liberating the oxygen.

When there is no sufficient exposure to the sun, none of 
this aeration takes place; the oxygen of the water is exhausted, the plants become diseased, and the aquarium is a failure. The difficulty is, to give sufficient light, without affording too much.

Occasional sunshine, if gentle, is essential, but if the water becomes heated, the vegetation will be injured and the animal life be destroyed. A shade, sufficient to admit the light, but to retard the fierce rays of the sun, will be beneficial.

Ground glass, or oiled paper, may be used; in fact, any thing that will admit light without heat.

Suppose we have constructed our aquarium. The bottom may be formed of loam and sand, or of small pebbles and sand, in which almost any aquatic plant will flourish.

In planting, remove a few pebbles, lay out the roots, and, by replacing the pebbles, hold them in their place.

For ordinary tanks, almost any of the common aquatic plants found in brooks or ponds will be suitable.

It is an interesting fact, that the coarsest plants soon adapt themselves to circumstances, and that their growth becomes more delicate. The common Pond weed (Potamogeton) appears too rank a plant for an aquarium, but in less than a month its character becomes changed; 
it throws out delicate white roots, sheds its coarse foliage, and acquires a smaller, neater, and more delicately veined dress of leaves, and is a beautiful plant.

The same may be said of the pretty Starwort (Callitriche), which acquires a lovely emerald hue and a neat growth.

The Callitriche ( $C$. aquatica) of our streams differs somewhat from the European, but is a very pretty plant. The flowers are minute and solitary, but the leaf is very ornamental. It is a pretty little annual; grows in Roxbury, near Boston.

The Limnocharis Humboldtii is a splendid water plant; an exotic, and producing bright yellow flowers in abundance all summer, of the size of a half-dollar. It is probably more easily grown than any water plant, for, though a green-house inhabitant, our parlors would be quite warm enough for it in summer.

The pretty white Lily (Nymphoea odorata) of our rivers and ponds will do well, but needs a large tank.

The same may be said of the beautiful blue Lily of the Nile ( $N$. coerulea), which will even bloom out of doors in summer, but which requires care and heat to carry it safely through the winter. This and the Limnocharis, 
together, make a splendid show. They may be obtained at many of our green-houses.

The Vallisneria Spiralis, or Tapegrass, is a very pretty plant in an aquarium, and flourishes well. It is a common inhabitant ot slow rivers, and its flowering and fructification are very curious.

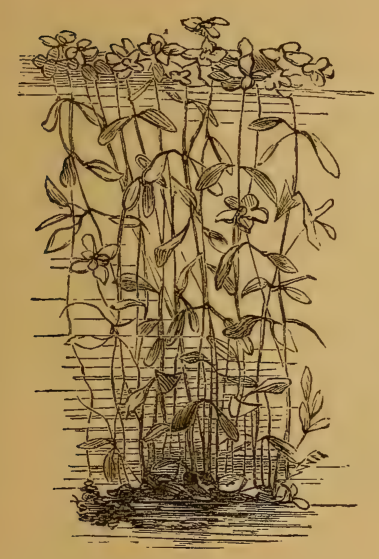

Callitriche or Starwort.

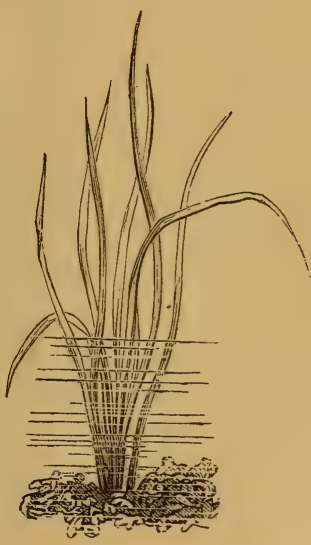

Vallisneria Spiralis.

The Anacharis Canadensis, a common inhabitant of our streams and ponds, is by no means the homely plant, in an aquarium, which its name implies. The name signifies " wholly unattractive." It will do well in any situation, and 
grow very beautiful as its foliage becomes adapted to the case.

Alisma Plantago, or Water Plantain, is a pretty plant, with varying leaves, some round, others ovate, others oblong, and producing .small whitish flowers. It is found very plentifully in ditches.

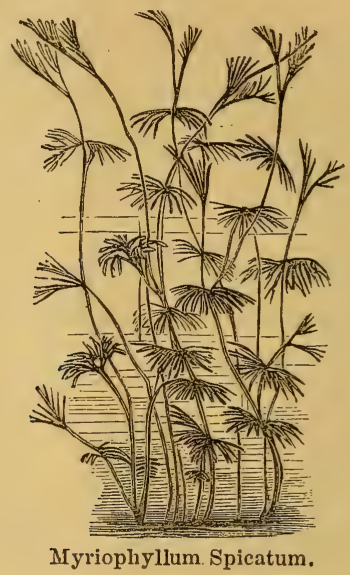

The various species of Myriophyllum, or Water Milfoil, are rapid growing plants. Of these, the best are $M T_{\text {. spica- }}$ tum, a common inhabitant of deep waters, and $M I$. ambiguum, with its varieties, a native of ponds and ditches. . The many varieties of Potamogeton, or Pond Weed, are 
all pretty plants, of easy cultivation. Those most commonly met with are perfoliatus, fluitans, natans, and heterophyllus. They bloom above water, and need constant thinning, or they would occupy the whole tank.

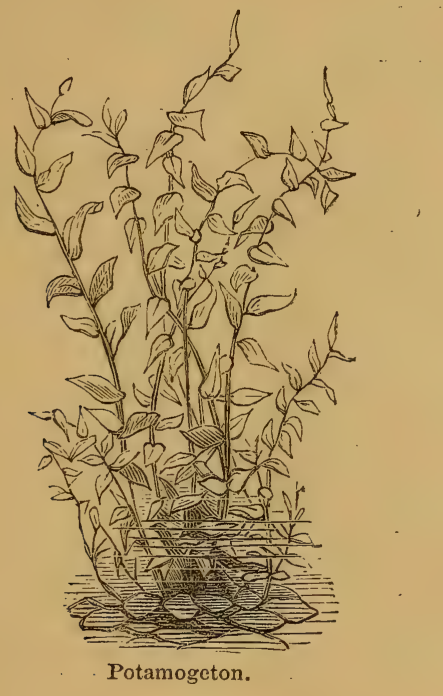

The pretty Sagittaria, or Arrowhead, producing its spike of white flowers in August, should not be overlooked, or its near neighbor on the river shallows, the Pickerel Weed (Pontederia Cordata), so conspicuous for its purple flowers from July until autumn. 
The Water Star Grass (Scholleria Graminea), is a little grassy plant, producing its pale yellow flowers in summer. The growth is wholly beneath the water, the flowers only coming to the surface.

The Water Buttercups (Ranunculus Aquatilis and Purshii), the former with white, the latter with yellow

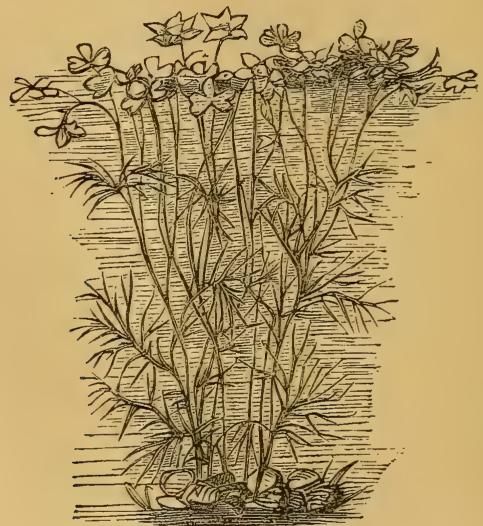

Ranunculus Aquatilis.

flowers, are beautiful aquatics. The divisions of the foliage of the former are particularly graceful and pretty, and no lover of beauty who has once grown it would be without it.

The pretty Water Violet (Hottonia Inflata) is a little 
gem of a plant; the leaves are curious, and the flowers rise on a stem whorled at the joints, and are at once interesting and ornamental.

All the Bladderworts (Utricularia) are pretty and common plants. U. inflata and vulgaris are the most common.

But we. are sensible of the difficulty of giving any thing like a complete list of the many natives of our ponds and streams adapted to the aquarium. These we have mentioned are, with the exception of the exotics, to be found every where, but there are many others equally common, and no less beautiful.

Our advice to the amateur is, go to the nearest pond or stream, transplant what seems to you suitable, and watch their growth and development. You will find enough to admire in what are called our commonest weeds, for the many species of water plants have been sadly neglected, and their beauty is not appreciated.

Some bloom above, some below the water; some produce foliage floating on the surface, others have it suspended in the water. New plants will give you new beauties, and you will the more reverence the power of the Creator, by the study of these, his almost unknown works. 
As we have before said, the great element of success is proportioning the quantity of animal and vegetable life.

The usual rule is, two fish to every gallon of water, with snails to eat up any slime or refuse. If well managed, the water need never be changed. To attain this, you must use only healthy plants, and not too many of them, and have the bottom of clean pebbles and sand.

If the water evaporates, it must of course be renewed, and should it become stagnant, it may be aerated by turning portions of it from one vessel to another. Of course if decay of the plants takes place, or animals die in the water, the only remedy is to empty, thoroughly cleanse all, and begin anew.

The Wardian case and aquarium may often be very prettily combined by raising rock-work in the water, planting ferns, and other moisture-loving plants upon it, and covering the whole with glass.

Where access to water can be easily had, a fountain in the centre might be contrived, and the effect would be most beautiful. There is, however, a water plant which will thrive very well in the parlor, and require but little care. 
About the middle of November, procure a large bowl, or wide-mouthed vase, or, what is better, one of those fancy stands, representing the trunk of a tree. Fill it with water, and in it set a plant of Sarracenia Purpurea, the common side-saddle flower, or pitcher plant, of our meadows.

This plant is not only remarkable for its curious pitchers, but is very ornamental in flower. With this treatment it will soon begin to grow; young leaves, or rather pitchers, will be produced; the flower buds will appear, and all winter the plant will be a mass of fresh foliage. The only care is to keep the leaves clean, and to refill the bowl when the water evaporates.

In conclusion, let us say, that in all the details of management there is no teacher so good as experience. In a volume like the present we can only lay down general rules. The little minutiæ, the daily care, the ceaseless routine of attention, on which success so largely depends, we cannot prescribe. Each amateur will find those rules suited to his own case by experience and practice; but we trust we have, in our limited space, said enough to urge upon all to undertake the study of water plants, and the care and pleasure of an aquarium. 


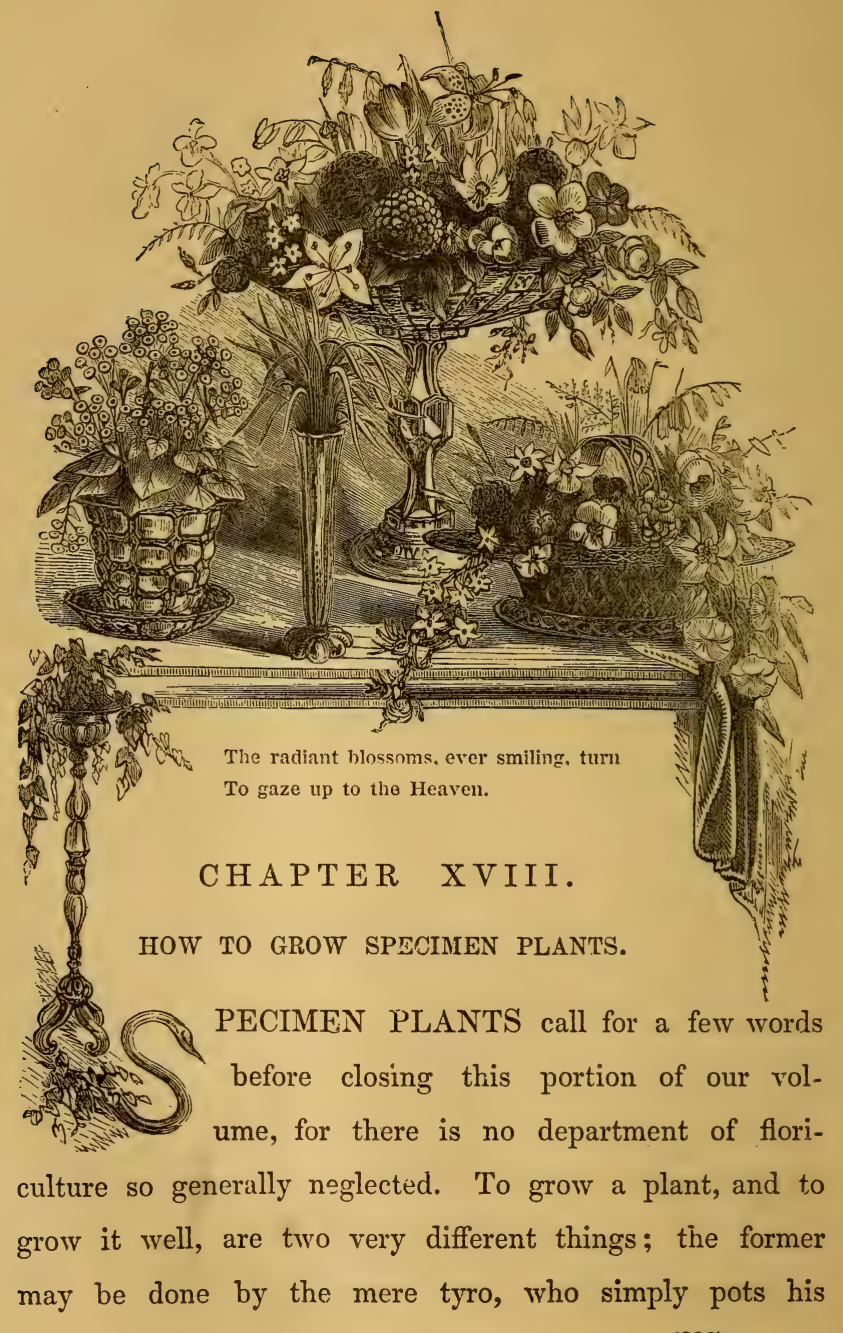


plant in good soil, and supplies water enough to keep it in vigorous growth; the latter is one of the highest arts of horticulture, and very few of our professed gardeners understand any thing about it.

The general ignorance on this subject is the more surprising, as all are ready to admit the beauty of a wellgrown plant, and to decry the long-jointed, straggling specimens, so often a disgrace to our collections. Yet we see our green-houses filled with illy-grown plants, poor, drawn specimens, struggling up to the light, and crowned by a bunch of bloom, on stems several feet long, and entirely destitute of foliage. All this is doing violence to nature; in their wild state, free and unconfined in the open air, most plants and trees are symmetrical pictures of beauty. Nature does all things well, and art but approaches perfection when it approximates to nature. Could our greenhouses be ample enough to allow to each plant the same space and conditions of growth which it obtains in its native climate, could we allow free room for both roots and branches, each plant would be a specimen needing only the free use of the knife to repress and prune out too great luxuriance. Nature would do all the rest; a tree would develop into a tree, and when rcots 
and branches were, by a growth of a series of years, prepared for the development, the display of flowers and fruit would equal that of the same species in its native clime. In like manner a bush, herb, or annual would attain all its full Zuxuriance and proportions, and the art of growing specimen plants be simple indeed. But our space is limited, the luxuriance of roots and branches must be restrained, and the plant, by the cramping of the roots and pruning of the branches, forced into early bloom. The desideratum is, therefore, to obtain as much bloom as possible in a small :space. The question, - How is this to be done? we answer, - By growing specimen plants.

It is a prevalent error that an illy-grown plant produces more bloom than one well-grown; the former may come :sooner into bloom, but the flowers will neither be as fine or as plenty as on the latter.

There are two methods of growing specimen plants: one by confining the plant within a wire frame, and tying out the shoots so as finally to hide it completely with foliage and flowers, or by tying the shoots to stakes cause them to assume a regular position, which stakes are soon hidden by the foliage. The other method is, to grow the plant slowly, so that the shoots become stout and stiff, 
the plant bushy, and able to bear the weight of bloom and foliage; the former is best for climbers, or halfclimbers, but is much used by those who grow their plants quickly; the shoots are weak, and without supports the plant would have no shape; the latter is the true way, but the plants must be grown slowly, as otherwise the requisite stoutness cannot be attained.

The one rule to be observed, whether in growing specimen plants for exhibition or for home decoration, is, Grow your plants slowly.

We copy a few hints from an English work, where the author condemns growing plants with supports, but acknowledging that thus more bloomș may be brought into sight, declares it necessary in competing for prizes, as the plants thus grown bear carriage well, which those naturally grown do not. The distinction observed in his remarks is between plants naturally grown or raised for home decoration, and those artificially supported or grown for exhibition. We have also, in many instances, changed the language, and made many interpolations, in order to adapt the article to our own locality; we wish, however, to give due credit to the writer, though in some things his statements are erroneous; these we have corrected. 
The great difference between growing plants for homs decoration and for exhibition will hardly be realized. There was always an opposite mode of treatment required in many particulars, but the system of showing has become so widely opposed to judicious management at home, that gardening for the home and the foreign department affect us like two different sciences. The necessary preparation for transmission from one place to another, and constant jumbling about, has converted all our natural plants into artificial ones. Not one production in a hundred is shown in its natural form. We can excuse this when we remember that plants have to be taken for miles, jumbling up hill and down dale, over rough roads and stone streets, before they reach their destination, and then have to be got into the carts and got home again the same day; for, if the branches were in their natural state, playing freely in the air, they would be frayed to destruction by the mere action of rubbing against each other. But we must own, at the same time, that a plant, with every branch and bloom constrained in its place, and bound mechanically to some formal support, is no more fit to compare with one fairly grown and unconstrained than an artificial plant would be with 
a real one. It is to the ambition of growers to produce enormous plants that we trace the great change which has taken place in our exhibitions.

There is as much difference in a plant grown properly, and standing undisturbed in its place at home, and one grown artificially in an iron cage, as it were, and all the branches and blooms bent about so as to come to the outside surface, as there is between the sham flower and the real one; and he who for one moment gives himself the trouble to think of the formal, stiff, and unnatural shape of plants at a show, and the beautiful free growth of the specimens in a private collection or a nursery, where there is no showing, will not hesitate to pronounce those at a show altogether spoiled for the lovers of plants.

Nevertheless, those at a show form masses of flowers, which in some measure compensate for multitudes of wooden legs and iron bird cages. Geraniums, as formerly exhibited without sticks were very beautiful, far before any thing we now have as specimens of growth, though the prodigies of the present day rank far higher as specimens of mechanical ingenuity and skill. The system is altered; plants naturally grown would stand no chance against those with wooden legs; the plants could 
not be as large, nor could they show so many flowers without being drawn. As now shown, they are always drawn, and legs or supports are given them because drawn plants cannot support themselves.

This mode of exhibition is a perversion of the nature of the plant, and we can see no remedy for it unless it is in the power of the judges to control it by giving the preference to plants naturally grown, and without legs or supports.

In our remarks we do not, of course, mean to include climbers, half-climbers, or trailers; we only censure growing azaleas on hoops, pelargoniums on sticks, et id omne genus.

The best growers freely acknowledge that props are objectionable, for the reasons we have given above, but they are necessary while size remains so captivating as it is at present, and he is the best artist, we cannot say gardener, who can make his props the least conspicuous. The cultivation of plants for show, then, involves an early and intimate acquaintance with the use of supports, and in proportion as a man acquires this, he becomes careless as to whether his plants are drawn or not. He stops his plants back that they may make more shoots 
than usual, or than is graceful, because he wants all the branches he can procure to make a surface of flowers, and as soon as the plant assumes any thing like a moderate size, twigs are placed to guide them outwards or upwards, and at equal distances; for all the harm it would do, he might almost roll the plants about the floor, without displacing a shoot or leaf. As the plant advances beyond the distance provided for by the sticks or twigs that support them, others must be placed there for as much more growth as the specimen is likely to make. This applies to all kinds of plants grown by propping with wooden supports, - roses in pots, fuchsias, pelargoniums, geraniums, to many of the hard-wooded plants, verbenas, petunias, and many others.

There is yet another unnatural and yet popular mode of growing plants for show. We have seen complete iron frame-works or cages, and inside these the plants, such as Rondoletia, Hovea, Eriostemon, Chorizema, and many other plants of great merit, crowded, the stems distorted all manner of ways, totally destroying the nature of the plant, concealing its habit, and contriving to bring just the shoots through upon the surface.

It is true these cages are made of a conical or a pyram- 
idal form, and by gardeners of taste, as near the natural form of the plant as may be, and that sometimes the shoots are allowed to protrude as far as they safely can, to break some of the stiffness which too many have not the ability to conceal; but constraint seems to be the prevailing appearance, and some of the most graceful of our favorite plants are thereby rendered artificial. The growing of plants for exhibition is, under these circumstances, almost a science of itself, and the chief evil to avoid is that of allowing the specimens to get ahead of the training, whatever that may be. Strong supports for the centre branch, and very little else, will do if they are to remain at home; but for exhibition, the several branches must be supported independently, with upright props of wood, until the specimens have attained, within a season or two, the requisite size; then they ought to have their principal shift, and their "cages" must be put to the pot or tub, and the branches trained to the outer wires instead of to the uprights. By keeping this frame well within the rim of the pots with regard to size, and allowing for the growth of a few inches outside, the plants will soon conceal the obnoxious appearance of the frame, because in many plants 
even these shoots may be stopped back, and the laterals make all their growth outside. It is at this time, when we may at least either prune back irregularly, or leave the uneven growth to make its own way, that a good deal of the stiffness may be got rid of, and some approximation to nature be made. Epacris, Hovea, Chorizema, and many other plants which are naturally weak in their branches or straggling in their growth, being assisted up to a certain point and then allowed to push naturally, may be produced much better even in constrained growth, and may, to unobservant spectators, appear to show a fine natural cultivation. The more robust heaths, ixoras, and many other hard-wooded plants, can be well grown without much support, if not grown too fast; but if too much excited, they will be weak, and need props in plenty, instead of here and there one.

The Fuchsia, which is a favorite exhibition plant, may be grown very rapidly, but always at the expense of quality. The fuchsia, for style and appearance, as well as for the full development of the capabilities of a variety, should be grown in a pyramidal or conical form, and full of branches. They may also 
be well shown, and with fine effect, as standards, with an umbrella-shaped head, - a mode of growth specially adapted for showing off the drooping flowers. This mode requires much care; it is very difficult, unless the plant is grown on a wire frame or hoop.

To grow fuchsias well and effectually the plant should not be hurried. It should be strong in the main shoot, and not be so weak as to require a prop. It should, at the end of the season, be allowed to rest; as soon as it indicates a desire to grow it should be re-potted, not in too rich a compost, and be pruned with short branches at the bottom, shorter as we go upwards, till they are mere spurs when we get half way up, and tolerably close at the top. By growing the plant gently in the green-house, the branches of the season will be multiplied greatly, and with a very little checking, form a beautiful close cone or pyramid (according as the plant has been pruned), full of foliage and bloom, and with colors in perfection. The fuchsia will also grow well as a bush. We have, to do this, to stop the cutting when it is two inches high, and to continue stopping all growth which is too vigorous, and all early growth, directly two eyes can be left, so that by inducing lateral shoots we secure a bush in 
miniature at an early stage, and need only shorten such branches as are getting on too fast for the remainder. All weakly shoots should be cut away close home, for they only weaken the rest and confuse the order; branches should not cross each other, nor should the plant get confused by reason of the number of branches allowed to remain. The habit of the variety - under cultivation should be studied, for there are many kinds grown which are worthless; a bad habit is seldom compensated for by a good flower, because the fuchsia depends for its value a great deal on habit.

Prince Albert, Gem of the Season, Duchess of Lancaster, Prince of TVales, Souvenir de Chiswick, Madame Sontag, and Venus de Merlici, are all of fine habit. Few can equal them in this respect, while all may lay claim to most of the requisites of a good flower. Set them in pots, in moderate soil (not rich); and after this give them only water when they want it, and all the air and light you can. They will scarcely require a shoot to be lopped; so fine is their habit, that unless accident blighted the leader, they would be compact, and at their season full of bloom. At the end of the year, when, as it were, they had done their work, they would 
lose their leaves, and only require to be kept from the frost; they would want larger pots at the beginning of the year, all the side branches shortened, and if the leaders chance to be injured, they should be shortened to a strong shoot, and that trained upward by a temporary support; but it is far better to save the original leaders. The next year's growth would be better than the first. It would, however, be necessary to thin out many of the shoots, because they would otherwise be too thick and confused. They would be one mass of bloom from top to bottom, and models of what fuchsias should be; but they must be grown without heat the second year as well as the first, and as a general rule fuchsias should have no artificial heat; they should be grown in a green-house, though we have often seen them out doors; but the changes of weather are too severe for them, and though of brighter and firmer color, and more robust growth, they lack much of the grace and delicacy of tinting, which is so attractive in the fuchsia. While growing they should have plenty of water, and be shaded a little from the intense heat of our summer's sun. The white corollaed varieties are all of weak growth, and not adapted for specimens; the 
double varieties are, many of them, of good habit, but are no favorites of ours; the best of all is Sir Colin Campbell.

To grow plants for home gratification alone we need not be at half the trouble, and certainly produce twice the effect. We may allow them to grow without extraordinary support. They have at most to be removed on a hand-barrow from the stove or green-house to the conservatory, and the natural play of the branches for that short distance damages nothing. The shortening of branches, the training and general management, have reference only to their intended situations, and the principal thing to guard against is, not to excite any thing too much.

Very few things bear growing fast; it always makes a greater distance between the leaves, and consequently the plant looks poorly. But this is of the greatest consequence, because more conspicuous when the plant comes into flower, for bloom depends upon the number of branches in a given space, and if the branches and leaves are more distant, the bloom must be so likewise. This is shown very conspicuously in plants which bloom from the axils of the leaves, as fuchsias, epacris, and others of the same habit. Besides, com- 
pactness is a great point in all plants; not when carried to confusion, which should always be avoided, but when induced by moderate growth and judicious pruning and stopping.

The Hovea, a plant very popular in England, but little grown in this country, is never seen in good condition; yet its treatment is very simple. We give, for illustration, the method of growing a specimen, and the rules apply to many hard-wooded plants of kindred nature and habit. It naturally grows fast in excitable compost, but can scarcely be grown with too little dung, or soil too simple, so it be healthy and clean. The earliest stopping, even when first struck as a cutting, is necessary; not more than the pair of leaves next the soil should be left, and the eyes, throwing out two lateral shoots, give us an opportunity of stopping both at the first joint, and thus obtaining from each two more lateral shoots, to be stopped in turn for the same number again, and so continuing until there is a perfect bush; but the plant cannot be neglected many days. This constant stopping, until we have branches enough, will produce an excellent plant. It is, then, by taking off all branches that are in the way, and learing 
only such as will help to make a handsome plant, we may allow the growth to go on till they bloom; but after flowering, the plant requires pruning as regularly as a wall fruit tree, and the new shoots must be watched and regulated, and the same provision made for the beauty and symmetry of shrub as was made in the first instance.

Were the plant left to itself, and planted in a rich soil, it could be made to grow six or eight feet in a single season, and be altogether unmanageable in a season or two, because the bloom only comes at the end of the branches, and the long under portions are both leafless and flowerless. If a plant has thus, through neglect, become shapeless and unmanageable, the evil is past cure; the best thing to do is, to root cuttings and throw away the old plant; pruning would not remedy the evil, for eyes break reluctantly on old wood, and seldom with any regularity. To grow Heaths, as specimens, requires great care, and the study of the habit of the species. Some, like Epacris, run up to great length of branches; therefore, before we allow them to shoot their full length, we must, by stopping, secure plenty of them. In this one thing lies, also, the secret of growing fine specimens of epacris. 
Others are naturally of a bushy habit, and require thinning out rather than stopping. But in all plants we have to look well to the growing state when they are manageable, for a very brief neglect, only for a single season, will give us bare stems, naked undergrowth, ill shapes, and often unhealthy plants, and the best thing we can do then is to strike the tops of the young plant for young stock, and to cut down the stems to within a few inches of the pot, for the mere chance of their breaking and making fresh growth. There is, however, one method by which we may occasionally convert an ugly plant, with long, naked stems, into a handsome standard; but there are few plants which look well under such a change. One of these is the Azalea Indica, in its numerous species. If there be one straight stem among them, cut all the others close down, and cut the branches of the single stem off up to the part where the head is to begin; top the shoot to cause a side growth, and the head will soon form well, but until the head is large enough to be proportioned to the height of the stem the plant will look poorly, and only be fit to remain in the plant-house. 
Fuchsias of some kinds, particularly Corymbiflora and its rarieties, naturally carry large bunches of blossoms, tassel-like at the ends of the branches. The best thing we can do is to remove all the side growth to the height we wish the head to begin, to stop all the other branches to two joints, until we get a sufficient number of branches to hang all round, and then to let them grow to bloom. The pendulous habit of the plant is favorable to this, and the blooms fairly weigh down the most obstinate of the shoots, so that the plant forms a pretty object.

These varieties of fuchsia do not receive the attention their beauties merit; probably because they do not bloom as freely as others with little care; but a wellgrown plant is a conspicuous object in the green-house. They also bloom with us at a season when other fuchsias have not come on, that is, from February to May.

In growing plants for exhibition, we excite them to what we call perfection by restraint; for convenience of carrying, we limit the size, and thus the number of flowers; to color, by unnatural means (this applies chiefly to out-door flowers); to compactness, by vicious training. Specimen plants may be made of hardy plants and shrubs, and of annuals. The pruning and training must be adapted to 
the habit of the plant; it is useless to fight against Nature. We may succeed in producing a monstrosity, Bout depart far from perfection. To all growers we say, :study the habit of the plant, and be guided by Nature, never attempting to be Nature's guide.

Before closing our article, we wish to give a list of plants, which, generally neglected, make fine specimens.

And first, the Camellia, a plant naturally of most symmetrical growth, with but little pruning will make a :superb specimen.

The Daphne Odorata, never seen in good condition, can, by a free use of the knife, be made a beautiful plant.

Azaleas will do well, and may be grown in almost any form.

Acacias are mostly trees, and seldom make fine plants under pot culture. Planted out in the green-house border, they grow large and look well. We may, however, except some of the shrubby species - as Armata, Grandis, and the newer kinds, which, being low growers, do well in pots.

Achænia Malvaviscus : a favorite plant with us, and a superb sight when in fruit and flower. It possesses the advantage of being never out of bloom. The kin- 
dred species of Hibiscus are pretty plants, but not generally grown.

Allamandas, Kennedia, Stephanotus, Combretum, Rhyncospermum, and a host of other hard and soft-wooded climbers, grow to perfection on balloon trellises, and if the foliage is kept in good health, are pictures of beauty.

Pelargoniums and Geraniums need only to be grown slowly, and to be properly pinched to make side shoots, and are among the finest plants for specimens.

Orchids need great care, and the growth is slow; but well grown, are most splendid when in bloom. Nothing can surpass well-grown plants of Cypripedium, Cattleya, Lælia, Stanhopea, Oncidium, and hosts of others. The Cyclamen, in perfection, is most beautiful, and many of the Cape bulbs, in profuse flower and foliage, are very pretty.

We need not now explore the widely extended region of variegated-leafed and ornamental-foliaged plants. Those who have seen the Cyanophyllum, Rhopalas, Cordylines, Crotons, the many beautiful Caladia, and the unapproachable and unique Alocasia Metallica, need not be told what magnificent plants are given us for specimens, and to those who have not seen them, no words can 
convey an idea of their beauties. In conclusion, we can give no time for beginning to grow a specimen; for softwooded plants, four or five months will suffice to make a specimen from a cutting; but many plants require years to approach perfection. The general rules may be laid down thus :-

Study the habit of the plant, and by it regulate your treatment.

Grow your plants slowly, with plenty of light (except orchids, some ferns, and lycopodia), and free circulation of air.

Keep the plant from sudden changes of temperature, and never let it suffer from want of water, or become pot bound. Do not be afraid to use the knife freely, prune whenever necessary, whatever you may sacrifice.

Grow your plant well first, and then the plant will give you the bloom.

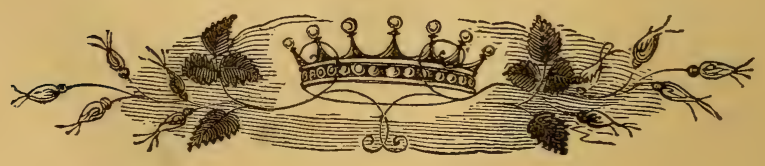




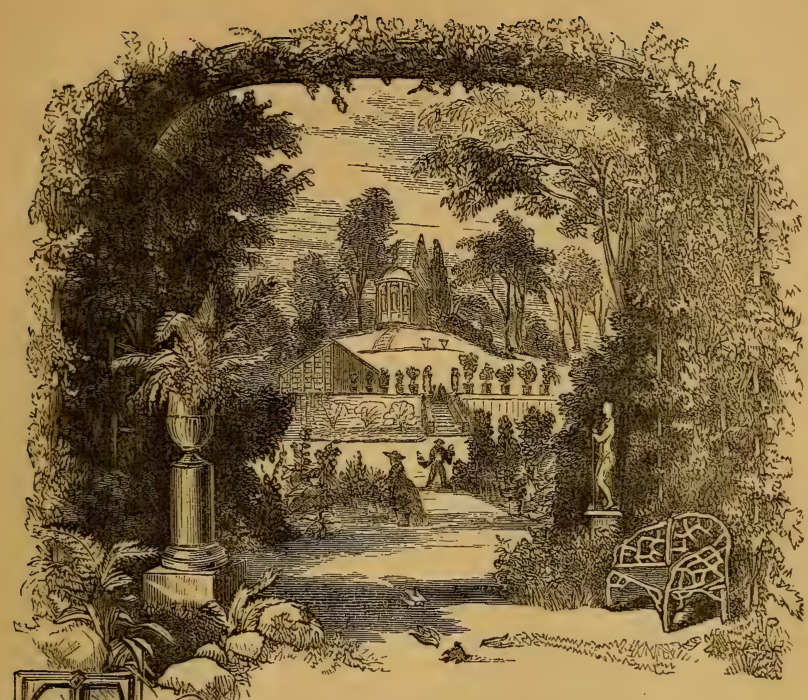

HE grass is wet with shining dews,

Their silver bells hang on each tree, While opening flower and bursting bud, Breathe incense forth unceasingly.

\section{CHAPTER. XIX.}

\section{OUT-DOOR GARDENING. - HOT-BEDS.}

Uses. - Time of Preparation. - Construction. - Size. - Sashes. - Manurc. - Other Materials needed. - Height. - Materials for Potting. - Heat. Planting. - Sowing in Bed. - Permanent Hot-Beds. - Watering. - Airing. - Protection. 


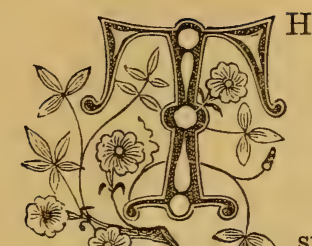

$\mathrm{HE}$ bright days of spring have succeeded to the cold of winter. Day by day the sun grows warmer, and in spite of the occasional flurries of snow, the snowdrop nods in the sunny he border border, the crocus goldens the garden, and the hyacinths and tulips look out from their winter's sleep. Our window garden, a source of unfailing pleasure during the months of snow and ice, and now clad in its spring dress of glossy leaves and gay flowers, fails to satisfy, and only makes us long for a more extended range, a larger field of operations. Even our Wardian case, always beautiful, claims less of our time, and we eagerly watch each new growth in the out-door garden. But as yet it is far too early to begin our out-door work. Did we plant our seeds, they would decay in the cold ground; the delicate roots of bedding plants would be chilled and die. There are yet to be many days before we can trust to the capricious weather, many days during which, little by little, the earth will become dry and warm under the potent heat of the sun and the sweet influences of the vernal breezes.

But still there is work that may be done, though it is as 
yet too early to uncover the flowemborders, or to turn over the still damp and heavy soil.

We may build our hot-beds, and in these bring forward the seeds and plants, so as to be ready to avail ourselves of the first days of settled weather, and to insure an early display of floral treasure in the flower garden.

It is out of our province, in this connection, to treat of the hot-bed as a means of forcing early vegetables, or of bringing forward seeds for the kitchen garden. Suffice it to say, that by means of it, if well managed, we may have such spring vegetables as lettuce and radishes, from February until they mature in the open ground; and that the process of starting vegetable seeds is the same as that we employ for flower seeds.

We propose but to treat of the flower garden and its adornments, and it will be quite early enough for our flower seeds if we start our hot-beds about the first of April.

The making of a hot-bed which will keep the heat, and not burn the plants, is by no means an easy task, and often, in this branch of horticulture, the most experienced gardeners fail; the process seems very easy, but in this, as in most gardening operations, success depends on a careful attention to little details. 
A friend has kindly furnished us with his method, and, as we cannot improve upon it, we give his instructions almost in his own words, gladly availing ourselves of the aid of one who, with his hot-beds, accomplishes wonders; and whose flower garden presents a gayer appearance than that of many who have unlimited green-house facilities at command.

To those who have a green-house, or a forcing pit, the hot-bed is not a necessity. With these aids it is easy to raise flower seeds and cuttings sufficient for every want. We are writing more especially for those who have no green-house, but to whom flowers are, nevertheless, a necessity. Such must depend upon the hotbed, and we would tell them how to make it.

And first we must make our frame. A good size for our use is five by ten feet square, ten inches high in front, eighteen in the rear; with the ends shaped, of course, to match. Let these be cleated so as to prevent warping, and fasten together at the corners with hasps. Let in, flush with the edge, narrow strips at proper distances for the sashes to slide on, with a narrower one in the middle for a guide. These will accommodate four sashes of proper proportions for glass eight inches wide, 
which should be inserted in grooves, rather than by the old method of puttying, as putty soon crumbles with such severe exposure.

Now this work may be done by us, if we have but a slight mechanical turn, or we may employ our carpenter, who will construct the frame in a few hours. The sashes can be bought at a low price, as they are always kept for sale at any window factory. The whole structure, including sash bars, should have two good coats of coarse paint, which will be most serviceable in protecting it from the weather; and if we can contrive to char any portions which touch the ground, it will conduce much to durability by preventing decay.

As we design manuring the garden, we buy stable manure in March, wherewithal to do it. No matter if it be coarse and cheap, we can improve the quality before autumn many fold, and be richly rewarded in the process. We begin by throwing it in a heap, so as to present as little surface as possible to the atmosphere, and let it ferment, or, as gardeners say, "heat."

Our frame is made.

We will now suppose the manure is ready to move, and the time almost the first of April, long before it 
would be safe to put seeds in the ground, and when but little else can be done outside. Now we measure a space twelve by seven feet (to give a projection of a foot all round outside the frame), on a spot well sheltered from cold winds, and open to the sun. Begin by setting boards on edge, secured by stakes, and fill in, first with a layer of straw, leaves, or other similar material, and then a layer of manure, beating it down with the fork, but not treading it hard. Thus continue, until you have used sufficient litter to make it, with the manure, about two feet high. Put on the frame, cover the outside bank with boards laid flat, fill in with about four inches of tan, put on the sashes, and while the heat is getting up, we will get ready our seeds, and prepare materials for potting.

We shall want some bits of charcoal for drainage, from which we can sift the dust to mix in the soil for potting. We last fall secured some excellent peat, laid up a little loam, and saved a remnant of the old hot-bed (if we had one). These, in equal parts, with a generous sprinkling of the coal dust, make a good soil for present purposes.

In about a week after the bed is made, the heat will be up, as we may find by thrusting a sharp stick into 
it, and we may now begin to sow in pots seeds of such plants as are of slow growth, or will soonest bear turning out. A little practice will teach us when is the best time to start with the various kinds. Plunge the pots to the rim in the tan, and the bottom heat will soon start the seeds into growth. We see that by having the seeds in our power, we can control heat and moisture at pleasure, and will scarcely make a failure, unless we are careless enough to leave the glass on too long during hot sunshine.

Here, too, we will start such summer bulbs and tubers as require a season longer than ours, and of others, a few, to secure a longer season of bloom. Soon we begin to "prick out" the young plants, and "pot off" and "shift," in order that they may have a freer growth than they could attain if all grown in one pot, and as they are thus sure to become more stocky, of better habit, and larger size.

To watch, carefully to prevent burning, to water as may be necessary, to give air to prevent damping off, and to close before nightfall, covering with mats, are amongst our cares; until now, the ground is warm enough 
to begin to "turn out" the young plants, - which operation brings us to the out-door garden.

The duty of the hot-bed is done; and we have now only to store away frame and sashes in a dry place for another spring.

We have said, plant the seeds in pots. This is the best plan, as thus the young plants suffer less in transplanting; but we may sow the seed directly in the hotbed. To do this, sift fine rich loam on the manure (instead of the tan, as above directed), and in this, plant the seeds in drills : the loam should be about eight inches deep, and the seed should not be sown for a few days, in order to let the fierce heat and steam pass off. A far better and more durable hot-bed may be constructed of masonry. Excavate trenches of proper depth, below the reach of frost, and build up walls of solid rough stone, to about eighteen inches above the ground behind, and eight inches in front; or, if preferred, the walls above ground may be of brick laid in cement; on these walls place the sill and cross bars for the sliding sash; fill in the manure and loam, or tan, and manage as above. A hot-bed, constructed as thus directed, will last for twenty years; and even if not.wanted for a hot-bed, 
is very useful for growing violets and polyanthus for early blooming, as directed in a former chapter, or for protecting roses and half-hardy plants during the winter. The accompanying figure may give an idea of its appearance.

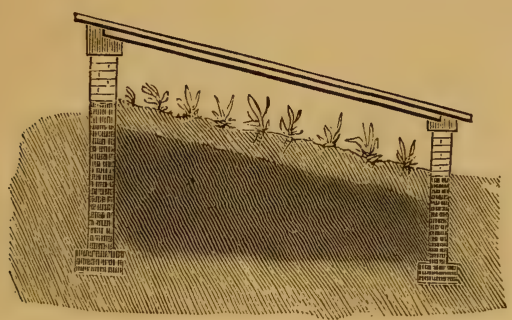

WATERING.

A hot-bed should be watered when the soil becomes dry. The rule is, keep the soil moist but not wet: Never water when the sun is on the plants, unless you water only the soil, and do not allow a drop of water to touch the foliage of the plants. Morning and evening are the best times for watering; but watering should never be done on a cold, freezing day. The water used should be of a moderate temperature; cold, icy water injures the plants. 


\section{AIRING.}

Air should be freely given when the weather is warm and sunny; on cold, cloudy days the sashes should be kept closed unless it is necessary to get rid of damp, which may be effected by opening the frame about an inch at the top. If the weather is very cold, the mats should not be removed from the sashes.

The best way to ventilate is to draw the sash down from the top. If, however, more air is required, prop up the sides; which, by securing a draught through, will effectually carry off the surplus heat, - an inch will be high enough.

As the season advances, and the days becrme warm and sunny, the sashes may be entirely removed after the sun becomes high; replacing them at night and in stormy weather. And finally, they may be removed altngether; which will much contribute to the sturdiness of the plants.

\section{Protection.}

If we do not start our hot-bed until the first of April, we shall probably need no protection other than 
that afforded by the sash, the internal heat being sufficient to overcome any external cold.

If we start our hot-beds in winter, we shall need protection. The best is a thick straw mat; and, if very cold, this may be covered by a board shutter. One mat should be sufficiently large to cover two sashes.

These mats, if properly cared for, will last many years.

We have not treated of the use of a hot-bed for striking cuttings; it is, however, most serviceable for this purpose; and with a small hot bed, a good supply of verbenas, salvias, heliotropes, and such plants, may be obtained.

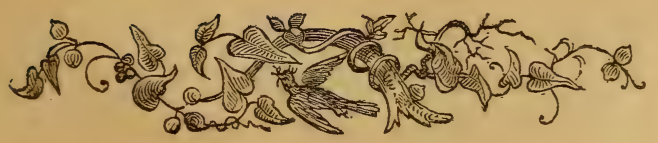




\section{CHAPTER XX.}

THE GARDEN.

Time for Gardening. - April Work. - Uncovering Bulbs. - Preparation of Border.-Dividing Herbaceous Plants.-Grass Edgings. - Manuring. - Weeding. - Watering. - Temperature of Water. - Staking. - Trim-

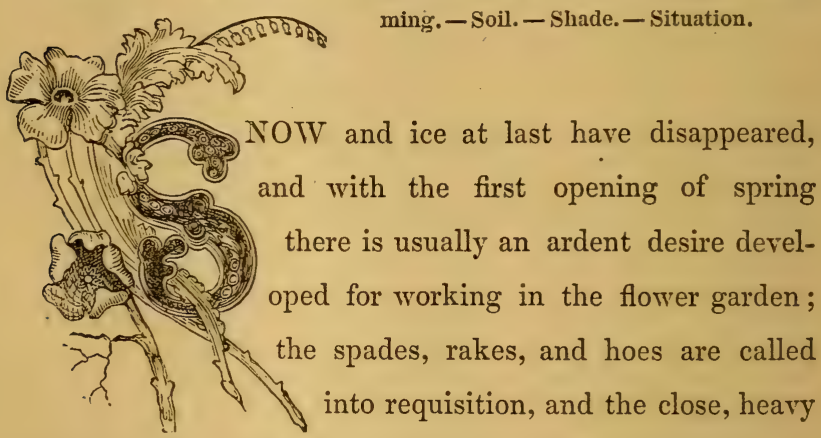

- soil receives a vigorous upturning, and the garden is put in order.

All too soon, however; there are yet to be cold rains and, perchance, chilling snows. The young shoots of the herbaceous plants are not benefited by being deprived of the protecting dead foliage of the last year; and the tender plants, covered during the winter, are not im- 
proved by being stripped of the mats, or other covering, in season to receive the chill of a snow storm.

The tenth of April is full early enough with us to uncover trees and shrubs. The digging of the garden beds cannot be advantageously undertaken before the first of May.

The only April gardening, is" uncovering the beds of snowdrops, crocus, and other early bulbs. The time for this varies from the first to the last of the month, according to the exposure of the bed. The rule is, when the bulbs shoot up through the manure and straw, and begin to bloom, then uncover. We shall, doubtless, have frosty nights; but unless the cold should be very severe, far greater than the average after the first of April, the young shoots and flowers will not be injured.

Let us suppose the warm, sunny days of May have come, the bloodroot and violets are in full bloom, and Nature is rapidly assuming her spring vestments. Now is the time to dig over our flower border; we shall find the soil, instead of being hard, sodden, and cold, as it is in April, soft, porous, and crumbly, breaking readily under the blows of the spade. If we hare given the border, in autumn, a good top-dressing of manure, as is 
always a, good plan, we have now no manuring to do. First, cut off all dead stems of herbaceous plants, and clear up the border; some prefer to do this in autumn; this is only advisable where the flower garden is in the immediate vicinity of the house, where the dead stalks would present an unsightly appearance during the winter. If we have no such good reason, it is far better to leave the stalks and dead leaves on the plant, as they serve as a great protection against the winter's cold and sun.

The border being cleared, it should be dug over, a foot deep, with a sharp spade, the ground levelled, and the earth well pulverized; care must be taken not to injure any herbaceous plants; if they are a little covered it will do no harm, as their tendency is to grow out of the ground; and if too high, they must be taken up and replanted. Now is the time to divide them, which may be done with the spade or with a sharp knife.

If you have grass edgings, they should be neatly cut; this may be done with the spade, or with one of the tools made expressly for this purpose.

If you have not manured the border in the fall, now 
is the time to do it. A flower garden should have a liberal dressing of manure once a year, and autumn is better than spring.

But if we did not manure in autumn, let us do the next best thing, and now give a heavy top-dressing; cover the soil four inches deep with the best well-rotted manure, the finer the better, and dig it in immediately, and prepare our border as above directed.

Let a day or two elapse before we begin to plant, for the soil is now light, and will settle very much.

We may then transplant, sow seeds, set bulbs, or turn out bedding plants; the latter, however, should not be done before the 20th of May, as they gain but little, and may be nipped by a late frost.

\section{WeEDing.}

Our spring work is over; the flowers are blooming gayly, and the hot June suns are shining. The flowers grow rapidly, but the same sun is bringing up a growth of weeds; we must be on the alert, or our delicate annuals will be smothered, and our garden soon lose its neat and attractive appearance. The weeds must be pulled up, and for this there is nothing so effective as 
the thumb and finger. Do not be afraid of dirtying your hands; this weeding, though often rather backbreaking and tiresome, and, withal, dirty work, is rery good exercise; and delicate fingers may be protected by a pair of gloves. The best time is early morning of a summer day, - say, from half past four to seven, on a clear, bright morning; one feels invigorated with the fresh early air, charmed by the beauty of morning, and really pities those who waste these, the best hours of the day, in sleep. It is not well to weed at night, or on a rainy or cloudy day, for there is no sun to kill the weeds, which it is better to expose to the sun, that they may be thoroughly killed; pull them in the morning, let them lay during the day, and gather them up at night.

It is poor gardening to cut off a weed just below the level of the ground with a scuffle or weeding hoe, for the root remains alive, gains strength, and often sends up many shoots to trouble us again. In large gardens a hoe must be used, for hand weeding is too laborious; but if we have time, use the thumb and finger.

During the summer, the earth will need an occasional. stirring with the rake or hoe, especially if the summer is dry, and may need the further attention of 


\section{THE GARDEN.}

\section{WATERING.}

In this, there are many mistakes made; often, the water is poured on from a pail or from the nose of the watering-pot. In both cases, the upper soil is wet, but the greater portion of the water runs off, and fails to benefit the garden. Now, our rules for watering are, never water unless the soil absolutely needs it: some think watering a daily duty, to be attended to whether the need exists or not. If the soil is close or clayey, very seldom will water be required; if sandy or loose, more often, but each locality will have its own rules.

Again, never dash water on the plants or ground; give it slowly and gently from the rose of a wateringpot, and let it soak into the earth.

A good way, if a plant specially needs water, is to put a flower-pot close to it, press the pot down into the ground and fill it with water; gently and slowly the water will soak through the hole at the bottom of the pot, and the roots of the plant receive the needed moisture. In time of drought, a syringing is of much benefit to shrubs and plants.

The water for plants should not be very cold; rain 
water is the best, and it may always be obtained by having a hogshead standing in some place out of sight, under a spout connected with the roof.

There are always the little cares of staking plants, trimming too luxuriant branches, removing dead stalks, leaves, and flowers, watching lest the storms beat down the tender shoots; looking carefully for insects, and all the little routine of duties which makes the pleasurable care of the flower garden.

A well-kept garden is a constant source of pleasure; it supplies out-door exercise and employment, and will always furnish a bouquet for the mantel or for the table.

In future chapters we will treat of what to plant; and when speaking of each plant, any peculiar mode of culture required, will be given.

The soil of a garden, for the growth of common species of shrubs, perennials, and annuals, should be a rich loam: if any plants require sand, it can be easily supplied. Peat is but little used in general gardening; it is required only for rhododendrons, azaleas, and in the culture of some of our fine native plants.

A garden should not be shaded by large trees; but 
few plants flourish under shade and drip, and the strong roots of trees often usurp all the soil, and appropriate to themselves all the best of the garden.

A garden should be sunny; soil, rich black loam; and sheltered from the wind.

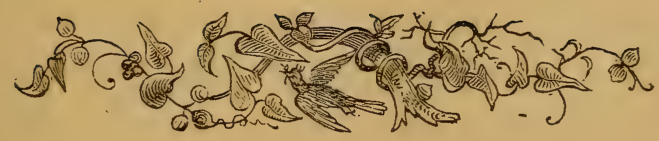

28 


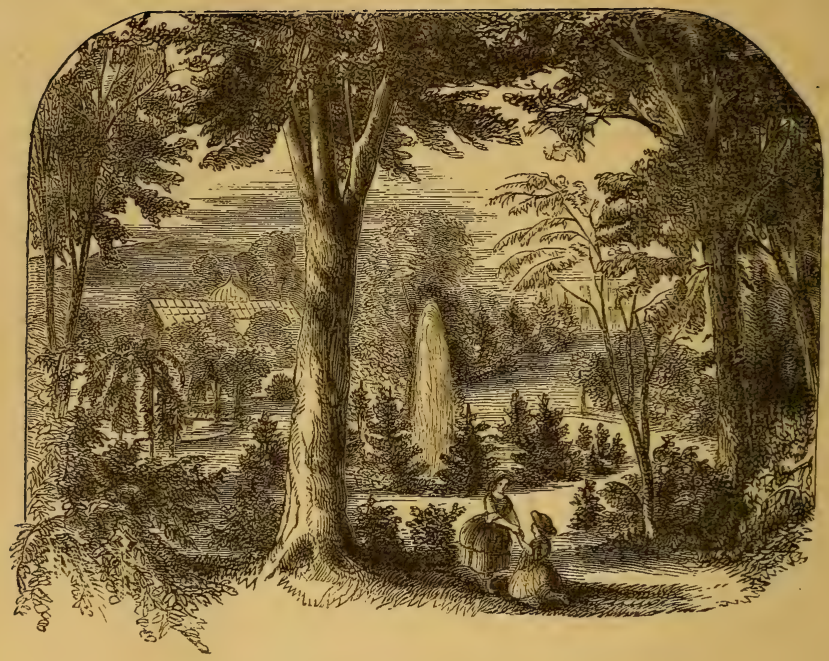

\section{CHAPTER XXI.}

\section{SIIALL TREES AND SHRUBS.}

Planting. - General Treatment. - Watering. - i'wivestic. - June Berry. Acacia.-Flowering Almond.-Catalpa.-Flowerıng Dogwood.-Kolreuteria. - Lilacs. - Syringa. - Laburnum. - Stuartia. - Pea Trec. Pronias. - Magnolias. - Azalca. - Spice Bush. - Purple Berberry. Fringe Tree.-Smoke Tree.-Bladder Senna.-Corchorus.-Dwarf Horse Chestnut. - Tartarian Honeysuckle. - Spireas. - Silver Bell. Sorrel Tree. - Deutzia. - Daphne Mrezereon. - Japan Quince. - Snowball. - Cranberry Tree. - Weigela. - Vircinia Silk.-Dutchman's Pipe. - Virginia Creeper. - Honeysuckles. - Wistaria. - Climbiug Roses. June Roses. - Mross Roses. - Perpetual Roses. - Culture. - Rhododendrons. - List of Hardy. - Mountain Laurel. - Andromeda. - Ledum, or Labrador Tea. 
SMALL TREES AND SHRUBS.

OO GARDEN is complete without a judicious selection of small trees and shrubs, and the many splendid acquisitions of the last few years have made them take a place among the most desirable objects : f floral decoration. They occupy but little space, require but little care, and give a large return of flowers and foliage. Their culture is very simple. They will thrive in any good garden soil.

In planting, dig a hole about three feet in diameter, unless the shrub is very small, when two feet will do; fill in with rich loam, and set the tree or shrub carefully in the centre, treading the soil well around it, so it may be firmly established. There is nothing gained by digging a small hole, and crowding in the roots of the plant; you may save in labor, but you dearly pay for it, year after year, in a sickly plant and starveling flowers. You must give the roots generous treatment if you wish the plant to afford a wealth of foliage and flower. .

If the shrub droops from drought, the best way to rovive it is by syringing the foliage in the evenine and 
by giving water at the root from a flower-pot, as described in the last chapter; or, if a pot of sufficient size cannot be obtained, an old butter firkin, with an auger hole in the bottom, will answer admirably.

Our autumn treatment is, only to give a top-dressing of manure, to be dug in lightly with a fork (a spade injures the roots) around the plant in early spring, when the border is dug over.

The only pruning necessary is to cut out any too luxuriant or unsightly branches, which should be done with a sharp pruning-knife.

If the plants are somewhat tender or weak, it may be well to protect them against the winter's cold by tying them up in straw, or, still better, cedar boughs, which may be prettily trimmed off, so that all winter the plants look like trimmed evergreens. The time for doing this is about the middle of November, and the covering should be removed about the first week in April.

Protection from the sun may also be given by setting small evergreen trees in the ground around any plant requiring such protection. The trunk of the tree may be sharpened and thrust into the ground; it will freeze in, and stand firmly all winter. 
This chapter can be but a list of the best trees and shrubs, with brief descriptions of each, from which the reader can select those which best suit his taste. All are sufficiently hardy to stand our ordinary winters without protection. We have not given a list of large trees, gladly as we would have done so, because a chapter on trees would treat more of the woodland and park than of the garden; but we hare mentioned many small trees, which are exceedingly ornamental, and may be grown in a limited space.

The June Berry, or Shad Bush (Amelanchier botryapium), is a pretty native tree, rarely attaining a greater height than twelve feet, and in earliest spring loaded with white blossoms, succeeded later by clusters of purplish black berries.

Both in leaf and flower it is very showy, and is one of the ferv natives which seems to be appreciated. The flowers come out before the leaves.

The Flowering Acacia (A. viscosa) is a small tree, covered with a profusion of pea-shaped pinkish white flowers, on short, close racemes in June. It has the merit of growing any where, and always flowering well. Its foliage is neat, locust-like, and pretty. 
Another little gem, of the same family, so common that its beauty is not appreciated, is the Rose Acacia (A. hispida). Its clustered bunches of pink pea-shaped flowers are familiar to all. If trained to a single stem, it makes a fine plant; its fault is, a tendency to throw up suckers, which renders it a troublesome plant in a small garden. It is, however, a favorite of ours, and we willingly bear its fault to enjoy its beauty. Both these species will bear neglect and hard treatment; indeed, they will grow in spite of you.

A well-known and always popular shrub is the little dwarf-flowering Almond (Amygdalus pumila $f^{\prime} p l^{\prime}$ ), found every where, and yet, as is usually the case with our best and most common blessings, not appreciated. A little care would improve this plant wonderfully. It flowers on the young wood, therefore the more shoots we can get in the summer the more flower the next spring. If, therefore, your plant is thrifty and well-established, as soon as it is out of bloom cut it down to - the ground; it may be hard to do it, but patience a while, and before autumn you will have a fine growth of young wood, which the next spring will give you profuse bloom. 
is fine tree, and beautiful, both in foliage and flower, blooming withal late in the season, is the Catalpa (C. syringafolia). It is, however, too large for a small garden, but yet is so beautiful, a space should be made for it near the house. Flowers in July, in large terminal bunches on the ends of the branches; white, marked with purple and yellow, and deliciously fragrant.

As a companion to the June Berry, we may have our flowering Dogwood (Cornus florida), a beautiful native tree, whose flowers are surrounded by very conspicuous white floral leaves, which render the plant very attractive, and which are succeeded in autumn by red berries. The foliage also turns blond red with the autumn frosts. It is a small tree, occupies but little space, flowers when quite young, and should be more generally cultivated.

Kolreuteria Paniculata is a low tree, producing in August bunches of bright yellow flowers. It is but little known, however, or it would be more commonly grown. The foliage is handsome, and the flowers come out at a season when few trees are in bloom. It needs a rich soil, and a sunny situation:

The Lilacs (Syringa), of which there are some twcnty 
trarieties, and the Syringas (Plitadelphtus), are too wcll known to need description; they are all pretty, and flourish in any garden soil. The Persian Lilacs are most isuitable for a small garden. All these plants will bear any exposure and thrive, where other shrubs would divindle and die.

The English and Scotch Laburnum (Cytisus) are somewhat tender in the vicinity of Boston; they will, however, flower splendidly in a somewhat sheltered location; their golden chain of blossoms is rery beautiful.

A few years since, one of the natives of the mountains of the Middle and Southern States was introduced to us by Messrs. Parsons. We mean that lovely shrub, Stuartia Pentagynia, which has safely stood our winters, and delights us each August by a profusion of large, camellialike flowers, white, with purple centre.

Plant this shrub, however small the garden; you will never repent it, for it will repay you a thousand fold.

For a pretty, hardy tree, eminent for delicate foliage and pretty blossoms, give us the Siberian Pea Tree (Caragana arborescens). It gires a profusion of pea-shaped 
yellow flowers in May, and its foliage has a dark, healthy green hue until late into the fall. It is small, occupying but little space. There are other species; all are pretty, but many require to be grafted on a tall stock to show to advantage, as they are low, trailing shrubs.

IVe must also have Tree Pæonies; there are many varieties, but, after the poppy-flowered and the double blush, they differ but little. They bloom in May, and are always ornamental; a little protection in winter is advisable, though not necessary. Elizabeth and Roi Leopold are magnificent varieties.

Magnolias are always favorites, and could we have but one species of flowering tree, this would be our choice.

M. conspicua is the Yulan Tree, perfectly hardy, blooming profusely about the last of April, producing large white flowers. M. Soulangiana is about a week later; flowers, rosy purple.

There are many hybrids from these two; all are worthy a place in the garden.

II. tripetala, the Umbrella Tree, is too large for small gardens, but where there is space, should be extensively planted; flowers large white, and very fragrant in June. 
M. glauca is our own little swamp Magnolia, but it does poorly in cultiration; a damp soil, with deep loam, suits it best; it is an evergreen.

M. Thompsoniana is a fine hybrid between the last two mentioned, and hardy.

M. macrophylla produces enormous leaves and flowers; it needs liberal culture, but is perfectly hardy; the flowers are white, very fragrant, produced in July.

$M$. purpurea or olovata is not hardy, yet if well protected will succeed.

Azalea Nudiflora and Viscosa are two fine native species, the former with pink flowers in May, the latter with white flowers in July. Both succeed well in any garden soil.

The Spice Bush (Calycanthus), in its many species, is very pretty, and a general favorite. The flowers have but little beauty, being dull colored, yet their fragrance recommends them to all. All the species have ornamental foliage, and being low growers, are suitable for small gardens. The whole plant is highly aromatic.

The foliage of the purple-leafed Berberry (Berberis purpurea) is attractive and ornamental in the garden. It is a neat-growing bush, with yellow flowers and red berries. 
A favorite with all is the Fringe Tree (Chionanthus Virginiacus), producing long fringes of white flowers in June; it delights in a rich, loamy, moist soil.

The "purple fringe" or Smoke Tree (Rhus cotinus) is too well known to need description; it is very ornamental from midsummer to autumn, and does well with but little care.

Colutea Arborescens is the Bladder Senna, and is deserving a place in the garden, because it is always in bloom, and is withal very ornamental with its yellow flowers.

We cannot say the Altheas (Hibiscus Syriacus) are favorites of ours; their recommendation is, the late season at which they bloom. The flowers are produced in August, and are of all shades between red, purple, and white, and double and single.

An old farorite is the Corchorus (Kerria japonica), always esteemed for its bright orange globular flowers, and conspicuous for its light, glossy, green wood. The shoots are, however, liable to be winter-killed, and should in autumn be laid down and covered with earth.

There is a dwarf-flowering Horse-chestnut (Pavia Macrostachya) which makes a pretty ornament for a 
lawn; the flowers are white, produced on long spikes. The plant produces suckers so freely it sometimes becomes troublesome.

All the Tartarian Honeysuckles are to be recommended as garden shrubs, being equally ornamental, whether in flower or fruit.

Of the Spireas, whose "name is legion," the best for :general cultivation are, -

S. Opulifolia. Flowers white in June.

S. Bella. Flowers pink in June.

S. Prunifolia. Flowers white in May.

.S. Reevesii $f^{\prime} p l$ '. Flowers white in May and June.

S. Callosa. Flowers red and pink all the season.

The Snow Bell, or Silver Bell Trees (Halesia dipterca and tetrapterc () , are always admired; the former is somewhat tender in New England, however. They are small trees, loaded in June with white, bell-shaped blossoms.

One of our most beautiful small trees is the Sorrel Tree (Andromeda arborea). From July to September it is loaded with bloom, and a more attractive object cannot be found. It is suited to a very small garden.

Who has not admired the Deutzia (D. scabra), as hardy as a Syringa, and far more beautiful, - stretching out to 
us its branches, loaded with white blossoms; yet, alas, they have no perfume!

In the earliest days of spring, would we have a shrub in flower in the garden, we must have planted the white and purple Daphne Mezereon, and long before winter has departed, these little shrubs will be loaded with bloom.

Before they have faded, we may gather a rich, golden bouquet from Forsythia Viridissima, and wreathe among them the flame-colored buds of the Japan Quince (Pymus Japonica).

There is also a white, a red, a double, and an orange variety of this last-mentioned flower, which to us is one of the early glories of spring.

Our list of shrubs would be incomplete did we omit the Snowball (Viburnum opulus), and the Cranberry Tree ( $V$. oxycoccus), both of which are ornamental in a high degree. These pante are botanically identical.

One of our modern introductions, the pretty Weigela Rosea, is already common in the garden, and perhaps there is no shrub a more universal favorite, certainly none that will give a greater profusion of bloom.

Our garden is, however, in need of some hardy climbing plants: we therefore give a list of fine species:- 
Periploca Græca (Virginian silk), a rapid grower, with curious brown flowers.

Trumpet Flower (Bignonia radicans), producing dull, crimson flowers in August.

Dutchman's Pipe (Aristolochia sipho), a fine climber, with large leaves and curious flowers.

Virginia Creeper (Ampelopsis Virginica); very useful for covering walls and fences. A rapid grower, and very beautiful in autumn.

The different species of Clematis are very ornamental. C. Alammula, Viticella, Virginica, and Azurea grandiflora, are the best.

Honeysuckles are favorites with all, and our selection from the many varieties would be Scarlet and Yellow Trumpet (Lonicera Periclymenum and aurea), Dutch Monthly (Belgica), Japan Twining (Japonica).

And, lastly, the Chinese and our native Wistaria ( $W$. sinensis and frutescens), which are always favorites from their clusters of purple flowers.

We must have some climbing roses. Let us, then, choose the pink and red Bousault for early bloom, and from the prairies, Queen of the Prairie, Baltimore Belle, Superba, Milledgeville, and Perpetual Pink. If we can 
bave but one climbing rose, let it be the Baltimore Belle. The Greville Rose is a fine, hardy species.

Let us choose-

\section{For Hardy June Roses.}

Madame Plantier. White.

Victor Hugo. Lilac.

George IV. Crimson.

Brennus. Crimson.

Provence. Rose. .
Centifolia Cristata. Blush. Madame Hardy. White. Grobe White. White. Four Seasons. Blush.

Unique. White.

\section{For Moss Roses.}

Common Blush. Rose.

Cristata. Rose.

Glory of Moss. Rose.

Luxembourg. Crimson.
Princess Adelaide. Red.

White Bath. White.

Multiflora. Rose.

Etna. Crimson.

\section{For Hybrid Perpetual.}

Auguste Mie. Rosy pink.

Baronne Prevost. Rose fine.

Geant des Batailles. Crimson.

Edward Jesse. Lilac Rose.

L'Enfant du Mont Carmel. Purplish red.

General Jacqueminot. Splendid crimson.

Lion des Combats. Scarlet.

Jules Margottin. Carmine.

Compte de Brobinski. Crimson.

Duchess of Sutherland. Rose.

Caroline de Sansal. Flesh color.

Baronne Hallez. Light crimson.
William Jesse. Crimson.

Sydonie. Light pink.

Rivers. Rosy crimson.

Portland Blanche. White.

Marquise Bocella. Rosy blush.

Madame Laffay. Rosy crimson.

Mrs. Rivers. Flesh color.

General Cavaignac. Light rosy crimson.

Pius IX. Purplish red.

Mrs. Elliott. Rosy purple.

La Reine. Rose.

Lady Alice Peel. Rosy carmine. 
The treatment of roses in the garden is very simple. They need a deep, rich, well-manured soil, rather moist, but never wet.

In early spring they should be cut down to a few eyes; and, if autumn bloom is desired, pruned again in July. When the frosty nights come, and just before the ground freezes, lay down the shoots, and cover them several inches deep; or, in the case of June roses, lay them down and cover them with evergreen boughs. Take them up about the middle of April.

Our lists of Bourbon and China Roses have been given in a previous chapter, and we have only to add to these a plant of the favorite Yellow Harrison and the Persian Yellow, and a few plants of the little early-blooming Scotch roses, to have our rosery well stocked.

Before closing this chapter, we wish to say a few words about a much neglected class of plants, the socalled American plants; i. e., Rhododendrons, Kalmias, and Ledurn.

The proper soil is peat, leaf mould, and sand, in proportions of one half part of the latter to two of the former.

The plants should be planted in a bed specially prepared, where they can be sheltered from the winter's sun. 
We do not propose to write a treatise on their culture, but merely saying there can be nothing more ornamental than a collection of these plants, to give the following list of varieties which have been proved hardy in the ricinity of Boston:-

Rhododendron Atrosanguineum. Intense blood red, fine foliage; one of the hardiest and best.

$R$. Archimedes. Bright rose, light centre.

'R. Barclayanum. 'A fine, light blooming kind; good foliage; large trusses, of a deep rose color.

R. Blandyanum. Deep crimson; fine.

R. Chancellor. Finely spotted purplish lilac; good.

R. Brayanum. Rosy scarlet, lighter centre; fine foliage; a very fine variety.

R. Correggio. Dark crimson; fine.

R. Delicatissimum. White, delicately edged with pink.

R. Duc de Brabant. Yellowish white, spotted with red, semi-double.

R. Everestianum. Rosy lilac, spotted and fringed; a fine kind.

$R$. Leopardii. Rosy lilac, intensely spotted.

R. Giganterm. Bright rose, large truss; foliage good.

$R$. Nero. Fine dark rosy purple, spotted; fine truss.

$R$. Standard of Flanders.

R. Roseum Elegans. Fine rose.

R. Roseum Pictum. Rose, with yellow eye.

$\left.\begin{array}{l}R \text {. Grandiflorum, } \\ R \text {. Superbum, }\end{array}\right\}$ Late blooming; fine rose-colored; good trusses.

There are many hardy Rhododendrons, seedlings of R. Catawbiense, which are, perhaps, better adapted for $29 *$ 
general planting than those above mentioned. We describe a few kinds :-

R. Catawbiense Album: Fine white.

R. Catawbiense Album Elegans. White, with green spots; the best of the hardy light varieties.

$\boldsymbol{R}$. Grandiflorum. Blush, changing to white.

R. Acubafoliam. Light lilac.

R. Azureum. Blush lilac, distinct and fine.

R. Bicolor. Rose; distinct white spot on upper petals.

R. Candidissimum. Pure white.

R. Colestinum. Fine blush, yellow eye.

R. Corulescens. Lilac pink.

R. Delicatissimum. Delicate blush, changing to white.

$R$. Gloriosum. Large blush.

R. Perspicuum. Clear blush.

R. Purpureum Elegans and Grandiflorum. Fine trusses; clear, fine purple.

R. Grandiflorum (Waterers). Rose; fine truss.

$R$. Roseum Splendens. Fine rose.

R. Blandum. Pale blush, fine foliage.

$R$. Guttatum. Clear white, distinctly spotted.

$R$. Hyacinthiflorum. Very double and distinct.

R. Macranthum. Blush white, tinged with pink.

R. Multimaculum. White, finely spotted with red.

R. Nivaticum. Pure white, yellow eye.

R. Pictum. White; intense spot on upper petals.

All the above are hardy enough to withstand a Canadian winter. Rhododendron Ponticum, and its varieties, are not hardy with us. Kalmia Latifolia, the fine mountain laurel, 
is worthy a place in every garden. There are also rarieties of the common Kalmia Angustifolia, or Lambkill, which are very pretty. K. Angustifolia carnea, pumila, and rubra, our swamp Kalmia, $\mathrm{K}$. glauca and its varieties, stricta, and superba, are very ornamental. Kalmia Myrtifolia is a fineleaved variety. All these are perfectly hardy.

The Andromedas are a very pretty tribe of plants; of these, the following are hardy: A. Catesbæi, Floribunda, Mariana, Polifolia, and its varieties.

The Ledum is a very pretty evergreen, and all its species are hardy. L. angustifolium, buxifolium, pracumbens, intermedium, latifolium, palustre, and thymifolium.

These are all low-growing evergreens, and very pretty miniąture plants. In June they are covered with small white blossoms.

We have been thus diffuse on this subject, because it is one on which there is general ignorance; and large sums are annually spent in importing plants which never survive , the first winter. All we have mentioned are perfectly hardy, and well adapted to our New England climate. 


\section{CHAP'IER XXII.}

\section{HARDY HERBACEOUS PLANTS.}

General Treatment. - Transplanting. - Propagation. - Dielytra. - Lily of the Valley.-Adam's Needle. - Larkspur. - Globe Flower. - Phlox. List of Choice Varieties. - Canterbury Bell. - Hepatica. - Pink. - Fraxinella. - Cowslip. - Foxglove. - Day Lily. - Iris. - Everlasting Pea. Lupin. - Ragged Robin. - Spirea. - Veronica. - Bloodroot. - List of fine Species.

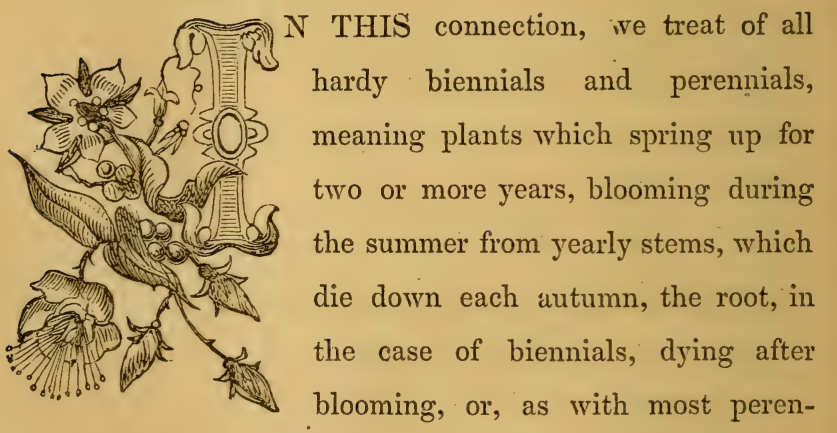
nials, living many years, and springing up every season.

These plants are to be especially relied upon for the flower garden, because they require but little care; in fact, they care for themselves. Give them the common garden. 
soil, dig round them, to loosen the earth, each spring, and they will bloom.

Yet a little care is well repaid by increased luxuriance of foliage and beauty of flower. In spring each clump should be examined, to see it is not too high out of the earth; there is a tendency with most of these plants to grow out of the ground. When this is found to be the case, take up the plant and re-set it.

'Transplanting should always be done in the spring; not but what these plants will live if removed in the autumn, but they will succeed so much better by spring planting, that that season is always to be chosen if possible.

During the summer, if very large and fine bloom is desired, prune out all the weak stems.

In the autumn cover the crowns of the plants with coarse manure or litter; if the plant is an evergreen, protect it with pine boughis from the winter's sun.

In spring, dig a few spades full of manure around each plant.

These plants are propagated by division of the root, which should be performed in early spring, just as the plants start into growth, or in the latter part of summer, when they have done flowering; this latter treatment is 
especially adapted for the Phlox. Every eye, with a bit of root, will make a plant. They also produce seed freely, and seedlings usually bloom the second year.

We give a list of species, with short descriptions, mentioning the plants in the order in which they are adapted to general culture, considering them as flowering plants.

Dielytra Spectabilis. This beautiful plant is one of the most elegant in cultivation, whether we consider its foliage or flowers. It grows freely, flowers well, and is subject to no insects or disease; and if, after the flowers have faded in the spring, the stalks are cut down, it will throw up a second set and bloom again. Perennial. Flowers, rose and white in May.

Lily of the VAlley (Convallaria Majalis). This lorely flower grows alike for the rich and poor. It does well in any rich, loamy soil, and thrives in shade or sun. It produces its fragrant white flowers in May, which are succeeded by red berries in September. Perennial.

Adan's Needle (Yucca Filamentosa). An evergreen plant, with strong roots and sharp leaves, of a rery tropical aspect. In June it throws up a tall spike of white flowers. During the winter, cover the plants with pine boughs. They need a rich soil, and it is a good plan to dig, every fall, 
well-rotted manure into the bed. Perennial. One of the conspicuous features near our house is a large circular bed of these plants.

Delphinium Hendersonit and Formosum. Two beautiful varieties of Larkspur. Flowers deep blue, with white centre. Produced in profusion from July to Norember. Perennial.

Trolluus Europerds (Globe Flower). A lovely little plant. A mass of light yellow globe flowers in May and June. This is a favorite flower with us. Perennial. T. Asiaticus has orange flowers.

Phlox. This is a large family, containing many species and fine varieties. We give a list of desirable varieties of each of the early summer and autumn kinds, only premising that we mention but a few, while there are hundreds worthy of cultivation.

\section{Early Spring Flowering.}

Phlox Subulata (Moss Pink.) Pink, white, purple, and eyed varieties. $P$. Divaricata. Light and dark purple.

P. Stonolifera. Deep red.

P. Nivalis. White.

Summer Flowering.

P. Maculata. Red. $P$. Suavolens. White.

P. Countess of Home. White, crimson eye. 
P. Louns Van IIoutte. Striped.

$P$. Beppo. Purple or crimson.

$P$. Speculum. White, red eye.

P. Roi de Leopold. White, striped with purple.
P. Mad. Carl Wagner. Whitish rose, rosy eye.

P. Henvi Lierval. Purplish crimson.

P. Rival. White.

\section{Late Flowering.}

P. Decora. White, red eye.

$P$. Souvenir de la Mer. White, violet centre.

P. Le Croix de St. Louis. Rose and white.

P. Osiris. White, red eye.

$P$. Hersine. Purple and white.

$P$. Dianthiflora. Rose and white.
P. Madame Basserille. Rosy white, red eye.

$P$. Madame Le Cerf. Pure white. $P$. Oculata. Lilac, white certre. $P$. Atropurpurea. Dark crimson. $P$. Camarina. White, red eye. P. Mr. Regel. Violet, purple, and crimson.

\section{All these species of Phlox are perennials.}

Campanula Medium (Canterbury Bells). An old-fashioned, but very pretty flower. It is, however, a biennial; so we must sow seed every year to keep up a stock. There are white, purple, single and double varieties. Blooms in June.

C. Persicufolia. Our common garden species; flower, blue, white; single and double; perennial, blooming in June and July. There are many other species, all fine.

Hepatica Triloba. This little spring flower we have previously described. It is the first flower to open after the snowdrop and crocus, usually expanding about the fifth of April. The leares are evergreen, the flowers double and single, white, blue, rose, and red. Perennial.

Garden Pint: (Dianthus Hortensis). A pretty and common flower, vorthy of a place in every flower garden. Perennial. June.

Fraxinclla (Dictammes Fraxinclla). The red and white fraxinclla 
are old-fashioned favorites. They increase slowly, and are never very plenty. The plants possess a strong aromatic fragrance. Perennials. May, June.

Dodocatheon ILedea (American Cowslip). Flowers in large umbels of white and purple blossoms, with reflexed petals. Very ornamental. May. Perennial.

Foxgloce (Digitalis). There are many varieties, with purple, white, yellow, rusty, and variegated flowers. The plant is a biennial, and therefore seeds should be sown each year. July and August.

Day Lily (Hemerocallis and Funkia). Pretty plants, with lilyshaped flowers. Colors, yellow, orange, blue, white, and variegated, blooming from June to August... Perennials.

Iris and Fleur de Lis. A large genus of ornamental plants, all perennials and hardy.

I. Pumila. Purple, in May.

I. Cristata. Light blue, in May.

I. Florentena. White, in June.

I. Germanica. Blue; in June.

There are many splendid varieties of this flower, all of which are very ornamental.

Everlasting Pca (Lathyrus Latifolius). This plant possesses all the beauty of the sweet pea, wanting only its fragance. It comes up year after year, flowering abundantly. Perennial. Flowers, white, pink, rose, and purple; worthy a place in every garden.

Lupinus Polyphyllus. A fine, hardy species, producing rich, purple flowers. Biennial. June.

Lychnis Floscoculi is the well known Ragged Robin, the double variety of which is deservedly a favorite. Perennial. June.

Spirec Aruncus (Goat's-beard). A rery showy species; flowers white, in June.

S. Filipendula $f^{\prime} p l$ '. Bears fine clusters of double white flowers. June to September.

S. Japonica is a delicate species, also with white flowers. 
S. Palmata. A variety of tall habit, bearing immense corymbs of red flowers. June. All perennials.

Veronica Virginica is our common tall-growing species, producing white flowers in August.

$V$. Speciosa and Spicata produce fine blue flowers, and are of dwarf habit. Perennials. June.

Sanguinaria Canadensis, our wild Bloodroot; succeeds admirably in cultivation, and increases in size and vigor. It is one of our earliest spring fluwers, and should be more generally cultivated. Flowers, pure white, with yellow stamens, in early May.

The following plants are all well worthy of cultivation, but we have no space to describe them. Unless otherwise noted, all are hardy perennials.

Saxifraga Crassifolia. Flowers pink, in May. - Monarda Didyma. Flowers scarlet, in July.

Chinese Pronies. Red, white, and blush. May to July.

Papaver Orientalis. Flowers scarlet, in June.

Perstemon Coruleum. Flowers blue. August.

Aconitum Napellus (Monkshood). Flowers blue. July. Alyssum Saxitile. Flowers yellow. May.

Columbines, in variety. Biennials. June.

Lunaria Biennis (Honesty). Biennial; white or pink, in May.

Sweet William, in variety. Biennials. June.

Verbascum Pyramidalis. Biennial; yellow. August.

Polemonium Cocruleum. Flowers blue or white. June.

Rudbeckia Fulgida. Flowers yellow. July.

Iberis Tenoriana. Flowers white. May.

Potentilla Astrosanguinea. Flowers blood-red all summer.

Dracocephalum Virginiacum. Flowers purple; July. 
Convolvulus Panduratus. A fine, hardy climber, with profusion of large white flowers, with purple tube.

Coronilla Varia. Flowers pink, in May and June.

Achillea Ptarmica. Flowers white, all summer.

Cassia Marylandica. Flowers yellow, in August.

Catananche Cocrulea. Flowers blue, in July.

Adonis Vernalis. Flowers yellow, in May.

Geum Coccinium. Flowers scarlet, in July.

Hesperis Matronalis. Flowers white and purple, in June.

Pulmonaria Virginica. Flowers blue, in May.

Tradescantia Virginica. Flowers white and blue, all summer.

This list might be indefinitely increased, but enough have already been given to enable the ignorant to selcct a choice collection

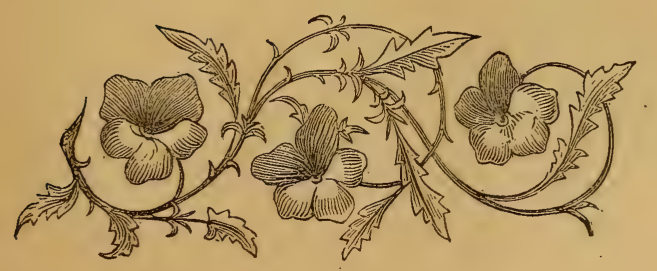




\section{CHAPTER XXIIT.}

\section{HARDY ANNUALS.}

Treatment. - Sowing. - Saving Seed. - Watering. - Mignonette. - Sweet Pea. - Asters. - Balsam. - Salpiglossis. - Abronia. - Nigella. - Ageratum. - Coreopsis. - Sweet Allyssum. - Candytuft. - Clarkia. - Convolvulus. - Eschscoltzia. - Lupins. - Portulacea. - Indian Shot. - Larkspur. - Amaranth. - Gillyflower. - Schizanthus. - Zinnia. - List of Choice Species. - List of Climbing Anuuals. - Cypress Vine.

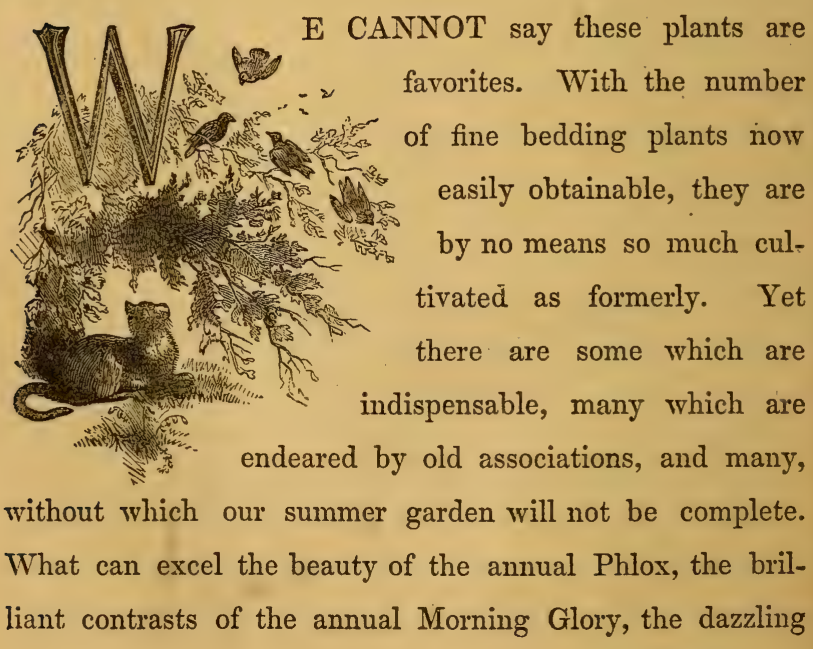


colors of the Portulacca, the fine-cut and curiously-marked leaves of the Schizanthus, the sweet perfume of the Mignonette and Sweet Pea, or the delicate pencillings of the Salpiglossis!

The treatment of annuals is very simple; they may be divided into two classes.

Hardy annuals, whỉch may be sown in autumn and come up, surviving the winter and blooming early the next summer; or which may be sown in spring, in the open border, for summer bloom.

Half-hardy annuals, which are sown after the ground becomes warm in the spring, blossoming the same summer. This latter class may again be subdivided, according to the treatment required, into garden annuals and hot-bed annuals ; the former rapidly coming to perfection when sown in the garden, about the first of May; the latter requiring a longer season, and thus needing to be started and brought forward in a hot-bed, and then transplanted to the garden.

Strictly speaking, annuals are plants which live but one year, that is, spring up, make their growth, bloom, and perfect seed in one season; but many plants treated as annuals may be preserved many years in a frame or green$30 *$ 
house, while at the same time in the garden they bloom and seed in a single summer, as for instance the Petunia and Nasturtium.

Others, again, form tubers, which, if properly cared for during the winter, and planted out in the spring, grow again with vigor and flower profusely, and so on indefinitely, as the Four O'Clock (Mirabilis), the Commelina, the Scarlet Bean, and Salvia Patens.

There are, however, some annuals which must be sown where they are to grow, and which will not bear transplanting. Of these, our most familiar examples are Larkspurs, Poppies, Candytuft, Lupins, Mignonette, Convolvulus, Sweet Peas.

If, however, it is desirable to force these plants, they may be started in pots in hot-beds, and then turned out into the open ground, without breaking the ball of earth enclosing the plants.

In the following list, we cannot pretend to give more than a ferw of the best species. Our descriptions are necessarily brief, but we give, in as few words as possible, the name, color, season of blooming, and culture. Where we have been more diffuse, it has been because the beauty of the plant demands special notice. 
But first, a word as to sowing; the general fault is planting too deep.

No rule of general application can be given, for the proper depth must be regulated by the size of the seed. Lupins, Sweet Peas, and such large seeds, may be covered one inch, while very small seed, such as Portulacca, should be sown on the surface, and a very light covering of fine earth sifted over it.

The border for annuals must be finely dug, and the soil well pulverized and raked smooth; if the surface is coarse and lumpy, most of your small seeds will fail.

Hardy annuals may be sown in August, for early bloom the next season; or about the middle of April, for bloom in the latter part of the summer.

Half-hardy annuals may be sown in the open ground about the first of May.

The terder species should be started in the hot-bed, sown either in pots or in the bed, about the first of April, and transplanted to the open border about the tenth of May, or when all danger of frost is past.

If the plants come up very thick, thin out the weakest; you will thus give more room for the others, and secure a better and larger bloom. 
A word as to saving seed. It is usually ripe when the seed capsule begins to turn yellow; it should then be gathered, exposed in an airy, sunny place for a few days, to allow it to become perfectly dry, and then put up in carefully labelled papers. In purchasing seed, buy nothing in " fine mixed varieties," unless you wish the refuse ; for one good you get a dozen poor kinds; learn what you want, and buy only that. Again, select the best varieties, and buy only those; a poor variety occupies as much room as a good one.

In autumn, when the frost has killed down the plants, pull up the old stalks, and clear up the border, for the season's work is done, and the next spring new seeds will give you new plants.

Watering, which is sometimes needed by delicate growing species, should be given from a fine rosed watering-pot, either early in the morning or late in the evening.

Mignonetre (Reseda Odorata). Sow in the autumn, very late, when it will vegetate the next spring, or early in April. Flowers, greenish white all summer, of an exquisite fragrance. Where this plant has once grown well, it will come up year after year, without further care, from selfsown' 'seed. . 
Sweet Pea (Lathyrus Odoratus). Sow as early as possible in the spring, in rich soil; the flowers are pink, purple, white, and variegated. Grows from two to five feet high, blooming from July until killed by the frost.

They may be trained on strings or a trellis, against a wall or fence, or on neat pea sticks; we prefer the latter method. Asters, Chinese, German, or French (Callistephus Chinensis var.) A long treatise might be written on the different varieties of this beautiful flower. All the kinds should be sown in a hot-bed about the middle of April, and transplanted to the garden about the middle of May. A pretty effect is produced by planting in a bed, setting the plants one foot apart each way. Colors, red, white, blue, pink, and all possible shades. The flowers are also "quilled," or "pæony flowers." A rich, deep, rather moist soil suits them well. The best varieties are Traffaut's new Pæony Flowered, Chinensis, Dwarf Chrysanthemum Flowered, German, Pyramidal, Hedgehog, and Ranunculus Flowered.

Balsam (Impatiens Noli-tangere). Flowers white, flesh color, pink, red and purple, spotted and striped; blooming from June to October. Treatment the same as for Asters. SAdPiglossis Atropurpurea is properly a green-house 
plant, but does well started in a hot-bed in April, and transplanted into a highly manured, sandy loam. Flowers of the different varieties, purple, white, straw color, and beautifully marked. It may be kept in the green-house for years, if not allowed to seed. Blooms from June to September.

Abronia Umbellata, a beautiful little trailer, with heads of fragrant rose-colored flowers. Grows well in light, rich soil. Sow in frame in April, or in open border in May.

Nigelda Hispanica and Damascena (Love in a Mist). Very free flowering plants, with curious seed vessels. Colors, white, blue, purple, yellow. June to October. Sow in the garden in May.

Ageratum Mexicanum. A class of pretty summer flowers, growing freely in any soil. Blue and white. June to September. This is often used as a bedding plant, and propagates freely by cuttings. Sow in open border in May, or in frame in April.

Coreopsis, in its many varieties, with yellow, crimson, and brown flowers, all summer. Sow in May, in open border. These plants will come up for years where they have once been grown.

Allyssum Maritmum (Sweet Allyssum). Flowers 
white and fragrant, resembling miniature Candytuft. Sow in open border in April. It will come up, year after year, from self-sown seed.

Iberis Odorata and Umbeltata (Candytuft, and varieties). Fine, hardy, free-blooming annuals, with white, red, and purple flowers, from June to August. Sow in open border in May.

Clarkia Elegans and varieties. Hardy annuals, blooming from June to August. Sow in open border in May. Flowers white, rose, and purple.

Convolvulus Mrivor. The pretty dwarf Morning Glory, with blue, white-eyed flowers, from June to September. Sow where it is to bloom in May.

Eschoützia (Chrysers) CaLifornica. Very showy plants, with yellow, orange, and white flowers. Sow in May where they are to bloom.

Lupiss, varieties. Flowers blue, white, yellow, and pink. Sow where they are to bloom in May. They will flourish in poor soil. Bloom from June to September.

Portulacca. Flowers white, red, scarlet, crimson, yellow, and variegated. We know of no better plant than this for a hot exposure. It blooms from June until killed by the frost. Sows itself, and comes up year after year. 
CAnna Ixpica and rarieties (Indian Shot). A tall plant, of tropical aspect, with light green leares and yellow flowers. There are many fine varieties, which are rery ornamental. Sow in pots, in a frame, and transplant. The seeds should be soaked in boiling water before planting, otherwise they are a long time regetating. Soil, rich deep loam. Blooms from July to October.

The roots may be kept in the cellar, and re-planted in the spring, when they will make finer plants, and bloom earlier.

The following are fine varieties:-

C. Warscewiczii. Brilliant red.

C. Nobilis. Red.

C. Anneii. Crimson.

C. Angustifolia. Light red.

C. Gigantea. Scarlet yellow.

C. Aurea Vittata. Golden.

C. Limbata. Scarlet and yellow.

C. Sellowii. Scarlet.

C. Bicolor. Red and yellow.

Delphineum Ajacis (Rocket Larkspur). A popular garden flower. Sow where it is to stand, in August, for the next year's bloom, or in April. Colors, red, blue, white, and purple. Blooms from June to September.

Gomphrena Globosa (Globe Amaranth). A fine plant, needing to be brought forward in the hot-bed. Colors, purplish red, white, and orange. Blooms all summer. The flowers dried form pretty winter bouquets. 
Mathiola (Ten-Week Stock). The annual varieties of the Gillyflower are very pretty summer blooming plants. They should be sown in the hot-bed in April, and transplanted with care, for they bear it poorly, owing to their long, fibreless roots. Flowers white, purple, red, and yellow all summer.

Schizanthus Pinnatus. Very ornamental little plants, with red, white, purple, yellow, and variegated flowers. They should be started in pots, in the frame, and carefully transplanted. Bloom from July to October.

Zinnia Elegans fl' PL'. The single Zimnia was an old favorite in the garden, but is now completely eclipsed by the fine double varieties. The seeds should be started in a frame in April, and transplanted in May. They grow to a large size, and produce a profusion of red, yellow, and purple flowers, as large as a rose, all summer. They are among the most ornamental plants of the garden.

The following list includes many fine species, all of which are worthy a place in a large garden.

Acroclineum Roseum. Open border. Bartonia Aurea. Frame.

Didiscus Corruleus. Frame. Annual Chrysanthemum. Open border.
Cacalia Coccinea. Open border. Amaranthus Tricolor. Open border. Hibiscus Africanus. Open border 
Erysimum Peroffstianum. Open Clintonic Elegans and Pulchella. border.

Open border.

Browallia Elata. Frame or border. Perilla Nankinensis. Frame or Gilia, in variety. Frame or border. border.

Anagallis, in variety. Open border. Helichrysum, in variety. . Frame Lavatera. Open border. or border.

Calendula Officinalis. Open border. Collinsia, in variety. Open border. Brachycome Ibiridifolia. Frame or Phlox Drummondii. Frame. border.

Calliroho Pedata. Frame, in pot.

Antirhinum, in variety. Frame in Scabiosa Atropurpurea. Open borpot.

Four O'Clocks. Open border. Martynia Fragrans. Frame. Centaurea, in variety. Frame. Rhodanthe Manglesii. Frame or border. der.

Godetia, in variety. Open border. Linum Grandiflorum. Frame in Nolana Atriplicifolia. Open border.

Silene or Catchfly. Open border. Tournefortia Heliotropoides. Frame or border. pot. Petunia, in variety. Frame.

The following are climbing annuals, adapted for corering walls or trellises. They should all, except the Ipomeas, be started in pots, in the frame, and turned out into the border about the first of May.

Ipomea Quamoclit is the pretty, graceful cypress rine. The seed vegetates with difficulty. Delay planting until about the first of June, then choose a rery hot noon. Plant the seed where it is to stand, in a large circle, so a pole may be set in the centre, and strings led to the top from the plant, for this is the prettiest way of growing it. Then 
take a large water-pot full of boiling water and water the seed. Under this treatment it will often come up in twenty-four hours.

Tropceolum (Nasturtium). Open border.

Thunbergia. Frame in pot.

Maurantia. Frame in pot.

Loasa Lateritia. Frame in pot.

Ipomea. Open border.

Convolvulus Major (Morning Glory.) Open border.

Cobea Scandens. Frame in pot.

Cardiospermum (Balloon Vine). Open border.

Adlumia Cirrhosa (Mountain Fringe, or Traveller's Joy). Open border.

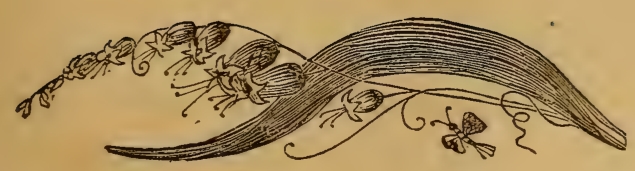




\title{
CHAPTER XXIV.
}

\author{
BEDDING PLANTS.
}

Propagation. - Gazania. - Verbena. - Lantana. - Heliotrope. - Calceola. rias. - Geraniums. - Petunias. - Cuphea. - Feverfew. - Nierembergia. Salvia. - Tritoma.

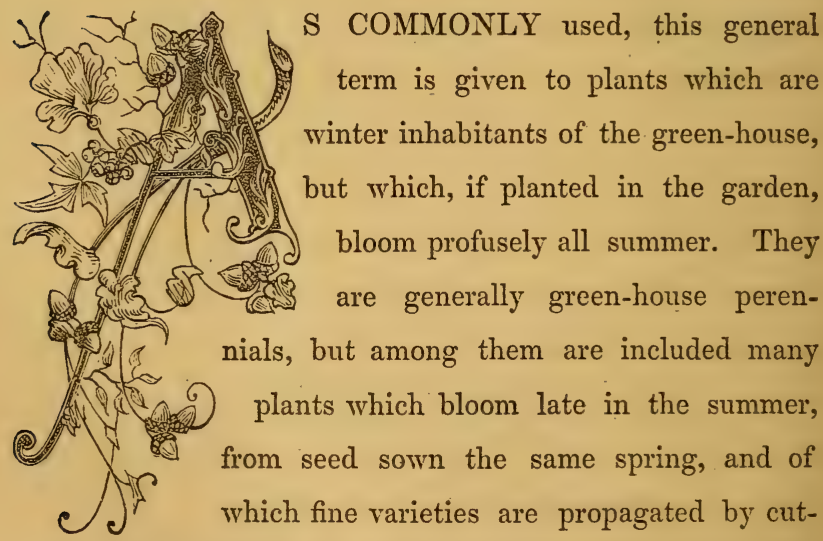
tings. As examples, we may mention petunias and verbenas.

The treatment of these plants is very simple; about the middle of May turn them out into the flower garden; they 
will grow finely, and give profuse bloom. In August take off cuttings, and root them in the green-house, or in a frame for your winter's stock, unless you wish to preserve the old plants; if so, leave them in the garden until just before the frost comes; then pot them, and winter in the green-house, parlor, or conservatoly. It is, however, always a good plan to have a stock of summer cuttings. Some species, as Scarlet Geraniums, and Erythrinas, are wintered in a dry state in a cellar, secure from frost, and again set out in the spring.

We describe a few of the principal plants coming under this head:-

Gazania Splendens. During the past season this plant has attracted considerable attention as a new and desirable bedding plant. Its recommendations are, its small size, the brilliancy and number of its flowers, and the rich contrasts of color; it is also a plant of easy growth, and small plants soon become rigorous specimens.

The colors are rich orange yellow, a circle of black, banded and mottled with white and brown or chocolate at the base of the petals, the centre a reddish orange; foliage dark green. In form, the flower somesihat resembles a small sunflower, or chrysanthemum. $31 *$ 
The present variety somewhat resembles the old $G$. uniflora, differing from it in its dwarf habit and compact growth; the branches are sometimes erect, but bend down with the weight of the flowers. The contrast of the orange yellow, black, white, and chocolate in the flower, produces a most brilliant effect.

The culture of this plant is very simple; it will do well in almost any soil, and produces flowers in profusion, from early spring until late in the autumn. It is not dried up by the heat of summer, or affected by atmospheric changes, but flowers throughout the season, closing its splendid flowers during the night, and opening them during the day. It is well adapted for pot culture; its growth is vigorous as well as neat and clean, and it is not subject to the attacks of red spider and other troublesome insects.

There are about forty species of the Gazania, of which most are unknown to our gardens; all are natives of the Cape of Good Hope.

As a bedding plant, this variety is invaluable; plant. in early spring, and take up just before the first frost.

Verbeisa. We have treated so fully of this plant on previous pages that further mention is unnecessary. As 
a bedding plant it is unsurpassed. If planted in a compost of peat and leaf mould it makes rampant growth, and gives flowers of great size and brilliancy.

Lantana. This is a showy, shrubby plant, of easy culture in any garden soil; the flowers are in small, rounded, or flat trusses, resembling in form a verbena. It may be wintered in a light cellar. The following are fine kinds :-

L'Abbe Leautier. Yellow, shading Victoire. Pure white, yellow to erimson. eye.

Lutea Rosea. Fine yellow, shading Speciosa. Orange scarlet. to white. Lilacina. Lilac rose.

Delicatissima. Fine rósy purple. Alba Grandifora. Fine white.

Heliotrope. In addition to varieties mentioned in a former chapter, we can recommend, -

Miss Nightingale. Deep violet. Reine des Heliotropes. Violet and lilac.

La Petite Negress. Very dark, dwarf.
Jean Mesmer. Very light blush. Beauty of the Boudoir. Dark. Flore. Violet, light centre.

Calceolarias. The shrubby varieties are very ornamental during the whole season. The following are good:-

Queen of Oude. Orange crimson. Prince of Orange. Orange and Sulphuria. Yellow. brown.

Gen. Outram. Bronze scarlet. 
Horseshoe Geraniums. The following are fine varieties :-

Perfection. Scarlet flower; variegated foliage.

Scarlet Globe. Scarlet; white eye.

Shottesham Pet. Cerise scarlet; variegated foliage.

Golden Chain. Scarlet; variegated foliage.

Amie. Brilliant scarlet; variegated foliage.

Duchess of Kent. Scarlet; white eye.

Bijou. Scarlet; variegated foliage.

Princess Alice. Pink.

Petunias. As we have before said, the fine rarieties are always propagated by cuttings. The following are fine kinds:-

Countess of Ellesmere. Scarlet; white eye.

Victory. Dark crimson.

Flag of America. Striped.

General Mc Clellan. Purple and white, double.

Miranda. Purple and white.

Solferino. Purple, double.

Blonde. White, carmine edge.

La Reine. Violet rose.

Cuphea Platycentra, of which we have before spoken, makes a fine bedding plant.

Double White Feverfew is fine for garden culture.

Nierembergia. A delicate little plant, with fine foliage, and salver-shaped flowers, covering the whole plant, 
N. gracilis, flowers blue and white. N. grandiflora, pure white, very large.

Salvias are indispensable for autumn bloom: the two best are those we have before described $-S$. splendens, with scarlet, and $S$. patens, with blue flowers.

Tritoma Uvaria is a stately-growing plant, with reedy leaves, throwing up a tall spike of crimson orange flowers. It must be preserved in the cellar in winter. The rariety Glaucescens is not so highly colored, and Serotina blooms late into the autumn.

In addition to these, the various kinds of Carnation and Picotee Pinks, Tea Roses, Pansies, Daisies, Ageratum, Lychnis, Bouvardias, Anterrhinums, Gaillardia, Lemon Verbena, and Lobelia, can generally be obtained at the green-houses. All these make good summer-blooming plants.

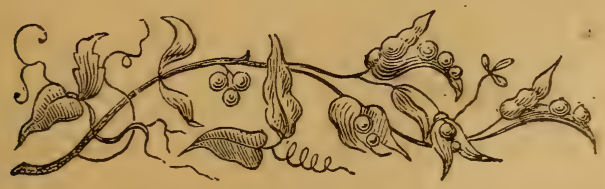




\section{CHAPTER XXV.}

\section{HARDY AND HALF-HARDY GARDEN BULBS.}

Preparation of Ground.-Planting.-Protecting.-Summer Treatment. - Tulips. - Crown Imperial. - Guinea Hen

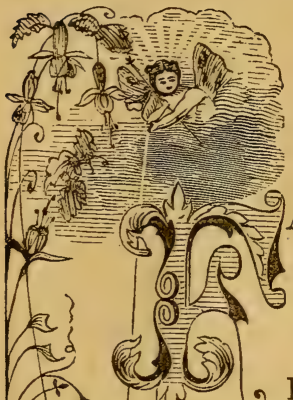
Flower.-Anemones and Ranunculus. - Colchicum. - Dog Tooth Violet. - The Lily. Preparation of Soil. - Species. - Tiger Flower. - Dahlia. - Tube Roses. - Gladiolus. - Amaryllis.

AR THE greater part of the Dutch bulbs, which we have so fully described in former pages, will, if planted out in the open border, and slightly covered with manure, endure the winter, and bloom in spring or summer. The हकीये species and varieties have already been described. Their out-door treatment is very simple. Select a warm, sunny spot in the garden, where good drainage can be secured; trench this about eighteen inches deep, digging in a liberal quantity of well-rotted cow manure, and enough pure sand to make the soil rather 
loose. This being done, about the first of October plant the bulbs in lines and circles, or as may suit the fancy.

The usual fault in planting bulbs is not setting them deep enough; they are often thrown out by the frost.

Hyacinths should be planted four inches deep; Crocus, two inches; Iris, three inches; Snowdrops, two inches; Jonquils and Narcissus, three inches.

The bulbs planted, a good covering of coarse manure and straw should be laid over the bed about the first of December, or just before the ground freezes up.

In the spring, say about the first of April, rake off the straw. The bulbs will be found well up; the blanched stalks will soon turn green, and an abundance of bloom will follow.

After the leaves have died down, if you have fine varieties, it is best to take them up, and keep them in a dry place until the season for planting comes again. The general practice is, however, to allow the bulbs to remain in the ground, where, if undisturbed, they will bloom year after year.

This treatment is suitable for Hyacinths, Crocus, hardy Gladiolus, Iris, Jonquils, Narcissus, and Snowdrops.

The Polyanthus Narcissus, of which we have before s?o'ken, are not perfectly hardy; the bulbs live, but 
they make too early a growth, and are usually frostbitten.

The culture of the fine varieties of the Tulip requires more care. A bed for choice tulips is prepared by excavating a pit a foot and a half or two feet deep; a piece of ground in an open, airy situation, and dry at hottom, haring been. chosen. In this pit a layer is placed of thoroughly rotten horse dung, at least two years old, and generally the remains of an old hot-bed, and the bed is filled in to within one inch of the top with rich sandy loam; old loamy turf, chopped fine and mixed with sand, and a little rotten dung, is the best, where it can be procured. The surface of the bed is then covered with sharp or drift sand, and in this the bulbs are planted about six inches apart every way, and the bed is filled up so as to raise it about three inches above the surface, and to bury the bulbs about four inches deep. The bed should be highest in the middle, and slope to both sides, to throw off the rain. The bulbs are generally planted in October, and as the tulip is very hardy; it seldom requires any protection, unless the winter should be very unfarorable, either from severe frosts or almost constant rain, in which case the bed may be protected by being hooped orer, 
and then corered with mats, care being taken to leave a part to open when the weather is fine. When the plants are near flowering, a frame should be placed round them to support an awning to shield them from the sun and rain. As the bed is generally four feet wide, the frame, which includes a walk round it, is about twelie feet wide; the length varies according to the extent of the ground, or the number of bulbs to be planted. When the flowers fall, and the leaves begin to turn yellow at the tips, the bulbs may be takcn up and laid on shelves, with the root end uppermost, to dry. When the fibrous roots are sufficiently withered to allow them to be rubbed off, the bulbs may be placed in drawers or - boxed, where they must be kept dry until the season for planting arrives.

If the bulbs are not taken up they soon deteriorate, the flowers returning to the original red self-color of the species.

The Crown Inperials (Fritillaria Imperialis) are the most stately of spring bulbs. The varieties are jollow and red, single and double, golden and silver-leaved, and many named varieties, which do not, however, differ much in color from those above named. 


\section{HARDY AND HALF-HARDY GARDEN BULBS.}

They are all highly ornamental, and will thrive in any rich, deep soil. They are impatient of being disturbed, and when taken up should never be long kept out of the ground.

The same treatment is required for Frittelaria Persica, a beautiful species, with glaucous blue foliage, and a large cluster of purplish flowers.

Fritiliaria Mele.sgris is the pretty little Guinea Hen Flower; there are also white varieties. The treatment above described for the crocus will suit it perfectly; it iflowers about the middle of May.

Anemones and Ravunculus seldom do well in our cli-mate under open culture; our winters are so long and wet :the tubers either sprout prematurely, and are killed, or rot in the ground. The hundreds of packages sold each autumn, at auction, are not worth the paper they are wrapped in.

Colchicun Autumale is a pretty bulb, with flowers resembling a crocus, purple, white, striped, single and double; treat as a crocus. The peculiarity of the plant is, that the flowers are produced. late in autumn; and the leaves appear, ripening the seed, in the following spring. It is a very pretty and interesting plant. The bulbs are very large, and when once planted should not be disturbed. There are also spring-blooming varieties. 
HARDY AND HALF-HARDY GARDEN BULBS. 375

Dog-тоотн Violet (Erythronium dens canis); a most lovely flower, purple and white. It is very liable to die out, and should not be disturbed after being planted. The bulbs should never be kept long out of the ground. This little bulb is worthy of every care; its flowers are among the most beautiful and graceful in the floral kingdom. It may be imported for a few pennies per bulb, but cannot, to our knowledge, be obtained in this country. The loss on importations is about fifty per cent., from rotting and drying. Our woods produce a pretty yellow species, with beautiful foliage. It succeeds poorly in the garden.

The LILY. This is a large family of ornamental bulbs; many of them are hardy, and indispensable in the flower garden.

The plants will grow in any garden soil, but a little attention will be repaid by greater luxuriance and more abundant bloom.

The proper soil is a compost of one part loam, one part peat, one part clean sand, and one part leaf mould. Excavate the soil for about two feet in depth, and fill in with the compost. The bulbs should be planted from three to fire inches deep, according to the size. Autumn 
planting is preferable. The bulbs, if kept long out of the ground, shrivel and are weakened; it is on this account that imported bulbs so seldom flower well the first year.

The soil should be frequently enriched, as the lily is a gross feeder, and will bear a large amount of manure, showing the effect in increased size of stem and leaves, and number of blossoms.

During the winter the bulbs should be protected by a covering of coarse manure, and in summer a little mulching placed over the bed, to protect the ground from the sun, is beneficial. The best species are, -

Lilium candidum, one of the oldest garden flowers; always a favorite, from its fragrance and beauty; too well known to need description. A variety with double flowers is destitute of beauty, and can only be regarded as a monstrosity; the variety with striped leaves is desirable. $L$. perigrinum somewhat resembles the last, but is botanically distinct. $L$. bulbiferum is the common orange lily. L. longiflorum, a lovely species; flowers, pure white, very long, and fragrant; requires slight protection during the winter. Lilium lancifolium album, $L$. $l$. roseum, L. $l$. speciosum: These three lilies are generally 
known as Japan Lilies. The former is pure white, and is a plant of most vigorous growth, the stems often producing from ten to twenty flowers; it is as hardy as the common white lily, and like it, will grow in any good garden soil. To produce the flowers in perfection, a rich, deep soil, as above directed, should be prepared, and the bulbs planted at least one foot from each other every way. The growth of the other two varieties is weaker, but the flowers are of surpassing beauty; deep rose or red, all spotted and rough, with brilliant shining points, resembling so many gems. Treatment for all the varieties is the same. There are many fine seedlings.

L. Japonicum, a variety with large, white, bell-shaped flowers, resembling $L$. longiflorum. Treat as the last two species.

L. monadelphum, a pretty species, resembling in growth the Martagon family, - sometimes called the Caucasian Lily, from its native country; flowers, yellow spotted, drooping. Will grow in any garden soil.

L. Philadelphicum, one of our native species, commonly called the Blackberry Lily. Soil should be rather sandy; flowers deep red, spotted with black.

L. Canadense, another fine native variety, with light $32 *$ 
orange and yellow drooping flowers. It improres wonderfully in cultivation, often throwing a stalk five feet in height, bearing twenty flowers.

L. superbum, our finest native species; flowers orange reddish, with numerous spots; drooping. Succeeds as well as $L$. Canadense in cultivation.

L. Martagon, fine varieties, with white and purple flowers; very ornamental, and hardy, if the soil is rather sandy.

L. chalcedonicum, the Scarlet Martagon; one of the most highly-colored species; hardy, and worthy of a place in every garden.

L. testaceum, or excelsum, a beautiful species, growing from two to four feet high; flowers in terminal umbels, yellow or straw color, with faint red spots. It should be planted deep, as the bulb makes roots both above and below ; perfectly hardy.

L. Thunbergianum, a showy, orange red variety, from Japan; hardy.

$L$. auratum is the new Golden-banded Lily, just introduced. In size and markings it is the most beautiful of the family. It will probably prove hardy, but as yet is rery rare. 
We have now to say a few words about summer bulbs, or tubers, which have not been mentioned in former chapters.

Tigridia (Tiger Flower). This is a beautiful class of Mexican bulbs, of easy culture, producing showy, spotted flowers all summer. The most common varieties are $T$. pavonia, rich scarlet, spotted with black; $T$. conchiflora, yellow, spotted with black; T. speciosa, a hybrid between these two species, and partaking of the character and color of both. T. Wheelerii, a seedling from conchiflora.

The "blue Tiger Flower" is not a Tigridia, but Philacallis plumbea.

The Dahula. This once popular flower is fast falling into unpopularity, and will soon be consigned to oblivion. It has seen its best days, and has been compelled to give place to the Gladiolus, Hollyhock, and Double Zinnia. It is hard to find what could have given the Dahlia its popularity. It has no grace of growth or flower, is a coarse, rank-growing and smelling plant, and beyond a certain mechanical rosette arrangement of petal, has nothing to recommend it. Its culture is simple. Set the tubers in any rich, deep soil, and if the plants are not beaten down by high winds, and the season is long, and no early frosts 
occur, you will have flowers enough. Preserve the tubers in a dry, frost-proof cellar during the winter.

We cannot, when there are so many beautiful flowers, recommend any one to fill the garden with dahlias, but as some may fancy them, we give a list of a few of the best.

Baron Alderson. Buff, white tip. Mrs. Charles Kean. Yellow, tipped Fanny Keynes. Straw, crimson with white. edge.

Bessie. Clear yellow. Queen of Whites. Pure white. Mont Blanc. Pure white. Lollipop. Buff and salmon. Loveliness. White, tipped with pur- Vesta. Pure white. ple.

Pioneer. Crimson.

Miss Vyse. White and purple.
Dandy. Blush, crimson, maroon. Lady Popham. Blush white. Peerless. Yellow. Admiral Stopford. Dark maroon. Ladly Franklin. Deep buff. Preëminent. Dark purple. Goldfinder. Deep yellow. Lady Paxton. Crimson, white tip.

\section{Dwarf Varieties.}

Cupid. White, tipped with claret. Golden Ball. Deep yellow. Zelinda. Purple. Alba Floribunda Nana. White. Captain Ingraham. Dark crimson. Victor Hugo. Crimson.

Of Gladiolus, Tube Roses, and Amaryllis, we have treated fully in former chapters. 


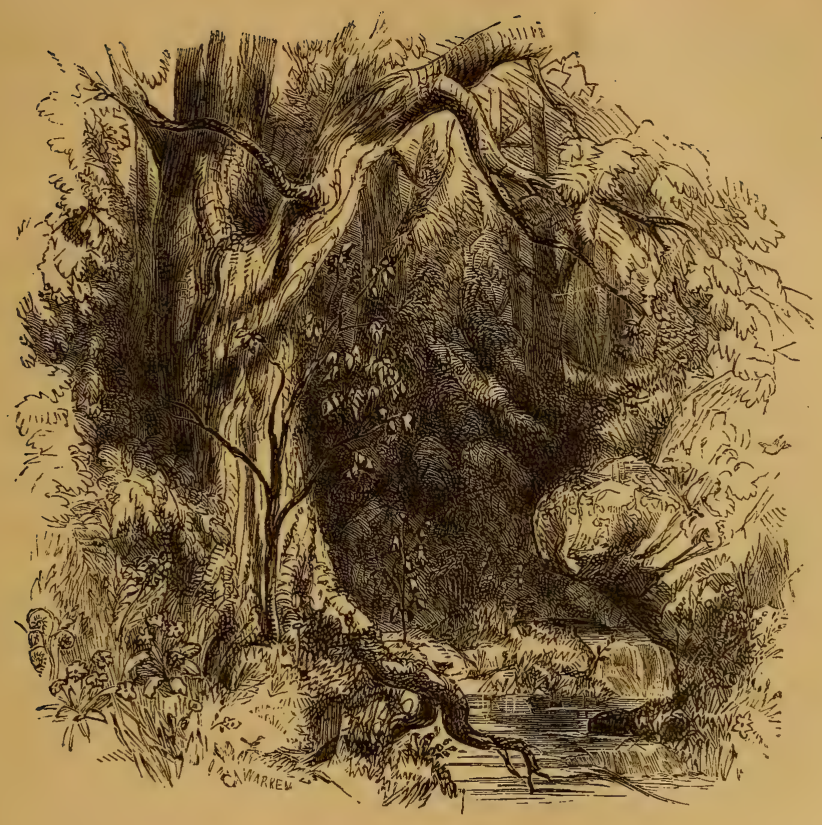

CHAPTER XXVI.

SPRING FLOWERS, AND WHERE TO FIND THEI.

TE have promised to lead the reader into the woods and fields, there to gather the rich blossoms which Nature scatters freely; which grow and bloom with no care from the hand of man, and often, in beauty, grace, and 
fragrance, surpass the most gorgeous inmates of our gardens. Scarcely have the March snows forsaken the sunny forest nooks, when the chilly winds are redolent with a strange perfume; it is unlike any other, - peculiar, and calls up balmy memories of spring, and buds, and flowers.

Whence comes it? The maples are still dark and gray, in their winter's sleep; not a crimson bud has yet dared to peep forth; and the willows, though glistening in the sunlight with their peculiar spring color (if we may so speak), still keep the downy catkins folded away beneath the sheathing bracts. Search the woods around, and if a stranger to woodland mysteries, if you have not that hidden sympathy with Nature which draws you to the flowers, your labor will be in vain. But brush away the fallen leaves, which have so tenderly warmed the earth during the long cold nights; see, amid tufts of rough roundish leares, some dark green, some brown, disfigured, a blossom which seems delicately fashioned by fairy fingers, or a gem from Flora's orm diadem. Gather it carefully; it is the first flower of spring, the promise of the year, a token of sunny days and leafy woods, of balmy winds and smiling skies. The botanist 
will call it Epigcea repens; some, the Trailing Arbutus, and Ground Laurel, and others, again, Mayflower, - and all are right. We have no patience with the pedantry which would supplant our old-fashioned names, homely though they be, by learned Latinisms or musty Greek; though in this case the botanical name, signifying creeping upon the earth, is peculiarly significant. The plant is low-growing, hardly attaining the dignity of a shrub; it is covered with rusty hairs, has evergreen leaves, rounded and heart-shaped, alternate; the flowers are rosy red or white. It is found in sandy soils, sometimes in rocky situations, especially in the shade of pines.

We have never known this plant to succeed well in cultivation, though doubtless it could be easily grown with slight attention; certainly its beauty merits every endeavor. In England it is valued, and found in the catalogues of nurserymen. A fine variety has been originated, called E. rubicunda, the flowers of which are larger than those of the species, of a rich pink, and the plant is quite hardy.

The Epigæa is found from Nova Scotia to the Carolinas; there is but one species, - the one above described.

Almost as early as the Epigæa, on the sunny hills, 
open the azure blossoms of the Hepatica, a pretty and favorite flower, always a welcome guest, and the next herald sent by approaching Spring to announce her advent. On a bright sunny day, what can be more lovely than a tuft of these beautiful harbingers of spring, gazing svith open eyes to the heavens!

"Blue, blue as if the sky let fall

A flower from its cerulean wall."

The wild varieties are found of every shade, from a ideep blue to pure white; the former are the most common; we also find shades of pink and purple. There are two varieties, distinguished by the shape of the leaves, and named respectively, $H$. triloba and $H$. acutiloba, of which the latter is the rarer; the two varieties sometimes run into each other. The common names are Liver-leaf, so called from the fancied resemblance of the leaves to the liver, and far prettier, Squirrel-cups. It is a delicate plant, the flowers always appearing before the new foliage, and pushing up in great numbers among the old leaves. The leaves are heart-shaped at the base, and divided into three or five entire lobes. This flower has been much improved by cultivation; we have spoken at length, in a previous chapter, of the double red va- 
riety, which is a perfect gem of beauty; the double blue is very common in England, and is very desirable; the double white is very rare in England, if, indeed, it be not lost from cultivation.

Next, as the spring advances, we find the dry hills and pastures covered with the common Mouse-ear (Gnaphatium plantagineum). It is a plant of little beauty to the naked eye (though it develops finely under the microscope), exhaling a rich spring fragrance. At seasons when flowers are more plentiful it would be passed by unnoticed, but in spring it is cherished as an added promise of sunny days.

The barren and fertile florets are on separate plants; the former are white, with revolute segments and brown anthers; the latter are cylindrical.

The warm sun soon calls out, on the dry, rocky hills, the early Saxifrage (Saxifraga vernalis). The flowers are white, crowded, arranged in corymbed panicles, and exhale a pleasant fragrance.

The leaves are radical, spreading upon the ground, producing the flower-stalk or stalks from the centre. It is a pretty flower, a favorite of children, and we always welcome its advent. 
And now, as the days lengthen and the sun gains power, as May-day has come and passed, the woods and hill-sides bloom with countless blossoms. The grass, taking an early start, has thrown up long green spires, and the hill-side grasses are already in bloom, and waving in the wind their delicate pollen-clad antlers. In the woods spring has come; the maple is lifting a censer of blossoms, the willows by the stream are yellow with bloom; the poplars begin to expand their delicate green foliage, and the elms have already dropped their brownish-red blossoms, and hang with their greenish seed-ressels, among which the shootings of the tender leaf may be perceived. Myriads of birds make vocal all the forest aisles, and each woodland path is carpeted with flowers. From so many candidates for our favor, which or what shall we choose?

In the woods grow the Anemones, and peep from their borders at the violets, which make blue the fields beyond. Therefore let Anemones and Violets be our choice, - flowers loved and welcomed by all.

How many associations cling around the Violet! What pleasing recollections it recalls! Who is there that does not love it? It is a modest flower, never obtruding 
itself upon us, except when its numbers make all the hill-sides blue, when he must be blind indeed, and insensible to floral beauties, who fails to notice it. About twenty species are natives of the northern Lnited States, of which about thirteen are found in New England. The colors are white, blue, and purple, in various shades, and yellow. Those most commonly met with are, -

Viola lanceolata (Lance-leaved Violet). This is one of our most common species; petals white, the lower ones slightly veined with lilac; it is generally found in meadows.

Viola blanda. Very nearly resembling the last, and often running into it; the leaves are roundish instead of lanceolate, and the flowers more fragrant; color white. Between this and the last almost every variety of leaf occurs.

Viola acuta, or primulaefolia seems to be intermediate between the last two; the flowers are white and small. A native of damp meadows.

Viola cucullata (Common Blue Violet). Too well known to need description; the flowers vary much in size and color, being deep or pale purple, nearly white, or variegated with white. Common in damp grounds.

Viola palmata seems only to be a fine variety of the last. 
Viola sagittata. This is our most common violet; it varies much according to the situation and soil in which it grows, and has been described under various names. In damp places its flowers are pale blue and large; on dry hills, where it is very common ( $V$. ovata), the flowers are pale purple and very numerous.

Viola pedata. Our finest species, easily distinguished by its pedate, fine-cut leaves, and its large handsome pale or deep purple flowers with orange centre. It is a native of sandy or gravelly soils, flowering about a week later than the common blue violets. The upper petals are sometimes deep violet and velvety like a pansy.

Though the Violet has always been the emblem of modesty, and is ever a favorite, to us the simple, blushing wood ANEMone is the fairest of the woodland flowers.

There are few which excel it in delicate grace and beauty. The foliage is most ornamental, and the tintings of the blossom most exquisite. The colors vary according to the situation where it blooms; in the shade, being deep, rosy, or light pink-purple, in its many shades; in the sun, pure white, or delicately flushed with rose. We speak now only of the common Wood Anemone; the other species, which loves the sunlignt better, is usually pure white, very 
rarely showing tintings of pink. These two species are found in almost every locality; in deep, low woods, or rocky pastures, often fringing the edge of the forest with their delicate blossoms, or clinging to the sides of shady rocks. As the woods are cut away, and the underbrush cleared up, the anemones gradually disappear, the rue-leaved lingering the longer. The common species are, -

Anemone nemorosa (Wood Anemone). Root, creeping; stem erect, supporting a single flower above a whorl of compound leaves. The flower consists of five petals. By cultivation the stamons have been converted into petals, and a double, variety produced. It is very handsome and ornamental, though lacking the simple grace and beauty of the single form. The Anemone succeeds well in cultivation if the exposure is not too sunny.

Anemone thalictroides, or Rue-leaved Anemone, called by later botanists Thalictrum anemonoides. A very pretty plant, distinguished from the last by its tuberous root and the number of flowers, which vary from one to fifteen. The stem bears two or three leaves at the very summit, like those from the root (which are compound, usually three times ternate), but without the common petiole, so that they seem like a whorl of long-stalked, simple leaves. 
Pistils, several in a little head, tipped in a flat stigma. This is a variable plant; scarce two individuals are found alike; in its wild state it is inclined to sport, and is sometimes found double. It is like the last perennial, and very ornamental, though lacking in graceful beauty.

Spangling the pastures and rocky hill, in pleasing contrast with the saxifrage and violets, we find the pretty yellow blossoms of the early Potentilla ( $P$. sarmentosa). It is a delicate species, blooming abundantly in April and May. In early spring the flower stems are very short, but, as they continue blooming, lengthen out often a foot or more, running along the ground, and rooting at the joints. The leaves are quinate, and resemble slightly those of the strawberry, to which the family is nearly related.

There are several other species of Potentilla, which bloom during the latter part of spring, or in the summer, some of which are quite ornamental. We have in cultivation Potentilla, floribunda and arguta, both of which are pretty additions to our bed of herbaceous plants. Some of the cultivated varieties are very fine, the flowers being all shades of orange, white, rose, pink, red, scarlet, and crimson. Two of the hardiest and most desirable are $P$. formosa and atrosanguinea. 
The Houstonia is a pleasing, simple little spring flower, in some localities so abundant as to whiten the ground. With us it is a favorite flower; the delicacy of the bud and flower is very marked; and the soft pearl-colored petals form a pleasing contrast with the pale yellow eye.

The common species is $H$. coerulea, or, according to Gray, Oldenlandia coerulea. It flowers in May and later, and is too well known to need description (often called Eye-bright).

While the hills are spangled with violets and potentilla, and the woods are gay with anemones, the low grounds are ornamented with the yellow blossoms of the Water-cress or Cowslip (Caltha palustris). The flower bears some resemblance to the common butter-cup, but is larger, and has the petals more spreading. It is a low-growing plant, of frequent occurrence on the banks of low streams or ditches, or growing in conspicuous clumps in very marshy ground. We have never cultivated it, because it is so plenty near us in its wild state; we have, however, no doubt that it could be localized to drier spots, without diminishing the size or detracting from the color of the flower. To those who cannot obtain it in a wild state, it would well be worthy of eultivation, and be a great addition to the flower border in carly spring. It ripens seed freely, and in a few years, from a single plant, will spread over a whole meadow. 
In this plant the bright yellow leaves composing the flower are not petals, but sepals ; the pistils are five to ten. Leaves round or kidney-shaped, crenate or entire; sepals six. The plant is used as "greens," or salad, in early spring, and sold in the markets under the name of Cowslips. Both this name, and the equally common one of Watercress, are obviously incorrect; the cowslip is a species of primrose, and the water-cress a species of nasturtium, a cruciferous plant. A better name for those who abhor Latin, is Marsh Marigold.

There is a double variety which we have in our garden, a very ornamental plant. The flowers, except in size, resemble the double buttercup, and like that plant often have a green centre. It blooms in May, about the time the single variety expands in the meadows, and continues some weeks. It does well with us in dry soil, and is perfectly hardy. It may be obtained of florists, but is not common.

Early in May the rocky hills are decked with the delicate and graceful blossoms of the Wild Columbine (Aquilegia Canadensis). The flower is to well known to need description. It is a hardy perennial, loving shady, rocky clefts, and clinging, with its slender roots, in almost inaccessible places. The flowers are very graceful and nodding; in fruit the stalk becomes upright. 
Till within a few years the scarlet of this species had never been obtained in varieties of the common garden columbine ( $A$. vulgaris of Europe). Latterly, however, some new species, and many new varieties, some of great merit, have been obtained, in some of which we find the peculiar scarlet of the wild columbine. This plant is greatly improved by cultivation. The stool increases in size every year, and gives a profusion of flowers. We have seen a single plant over a foot in diameter, supporting hundreds of flowers. In cultivation it seems to prefer a rich loam.

A companion of the Anemone nemorosa is the pretty Bellwort, or Straw Flower (Uvularia sessilifolia). For delicate grace it is not surpassed by any of the spring flowers. Leaves, oval or lanceolate, oblong, pale, glaucous underneath; height from six to nine inches; flower, cream or straw-colored, three fourths of an inch long. Easily cultivated and very pretty.

Uvularia grandiftora is a beautiful species, with yellow flowers. With us, in cultivation it is a conspicuous ornament of the flower border in May and June. Flowers more than an inch long. A native of rich woods.

$U$. perfoliata resembles the last, but is a smaller plant ; succeeds well in cultivation. 
The Convallaria, or Solomon's Seal, is a well known habitant of our woods; the little dwarf species, or false Solomon's Seal, in some localities fairly carpeting the ground with its light green, glossy leaves, and perfuming the air with the spicy fragrance of its starry flowers.

All the species love a damp, shady locality, but will flourish in almost any good rich soil. They are all plants of easy culture, and improve greatly in cultivation; plants not unfrequently attaining twice the size of those in the wild state. All love a rich soil, and will bear very high manuring. We have grown them to great perfection in a deep bed of well-rotted manure and leaf mould.

There have been some changes latterly made in this genus, all the plants commonly known as Convallaria being transferred to Polygonatum and Smilacina, except C. majalis, the well known Lily of the Valley, which is a native of this country and Europe, being found in th high Alleghanies of Virginia and southward.

Convallaria biflora (Smilacina bifolia). Our common low growing species, abundant in most situations. Flowers white and fragrant, in a short, erect cluster; berries white or spotted when unripe, scarlet when ripe. In bloom about the first of June. 
C. trifolia (Smilacina trifolia). Stem with three alternate leaves, oblong, lanceolate; spike of flowers erect, terminal. Native of cold bogs. Berries red.

C. stellata (Smilacina stellata). Stem clothed with from seven to twelve oblong, lanceolate leaves, downy when young; growing from ten to twelve inches high. Raceme terminal, consisting of a few white flowers, with six oblong petals and six stamens. Berries blackish.

C. racemosa (Smilacina racemosa). A common plant in moist, shady situations. Stem two feet high. Leaves alternate, nearly sessile, oval acuminate. Stem terminating in a compound raceme of white flowers on peduncles, usually of the same color. Berries pale red, sprinkled with purple. Blooms in June.

Convallaria (Polygonatum) biflorum. Stem two feet high, smooth, round, simple, nodding at top. Leaves alternate, oval, nerved, pubescent, pale green. Flowerstalks axillary, drooping; branched, supporting one, two, or more pendulous, pale green, fragrant flowers. A very pretty and not uncommon species. Native of shady woods and hills, about old walls and fences.

C. caniculata (Polygonatum giganteum). A very tall species, somewhat resembling the last, but distinguished 
by its size and angular stalk. Stem three to six feet, very stout; peduncles two to eight flowered. A native of woods and river banks, in alluvial soil. As remarked by Professor Gray, the stem is not channelled in the living plant, so the popular name of "caniculata" seems inappropriate.

Our common species of Corydalis are pretty, early flowering plants; natives of woods and rocky hills. They succeed well in the garden, and improve in size and . color. They are nearly allied to the well-known Dielytra spectabilis, in our opinion the finest herbaceous plant of recent introduction, which is alike valuable for its hardiness and the beauty of its flowers and foliage. 'The plants comprised under the name of Corydalis, hare been given to various classes, and have many synonymes; all belong, however, to the natural order Fumariacce, and to the classes Adlumia, Dicentra, Corydalis, and Fumaria.

Corydalis fungosa (Adlumia cirrhosa). A pretty climbing species; common to gardens, and known as Mountain Fringe. The plant attains the height of fifteen feet, climbing by means of the tendril-like young leaf-stalks; foliage very delicate; flowers, pale flesh color, in axillary racemes. Native of damp woods. 
Corydalis (Dicentra) cucularia (Dutchman's Breeches). A very delicate plant, bearing fine-cut leaves, and a scape of about half a dozen white flowers, tipped with yellow. Root, a collection of small solid tubers, enclosed in a common scaly sheath. A native of rich woods, blooming in May or later. Rare in New England. A very curious and ornamental plant.

Corydalis (Dicentra) Canadensis (Squirrel Corn). A pretty species, native of rich woods. Name given on account of the round, scattered, yellow tubers, which resemble grains of corn. Flowers greenish white, tinged with red, with the fragrance of hyacinths. A pretty plant.

Corydalis (Dicentra) eximia is a fine, large species, with reddish-purple flowers, resembling the Dielytra. In its wild state it is not, to our knowledge, found in New England, but is not uncommon in gardens. As an ornamental plant it is most desirable, and increases rapidly in rich soil.

Corydalis aurea. A very glaucous plant, native of rocky banks; flowers golden yellow, very showy; the richness of the color depends, however, on the location of the plant. The plant, unlike all above described (except C. fungosa), is biennial, and is often lost to culti- 
vation by neglecting to save the seed, and plant every year. A rich, moist, partially shaded border is very favorable for the growth of this beautiful plant.

Corydalis glanca. Much more common than the last, and less showy. Like it a biennial, blooming from early May to July. It is a delicate plant, of a smooth, glaucous appearance. Flowers whitish, shaded with flesh color, and yellow in panicled racemes. A native of rocky hills, often found in the shallow deposit of soil on large rocks, where it blooms very early, owing to the refiected heat from the rock. It flourishes well with us in common garden soil.

Sanguinaria Canadensis, or Bloodroot, is well known as one of our earlicst spring flowers. The flowers and leaf proceed from the end of a fleshy root, and all, on being wounded, emit a bright orange-red juice. We copy a good description of the root: "The bud or hybernaculum which terminates the root is composed of successive scales or sheaths, the last of which acquires considerable size as the plant springs up. By dissecting this bud in the summer or autumn, we may discover the embryo leaf and flower of the succeeding spring, and with a common magnifier even the stamens may be 
counted." The calyx consists of two concave, ovate, obtuse leaves, which are perfect in the bud, but fall off when the corolla expands. Petals eight or more. Seeds very numerous, dark shining red, with conspicuous white crest. The leaves grow during the summer, attaining a large size, so as to appear like a different plant. Flowers white, very handsome, contrasting beautifully with the golden yellow stamens. This plant increases in size in cultivation, and the flowers show a tendency to become double. It ripens seed freely.

The common Buttercups, which from May to August are so conspicuous in the fields, belong to the natural family Ranunculacece; they are generally plants with white or yellow flowers, annuals or perennials, with usually solitary flowers. The fresh juice of all the species is acrid, in some so much so as to raise blisters; the plants are, on account of this property, avoided by cattle; but in drying, this acrid property disappears, so the plants are not as injurious to mowing as to pasture lands; even, however, in the former, Buttercups are not regarded by farmers as acquisitions, and the plant is far more popular with children than with agriculturists. There are about twenty species in the northern United States, some of 
which are water plants. To describe, or even to name all these, would exceed the limits of our pages; we will only mention those which are called by the general name of Buttercups.

Ranunculus fascicularis. A low growing species, blooming on rocky hills in April and May. Perennial. Flowers yellow, about an inch broad.

Ranunculus repens. Flowers as large or larger than the last. The plant sends out long runners, by which it is easy to distinguish it from the other species, but in spring it often flowers from upright stems. Very variable in size and foliage.

Ranunculus bulbosus. The most common species in eastern New England, seldom found in the interior (Gray). Root solid, fleshy, acrid. Stem erect, leafy. Flower composed of six or seren petals, of a bright, glossy yellow.

Ranunculus acris. A taller species than the last; flower nearly as large, but not so bright a color. This and the last are those most commonly met with in pasture and mowing lands. The Double Buttercup is common in our gardens, and very ornamental. There appear to be two species, the one a low growing, running plant, which often increases so rapidly as to almost become a 
weed, the other tall growing, and only increased by division. The latter is by far the most desirable, the former often proving a troublesome favorite. The Double White Buttercup (Ranunculus aconitifolius), or "Fair Maids of France," is very rare. It is a beautiful little flower, very double, pure white, and the foliage is remarkably pretty. It is, however, very liable to be winterkilled.

It has often been a question with us whether we have a more beautiful wild flower than the common and much despised Dandelion (Taraxacum dens leonis). The foliage of pinnatifid or runcinate radical leaves, is very pretty, and of a pleasing green; the yellow flowers are of elegant form and pleasant fragrance; the single florets, when examined through a microscope, are of singular beauty; the globular head of seeds is very ornamental. If this flower was now first introduced from some distant country, the whole floricultural world would go into ecstasies over its beauty; but as it is common, it is despised, and we say, in scorn, "only a dandelion." We do not hope to induce any to cultivate the Dandelion (to observe its beauties this is not necessary), but if any will give closer heed to the beauties of the plant, and observe with what lavish hand the great Creator has 
endowed it, our purpose in including the Dandelion in our catalogue of spring flowers will be answered.

The early Meadow Rue (Thalictrum dioicum) is conspicuous on hills and in rocky woods in April and May. The flowers are greenish, with yellow anthers, and are noticeable for blooming so early in the spring; the foliage is very delicate. The white flowers of the larger species (Thalictrum cornutum, or corynellum), are very ornamental in meadows in June and July. The foliage is ornamental, and for this reason both of these plants would be additions to the flower border. They are too common and too well known to need further description.

Trillium. A strikingly beautiful plant is the Trillium, in all its species. It is a gem among spring flowers, but is rarely met with in gardens, and is not common in the woods and swamps. It seems to delight in old woods, and localities where the axe of the woodman has never found its way, but where the old, moss-hung trees still maintain the grandeur of the primeval forest. In such situations the Trillium is at home. In early spring, the stem pushes up from the short, tuber-like root, bearing at the top three large, broad, ovate leaves, and a terminal flower. The plant delights in shade and moisture, and the root is commonly 
found deep in the peaty turf or moss. In congenial situations, the leaves and flower are very large, and the whole plant has a somewhat rank appearance; but in drier soils, the growth is less rapid, and the plant, though less vigorous, is more sturdy. After the fall of the flower, the plant bears a large, six-sided, purple or red berry, which is very ornamental. The name is derived from the Latin triplex, triple, all the parts being in threes; leaves, petals, and sepals, all three, though monstrosities, sometimes occur. The plants are of easy culture, if planted in proper soil and transplanted at the proper season. The soil should be rich, peaty loam, and the situation moist, for in sandy, dry soil the plants never succeed.

We have known plants to flower several years in common garden soil, but if we except Trillium erectum and grandiflorum, which sometimes flourish in moist loam, all the species require a prepared soil; a rhododendron or azalea bed is well suited to them.

The proper time for transplanting is late in the autumn, after the stem has died down. They may also be moved in the spring, but as the root starts so early in the season the experiment is not safe. The principal species are, -

Trillium cernuum (Nodding Trillium). This is the most 
common variety of New England, and the least ornamental of the genus. Leaves, three large, roundish, or rather rhomboidal pointed; petals white, about an inch long, reflexed longer than the sepals; the flower bends down so as to be hidden by the leaves. A native of moist, shady thickets. This species is worthy a place in the flower border, and succeeds with little care; it has not with us, however, increased in cultivation, or improved in size or color.

T. erectum (Purple Trillium). Leaves nearly as broad as long, abruptly pointed; petals ovate, flat, spreading, broader, but not much longer than the sepals; flowers dark brownish-purple, green outside, of not a very pleasant odor, nodding on an inclined peduncle. A native of old, rich woods. Succeeds and increases in cultivation, but is not desirable for a bouquet flower.

T. pictum, or erythrocarpum (Painted Trillium). A very delicate and beautiful species. Leaves ovate, taper-pointed; petals ovate, or ovate-lanceolate, pointed, wary, wide, spreading, painted with purple stripes at the base, almost twice the length of the sepals, and shorter than the peduncle (Gray). This lovely species is difficult to cultirate. We have bloomed it in the border for three successire 
sears, but the plants dwindled year by year, and finally disappeared. The trouble appears to be a want of moisture. In the wild state the plant is never found except in cold, damp woods and bogs. Could this requisite be supplied, we see no reason why this fine plant should not do well; certainly from its beauty it merits every attention. It is not a common species in New England.

T. grandiflorum. This species is the largest and finest of the genus. Leaves longer than broad, rhomboid, orate; petals obovate, longer and broader than the sepals, spreading at the top; color pure white, turning before the flower fades to dark rose color; flower on a stem about two inches long. Petals from two to three inches long. Native of rich woods; not uncommon in the north of New England. Berry dark purple. This fine species is of the easiest cultivation. The soil, if rich loam, needs no further preparation; it does not succeed in light, sandy soil. We have seen it bloomed in gardens of a size surpassing that of the wild plant. Plants may be obtained of some of our florists, but the easiest way is to obtain them from their native woods in the proper season.

Our other native species are, -

T. sessile. Color dark and dull purple, varying to 
greenish. Native of moist woods, Pennsylvania to Wisconsin, and southward.

T. recurvatum. Color dark purple. Native of Wisconsin, Illinois, Kentucky, and southward.

T. erectum, var. album. Petals greenish-white, rarely yellowish; ovary mostly purple (Gray). Found with the species, from which it otherwise does not differ, especially from New York westward.

T. nivale (D warf White Trillium). Petals white, wavy. Native of rich woads, Ohio to Wisconsin.

The smooth, shining, evergreen leaves of the Goldthread (Coptis trifolia), are very conspicuous in wet bogs and low woods in early spring. In some localities they fairly carpet the ground, and when spangled with the white starry flowers the effect is very pleasing. The plant is a lowgrowing perennial, with creeping roots of a golden yellow color (whence the name). In places where the plant is abundant, they run through the dark bog earth in every direction, appearing not unlike threads of gold. The scape bears one small, starry, white flower, composed of five to seven club-shaped petals; stamens from fifteen to twentyfive; pistils from three to seven; seeds numerous, black, oval. Blooms from middle of May to June. 
One of our finest native plants is the Erythronium Americanum, commonly called Dog's-tooth Violet, though why called Violet has been a puzzle to botanists. The plant belongs to the Lily tribe, and is the smallest of the family. Root a solid scaly bulb, deep in the ground, white inside, brown outside. Plant smooth. Leaves elliptical, lanceolate, pale green, dotted or clouded with irregular spots. Flower drooping, solitary, composed of six pale yellow petals, dotted near the base, expanding in sunny weather. The rapidity with which this plant exhales moisture is very remarkable. It is almost impossible to carry it any distance in the hand, as it dries and fades very rapidly. This lovely flower may be cultivated in a deep, moist, loamy soil ; in any other it divindles year by year. It. is a native of moist woods and thickets, and is not uncommon.

According to Gray, E. bracteatum, of Boott and Bigelow, is only an accidental state of this species. The flower is larger, and the scape has a narrow lanceolate bract about an inch long, situated about an inch below the flower. It also differs slightly otherwise.

E. albidum, the white Dog's-tooth Violet, is not found in New England. The leaves are spotted, not dotted; fiower 
white. Native of low thickets from Albany, New York, to Western Pennsylvania, to Wisconsin, and southward.

Thus have we gathered our bouquet of Spring Flowers. We have roamed through the woods and fields, and culled their treasures without exhausting the store. Many flowers have we neglected; much have we passed by unnoticed. We lay no claim to completeness; it requires many a ramble to learn all the flowers teach; but if we hare introduced any one to a new flower, our purpose is answered.

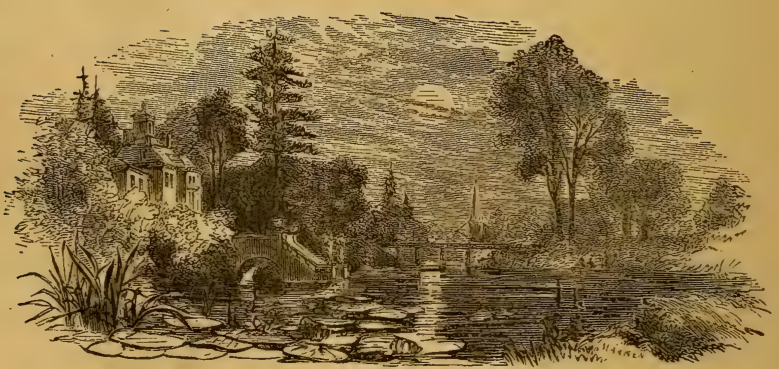




\section{CHAPTER XXVII.}

New Azaleas. - Notes on Cyclamen. - New Pelargoniums. - Verbenas. - Heliotrope. - New Poses. - Pinks. - Fuchsias. - Abutilon. - Callas. - Cuphea: - Chrysanthemums.

TN the previous chapters, first printed in 1863 , we have 1 followed the course of horticulture to that year. Now in 1876, twelve years since our first edition was issued, the progress of horticulture demands additional chapters to bring our subject to the standard of knowledge of the present day.

Each passing year has given us, both by discovery and hybridization, many new plants, and although in floriculture novelty is by no means a criterion of superiority, we have yet obtained many plants which are decided acquisitions.

In bedding plants, such as Verbenas and Pelargoniums, in bulbs, in roses, each year some old varieties are lost to cultivation, and their places are taken by new kinds, which in their turn often give place to others of yet more recent origin.

Some of the varieties mentioned in former pages, it 
would be difficult now to find in any florist's catalogue; thus supplementary lists become necessary.

\section{AZALEA INDICA.}

In this popular plant there has been great improvement. Although the old varieties are still cultivated, many of the new seedlings, especially those produced by continental cultivators, are superior to any of former years.

In substance of flower, brilliancy of color, form, and habit, they are far in advance of old varieties.

The double-flowered kinds, although in our opinion by no means as beautiful as the single, from the durability of the flower are most valuable.

It is a great question, upon which cultivators differ in opinion, whether the most effective way of growing azaleas is by the natural or artificial system.

In the former, the plant is allowed to grow as it will, too luxuriant shoots only being pinched, and it soon forms a spreading plant, which every year covers itself with flower. In the latter, each shoot must conform to a required style of growth, be it pyramidal, flat, or round, must be pinched in or tied out, until the plant becomes a symmetrical shape of green, hidden when in bloom by the mass of flower.

To us the natural growth is far more pleasing, although, perhaps, more brilliant effects are produced by the artificial. 
The catalogues of florists contain lists of hundreds of azaleas, all of which are beautiful. There is, however, great room for selection, and as none can grow all, we give a list of a few which cannot fail to give general satisfaction.

Flag of Truce. Pure double white.

Souvenir de Prince Albert. White and rose, very large double flower, - a late blooming variety.

Sigismund Rucker. A very distinct variety with large flowers, rosy lake with broad margin of pure white, large blotch of crimson-maroon on upper petals.

Decora. A very old variety, but unsurpassed for fine, compact habit and brilliant flower.

Mont Blanc. Pure double white flowers of great substance.

Mademoiselle Léonee Van Houtte. Rose with sulphuryellow blotch.

Chelsoni. Orange-scarlet.

Duc de Nassau. Rosy carmine, semi-double.

Alice. Double rose, vermilion blotch.

Baronne de Vrêre. Snow-white flowers, red stripes, sulphur blotch.

Eulalie Van Geert. Fine, large, variegated flower. There is also a variety with variegated foliage.

Dominique Vervaene. Bright, orange-red, double flow- . ers. 
Mrs. William Bull. Large, white, fine form. Marquis of Lorne. Orange-scarlet, saffron spots. Roi Leopold. Salmon, light centre. Stella. Orange-scarlet, violet spots. Roi d'Holland. Rich scarlet, finely spotted.

\section{CYCLAMMEN.}

Cyclamen may be easily raised from seed, and thus within the last few years many choice varieties have been obtained.

The seed should be sown as soon as ripe, say about the first of July, on a compost of rich garden loam and leaf mould, with a little sharp sand. Germination takes place in about six weeks; if, however, the seed has been allowed to dry, this period is considerably increased.

When once the plants have shown their first leaves, they should by frequent watering, be kept in a growing state for about eighteen months; that is, till after the second spring, at which period they would naturally rest. Rest the bulbs then out of doors for a short time, and then pot them separately in a compost of rich sandy loam, with well-rotted cow dung, and bits of charcoal. They will bloom freely that autumn: If, however, we wish, Cyclamen may be bloomed in one year from seed, by keeping the bulbs in 
active growth, and giving plenty of heat. The variety of color. obtained in these seedlings, is no less remarkable than the size of flower. Figures of some of these may be found in "Floral Magazine," plates 339, 387, 442, 488.

The most successful raiser of Cyclamen in the vicinity of Boston, is James O'Brien of Jamaica Plain, who has exhibited before the Massachusetts Horticultural Society, magnificent plants, remarkable for size, color, and profusion of bloom, and who grows this plant by thousands for the market.

\section{NEW PELARGONIUMS.}

Every year has shown progress in these plants. Many which we formerly recommended are now surpassed by better varieties.

We cannot do better than give a selection from the lists appended to the admirable paper upon the Pelargonium, read before the Massachusetts Horticultural Society last spring, by William Gray, Jr.; to which paper, embodying the results of careful experiment and close observation, we would call the attention of all growers.

Mr. Gray gives long lists, from which we select a ferr.

\section{Golden Tricolors.}

Achievement, E. P. Benyon, Howarth Ashton, Lady Cullum, Lucy Grieve, Miss Goring, Mrs. Little, Macbeth. 
Silver Tricolors.

Eva Fish, Excellent, Lady D. Neville, Mrs. Laing, Mrs. Clutton, Lass o'Gowrie, Princess Beatrice.

\section{Bronzes.}

Black Douglas, Earl of Rosslyn, Chieftain, Emperor of Brazil, Reine Victoria, Mrs. John Lee, W. E. Gumbleton, Maréchal McMahon, Mrs. Harrison Weir.

Round-Flowering Scarlets.

Beauty of Waltham, Coleshill, Lord Derby, Incomparable, Diana, Cœur de Lion, Orbiculatum, Omega, Sir Charles Napier, Vesuviius, Majestic.

Scarlet, Shaded with Rose.

Christian Dugin, Astival, E. J. Lowe, Renown, Crystal Palace Gem.

Scarlet, Shaded with Purple.

Ianthe, Peabody, Shade of Evening, Madame Mezard, T. Hammersley.

SALMON-SCARLET.

E. S. Dodwell, King of Roses, Paul Brie. 


\section{Pink.}

Master Christine, Mrs. Keeler, Rose Rendatler.

\section{SalmoN.}

Acme, Albert Grevy, Gloire de Corbenay, Mme. Jean Sisley, Polly King, President Thiers.

\section{White.}

Mme. F. Hoch, Mrs. Sach, White Clipper, White Princess, White Wonder.

White with Rose Centre.

Alice Spencer, Madam Werle, The Bride, Remus, Miss Gladstone, Marguerite Ponton.

Of Hybrid Nosegays the best Scarlets are Dr. Muret, Emilio Castelar, Jessica, Sunshine, Wellington.

\section{Rose.}

Caven Fox, Cherry Lips, Florence Durand, Lawrence Heywood, Mrs. Masters.

\section{Pink.}

Christine Nilsson, Delight, Lady Belper, Pink May Queen, M. E. Buenzod, Mrs. F. Burnaby. 
The above list may seem long, but it has been made from experiment with many hundred varieties, and all recommended are worth growing for house culture.

For bedding, however, a very short list will suffice.

Mr. Gray writes: "Orbiculatum, Sir John Moore, Coleshill, Wellington, Douglas Pearson, and Sir Charles Napier are the best among the Scarlets, and to these :must be added, for large beds, General Grant.

"For pinks I recommend but two, Master Christine and Pink May Queen.

"There are no white-flowering varieties fit for bedding, :but their place is well supplied by the white-edged Albion Cliffs.

"In the golden-leaved section, Crystal Palace Gem still holds the first place.

"Of bronzes, the Moor is the best. Harold, the Earl of Rosslyn, and the Marquis of Lorne are next, but at a long interval.

"There are no silver tricolors worth growing for bedding. Of the golden ones Mrs. Pollock is the best." 


\section{VERBENA.}

Each year produces new varieties of this plant, so that it is impossible to give a list of varieties which will prove of permanent value. It would be impossible to find in any collection of to-day the kinds described on page 102; yet at the time that list was first printed, now about twelve years ago, they were the popular varieties, and any prominent florist could have furnished any of them by the thousand.

The kinds grown to-day are probably no better in any respect. So many good verbenas have been raised that improvement seems almost impossible.

We give a short list for present use.

Amides Gerard. Dwarf purple.

Monstrosa. Large velvet-purple.

White Beauty. Fine white.

Silver Star. Crimson maroon.

Splendor. Vermilion, crimson eye.

Virginale. Large pure white.

Surprise. Rosy pink, yellow eye.

Austerlitz. Red, white eye.

Emily. Fine pink.

Scarlet Cirrle. Bright scarlet.

Colossus. Crimson, violet eye. 
Gigantic. Crimson, very large.

Zenobia. Purple, white eye.

Ultramarine. Fine blue.

E. G. Henderson. Fine scarlet.

\section{HELIOTROPE.}

We can almost say of this plant what we have said of the Verbena; yet though many new varieties have been produced the old have not been entirely superseded. The following is a list of choice kinds:-

Jane Messmer. Light blue, very sweet.

Alexina. Lilac blush, large flowers.

Garibaldi. Nearly white.

General Valubert. Violet.

Le Pape. Blue and lilac.

Mina. Deep violet, white centre.

Madame Fillion. Clear violet, passing to lavender.

Jersey Beauty. The best blue for pot culture.

Etoile de Marseilles. Deep violet, white centre, large truss, the best dark variety.

Souvenir de Leopold I. Dark blue, white eye.

Beauté des Parterres. Lilac, almost white when grown under glass. 
ROSES.

\section{ROSES.}

Of new tender Roses the name is legion, and all are so good it is difficult to make a selection.

When, a few years since we first saw Marechal Niél, we thought no more splendid rose could be raised, and yet, to-day, both Perle de Lyon and Belle Lyonnaise are its superior.

We thought no finer or more beautifully-colored bud than Bon Silene could be found, and yet Duchess of Edinburgh is superior in both these respects.

In fact it is hard to tell what not to grow. We give a few of the choicest kinds, not all new, but all indispensable to a choice collection.

Marechal Niél. Deep canary-yellow, very large, a rampant grower; should be budded on some strong stock, as thus it flowers more freely than on its own roots.

Bon Silene. Rich pink or cherry.

Bella. Pure white.

Safrano. Orange-yellow, fine bud.

Duchess of Edinburgh. Deep crimson.

Devoniensis (climbing). Creamy white, large.

Isabella Sprunt. Light-yellow.

Madame Villermoz. White, salmon centre, large and full. Madame Falcot. Dark apricot. 
Madame Margottin. Deep lemon, rosy peach centre.

Royal Tea. Pure white, very fine.

Belle Lyonnaise. Deep canary-yellow, changing to salmon.

Perle de Lyon. Deep yellow.

Niphetos. Pure white, very fine.

Canari. Bright canary.

Pauline Lebonté. Blush pink, - a lovely rose which will give more bloom than any we know. Fine globular flower, lasting long when cut.

Alba rosa. White, rose centre, large and full.

Archimede. Rosy fawn, darker centre, - a large flower of good substance.

La France. Rosy ; the most fragrant of all.

Souvenir d'un Ami. Pink, - a fine old rose.

Adam. Pink; fine long bud.

Souvenir de Malmaison. Large, flesh-color.

Mrs. Bosanquet. Delicate flesh-color.

Madame Ducher. Fine form; clear yellow.

For a showy bed in the garden Agrippina is the best rose; it is not hardy in New England, but requires frame protection in winter.

The bright-colored perpetual roses, such as General Jacqueminot, are much used for forcing, and bring high prices. A bouquet of this rose and Lily of the Valley, is most charming in mid-winter. 
The treatment is very simple: grow the plants in the border as strong as possible till the middle of November; pot them and keep them very cool in a cold frame or shed, - a little freezing does no harm. About six weeks before they are wanted, bring them into a cool house, letting them there remain till the shoots are an inch long, then remove them to the rose-house and force them with plenty of water, light, and heat.

The Cherokee Rose ( $R$. loevigata) is a charming plant for a cool house; the flowers are single, very large, pure white.

\section{PINKS.}

In forcing pinks we have some very fine varieties, the best for winter blooming are:-

La Purite, bright cherry, very free flowering.

La Belle. Pure white, very fragrant.

President Degraw. White, tinged with blush.

Louise Lenoir. Dark crimson.

Unique. Pure white.

Astoria. Yellow, marked with red. 


\section{FUCHSIAS.}

To the list already given we add :-

Wave of Life. Scarlet sepals, violet-blue corolla, goldtinted foliage.

Elm City. Crimson-scarlet, double.

Conspicua. Crimson sepals, white corolla.

Tower of London. Carmine-scarlet, sepals recurved, large violet-blue corolla.

Meteor. Fine bronze foliage.

White Eagle. White corolla, scarlet sepals.

Avalanche (Smith's). Double blush, sepals carmine-scarlet.

Arabella, or Mrs. Marshall. Pure white tube and sepals, rich rose corolla.

Balaclava. Carmine-scarlet sepals, violet corolla.

Emperor of Brazil. Reddish-crimson sepals, double violet-purple corolla.

George Peabody. Double white corolla, very fine.

M. Lauth. Long carmine sepals, plum-colored corolla.

Sir Garnet Wolseley. Flame-colored sepals, deep violetpurple, corolla double.

Sun-ray. Fine foliage, crimson, white, and green. 
ABUTILON. - CALLA.

\section{ABUTILON.}

Several new Abutilons have proved very valuable, of these the best is :-

Boule de Neige, a dwarf, free flowering variety, with pure white blossoms.

A. Pattersonii, or Santana, has large blossoms resembling the old $A$. Bedfordianum, but is a comparatively dwarf grower, and very free flowering.

A. vexillarium, or megapotamicum, has showy red and bright yellow flowers, which contrast well with the black anthers.

The variegated form has very showy foliage, and is one of the best plants we have for summer carpet-bedding.

A. Verschaffeltii has pale yellow flowers, and is a very handsome and desirable plant.

\section{CALLA.}

A new dwarf Calla (Richardia cethiopica nana) has proved worthy of cultivation from its flowering freely and occupying but little space. For house culture it is well adapted, requiring the same treatment as the species.

The Spotted-leaved Calla $(R$. maculata) has a hastate leaf spotted with white; the flower is green and not 
showy. This plant must be allowed to dry off after growth. Except for variety in a collection it is not desirable.

\section{CUPHEA.}

C. hyssopifolia is a very valuable plant for parlor culture. It is of dowarf habit, fine dark green foliage, and is always covered with delicate pink flowers.

It requires to be potted in good loam, and to have plenty of light, and not to be kept very hot; thus treated it will never be out of bloom.

\section{CHRYSANTHEMUM.}

Every year gives new varieties which supplant those previously grown. It is no easy task to make selections.

C. laciniatum is valuable for cut flowers, as it blooms very late. The Japanese species is not generally popular, the large ragged flowers being more curious than beautiful.

For general show the large-flowered kinds are the best, but the pompones are by far the prettiest flowers.

Some of the best large-flowered are Bijou, rose-purple; Countess of Derby, rose; George Peabody, white; Hero of Stoke Newington, rosy blush ; Prince Alfred, rose-crimson; 
Prince of Anemones, blush; Mrs. Forsyth, white; Baron Buest, red and yellow.

Of Pompones: Bob, rich crimson; Ernest Benary, white and rose; Marc Aurele, purple crimson; Reine des Anemones, white; Lilac Gem, lilac; Danton, rose-lilac; Fabeola, lilac; Golden Anemone, yellow; Précocité, yellow; Rose d'amour, clear rose. 


\section{CHAPTER XXVIII.}

New Hyacinths. - Gladiolus. - Forcing Lily of the Valley. - New Cannas. Lantanas. - Hardy Calceolarias. - Orchids for the Parlor.-Ferns for the Parlor.

\section{THE HYACINTH.}

NEW varieties are yearly sent out by Dutch cultivators. 1 To the lists already given we may add, -

\section{Double Red.}

Koh-i-Noor. Bright salmon-pink. Shakespeare. Large rose.

Double White.

Madame de Staël, Prince of Waterloo. Double Yellow.

Crœsus, La Grandeur.

\section{Double Blue.}

Comte de St. Priest, Sir Colin Campbell. 


\section{Single Red.}

Etna. Very fine large truss and flower.

Von Schiller. Very deep red.

Prince Albert Victor. Rich dark-crimson.

Princess Helena. Rosy pink.

\section{Single White.}

La Grandesse, Snowball, Alba maxima, L'Innocence, Leviathan, Lord Shaftesbury.

\section{Single Blue.}

Blondin, Feruch Khan, King of Blues, Lothair.

Single Yellow.

Bird of Paradise, Liberia, Anna Carolina.

\section{GLADIOLUS.}

The experience of the last few years has shown that in the production of seedling Gladiolus we are by no means excelled by English and French growers. We may import high-priced kinds, but from a collection of American seedlings we can often select superior flowers.

There is, however, a difficulty in bringing to public 
notice any new plant in this country. We have no large growers who are in a position to take such a plant, propagate it, and send it into the market, and many good seedlings are lost to cultivation.

To the general grower we say, buy, for general display, the old varieties, of which we have already given lists, or order from some dealer a few hundred unnamed seedlings, in which there will not fail to be many good flowers.

Of new French varieties the best are, -

De Michel. Rose veined with lilac, throat dark carmine.

Le Vesuve. Fiery red, very large flower.

Murillo. Cherry red, all petals lined with white, with large white spot on lower petals.

Psyche. Light satin-rose, lower petals darker rose.

Sirene. Salmon-rose.

In England the prize varieties the last summer were Mons. Legouvé, Ondine, Hercules, Orpheus, Pactole, Psyche, Warrior, Adolphe Brogniart, Sylvia, John Waterer, Seda, Madame Despertes, Almathea, Felix, Shakespeare, Xerxes, Meyerbeer, Triumphans, Talisman.

FORCING LILY OF THE VALLEY.

Within the last few years Lilies of the Valley have been very profitably forced by florists, the stalks bringing ten 
cents each. The clumps of roots, or the single crowns are usually imported, these giving better bloom than home-grown stock.

Single crowns are preferable to clumps, as they produce more flower, and bloom equally all over the pot.

The crowns should be potted firmly in any soil (for they will not make much root), the roots being cut off to within two inches of the crown, at equal distances, in pots, pans, or boxes. Keep the crown above the soil, as otherwise the plants come up irregularly, and an even surface of bloom is to be desired.

Place the pots in a cold-frame, and give moderate watering. It is a good plan to cover the crowns with a layer of sphagnum moss, as thus they swell evenly, and to keep them covered until they begin to develop.

Bring them gradually into heat, and plunge them in bottom-heat in a close frame, say from $80^{\circ}$ to $90^{\circ}$. They will stand any amount of bottom-heat, and may be forced into bloom in three weeks, but if forced too rapidly there will be all bloom and no foliage. This is desirable for cutting, but for beauty both flower and foliage should be produced together, and to do this the plants must be forced gradually.

It is a good plan to let the pots be exposed to frost before beginning the forcing, as thus the flower is much finer. 
This plant may be forced by placing the pots on the shelf over a kitchen range, or on the hot pipes of a green-house. The leaves and flowers will lack color if kept from the light, but a few days exposure will remedy this want.

\section{BEDDING CALCEOLARIAS.}

These plants are not favorites, as they fail to give continuous bloom.

There has, however, been an improvement, and some of the varieties are desirable, as in color they have no rivals, -

Crimson Queen. A free grower, with scarlet-tinted bronze-crimson flowers.

Pillar of Gold. Rich golden-yellow.

Sparkler. Yellow and maroon.

Aurea floribunda. Clear yellow.

Crown Prince. Golden-yellow, large truss.

Amplexicaule. Lemon-yellow.

William Lucas. Vermilion-crimson.

THE LANTANA.

An improvement has been made in these plants by the introduction of some dwarf varieties of continental origin. 
The best of these is a light yellow flower, named Boule $d^{\prime} O r$, which either as a pot-plant or in the garden, is a mass of bloom, and is well worth general cultivation.

\section{NEW CANNAS.}

If the production of new varieties means progress, more has been accomplished with this plant the past few years than with any other.

We have before us the Catalogue of Messrs. Huber, of Hyères, France, in which one hundred and fifty varieties are described.

The greatest improvement has been in the size and shape of the flower.

Cannas were formerly foliage plants, now they are among the most brilliant flowering plants of the garden.

In addition to the list we have given, the following varieties are very fine:-

Adele Levallois. Very dwarf. Seldom growing more than two feet high; thick dark-green foliage, large dazzling crimson flowers.

Premice de Nice. Foliage glaucous-green, flowers canary-yellow.

Senateur Chevreau. Bright green foliage, salmon-scarlet flowers. 
Auguste Ferrier. Large green leaves shaded with maroon; the tallest variety, often growing nine feet high. A very late bloomer, seldom flowering in New England; flowers red.

Iridiflora hybrida. Rich orange-scarlet flowers shaded with crimson.

The newest varieties, which, however, have not been yet proved in this country, are, -

Helvetia. Yellow, white, and carmine.

Auguste Buchner. Bright orange.

Capucine. Brilliant red.

Vulcain. Bright red.

Dr. Livingston. Orange-carmine.

Gloire de Provence. Pale yellow, tipped with carmine.

Victoria. Saffron-yellow and carmine.

Souvenir de Barillet Deschamps. Vivid red.

Alégatiére. Brilliant orange.

Bonneti excelsa. Purple-red.

ORCHIDS FOR THE PARLOR.

Some few of the "cool orchids" will grow and bloom well in the parlor.

They should be potted in rough peat and sphagnum moss, with lumps of charcoal or broken potsherds, to keep the 
soil open, and secure good drainage; given full light, and be kept warm, and in not a very dry atmosphere.

Those that we have found to succeed best are, -

Cypripedium insigne and C. venustum. 'Two East Indian species of Lady's Slipper, which grow freely and bloom profusely, the flowers remaining long in perfection.

Lycaste Skinneri. A choice and showy plant, with large white and purple flowers.

Odontoglossum grande. The largest flowered of the Odontoglots, which grows and blooms freely at a low temperature. Flowers rich yellow, veined with chocolatebrown.

In the volume on "Window Gardening," we have given full directions for the culture of these showy flowers.

\section{FERNS FOR THE PARLOR.}

Some ferns succeed well in the parlor, if the room is light and airy.

They should be potted in a compost of peat, loam, and sand, with good drainage. Over-watering must be avoided, and full exposure to sunshine. If there is plenty of light, they grow well on a centre-table. The best species for parlor culture are, -

Adiantum cuneatum. A lovely species of maiden-hair, 
from Brazil; the fronds are graceful, and attain a large size.

A. affine. A New Zealand species, delicate and pretty. Davillia canariensis. A graceful and pretty fern, of easy culture.

Pteris tremula. A large-growing species, which wh once established, soon makes a fine plant. It is one of the hardiest and best.

$P$. cretica albo lineata. A pretty variegated fern; fronds light green, with clear white centre and midrib.

Nephrolepis exaltata and pectinata, are showy ferns, with long, narrow fronds; they grow freely, and are very ornamental.

Polypodium vulgare is a well-known native fern, very common in shady, rocky places. Transplanted to the parlor, it thrives well, and is quite as ornamental as many of the rare exotic ferns. 


\section{CHAPTER XXIX.}

New Hardy Shrubs - Amygdalopsis. - Hydrangea. - Exochorda. - New Lilacs.

- Rhodotypus. - Rapheolepis. - Magnolia. - Spirea. - New Hardy Roses. Ampelopsis. - Lonicera. - Clematis.

TTHE introduction of a new hardy shrub is of more ben1 efit than the discovery of a host of new greenhouse plants.

The one can be grown by the people and all can enjoy it, the others must ever remain the pleasure of a ferw.

It is, therefore, a pleasant duty to describe some new shrubs which are real acquisitions, and adapted to general cultivation.

\section{AMYGDALOPSIS.}

This charming plant ( $A$. Lindleyana), more commonly known as Prunus triloba, is a dwarf-growing plant, which in early spring is a mass of large, bright, pink, rosette-like flowers; native of China. It has proved perfectly hardy, and. should be in every garden. 
The flowers resemble those of the double flowering almond, but are fuller and brighter, and three times larger.

The foliage is ornamental, and in autumn the round, hard, plum-like fruit is very showy.

\section{HYDRANGEA.}

A very showy summer-blooming shrub, known as $H$. paniculata grandiflora or deutzifolia, is coming into general cultivation.

The flowers are white, in immense corymbs, and remain weeks in full beauty, turning deep rose before they fade.

To produce large trusses, the soil should be rich and the plant should be pruned in spring, the weak growth being cut out. As this shrub blooms at a season when the shrubbery is generally barren of flowers, it is especially desirable.

It has been generally propagated, and is now very cheap.

\section{EXOCHORDA.}

This plant (E. grandiflora), known also as Spirea grandiflora, although for years grown in England as a greenhouse plant, is perfectly hardy. We have plants eight feet high, which stood the severe winter of 1872 without even the tips of the shoots being killed. 
The foliage is glaucous-green, the flowers an inch in diameter, white, with green centre, in long spikes, completely covering the plant in early June.

The only successful mode of propagation is by root cuttings in bottom heat.

It is not a common shrub, but is most desirable, and one of the handsomest we grow.

\section{LIIACS.}

The last few years have been prolific of new lilacs, which are far superior to the old varieties, in size both of flower and truss, and in rich coloring of flower.

Dr. Lindley is a magnificent variety, of strong growth, with very large rich purple flowers.

The following are very fine: Charles $\mathrm{X}$., Blanc virginal, Goliah, Ville de Troyes, Dr. Noble, Ambroise Verschaffelt, Gloire de Moulins, Nigricans, Lavanensis.

A mass of these gives charming variety of color.

\section{RHODOTYPUS.}

R. kerrioides. Is a pretty shrub, resembling in foliage the well-known Cochorus (Kerria japonica), but with large white flowers. 
It is a dense-growing plant; preserving its foliage in good condition to late autumn, and in winter is covered with clusters of shining, hard, black seeds.

It is perfectly hardy, and well worth growing.

\section{RAPHIOLEPIS.}

$R$. ovata is a low-growing shrub, with leathery dark :green foliage and spikes of showy white flowers, which are succeeded by black berries. It is not hardy in New England, but will probably prove so south of Philadelphia.

\section{MAGNOLIA.}

The newest Magnolia is M. Lenne, - a beautiful variety, with very large, deep purplish-red flowers.

It has proved perfectly hardy with us at Glen Ridge, and should find a place in every collection.

The flowers are produced before the leaves in early spring, about a week later than those of M. Soulongiana.

\section{SPIREA.}

Although there is nothing new in shrubby spireas we desire to call attention to $S$. Thunbergi as the earliest 
blooming species; very free in growth and profuse in bloom.

About the middle of May it is a mass of white flowers, and is a very showy plant.

Although not very common, it cannot fail to be generally cultivated when its merits are known.

\section{HARDY ROSES.}

To give a list of these would be to copy the florists' catalogues. English, French, and Continental growers every year send out so many new varieties, many of great merit, that it is difficult to make a selection, and to attempt a description would exceed the limits of our volume.

The following is a select list: -

Comtesse d' Oxford. Bright shaded carmine, large, full fine form.

General Jacqueminot. An old rose, but unsurpassed in color, brilliant velvety-red.

Abbe Garaudier. Fine rose, large and full.

Paul Neron. Deep rose, immense flower.

Baronne de Rothschild. Bright rose, very large.

Dr. Andry. Rich crimson-shaded carmine.

Auguste Mié. Light pink, — a good old rose.

Madame Vidot. Delicate pink, cupped, very double. 
Duc de Cazes. Deep crimson-scarlet.

Caroline de Sansal. Flesh color and blush, large.

Madame Lacharme. White suffused with pink, changing to pure white.

Paul Verdier. Bright rose, imbricated, very double.

Reine des Blanches. Fine rosy white, very large.

Boule de Neige. Pure white, fine cup, double.

Edouard Morren. Bright carmine.

Oriflamme de St. Louis. Brilliant scarlet.

Prince Camille de Rohan. Dark velvety-crimson.

Prince Leon. Vivid crimson, large.

Alfred Colomb. Bright rich carmine.

La France. Deep pink, very fragrant.

Charles Rouillard. Lilac rose, verý large.

John Hopper. Brilliant rose, crimson centre.

Princess Mary of Cambridge. Silvery pink, large and full.

\section{AMPELOPSIS.}

A very valuable introduction is the new Japanese woodbine, Ampelopsis Veitchii, or tricuspidata.

It is a perfectly hardy climber, with small neat foliage when young, and shoots which cling close to either wood, stone, or brick.

It is admirably adapted for covering walls, and will take 
the place of ivy which, unfortunately for us in New England, is not hardy. The foliage turns a rich dark purple in the autumn.

It is a rapid grower, is not attacked by insects, and is altogether the best hardy foliage climber.

\section{LONICERA.}

$L$. brachypoda aureo reticulata is a beautiful small leafed species of honeysuckle, with leaves beautifully reticulated with golden veins.

At a distance it appears a mass of yellow, and is invaluable for growing with dark foliage vines.

Although generally hardy this plant is sometimes winterkilled, and therefore should have a sheltered situation and be slightly protected in winter.

\section{THE CLEMATIS.}

When the first edition of this book was issued, there were comparatively few Clematis in cultivation.

The last three years have greatly added to the number, until now it is difficult to make a selection where all are so beautiful.

The general treatment has been given in the previous pages. 
These hybrid Clematis divide themselves into several classes, and in classification we follow that of English cultivators, giving a list of the best of each.

\section{FLorida TXPe.}

Fortunii. Double white.

John Gould Veitch. Double mauve. Floral Magazine, page 394.

Lucie Lemoine. Double white. Floral Magazine, page 102.

These like the species are precariously hardy; they are summer bloomers, and produce the flowers from the old wood.

\section{JACKMANni TrPe.}

In addition to those previously mentioned, we can recommend :-

Star of India. Reddish-purple, with red markings.

Magnifica. Reddish-purple. Floral Magazine, page 453.

Prince of Wales. Deep purple.

Velutina purpurea. Mulberry purple.

These are free bloomers, and flower on the new wood, and are hardy. 


\section{Landginosa Trpe.}

Gem. Deep lavender blue.

Henreyi. Creamy white.

Madame Van Houtte. Large white.

Aureliani. Light blue.

Lawsoniana. Rosy purple.

Regina. Light blue.

William Kennett. Deep lavender.

In this class are found the finest and largest flowered Clematis; they are summer and autumn bloomers, flower from the new wood. Should be moderately pruned in spring. They are not hardy in New England.

\section{Patens Trpe.}

Albert Victor. Deep lavender.

Fair Rosamond. Blush-white, red markings. Figured in Florist, 1874, page 169.

Miss Bateman. White. Floral Magazine, pp. 495̃-96.

Standishii. Mauve.

Stella. Deep mauve. Figured in Florist, 1874, page 169.

The Queen. Light mauve.

Mrs. S. C. Baker. French gray, claret bar.

Lord Londesborough. Deep mauve. 
Lady Londesborough. Gray. Floral Magazine, pp. 495-96.

These produce flowers in early spring, on the ripened wood. With slight winter protection, they will prove hardy.

\section{Viticella Type.}

Hendersoni. Bluish purple.

Lady Bovell. Grayish blue. Floral Magazine, page 370 .

Thomas Moore. Violet.

Mrs. James Bateman. Lavender.

These are summer and autumn bloomers, and are hardy if lightly covered in winter. 





\section{anderent?}

$$
414-90
$$








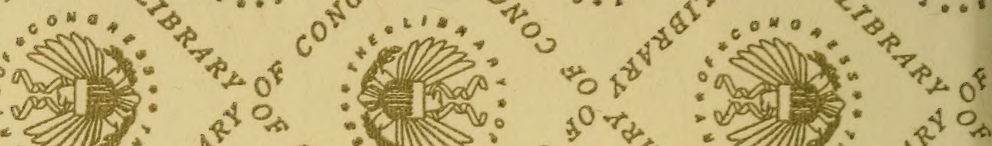
rats:

\section{से}

(1)

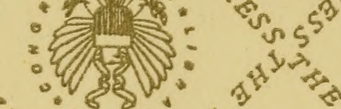

is

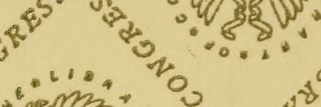

$\therefore$
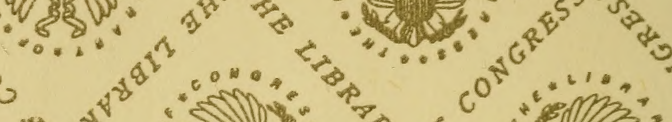

- 08

(1)

ing

.

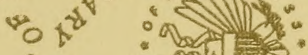

P. 0 位

$\mathrm{c}^{5}+11.20$

$R^{4} O_{6}$

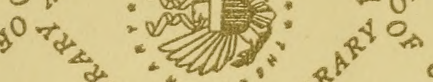

- $15.60^{\circ}$

(⿻)

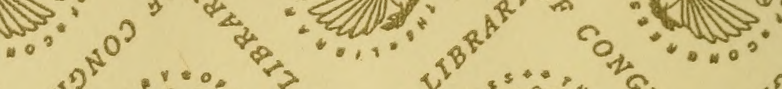

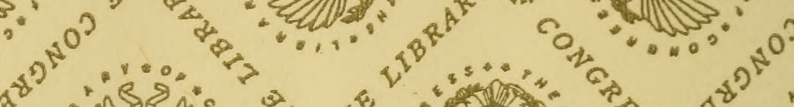

$3^{\circ} \mathrm{r} /$

$\mathrm{n}^{2} 5^{\gamma^{2}}$ *n

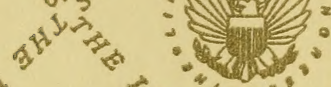

(2)

- El

(4) कै

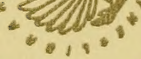

i

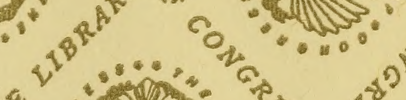

$10^{\circ}+4$

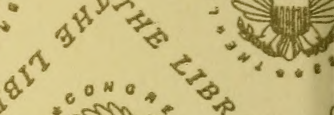

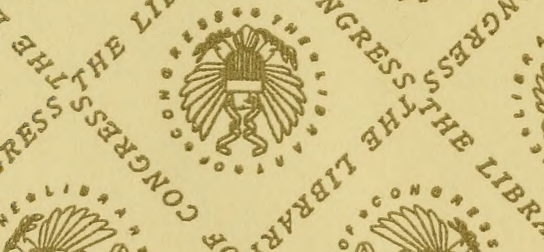

(1)

is

.

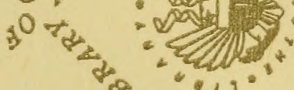

(t)

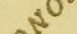

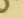

$\therefore$ "राmb :

$\rightarrow \infty$ on

P $0^{q}$

40 


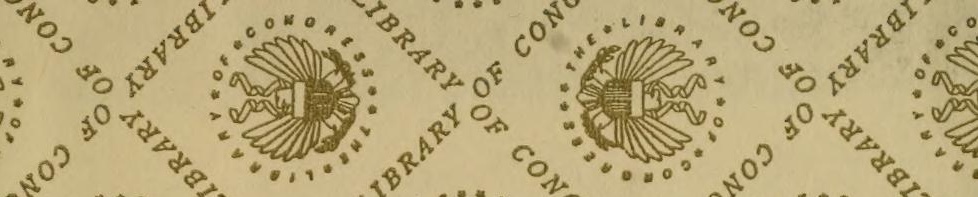

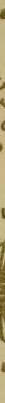
: $\Rightarrow$

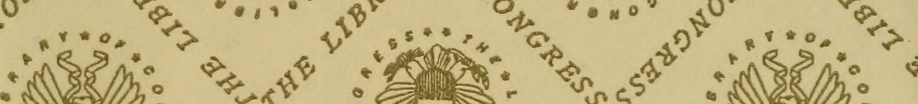

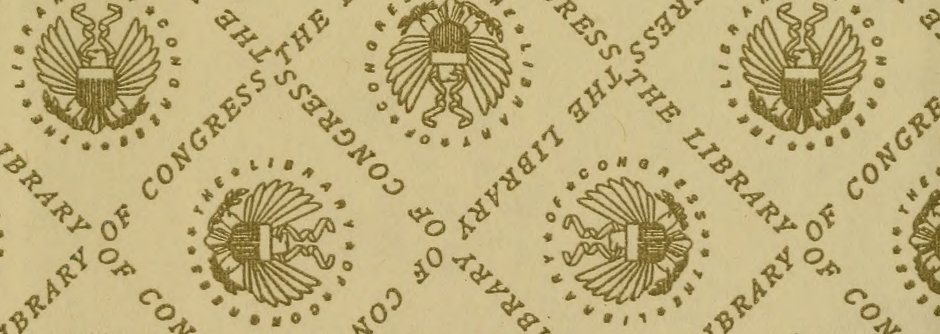

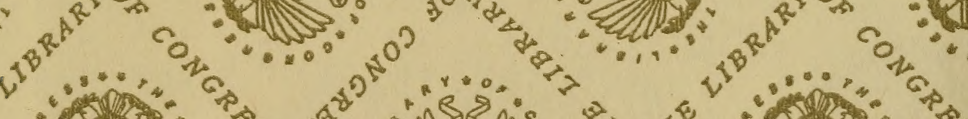
:

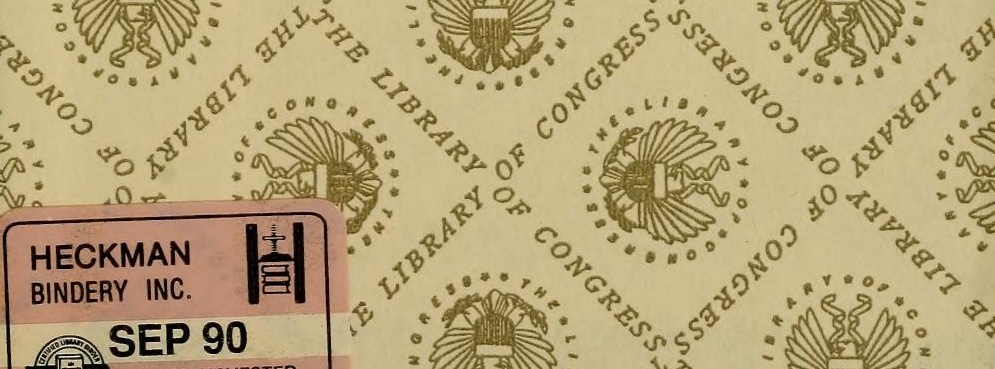
IEL Ir $2=0$ 


\section{LIBRARY OF CONGRESS

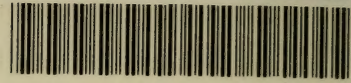

00009193042 